\title{
SYNTHESIS OF SEISMICITY AND GEOLOGICAL DATA IN CALIFORNIA
}

John G. Anderson

University of California, San Diego

La Jolla, California 92093.

U.S.G.S. CONTRACT NO. 14-08-0001-19766

Supported by the EARTHQUAKE HAZARDS REDUCTION PROGRAM

OPEN-FILE NO. $84-424$

U.S. Geological Survey

OPEN FILE REPORT

This report was prepared under contract to the U.S. Geological Survey and has not been reviewed for conformity with USGS editorial standards and stratigraphic nomenclature. Opinions and conclusions expressed herein do not necessarily represent those of the USGS. Any use of trade names is for descriptive purposes only and does not imply endorsement by the USGS. 


\section{DNTENTS}

\section{Cover pege}

\section{Costerts}

Techalcal Report 8 monery

Appeadiz I: Comparison of lastrumeatally rocorded sedemicity in Califorala vith predictions based on geological elip rates.

\section{Appendiz II: Coasequesce of slip rato constralats on} earthquake occurserce relatioss. 


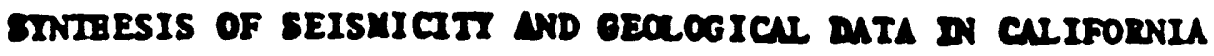

Deos DEDI 14-08-0001-0-501

\author{
Johe 0. Anderson \\ Institete of Geophysics and Plasetary Pustes (1025) \\ Bcrlpps Iastitetion of Oecasography \\ Dolversity of Callforala, Bas Diego \\ La Jo112, Callforala 02093 \\ (619) 452-2424
}

\title{
Terestletions
}

(1) Conplle es complete es posalble a cot of eldp rates lor anjor ferlts is Califorala.

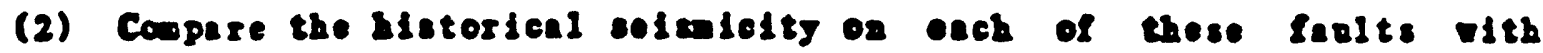
cetivity sates ahich are aecded to anistala the allp rate.

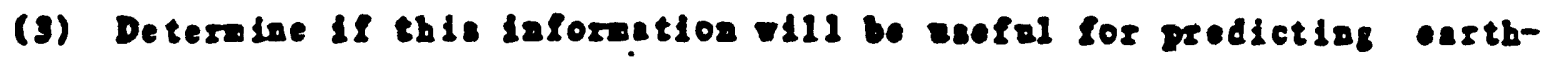
guk kes.

\section{Reseles}

Goologlcal ellp rates have beea conplled for 69 faelts do the state of Califorain. Dalted states of merica. Dorthercore. bounds or the

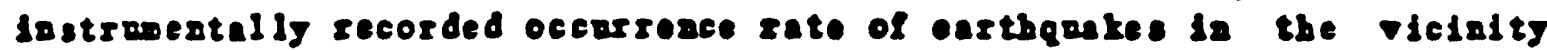
of esch of these fante ad addtionel obsostationel parateters heve also beea complled, Ineloding larlt leagth, and lastrameatally observed

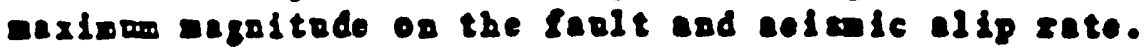

Bssed or these dets. sereral reletionshlps hate beea lavestigatod.

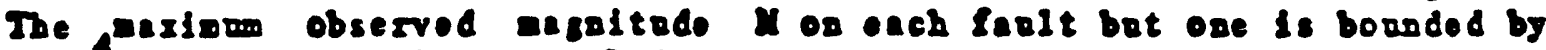
$U=\frac{1}{3}(108 L+3.29)$. Dhere $L$ ls the total leagth of the fant and the relationchip is derived fron the scaliag of Scholz (1982). Attentlor les bees peid to tho ratlo $I$ of observed occurgerce rate of ereats to the rate predicted from the selsmic allp rate. Nost of the observations shor $\mathbf{Z}$ betrees 0.1 and 20 , bet several cases of $\mathbf{Z}$ as suall as 0.01 have beez observod. On those fanlts abich have eppereatly seea a 1000 yeas ersthguke dorlag the period of inetrowental obsesvations. I is abont 10 et all agaltodes. Ioplyiag that eftershocks are sofficlent to assure thet. the Gotedberg-Richter relatlosehip betreea the logarithms of occurreace rates and aggitedo holds et eall atgitodes when occurrence rates are arezaged over complete selsole ejcle lavolving loag periods

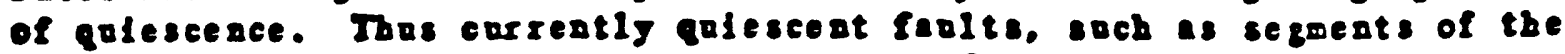
San Andreas fadt, are not eridence for the fallore of the GuteabergRichter selationship od individual fadts.

The ratlo I wes also lavestigated os a possible predictor for

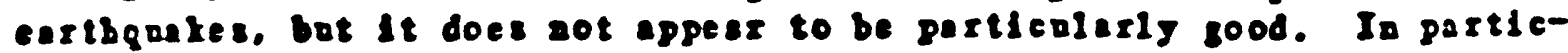
-las. the criteria 2$) 1$ appeass to have a assed lorecast rate of about

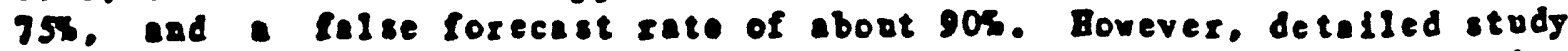
wlt betier constralaod al ip rates alght eventually al lor tbls criterloa to dolp alts the eartbquake predictlos problea on soov farits. 


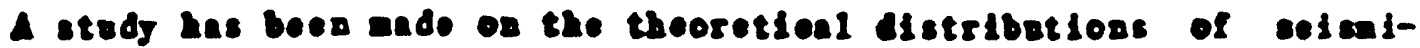

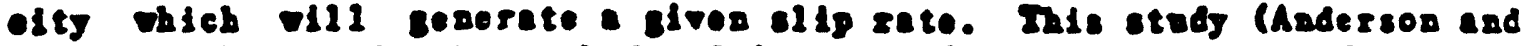
Lsco. 1983) exterds tho acthods of Adersos (1979) to esother for for We distribetios carve of the abber of earthquates at cach aspaitsde.

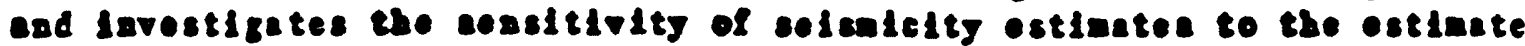
lor mexina agaltuda. It also explores rays is ableb polat observa-

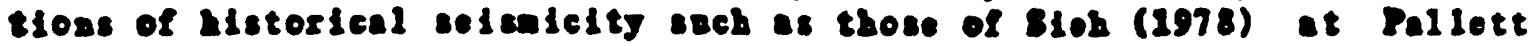

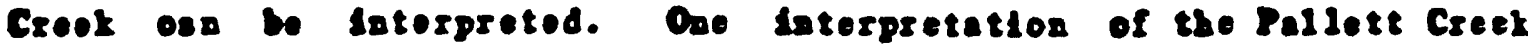

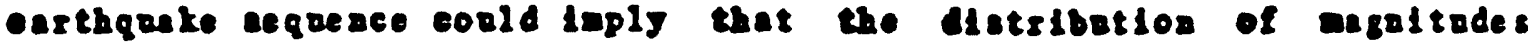
rocorded da the record is consistent vith 108 a = - bll distribetion

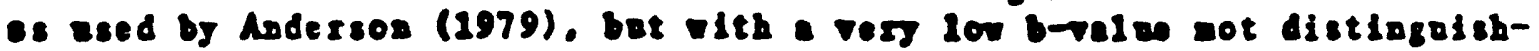
ablo Iros sero.

Althosg aot required for the complotios of this costract. B etedy wes ade or hot to ese precersor observatiose to obtalo predictioss.

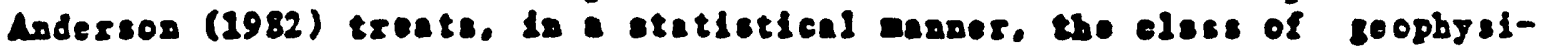
cal observatioss that conetlacs are procursors to a inge earthouke.

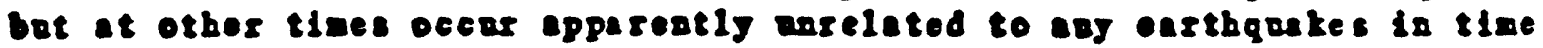

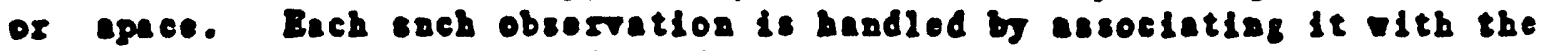

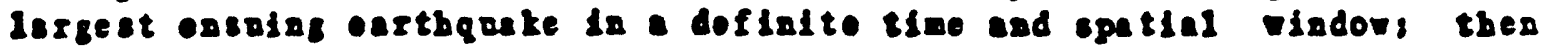
the probebllity that the observation is oseful is estiacted from the difference betrees this extrace valu distribotion and the losg-terw aterage extreme value distribotion for the ane seglos. Ints probabilIty that tho precarsor ds ecefal car thea bo lacorporated lato ealcalstlons of tho revised probeblittj of an enctbquke folloviag observation of one (a trifial cese) or several ancellable precursors to derive the zevised probability of a algalfleagt carthquak. To nodel takes foll acconst of the argatide detribatiog of eartbqukes and of discrote levels of precersor obsertations. Tho Dalted States encthquake prodictlog program is at111 aagy jears from belag able to obtala the foll beaeflts of tho aodel. Boreres. tho nodel esgests sefel statistics

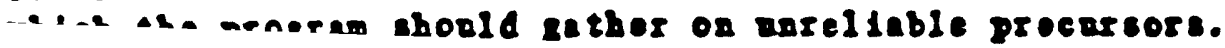




\section{Leferences}

Andersos, J.G. (1979). Estimetigs tho colenielty frow goologlenl strec-

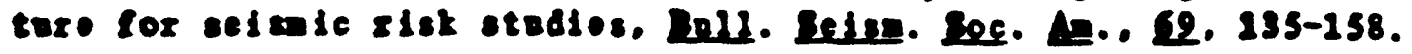

Andersog, J.G. (1981). A sinple way to look at a Bajesiag aodol for the stetietics of cartbqukt prodictios, pell. Selie. Sec. Am.. 12. 1929-1931.

Andorsos, J.G. (1982). Lerised estinetes for tho probebilitles of carthqukes lo1loulas observatloss of enrollable procursors. Bpll. Seis. Soc. …. 22. 879-888.

Andersog, J.G. (1983). Cowparisor of lastrameatalis rocorded seismielty is Calfforala alth prodictloss besod or geologlcal silp rates. (1a preperatlog).

Andersog. J.G. and J.E. Leco (1983). Cossequesces of alip rate corotreints or eartbquke occurrence roletioss. Bull. Seism. Soc. Am.. (19 press, Apr 11).

Sieh. I.E. (1978). Prebistoric large enthqueke produced by elip on the San Andreas farlt at Pallott Creek. Callfornia. I. Geophys. Res.. 13. 3907-3939. 
CONPARISON OF INSTRONENTALIT RECORDED SEISHICITT IN CALIFORNIA IITE PREDICTIONS BASED ON GEOLOGICAL SLIP RATES

\author{
John G. Anderson \\ Instituto of Geophysics and Planetary Physics, \\ Scripps Iostitutios of Oceanography. (1025) \\ Daitersity of Calfforala, San Diego \\ La Jolla, Califorala, 92093
}

\title{
Abstract
}

Geologlcal silp rates have been complled for 69 farlts in the state of Califoraia, Dalted States of America. Furtherwore, bounds or tbe Instruneatalig recorded occorreace rate of earthquakes in the vicinity of each of these fants and additional observetlonel parameters bave also been compiled, including fart leastb, and instrumentally observed

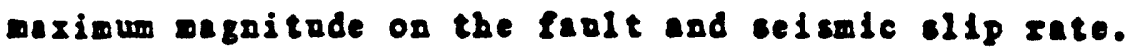

Based on these data, corezal zelationshlps have been investigated. The raximam observed angaltode $N$ on eacb farlt bat one is bounded by $u=\frac{1}{3}(108 L+3.29)$. Where $L$ is the total longtb of the fanlt and the relationsbip is derived from the scaling of Scholz (1982). Attention bas beea paid to the ratio $R$ of observed occurrence rate of events to the rate predicted from the solsalc slip rate. Most of the observatioss shor $R$ betrees 0.1 and 10 , bot cereral cases of $R$ as small as 0.01 bave beer observed. On those fadts which have apparentig seen a 1000 year -arthquake during the period of instrumental observatlons, a is about 10 at all agnitudes, implying that aftershocks are sofficleat to assure that the Guteaberg-Riclter relationshlp betreen the logarithms of occurrence rates and angitode bolds at sasil argnitodes when occurrence rates are averaged over complete selsmic ejcle involving long periods of quiescence. Thos curreatly quiesceat fanlts, sach as segueats of the San Andreas fault, are not oridence for the fallure of the GotenbergRichter relationship on individul farte.

The ratlo 2 wes also investigeted as a possible predictor for exthquakes, but lt does not appear to be particularly good. In particIar. the criteria $R>1$ appeass to have a olssed forecast rate of about 75x. and a false forecast rate of abont 90\%. Borever, detalled stady with better constrained sip rates wight eventoaly allow this criterion to belp with the cartbquke prediction problea on some fanits.

Introduction

It is well established that the slip rate or a falt is correlated wib the average occurrence rate of lerge earthquakes on the favit. Brune (1968) and Davies and Brose (1971) establisbed this or a worldride 
besis. Andersos (1979) and Nolner (1979) lave showa low ol ip rates can bo lavertod to cosstrats occrsonco relatlons. Asderson and Leco (2982) have generallzed that procedure to ceveral occurseace relatloas. Andersoz (1979), Greosafolder et 1.. (1980), and Dosor and Baitb (2982) have ased allp satos to study zoglonal colenielty.

Whilo the acthod works woll on a roglomel to global scale, inspection of results by Andersor (1979) ladicate thet for indifiduel farts, goological and lastrmental selsolelty ofter diffor considerably. This shorld cone as ao surpilse. for tho duration of instrumental records is

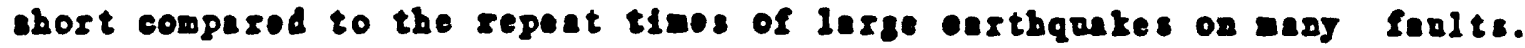
One reasorable ajpothesis would bo thet on fants with long gecargeace tines. the lastrumeatal sefselclty shorld be larger thes geolosical selemicity if aejor earthquke has occurred, and meller is lt has not occorred. There vonld be so discrepancy oaly when the observation period compares with or excoeds the rocurrence interval.

The posslbility that the discreparey is ejstemetic like that raises several questioss, also. One possibility wonld be thet the ratio of lor level selsmiclity to theory ls predictable. or can be bounded, based on the olip rate, even in the laterval botroen anjor earthquates. If this were provea, it corld heve ad inportant effect by allowiog bounds on the resully poorly defined lapots to colsmic rlsk anelyels. Another eseful observetion wonld be if this discrepacy vere sose function of the part of the seismicity cycle on the fadt, and thes coeld be raed in predictive capacity.

This paper oddertakes to larestigate tho discrepary between seo loglcal and lastramental selswicley or a fant by fant besis in Califoraia. The gegion is oxcellezt for unch a sody, as detalled earthquake catalogs extst and as there is a vealth of geological data pertolniag to slip rates on mang ajor fants.

Geolorical S1ip Rates

There ere now several compilations of estimates for the geological slip rate on the major fants of Califorala. These include Anderson (1979). Berd (1979), Moodward-Clyde Consultants (1979), Eguchl et al. (1979). and Bird (1982). Slip rate estirates for a fer additional fanlts are presented la Table 1. Table 2 lists the slip rate bornds and best ostimates for any of the important fants in Colifornda, as given 1. each of the above compliations.

Inspection of Table 2 shors that there is seneral agreemert of these sources for fauls alth large slip rate. We note, hovever. that these are secondary sources, and the conslatency may result oaly from consulting the same primary sources. In general. for faults with owaler elip rates, the conslatency is not as good. Also, for strikeol ip farts. the scatter in estlestes tedds to be lower than for thrust 
or noracl fandes. The estinates given by Egochl at 1 . (1979), besed on "expert oplaiog". eannot be rexifled by noreal seleatific procedures and are thorefore given $20 \mathrm{~s}$ weight then other estinates duriag further studies. A sobjective "best" estimato, and ressomble bonods on the slip rates of each farlt was culled from Table 2 , and is Ilsted in Table 4.

\section{Iastromedal Sedericitr}

Instrumetel occurreace rates hare been deternined in quadilateral

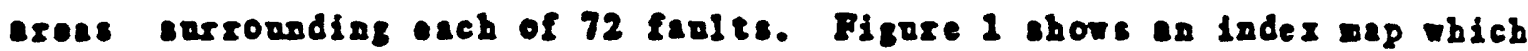
locates each of the elght regioss in Callforala considered. Figre 2 A-B show these elght reglons, mjor feolts, and quedrileterel bonadaries. Figrie 3 A-B repeat these rogions ad shor the lastrumeatal epicenters for $\| 24$. Table 3 lists the quarilateral corner coordian tes for each of the fandts chown on Figaros 2 or 3.

Quedrilaterals were drawn on the Fade lap of Callforaia (Jenoings. 1975) vithort specific refereace to the solsmiclity ueps. Some attempt was ande to evold ovorlapplag reglons where that was reasoneble. In the

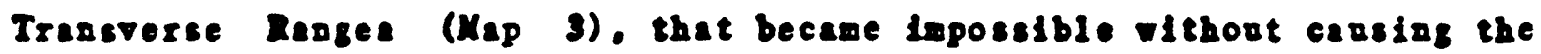
zore to be excessively arrov, and thero, In particaler, the zores over lap considerably. After the sones vere defined in this maner. bonnderies vere adjusted oxly to incorporate eny aigalficant earthqukes which were inltially excluded. On Figares 2 and 3 , armes followed by an asterlsk were motivated by sowe geographlcal factor other than the farlt name liself on Jennings (1975), as the fanlt ls nonamed on Jennings (1975).

Earthquke opicenters were read from the EDIS (Earthquke Data Iaformation Service) dete tape (Keyers and Von Baze. 1976) completo through December ig79. Odtput of each seisolctity search included a plot of cundative rowent versus tiae, and a plot from which occurrence rates were vessurod. The cmolative nowent was deffipeghy assigning to each earthquake of megaitude $\mu_{2}$ e someat $\mu_{0}=10$

The procedure for the dotermination of occurreace rates deserves some. more detalled oxplanation. It is assumed that one does not heve a fundamental basis lor seloction of the appropilate time taterval to deterwine the average occurrence rate bat that the most recent data is most Iltely to give completo coverage of a givea magnitude interval. One expects that the time interval is varleble betreen magnitide classes on any individuel farlt. Furthermore. It ls concluded thet reasonable opper and lower bounds on the occurreace rate ronld be an appropriate way to characterize the occurrence rates for tho porposes of this stady. Therefore, when earthquake satisfled the location criterie, they vere sorted loto magnitode classes $(3.0 \leq U<3.99 .4 .0 \leq U<4.99$. etc.) and the number of oreats per jear in each magnitude class was connted. Then - sequence of averages. $A_{k}$. wes formed: $A_{1}$ based on the most recent one 
jear of deta. $A_{2}$ besed on tbo nost recent two gears of deta. .... and $\mathrm{A}_{\mathrm{z}}$ besed or the nost recent 1 jears of data. The plots from wbich carthquke occurreace rates ere calculated shor los 4 as a fusctios of 108 L. These plots rese used to ohoose upper and lower bounds or instrumertal occurrasce rates.

It wes found that these plots. Blving erorage gate vorses duration of arezage. take ore of live tjpleal shapes. These are dilustrated id Figere 4. Shape 1 represents a fairly vell-defined arerage occurgence rate resulting from stable seisulelty and good isstrumental coverage. The average occurrence rate usully lo deterained to althis a factor of $108 s$ thas 2. cegardless of how losg the laterval ohich is everaged is choses to be.

Shepe 2 ocenrs for low occurrence sates, When two or nore earthquekes here occurged. The bounds one obtains are alder or aerrower depending on when the earthqukes occarred. Inds chape is recognired when the carthqukes aro widels separated la tiee. so that the bounds correspond to arerages orer losg tive periods, as is pigure 4 . Then the carthqukes occurred close together is tine. a differeat characteristic shape (usonily S) appeared.

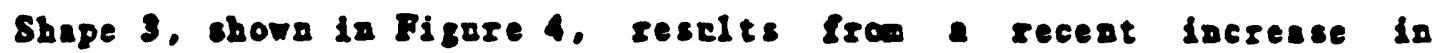
ectivity which is asall (loss thas a factor of abodt 5). resaltiag in en aspaptotic decay toward earlies levels. A lower bound on the actifity rate is aspalig easily selected, bet the apper bound is asbiguoss. This shape can roselt from expanding lastruental corerage. as well is the case in which the higher activity rates derired from the shorter aver ages dag represent losg-terc trends. The upper bound was sometimes chosen by selection of a time laterval bhich cared a relative marimam at other angitado levels. Shape 4 resolts when a earthquake early in the record carses very high ectivity. but subsequent rates have beed lower. In Pigure 4. a relatively well-deterwined everage, in the rost recent jears gives tho inpression that aftersbocks of the major ovent any be over. In other cases. a atable everage canot be recognized becase aftershocks are continging. The upper bound depends on the time tho alis shock occorred. This shape sives no laformation abort the occrirence rates prior to the main shock.

Shape 5 results when all the eartbgares occorged at aearly the sare tine (often there is only one). In this case additional assurptlons are seeded to define the lower bound (we dewlig took 50 or 100 reass. depending on angitude level), while the upper bond depends on when the eartbquke occurged, and probably overestimates the occurrence sate.

Table 4 1ists on a falt by fadt basis. the occurrence rate bounds and the type of curve bich the eartbquakes cased to define these bonds. The conplete set of occurgence rate plots, and the 
Appesiz I

Leterpretations, are shown lo Appendix I-1.

There aro sereral aditional obsorvatlons vhich are listed in Tablo

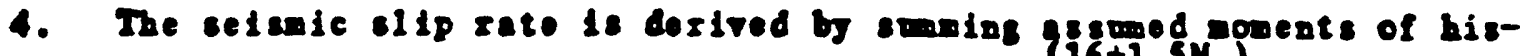
torleal orents,

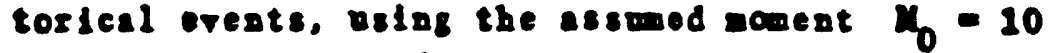
for creats -1th agnitude 4 (Bants and Ianamos1, 1979). The nonent is assumed to bo released la a Fant leagth, L, elros, and a fanlt width of $10 \mathrm{la}$. The tiae Interval $T$ is the duration ased is this average, vith all intervals oading Decerber 1979. The largest aronitodo in this time Interval is algo Itsted. From the fant leagth, and the assomption

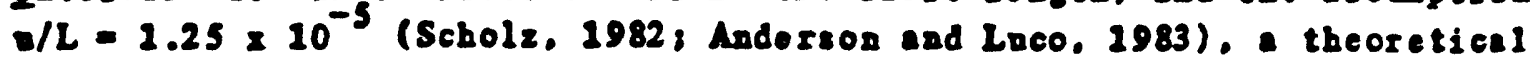

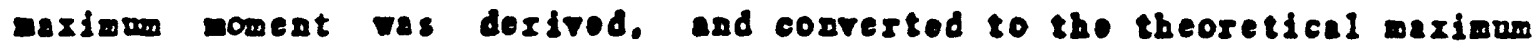

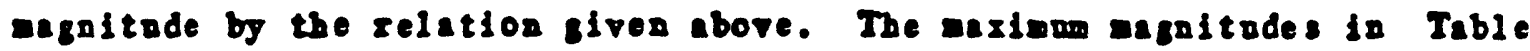

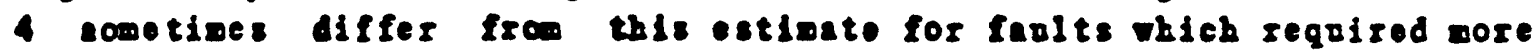
than one qudrilateral to carry ort tho search. The copirical b-value

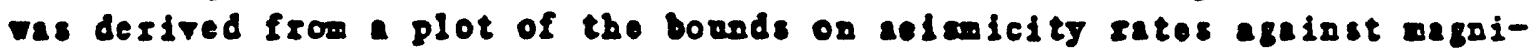
tade and a risul fit thropgb the data. Rigorors estinates of the bvalues (og. Inopoff et Ll.. 2982) vorld necessarliy laclode the estiates in Table 4 vithin formal error linits.

\section{Cherecteristics of Observed Occorrence Retes}

Figre 5 illestrates bow the estimated epper and lower bonds on occurrence rates which are gives is Table 4 compare. Mang of the points shor an upper bound equal to about twlce the lower bonnd, bat apper bounds of ter times the lower bound agf soen in a fer cases. The observed occurience rates are all between $10^{-2}$ and 30 eveats/gear, or abort 3.5 orders of magntude. Obviobsly. larger occurrence rates woold ocers if larger regicns had beon chosen. Tho lower 1 inte is simply a resolt of the short seismicity catalog and pot a physical property. There the rate is in reality less than $10^{-2}$ / year elther there were do events and the estimate is rero, or there vere events, and the sate becores estimated at greater then $10^{-2} /$ year.

Figre 6 shows lacremeatal occurreace sates $\left(a^{2}\right) 0$ each farlt for

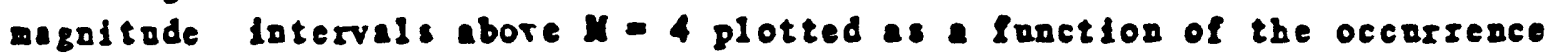
rates for events la the regnitade range $3.0 \leq 4 \leq 3.99$. For this plot, the opper boud or occurrence rates la each range has beed emplojed. This figare chors. In a compact format, the same laformation as a Gutedbarg-type plot of occurrence sate agadast angitode. On this figore. data frow each fanlt appeaf on a veftical line. If each of these date sets obejed the $1 a \pi$ los a $=10^{2-b j}$. Witb the same b-value on each fanlt, then all point would fall on diegonal lines with slope 1 is the separation rould be determined by the b-value. Such lines are shown for $b=0.83$, and date cluster ln the vicinity of these predictions. Becense of the difficulty involved in ecasuring small occurrence rates with a 50 gear tine sapple. data is the upper sight half of this plot are more reliable than data in the lorer-left balf of the plot. The 
Appondix I

cholce of $b=0.83$ ds estineted by a vismal fittigg procedure to these aore relieble data.

Cherecteristles of Meziman Mendtode

Plgare 7 compares the totel favlt lengtb and the enxtem observod accultade for eacb eatry to Table 4. In addition, a thoorotical relathoship of angitado and rupture leagth from Anderson and Laco (1983) lss been plotted. This relatlosship.

$$
\log L=0.75 X-3.29
$$

Where $L$ is the ruptra leagth in kilcoeters, was derived on the assup tion that the ratio of the average ilp (B) to the rapture lengtb is a constant equal to $1.25 \times 10^{-5}$ (scholz. 1982), that the rupture vidth is

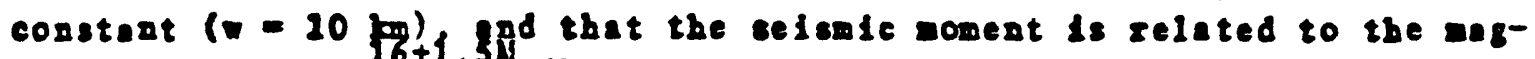
aitode by $X_{0}=10^{16+1.5 X}$ (Banks and Inmmord. 1979). The one detm to the right of this enrve is the 2952 Tera Confy earthquake on the White Wolf farlt. For throst earthqukes, the ratio o/L is typicalif greater than for strike elip events (Scholz, 1982), and for this perticular event, besed on perameters compiled by Papageorgion and Ari. (1982), a/L $\approx$ 3-6 $\times 10^{-5}$. Furtberwore, the fault oldth, $20 \mathrm{k}$, exceds the assmed $10 \mathrm{~km}$ widh which vas esed to propero the theoretical carte.

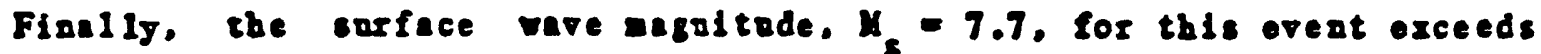
best estimates of the nowent aegaltode, $U^{5}=7.3$ to 7.5 , based on noment estimates compiled by Papegeorgion and Ati (2982). For strite-silp California earthgukes. It appears that as jet there are no bown excep tlons to the bond shorn in Figere 7.

Figore 8 compares the argaltode of the meximam observed earthquake and the selsmic silp rate eacb fandt in Tablo 4. As expected, the tro perameters are correlated. Thls correlation results becase the largest earthquates are the ones which carse nost of the silip. Scatter is introdnced by the different faolt leagtbs and to some extent by the digtribution of smaller earthqukes on cach fant.

Fignce 9 cbors the maximun observed magutade plotted against the best estimate of geolosical slip rate. Toodrard Clyde Corsultarts (1979) have previously prepared such a plot, for strike-silp fauts rorldwide. Based on an assmed occarrence-rate relationship. Anderson and Luco (1982) bave derived a theoretical relationship between these two parameters also, as a function of the average recorrence time of the maximum magnitude event. Te note that these theoretical curves assume a perticular shape of the occarreace rate relatlonsbip near the maximm agnitude earthguak, but that alterative shapes jield similar predictlons (Anderson and Leco, 1982). Figure 9 shors six events which epperently heve recurrence times of 1000 jears of more. These six fadts are designeted as follows on Table 4: White Volf. NewportInelewood, Stampede. Honey Lake Valley. Honey Lake, and Genoa. To note 
thet for a 69 farlt date set and abort 100 jears of seisolc history. dopendiag on the farlt, els observations of a 2000 jear eveat on tho faolt is about rhat ore roold expect.

At the call angitede extran, 12 faolts, or 20w, appeas bolow the 10-jear contonx on Fignzo 9 . These 12 faolts aro dosignated as follows or Table 4: San Androas 2,5,6, and 78 Garlock Bast, Garlock Tost, Crcanogga, Oakridge, Rose Canjog, Rayeond, Blz Plae, San Jua. In addition Santa Monica and Santa Suena are or the borderlise of this group. Formally this oaly neas that if the animom earthquke on the fadt

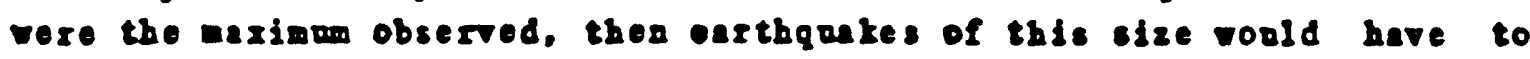
occur nore frequently, and is some cases algaiflcanty nore frequently. than oxce erery 10 years to achieve the slip rate which hes beed desiganted. Therefore, one canot ane atatistlcal infereace, besed on this figare, that farts is this groop hare had ungually 10w activity and aro statistically due for a larger carthquale. However. Figrie 8 shors at nost under 2 agnitude molts of scatter at a siven seismic slip rate, wile Figure 9 shows typically 3 to 4 eagnitode units of scetter. Becase the soological and solemic slip rates anst be the same orer a officieatly logs observetios period. It is ressomble to infer thet the date at frequent rocurreace contors in Figore 4 do not represent eitatlons in bich laxge ilp rates are achieved by frequeat small earthquaks, bot rather situtions is which lerge earthqukes here aot beed recorded in the earthquke catalog.

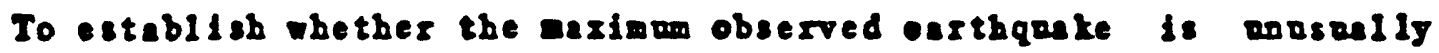
and1. a different type of procedare is aeeded. This is porsod is Table 4 ihich slres a thooretical estimete for the nean expected

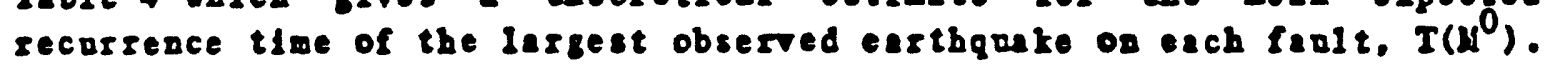
These estluates are based oa Eq. II.9 of Anderson and Lnco (1983) and incorporate the raloo of $\mathrm{H}_{\text {aex }}$ which has beed assued on Table 4 . One thisd of the faults have an expected recurrence tiae of the largest observed eartbguke being less than 10 jears seren of these recurrence times $(10$ ) of all fadts) are estimated to be less than two jears, and three of these (45 of all fants) are esticated to be less than one jear. One would not expect such large fractions of the total date to apper in these categorles 14 eartbquakes vere randomig distributed la time. Borever, It is reasonable to explain these fractions by a tea doncy for earthqukes to occur in aftersbock sequences of swarms during ective periods on a fant. Those fadts on which the $T\left(N^{0}\right)$ is less thas one Jear are degignated San Jana, San Andreas S, and Biz Pine on Table 4: those with $T\left(A^{0}\right)$ between ore gear and tro gears are the Bagward, Oakridge. Raymond, and Rose Canyon fants.

\section{Copparison of Observed and Predicted Occurrence Rates}

Predicted occurrence rates of eathquakes in apgitude intervals 3.0 to 3.99, 4.0 to 4.99, etc. vere derived by expressions in Andersos ad Luco (1982), asing occurrence relation $N_{2}(\mu)$, with the b-valio and 
Hpax for each favlt as listod in Tablo 4. AppendIx I-2 contains plots of observed and predicted occurrence rates, as a fuction of the anenitado

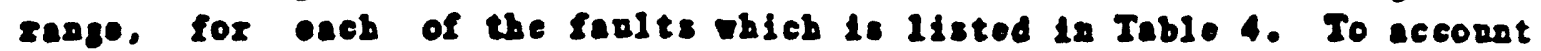
Cor the ucertsinty. these plots shor expected occurreace rates for the

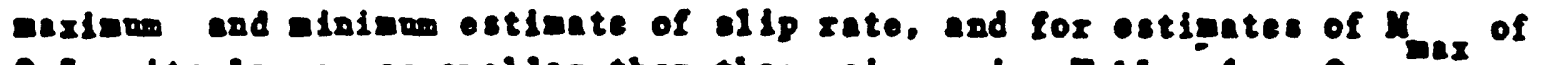

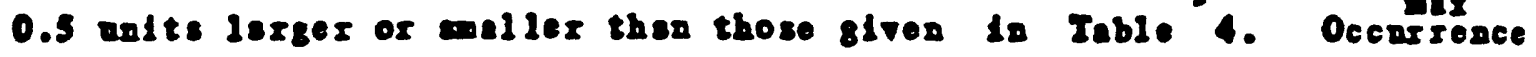
rates whlch correspond to the best estiretes appear es lerger eypbols.

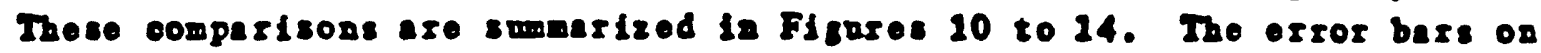
predicted rates on these figures correspond to the range of sl ip rates 1a Teble 4; the exror bers on observed retes apan the range between anz-

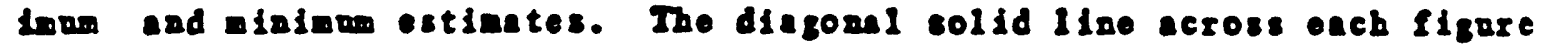
shows equality of the rstes, and the dashed lines show discrepencies of \pm 1 and \pm 2 orders of angaltode. Figre 10 show deta from all fants; Figare 11 bbows deta from some of the faelts which here had 1000 Jear certhquite. Figure 12 shows data from farlts ohich appear belor the cortour on Figure 9 , and Figres 13 and 14 show resalts broken down accosdIng to the reglonel aaps.

Figore 10, which contalas the entire cet of data, shows thet in the vast anjority of cases. the observed occursence rates are itbin a factor of 10 of the predicted rates. Nost exceptions to this fall in the ragge where observatlogs are waller than the prediction by a factor of 10 to 100. Incomplete recording at the angaitode 3 to 4 level probably coatribates to sowe of these low data points.

Fignre 11 compares the obsersed and predicted occurrence rates for the Newport-Inglewood fant and the White Tolf fant. The observed occurrepce rates on those tro fadts are abodt ted tiaes larger than the rate predicted from tho ilp rate. Date for forr other farls abich heve apperentif had their 1000 jear eartbquake (deslgneted Stampede. Boney Lake Valley. Boney Lake, and Genoa) have been loft off from Figure 11. Whes these date are plotted on Figare 11, they overlie the trend defined by the Newport-Inglerood and White Tolf fants. These data bave been left off becase the slip rates are rather poorly constrained. For the Thite Tolf fant and tho Newport-Inglenood fant, tho ip rates ere vell constrained, and the conclusion is that the earthquakes represent relatively rare occorrences abich happened to occur duriag the observatlonel time period.

Areraged orer abont a so-gear time perlod, tho average occorrence rate on the Newport-Inglerood and White Wolf fanlts is abort tea times that predicted from tho slip rates. Therefore, If all small certhquites on these two faults were to cease for the dext 500 gears. the average occurreace rates from the current so-gear interval. including aftorshocks vodd bo consistert Fitb the occurrence rate as ostimated frow the slip sate. Considering that low level activity ung continue on these fanls, or that additional segents ang rupture during cycles of duratios $\approx 10^{3}$ jears. It appears reasonabie to anticipate that an aver age of $10^{3}$ jears 111 jield average occurrence rates which are 
Appendiz I

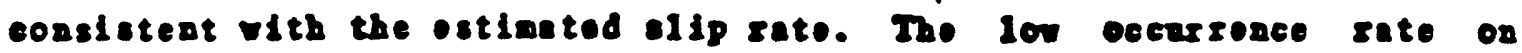

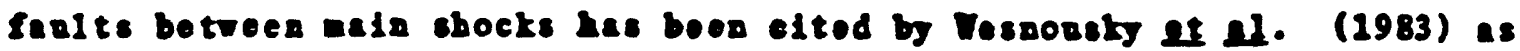
oridence that the Getenberg-2icbter cecurrence rate curve loes aot apply to a indifidual faelt. Figero 11, os tho coatrary. ladicates that the eftorshocks of anjor carthqukes aro sefficiont to ol iminato tho defieit

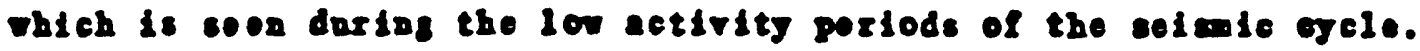

Pigne 12 bhors the faelts which aro bolor the 10-jos earthquake contorr or Pigure 9 . and does got shor the complezertary picture of observatlons all being lese than the observed occurrence rates. There are throe faelts, Sax Andreas 6. Carlock East, and Garlock West which have aore earthqukes than prodicted by the theory. Considering that these farlts aro considerod or Figare 12 becasse they have aot had large earthqukes. this observation vorld cocm to contradict the conclasior which was roached id conjusctios vith Figuro 11. The noro 11kels oxplaattog is that the ostiveted b-valus do not apply to complete cyclos of ceismicity. Figere 22 nses b e.46 lor San Andreas 6. b - .50 for Gar lock East, ad b $=.52$ for Gerlock Tost. These braloes, vbile motlvated by obsertatioss, are quite 10r. A larger b-ralue can probably be expoctod from anin bhock aad lts aftershocks on each of these farts, and can ressonably bo expected to elininte tho discrepancy.

Figares 23 a-b show this comparison for each of the sob-regions which have beed considered, and allow error bers on each datwin to be displejed.

Applicetion to enrtbarake prodiction

It is concelvable that the compardson of occurrence rates vith rates predicted from geologleal slip rate ang jleld information which is asefel to earthquate prediction. For this purpose. occurrence rates vere oramined op to the joar prlor to the occorrence of each of the orthquakes la Calffornia vith agaitude greater than 6.0. Eleven fanlts representing fifteen oerthquakes show onongh prior selswicity to establish these prior occurreace rates: Bosgri. Pleito-Thite Wolf. sierra Madre. San Andreas 9. San Andreas 10. Imperial. San Jacinto, Sierra Nevada-Oweas Valley. Bilton Creek, Stampede, and Hanalx. It is convenient to define $\mathrm{I}(\boldsymbol{U})$ as the satio of the observed occrisence sate at magnitode $X$ to the occurgence rate at magitude $A$ wich is predicted from the slip rate. On forr of the above-named fadts $R(A)>$ for $A$ Iess than 5, or the otbers $\mathrm{R}(\mathrm{L})<1$. The faults itb low observed occorrence rates indicate that if $R(X)>1(X<5)$ is osed as anearhquake predictor. there woold be a ignificant rate of missed cosecasts (abort 75\%), at least on a survey level soch as thle.

The fadts with high occurrence rates relative to the slip rate estimates aro San Andreas 10. Stampede. Sierra Nevada-Owcas Valley. and Biltos. If a bigh rate of earthquakes relative to the slip rate ostiate. In the absence of a aftersbock sequence. could be ised as a 
precarsor for oroa 25 of the esthqmkes is Calffornds, this world be a helpful observation for the esthquak prediction problem. Therefore. en effort was ade to detervine which ferlts, et the end of Docenber 1979. Lad occurronce rates et the ascitedo 3 to 5 lorel which vere larger than expected frow the olip rate estlates. Of the 69 or Figare 10. 26 (sbont 405) fell into this catogory. In 1980 or 1981. oaly one of these farlts (Bilton Creek) had earthquakes oith 126 . Abort 30 to 50 percest of the high ratios cas bo attribated to provions aftershock sequences. The Bilton Creek fenlt showed lacressing celsuicity (ejpe

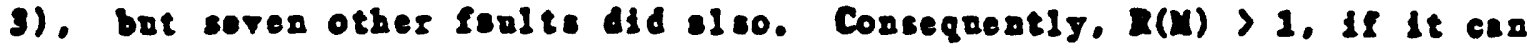
be regarded as predictor. Is Iikely to hare a lerge rate of false alares (ereater than $90 \%$ ) or a tine scalo of ore or two years. This conclusion is veak, primerily becanse of the large ucertalnties which ere prosent is the data.

\section{Conclosions}

This peper has compared observed occurrexce rates of escthqukes is the viciaity of active farlts is Calforals, Dalted states of America, -ith occusreace rates which hare bees estimated from allp rates on these farlts. The observed occurgeace rates soen to bo bounded, betreen oae order of argatide larger than prodicted to two orders of argitude andler than predicted. Host of the observed rates are vithin one order of argatide of the predicted rates. There are importent, bot ancer tain, parameters which exter to affect the estimate of occurreace rates from the slip rate: the arinum moment earthquke, the b-value, and the ilip rate itsell. Bowever, relotively vell-constralaed deta from some of tbe fadts ouggest that the scatter sbout the predicted occurreace rete is a real phenconenor for observed rates areraged for o 50-year time interval. No cases have sppered in which a linear relationship betreea negoltude sad the logerithm of occurgence rate ls serforily lasdequate.

There are sow several stadies of the seismle hazard in which silp rates or strain rotes ore converted to earthquke occurrence rates oith aethods ofwilar to those which have beed apployed by this etady (eb. Campbe11, 1977: Aodersoz, 1979: Papastametlor, 1980; Greensfelder et 1.. 1980, Doser and Smith, 1982, and Fesnodsky, 1982). Figure 10 ladicates that soch seismic hazard otodies way arrive st expected eartbquake recurrence rates up to a factor of 10 different from comparable studies -hjch ase instrumentaliy recorded eartbguekes a besis for the inpot. Te aote frow Tables 2 and 4 that the sabjectire ancertainty lo the sip rate on the fadt is considerably smaller thas aultiplication factor of $10 \pm 1$. Campbel1 (1977) hes upployed a procedure la which the geological estimate is osed os a plor model la Bayesian procedure. and observed earthquakes are ased so spplementary date to updace the prlor sodel. The apdated model tends to jield risk estinates wbich are inter nediate betreen the slip-rate based estimate and the historical seismielty besed estimete. Io rier of the results of this paper. It is not unlikely that the apdated ocenronce rates obtained by the Bayesian 
procedure -112 be lecosistent rith extreme estientes of the sip rate besod on geological observatiogs.

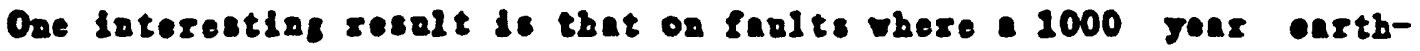
gukt has occurred, the observed ererage occriresce rater, orer 50 jears, at all angltudes ere abovt 20 tines the rates prodicted frow ilp rate. Therefore, these farlts cas underso 500 joars of quiescose. efter which the observed rate roold egree rith the prediction. It

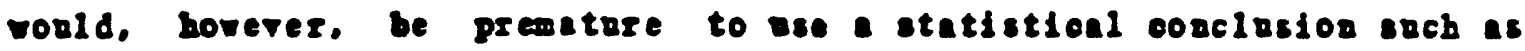
this as jostlficatior for aswiag that these fablts ang be seglected in

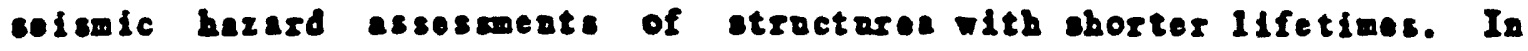
particular. these cartbqukes have not always ruptured the eatire longths of the fant. Partherwore, not exorgh ls bowa to justify an assumptior that a farlt is straiged at a costart rate in tiat.

An attempt bas beos ade to determine if a ligh level of coall earthquke occurreace relative to the olip rate estinates is helpfol for the problem of predicting carthqukes. Prolininary resolts are disconsagiz. In that they bply that thls indicator aay bo preseat before only and araction of the earthquake ( 25\%), and that the preserce of this ladicator aeg have arge fal se alasm rate ( 905). However, lt ang be raluble to cossider different rays of detorminlag the average occurreace rates, In conjunction vith better established olip rates as these become availablo. Furtbermoro. It is possible that this Indicator conld be helpfol in the futare at faelte where it has bees valid in the past.

\section{Acknowledsments}

This research was sopported by the United States Geological Survey Contract No. 14-08-0001-19766. 


\section{Reference:}

Anderson, J.G. (1979). Estinetigs the celsmicity fron seological etroc-

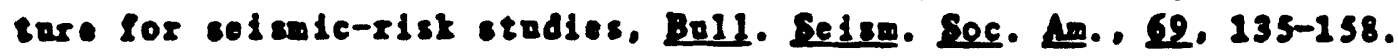

Andersoz, J.G. asd J.E. Lreo (1983). Consequesces of elip rate cor atralots on oerthquke occurrence relations. Bpll. Seism. Soc. Am.. in press, April.

Batemar, P.C. and C. Wabrbatis (1966). Goolosy of the Sierra Nevada, Is Geolory of Northerd Callfornis. Bal1, 190, Callf. Div. of Minos and Ge01085. 107-172.

Bird, P. (1982). Tinewatlcs of present ernst and antio llow is sonthera Californda. Geol. Soc. of Am. Bull. (ín pross).

Brane (1968). Seismic mowert, soismlelty, and rate of slip along asjor fant zones. I. Geophrs. Res.. 13. 777-784.

Bryast, W.A. (1979). Earthquakes near Bosey Lake, Lessed Conty, Cal1fordia, Californie Geolory. May 1979, 106-109.

Campbe11, X.W. (1977). The use of selsmotectoaics in the Bajesien estiation of seiswic sisk, Rept. No. DChA-ENG-7744, School of Eng. and Applied Selences. Univ. of Californie. Los Angeles.

Davles, G.F. and J.N. Braxe (1971). Regloarl and global fant slip rates frow selsmiclty. Netore. 229, 101-107.

Doser. D. and R.B. Soith (1982). Seismic moment rates in the Dtah rogion. Bull Seism. Soc. A. … 12, 597-614.

Durrel. C. (1966). Tertiary ad Quaternary geolosy of the rorthera Sierra Nevada, In Geology of Northerg Califoraia, Ball. 190, Calif. Dit. of Nines and Ge01085. 185-197.

Egochd, R.T., I.T. Campbe11, and J.H. Wigglas (1979). A survey of expert opinion on active snd potentially sctive fants in Califor ala. Nevada, Arizona, ad northera Baja California, Technical Report No. 79-1328-2, J.8. Tiggias Co.. Redondo Beach, Calif.

E11srorth, T.L., A.G. Lindb. T.B. Prescott and D.G. Herd (1981). The 1906 San Francisco earthquake ad the soismic cjcle, In Eartbquake Prediction: An International Revier.

Greensfelder, R.. P.C. Tintzer, and M.R. Summerville (1980). Seismotecconic regionalization of the Grcat Basid, and conparison of moment rates computed from Bolocene strale and bistoric seismicity. in 
Proc. of Conf. X, Eertbquke Rezards along the Fasatch and Sierza Nevade Frontal Fandt Zosos, Opea File Report 80-801, D.8. Geol. Surver. Menlo Park, Calif.. 333-493.

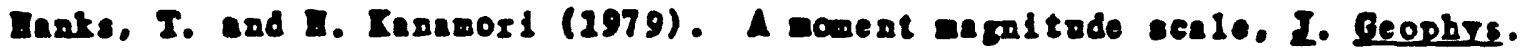
Res.. 84. 2348-2350.

Eord, D.G. (1979). Neofectonle framerork of central costal Califoraia and lts inplications to alerozonation of the San Francisco Bay reglos, in Brabb, E.E. (oditor). Progress on celsede zonation in the Ses Francleco Bay reglos, D.8. Gool. Surtoy Circeler 807. 3-12.

Toopoff, L. I.I. Ingan, and R. Toopoff (1982). b-velnos for foresbocks and aftershock in real and sinuleted earthquke sequences. Bufl. Se1sm. Soc. Am. 12. 1663-1676.

Hyers, B. and C.A. Vonbake (1976). Earthonake Dete File Summerr. Natiosal Goophysical and Solar-Terrestrial Date Center. Bonlder. Co.

Molar. P.E.(1979). Earthquake recorrence intervals and plate tector 1cs. Bel1. Selsm. Soc. Am.. 62, 115-133.

Papastamation, D. (1980). Incorporation of erastal deformation to seismic hazard analysis. Ball. Selsm. Soc. Am.. 20, 1321-1335.

Papageorgioz, A.8. and I. AzI (1982). A specific berrier nodel for the quatilative description of inbomogenoss farlting and the prodiction of strong ground notion II. Description of the model. Proceedings of Torkshop IVI. The Dyande Characterlstics of FandInt Inferred from Recordings of Strong Ground Hotion, Open File Report 82-591. D.S. Geol. Surveg, Menlo Park. Cal1f., 311-352.

Sharp. R.V. (1981). Varlable Rates of late Quterang strike slip od the Sad Jacinto fadt zone, southera Califorala, I. Geophye. Res.. 86. 1754-1762.

S1emmons, D.B.. D. Van Tormer, E.J. Bel1, and K.L. S11bermen (1979). Recent crostal wovenents in the Sierra Nevade - Falker Lake regios of Calforaia - Nevada. Part I, Rate and style of deformation. Icctonophystes. 52. 561-570.

Sylvester. A.G. and A.C. Dasror (1979). Structure and neotectondcs of th. western Sada Iner fant sjetem in soutbera Califorala. Tecto nophysics. 52, 389-405.

Taylor, G.C. and D.A. Bryant (1980). Surface rupture essociated With the Mammoth Lakes earthquakes of 25 and $27 \mathrm{Kay} 1980$, In Mammoth 
Lakes. Califordis ertborakes of Mer 1980. Special Report 150. Callf. Dir. of Mines and Geoloso. 49-67.

Wober, G.E., I.R. Lajole, and J.F. Wohndiler (1979). Canteraery crostel ceforestion along anjor branch of the 8as Andrees faelt in certral Callforaia. Tectonophreics. 22, 378-379.

Vesnorski, 8.G. (1982). Crastal deformation and carthquake risk in Japed, Ph.D. Thosis, Colmbia Dolversity, New Jork.

Tespopski, 8.G., C.8. Scholz, X. Shimazak1, and T. Katszde (1983). Berthquke frequency distribetion and the necharics of fantiag (preprint).

Toodverd-Clyde Conseliants (1979). Report of the eraluetion of aximum orthquke and sito ground notion paraneters assoclated Fith the offshore zone of deformation San Onofre Neclear Generating Station. prepared for Sonthern Califorale Edison, Rosenead, Califoraia. 1754-1762. 
Table 1 - Supplecestal ilp sate estlantes.

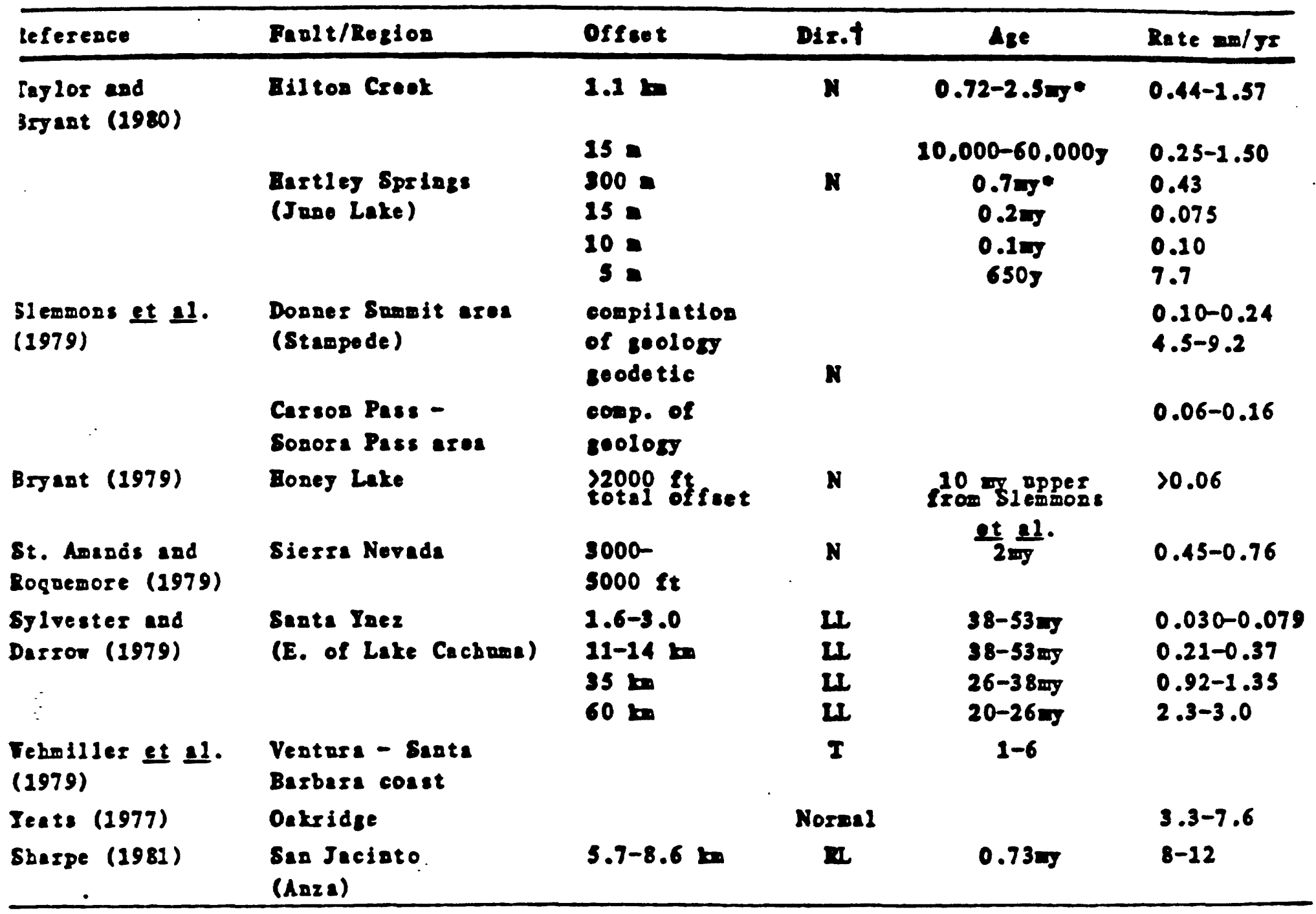

- Ages based on chrogology of Bateman and Tahrhaftlg (1966).

- Additional estimates la this.

fDirection

$N=805021$

DI = right lateral

LI = left lateral

$I=$ thrast 
TABLE 2

GEOLOGICAL SLIP RATES (MM/YEAR) OBTAINED FROM SEVERAL COMPILATIONS

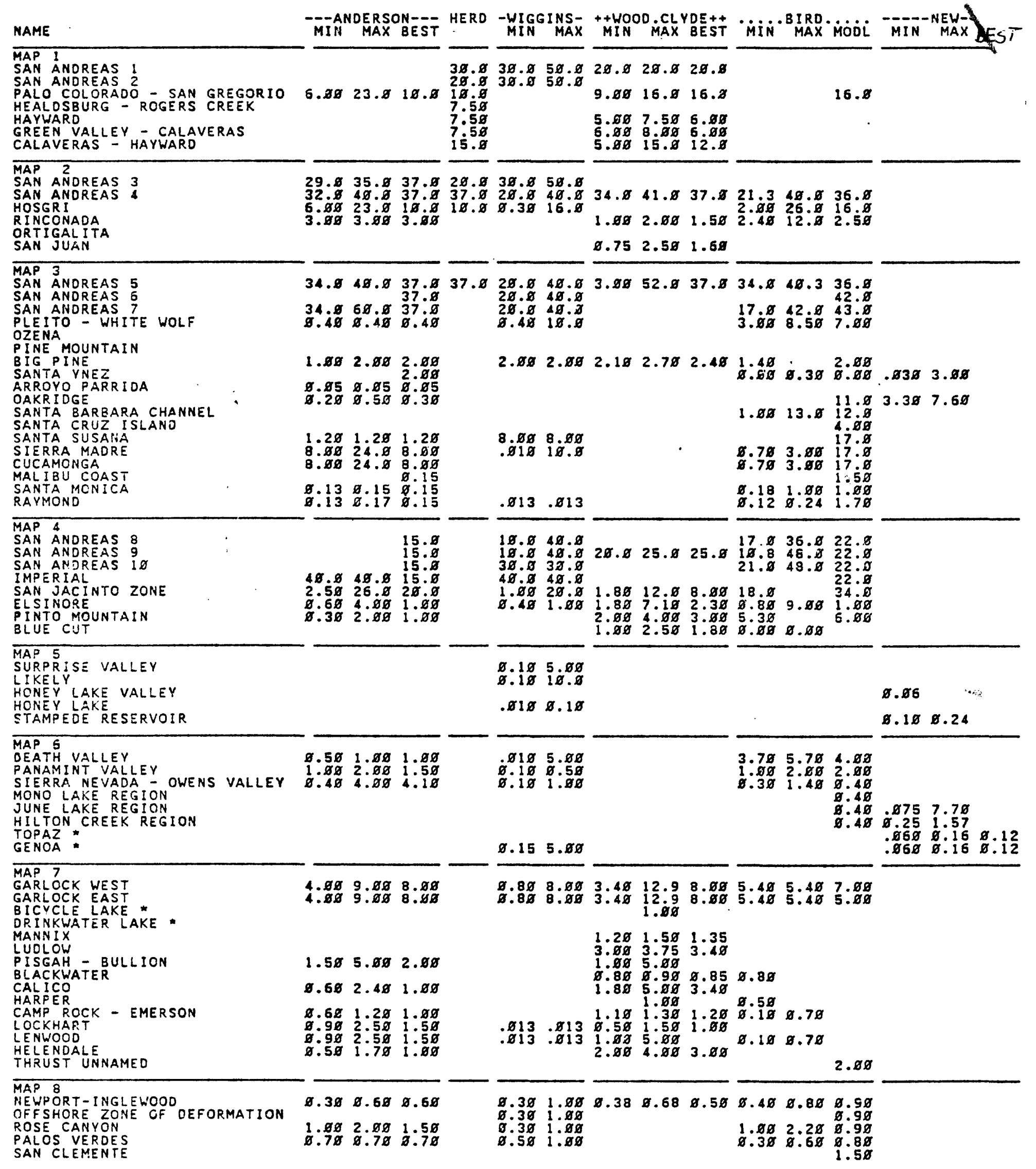


TABLE 3

COOROINATES OF CORNERS OF ZONES USED FOR SEISMICITY SEARCHES

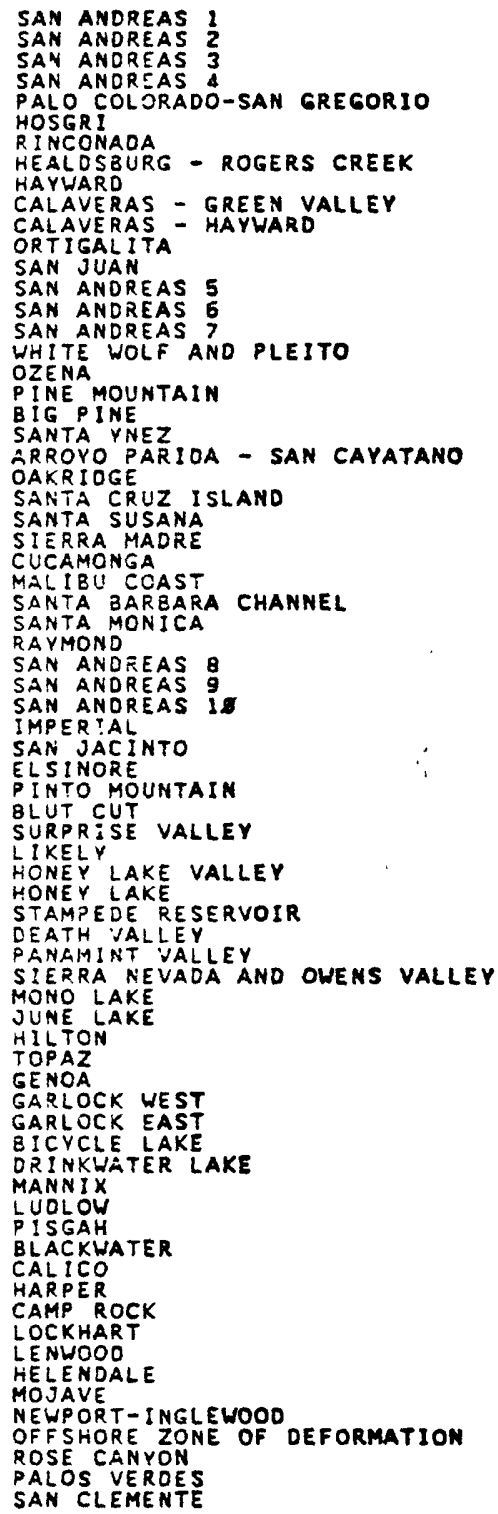

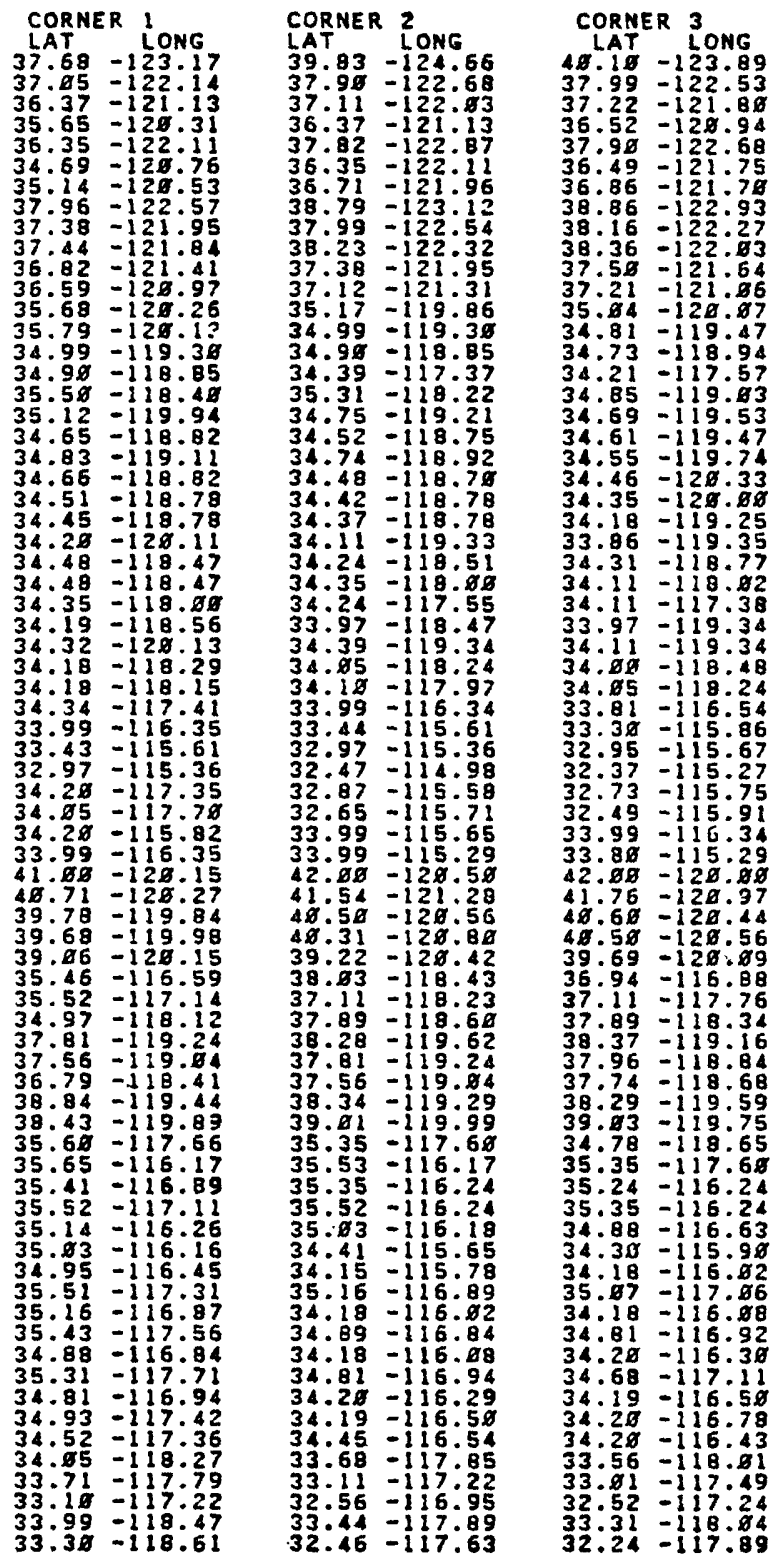


TAOLE 4

COMPILATIOH OF GEOLOGICAL ANO SEISMOLOGICAL PARAMETERS FOR SEVERAL FAULTS

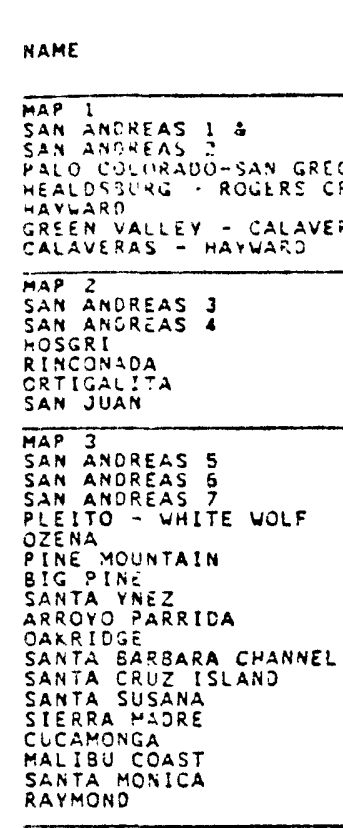

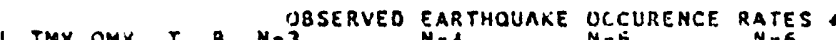
5 MIN MaX $S^{N-4}$ MIN MaX $S^{N-5}$ MIN HaX $S^{N-6}$ MIN MaX $S^{N-7}$ MIN MaX

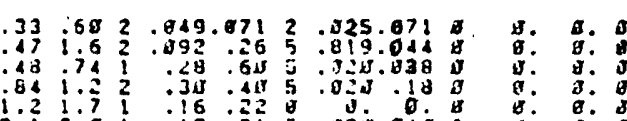

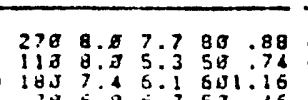

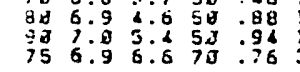

$2 . \frac{1}{5} 3.8$ 1 8. 8

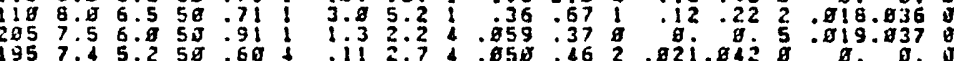

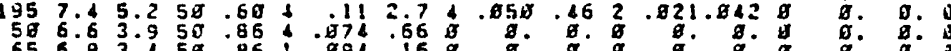

$1188.65 .658 .79+13.15$.
SLIP RATES IMMTVEAR SEIS MEOL MAX BEST IT(M)

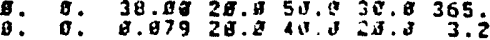

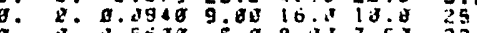

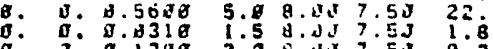

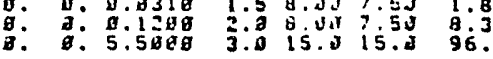

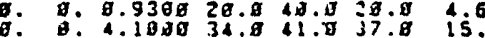
g. 3. 8.3308 9.98510 .0518 .519

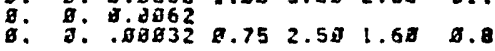

MAP A'NDREAS 8

SAN ANDREAS 3

IMPERIAEL TO ZONE

PLSTNORE

BLUE CUT

MURPRISE VALLEY

HOYELV LAKE VALLEY

HOPE Y LAKE

MAP 5 VEAT VALLEY

PANAMINT YALLEY
SIERRA NEVACA-OUENS VALLEY

JURE LAKE RETH

HILTONCSEEK REG:ON

GEMOA

MAP 7 GARL WEST

GARLOCK EAST

SI Y YCLE LAKE

MANBIX

PISTEH BULLION

BALICO

CAMP ROCK - EMERSON

LOCKHART

MELENOALE

$M \triangle P B$

MEWTORT-INGLENOOD

OFE SHORE ZONE DEFOPMATION

PALOS VEQDES

BEFORE EARTHGUARES

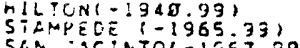

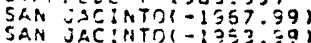

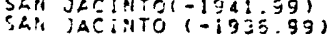

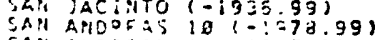

SAPANC2EAS $3(-1947.99$

TOGP $(-1951,33)$

(1)

SIEPA MAOREYIJ73.991

HON OF SOME COLUMN HEAOINGS

ATION OF SOME COLUMN HEADINGS CARGEST CSSERVED MAGNITUDE ON THIS FAULT SEGMENT IN TIME

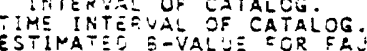

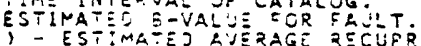

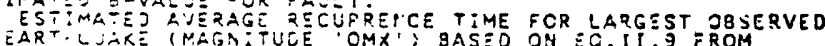

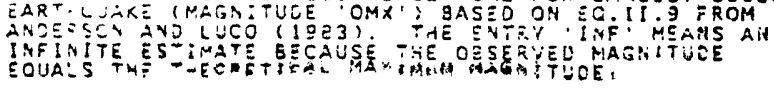

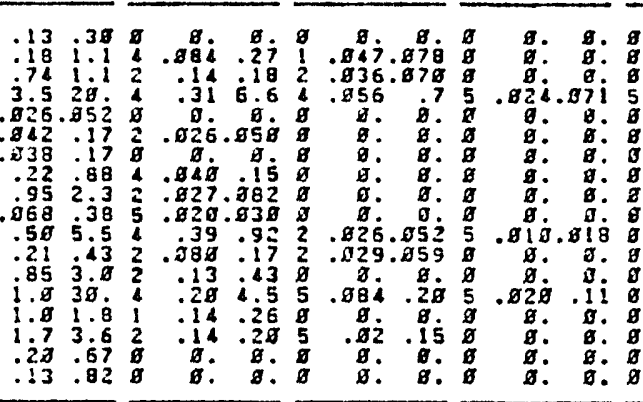

g.: g.

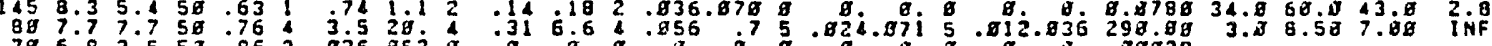

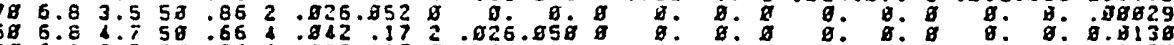

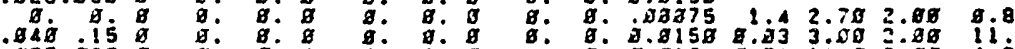
.068 उ8 5 .820.938

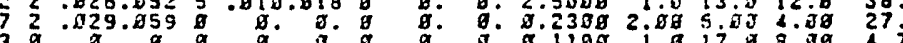

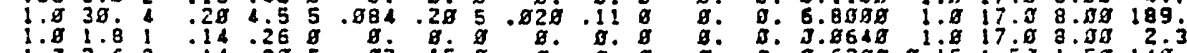

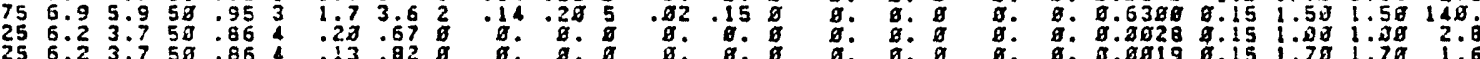

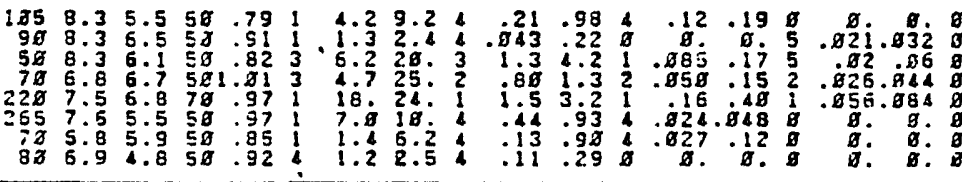

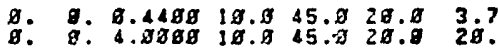
g. ह. 3.2909 10.8 45.J 28.8 18. g. g. 18.99319 .845 .828 .8328$, g. ब. B.

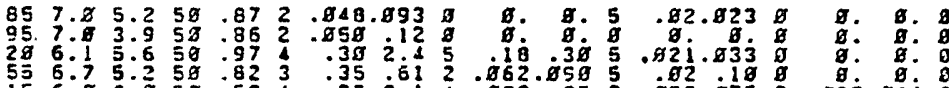

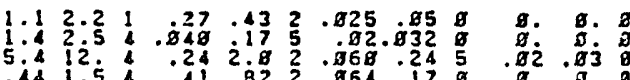

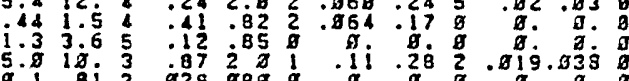

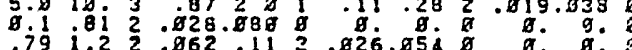

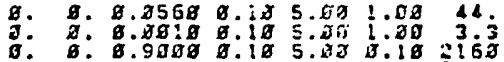

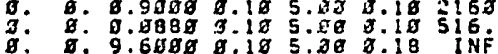

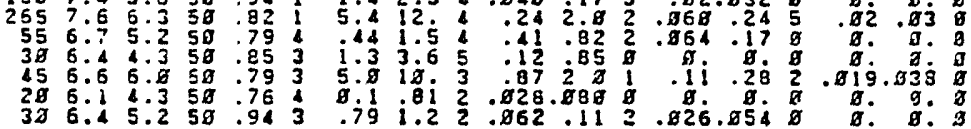
g. $2.0 .9258 \quad 2.285 .782 .88$
๑. ब.

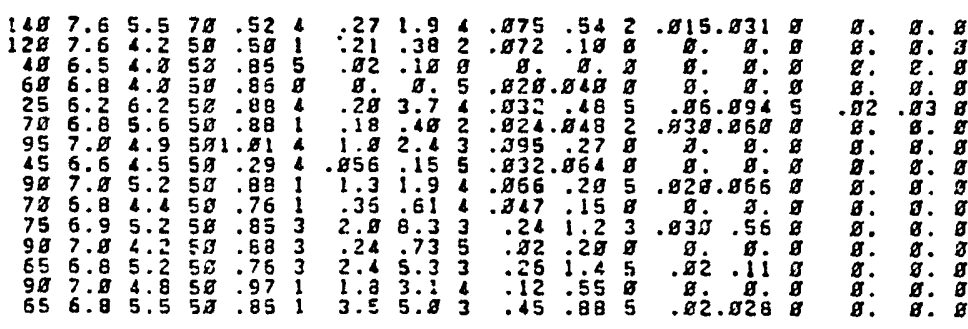

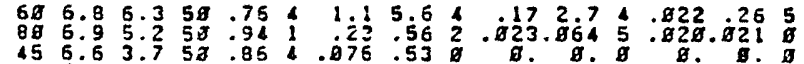

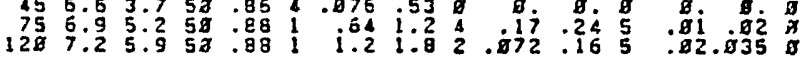

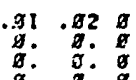

:

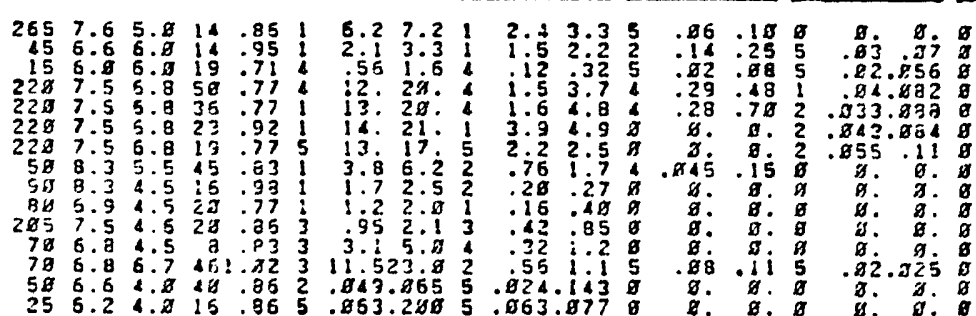

\footnotetext{
- Mame is for reference with figures 2 a-h only.
}

- 19g6 EARTHQUAKE AFFEETED SFN ANDREAS 1 . . AND 3 SL SP GIVEN HERE ON THIS SEGMENT ONIY. STIP OH SAN ANEREAS 2 ANS 3 WSICH OCCURRE

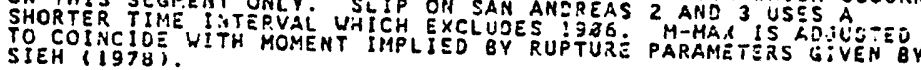

- S - GIVES SHAPE OF OCCURERCE RATE AVERAGES CURVE MIN - GIVES MINIMUM RATE IEARTHDUAKES,YEAR, COHSISTEHT WTTU

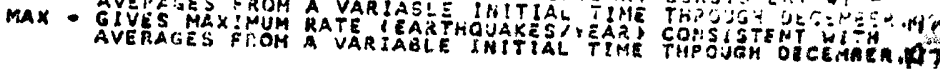


Append1x I

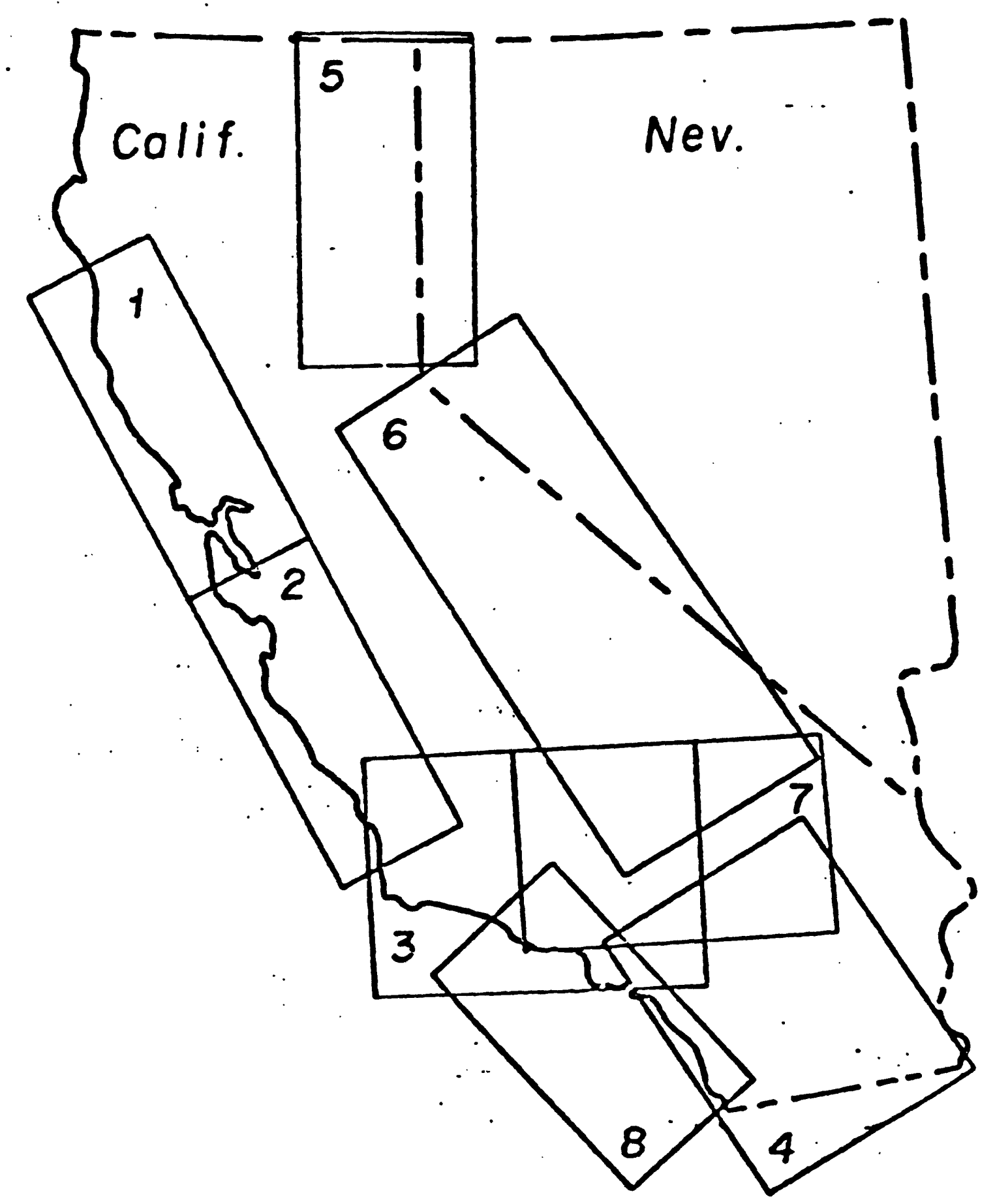

Figure 1. Map of California showing boundarles of detalled maps for reglons 1 to 8. 
Append1x I

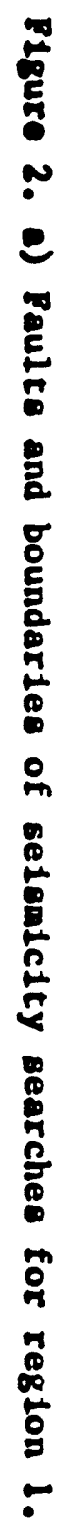

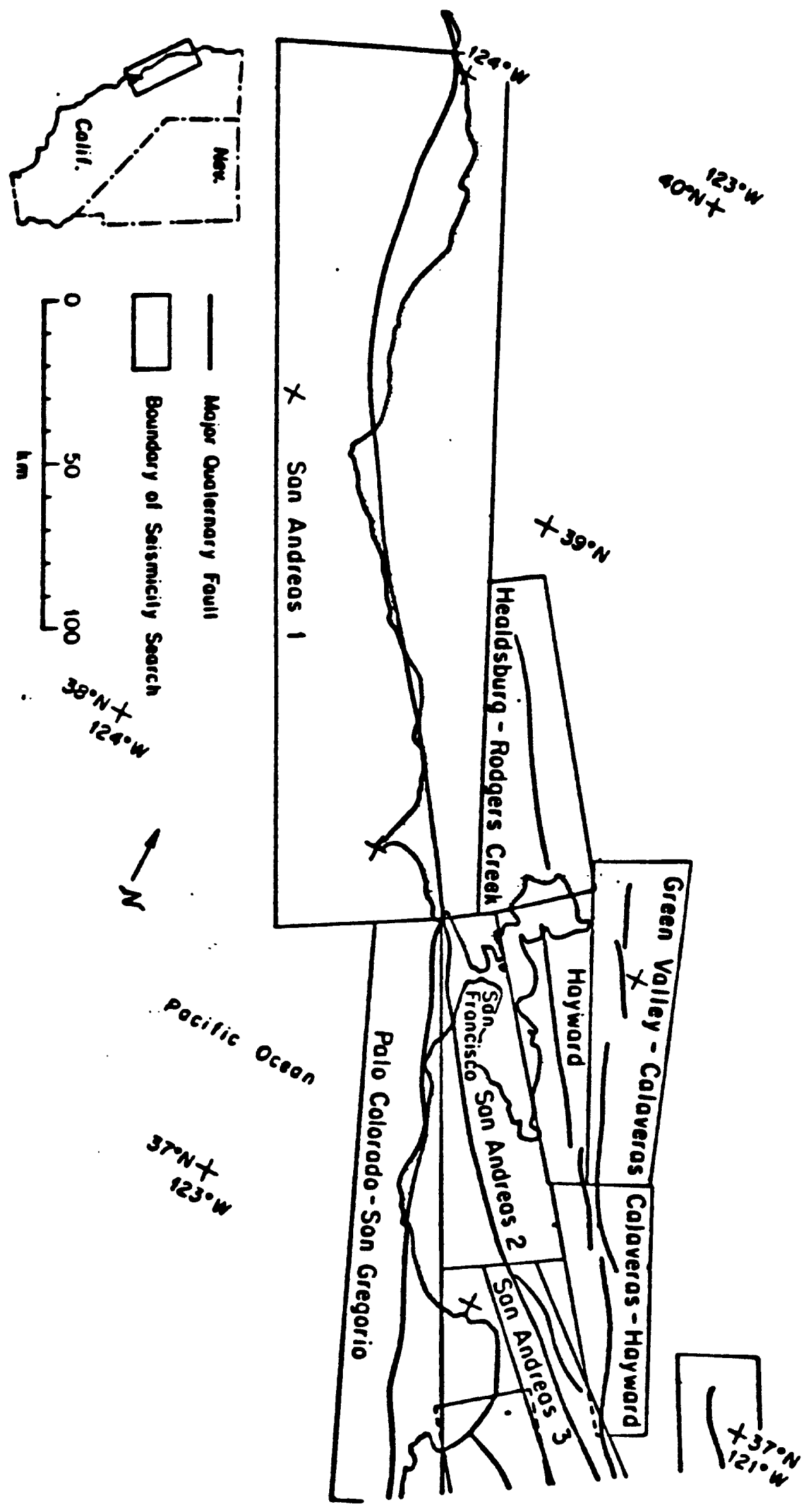




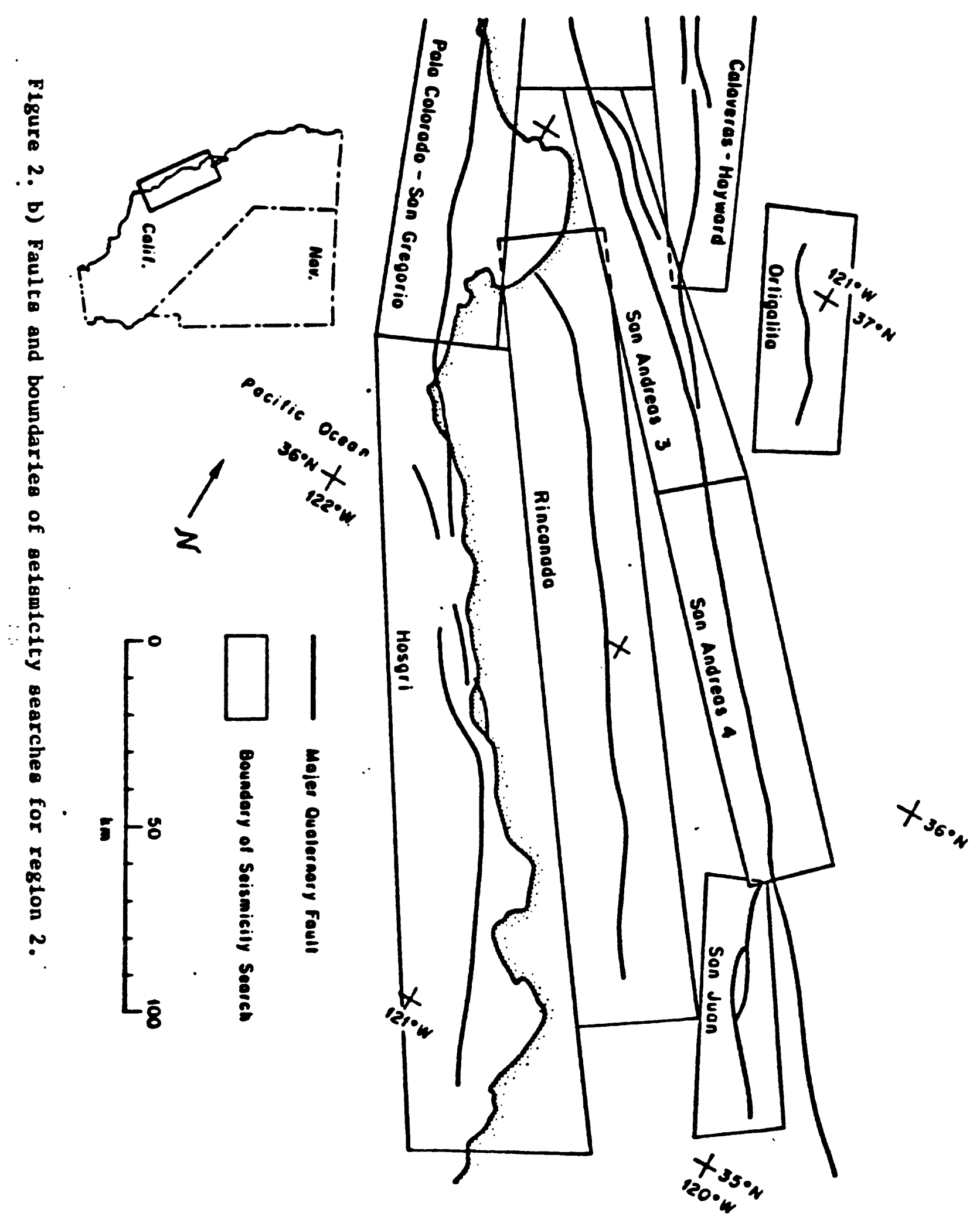


Append1x I

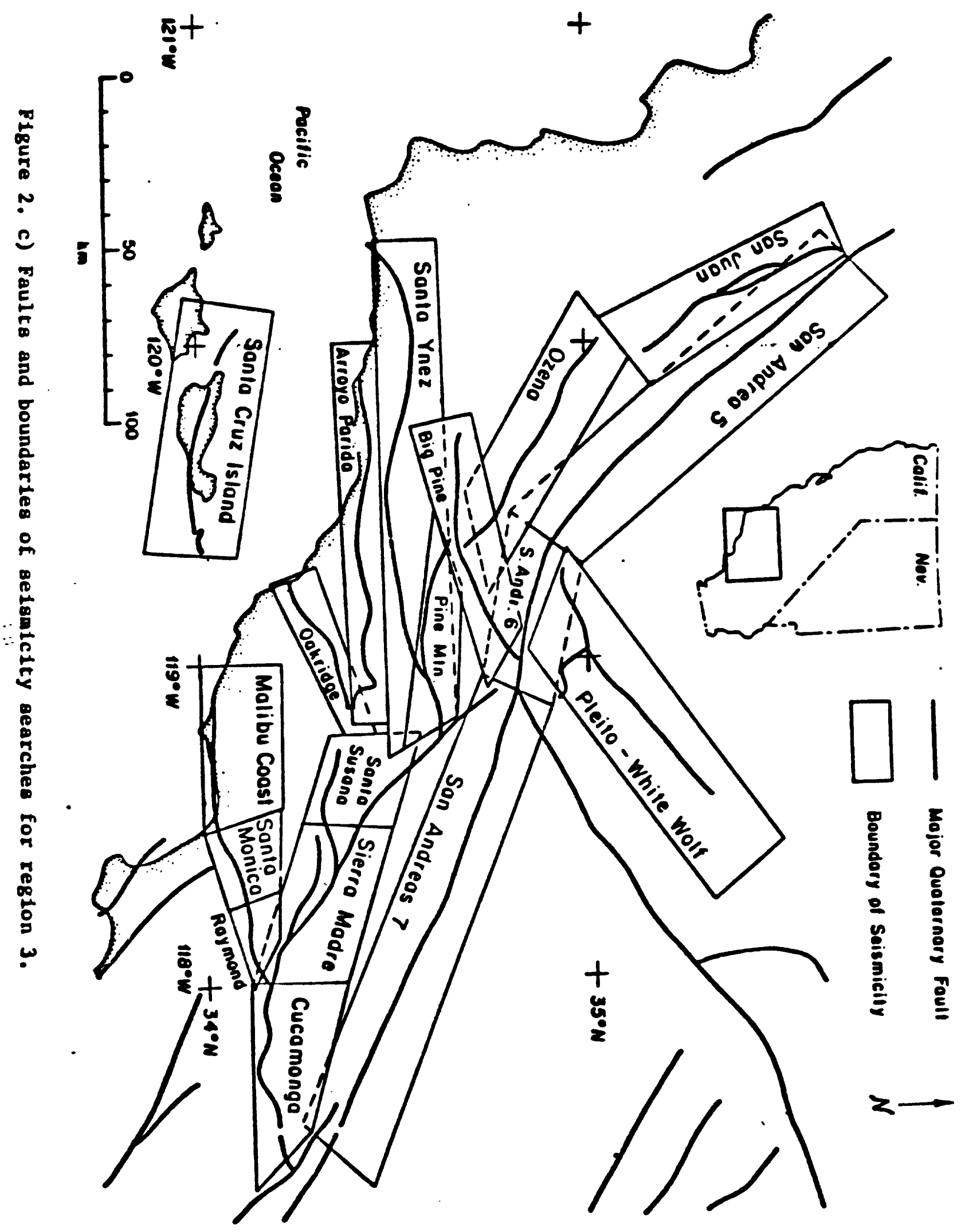


Append1X I

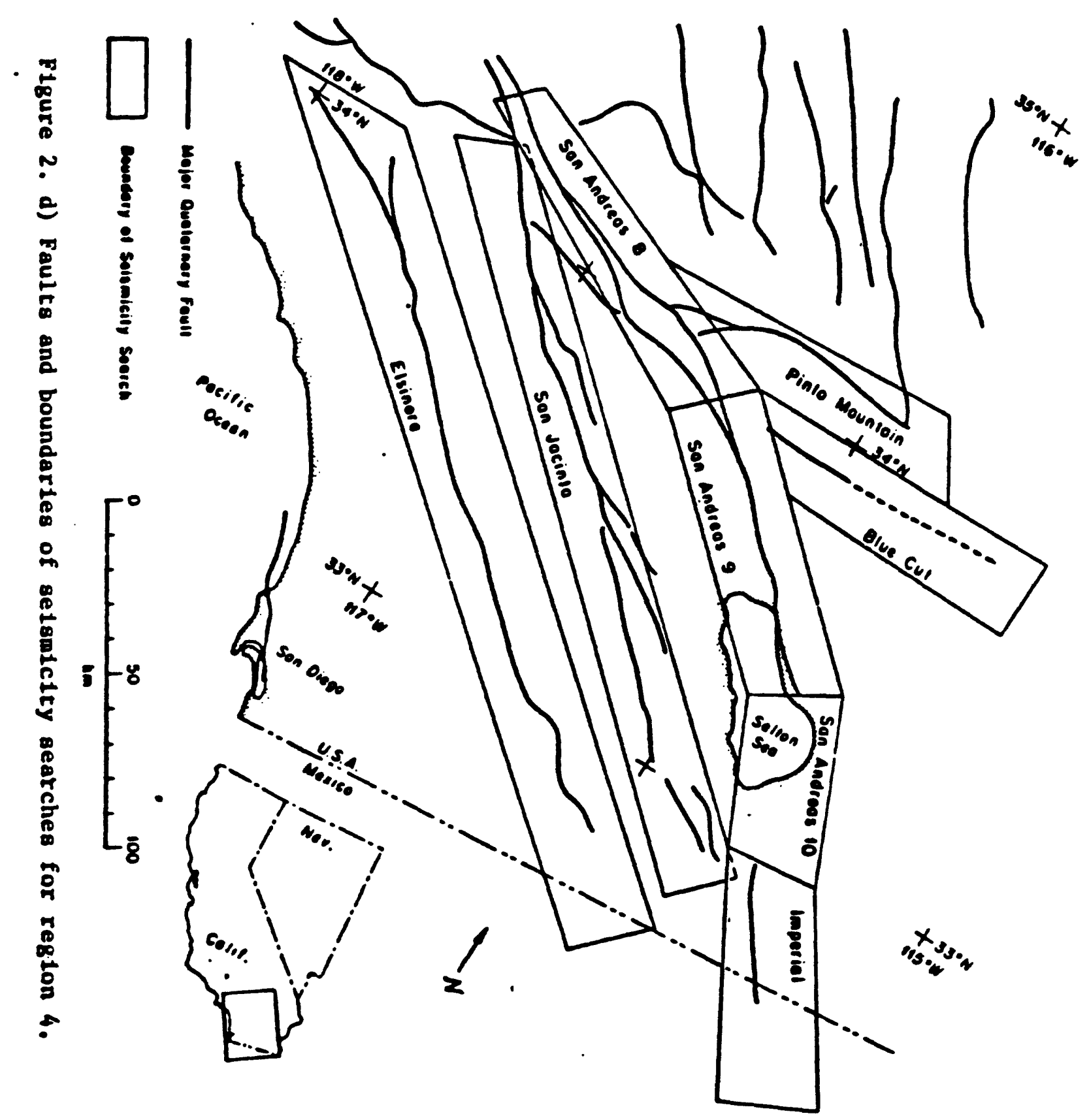


Append1x I

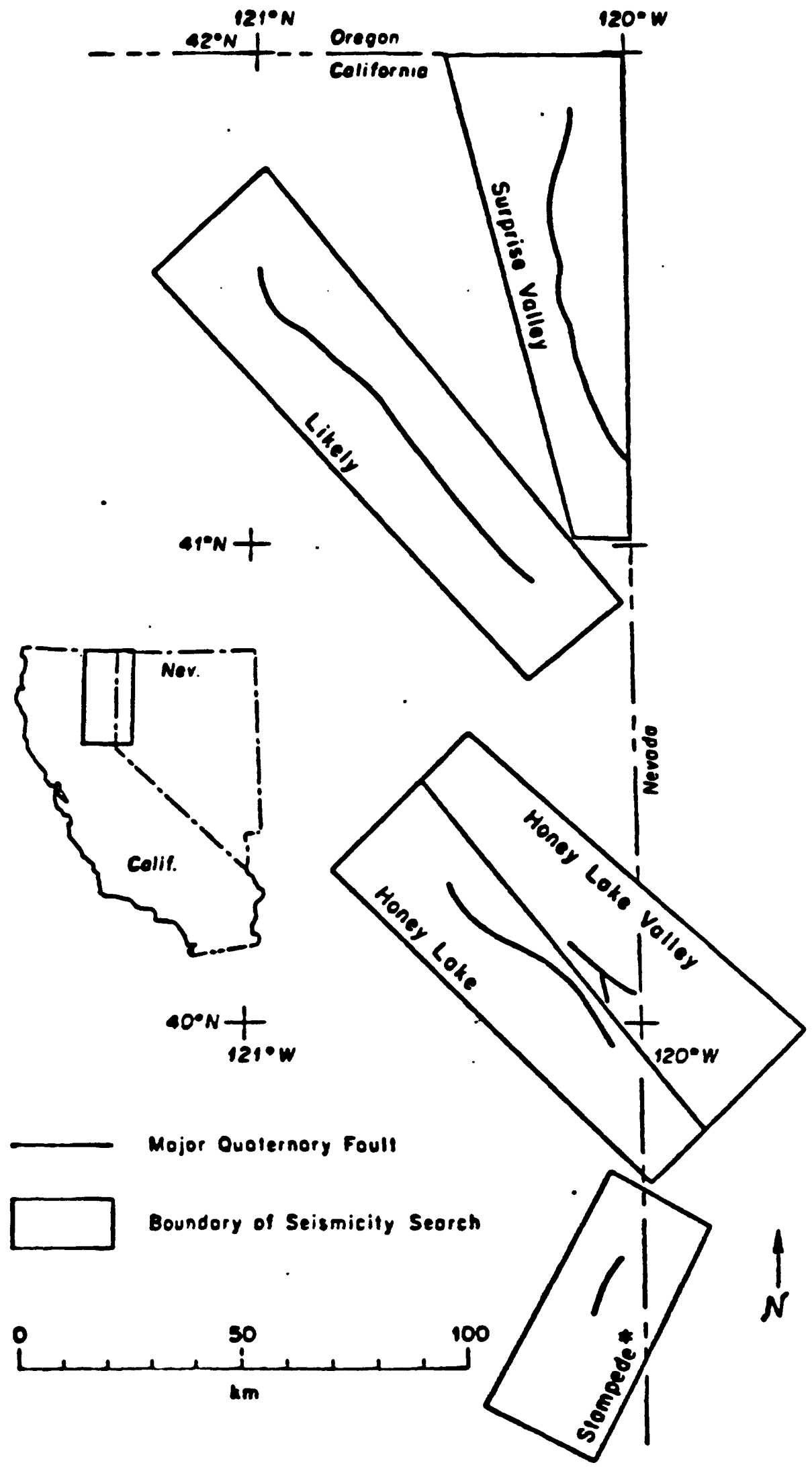

Figure 2. e) Faults and boundaries of seismicity searches for region 5 . 


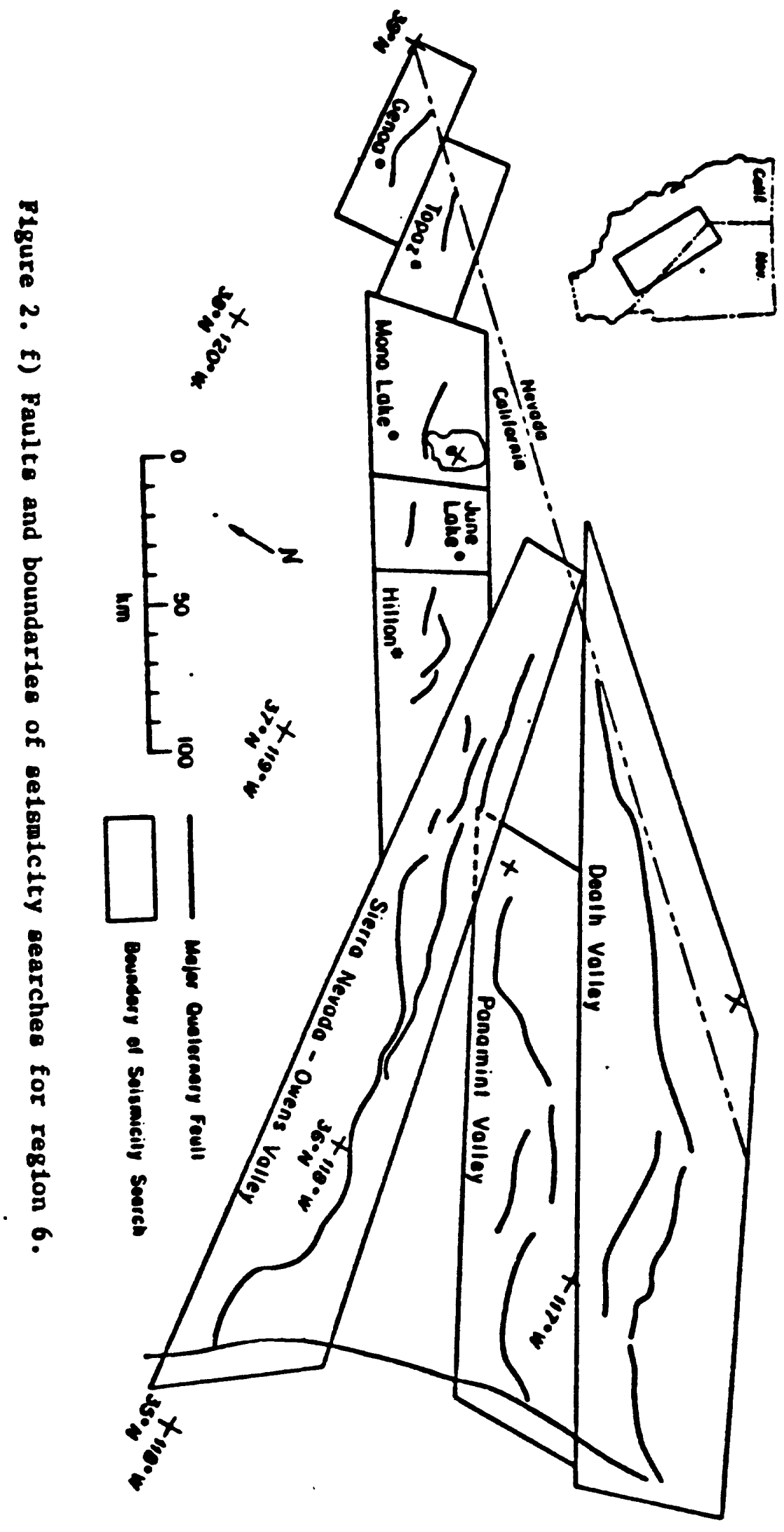


Append1X I

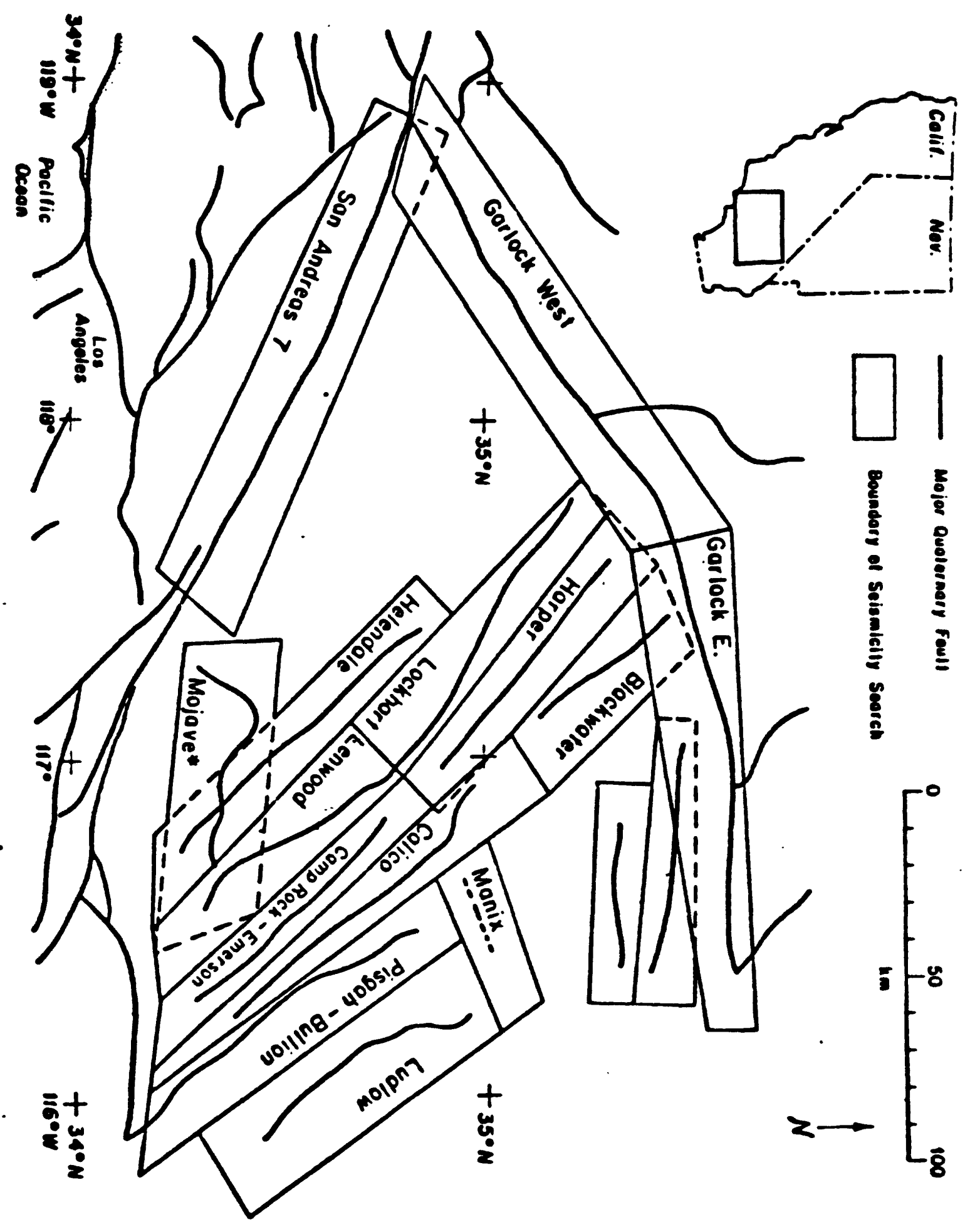


AppendIx I

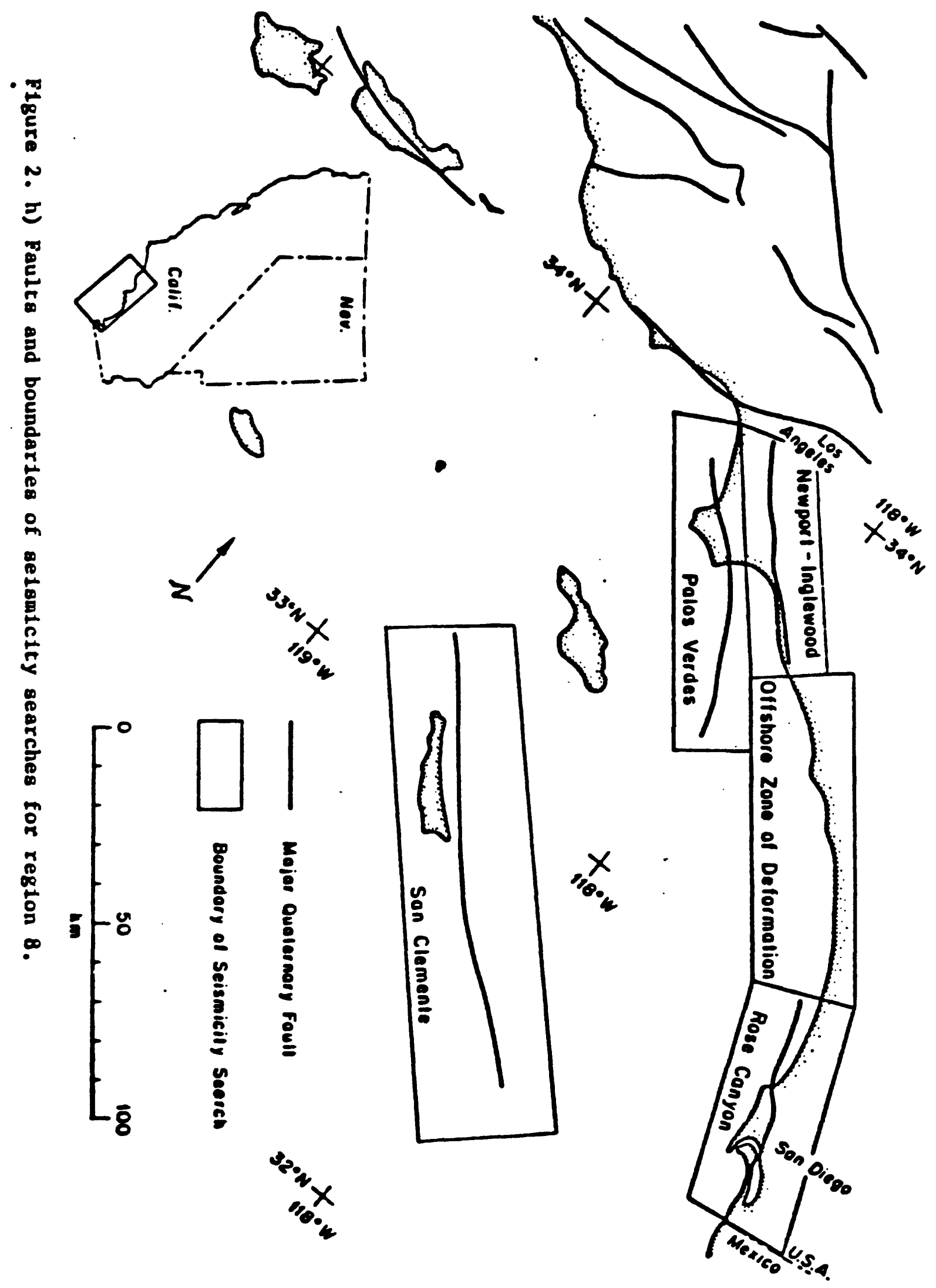


Append1x I
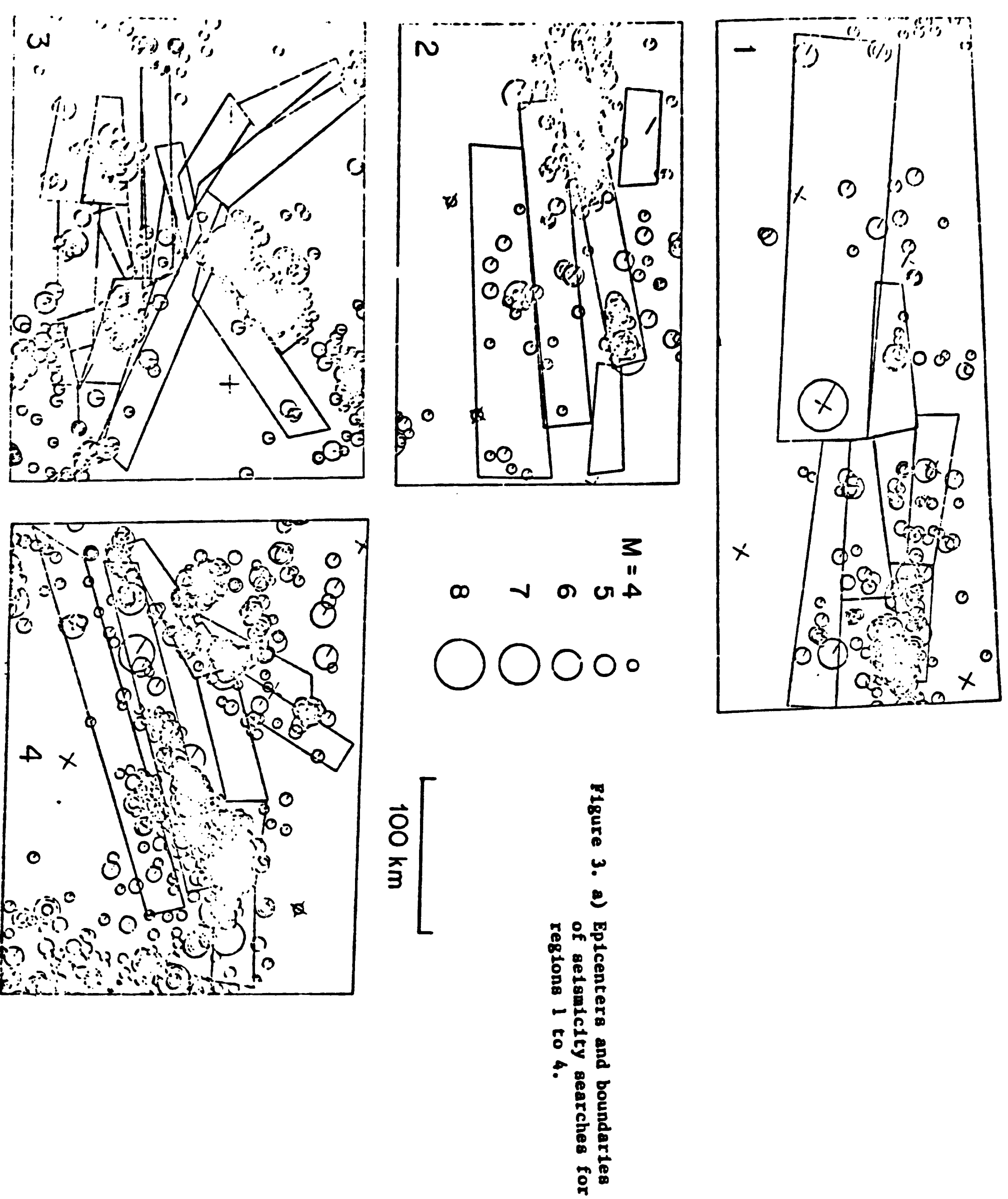
Append1x I

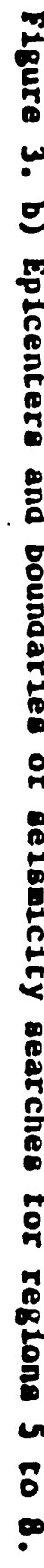
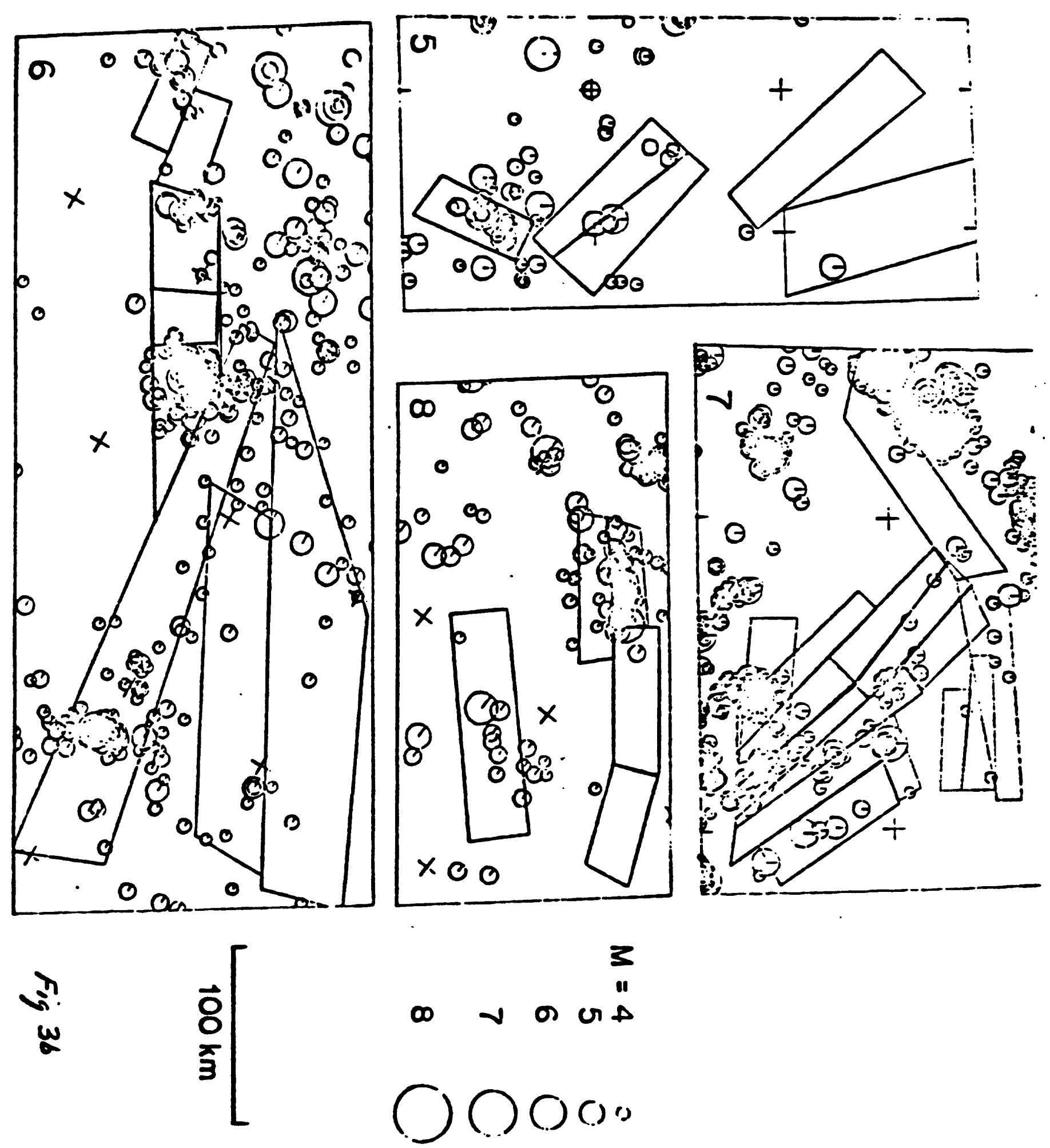
Append1x I

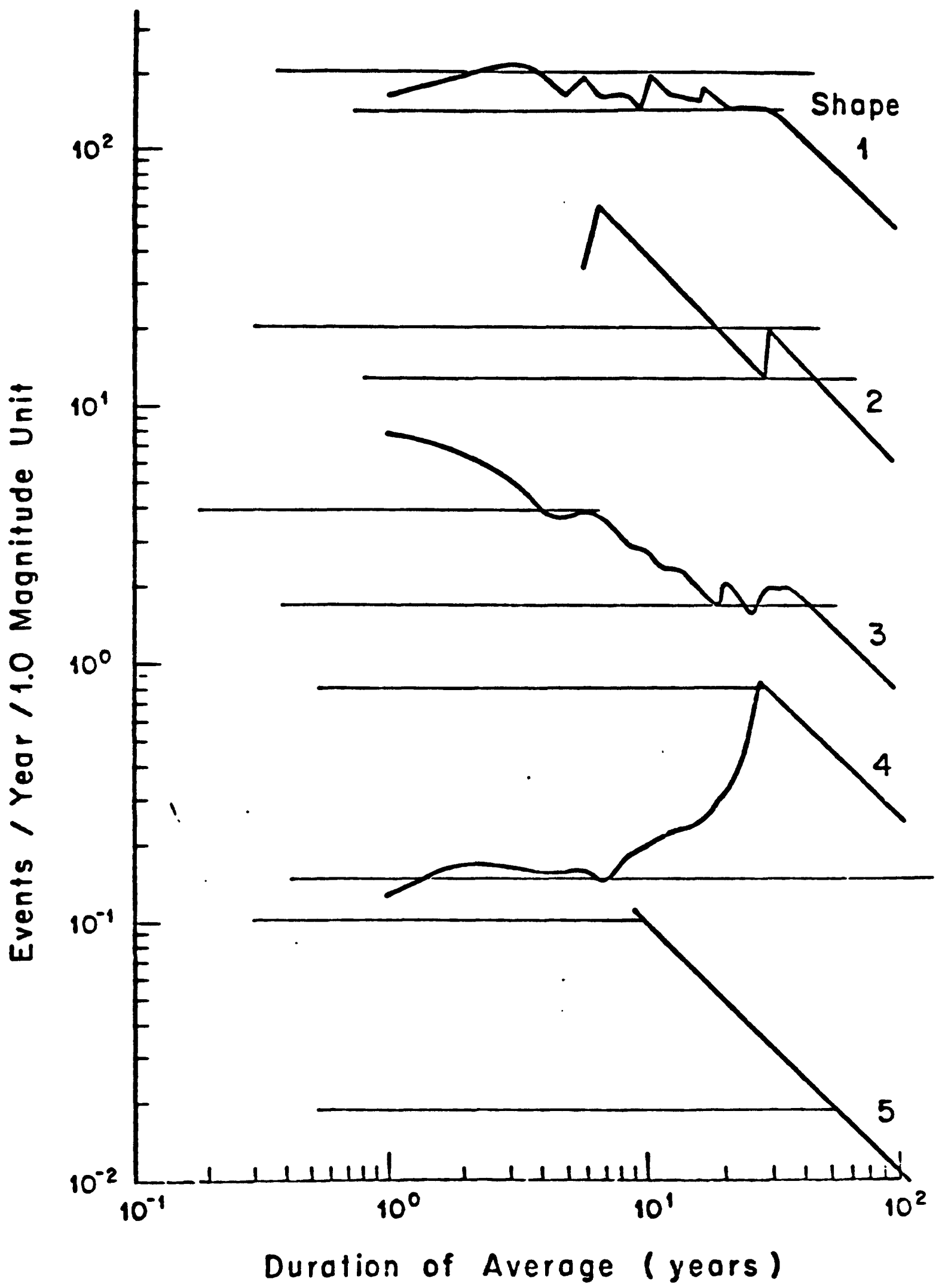

Figure 4. Characteristic shapes for the sequence of averages $A_{k}$. The valde of At for a k-year duration for the sverage is tbe nubbr of eartbquakes per jear listed in the catalog over the most recent gears. Bounds on the average occurrence rate are shown consistent with the way these bonds bave been chosed in each of the seismicity searches. 
Append1x I

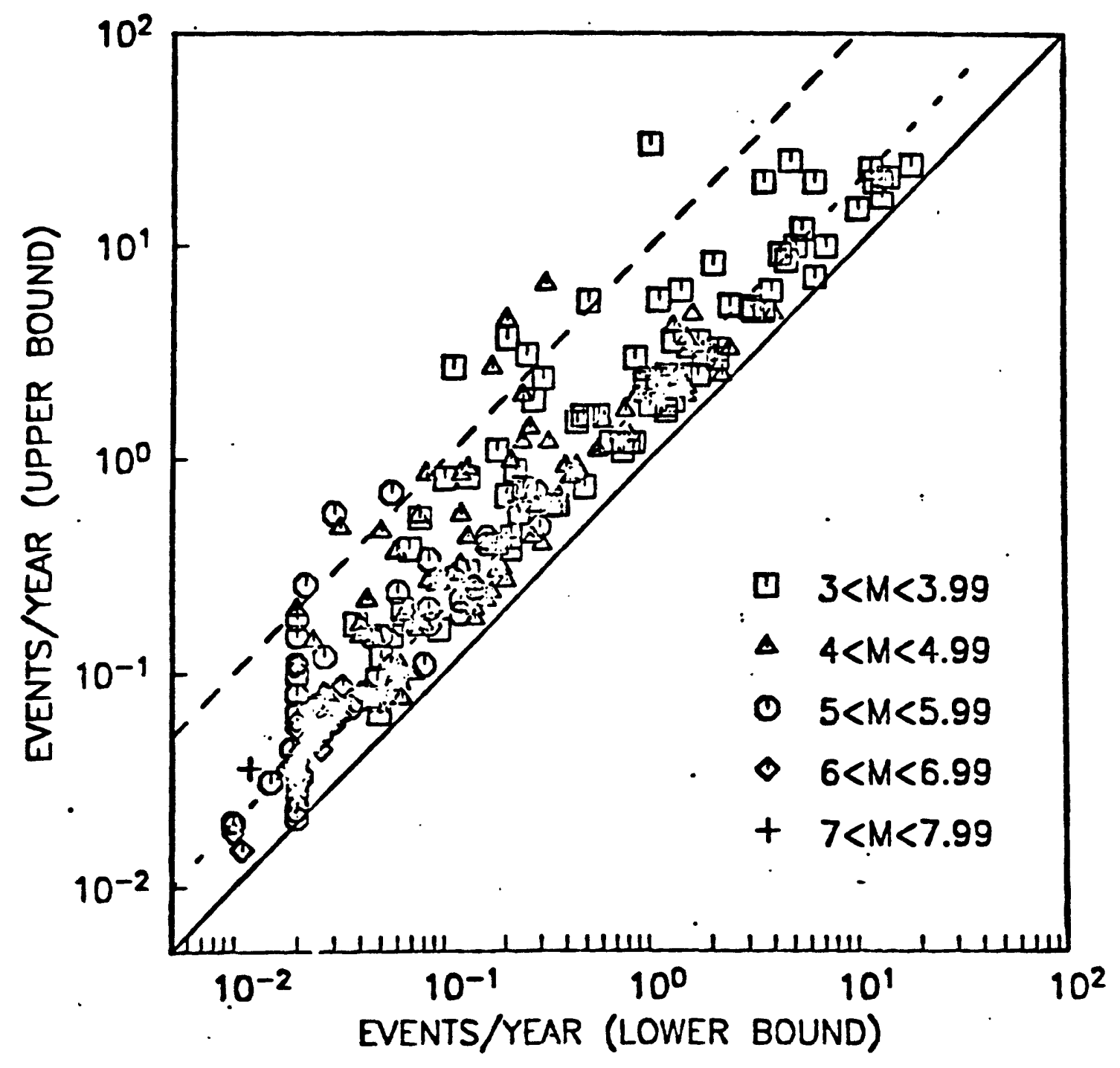

Figure 5. Reletionship of apper and lower bounds on occurgence sates for al selsicity zonos listed in Table 4 and llingtrated in Figre 2. 


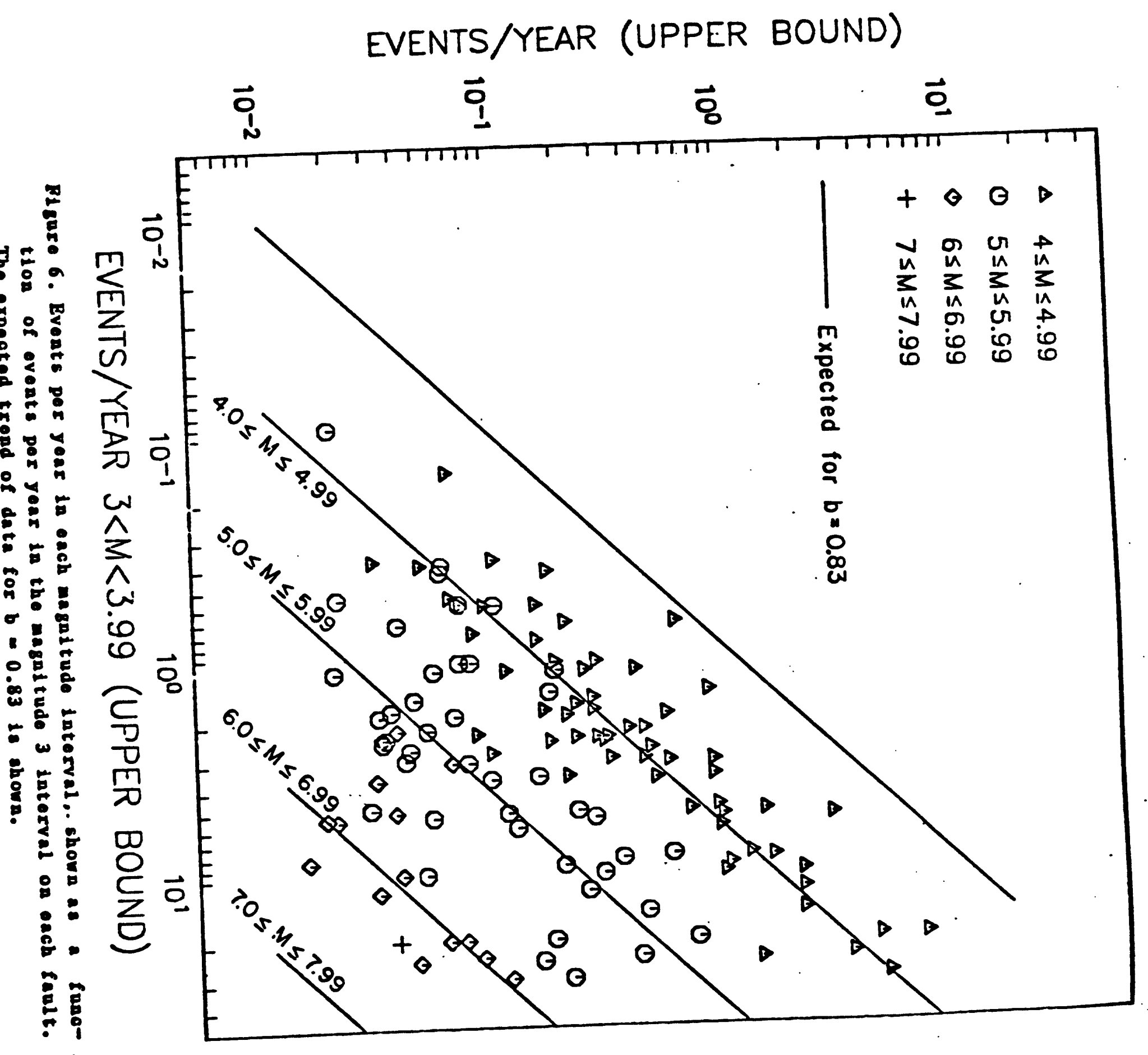




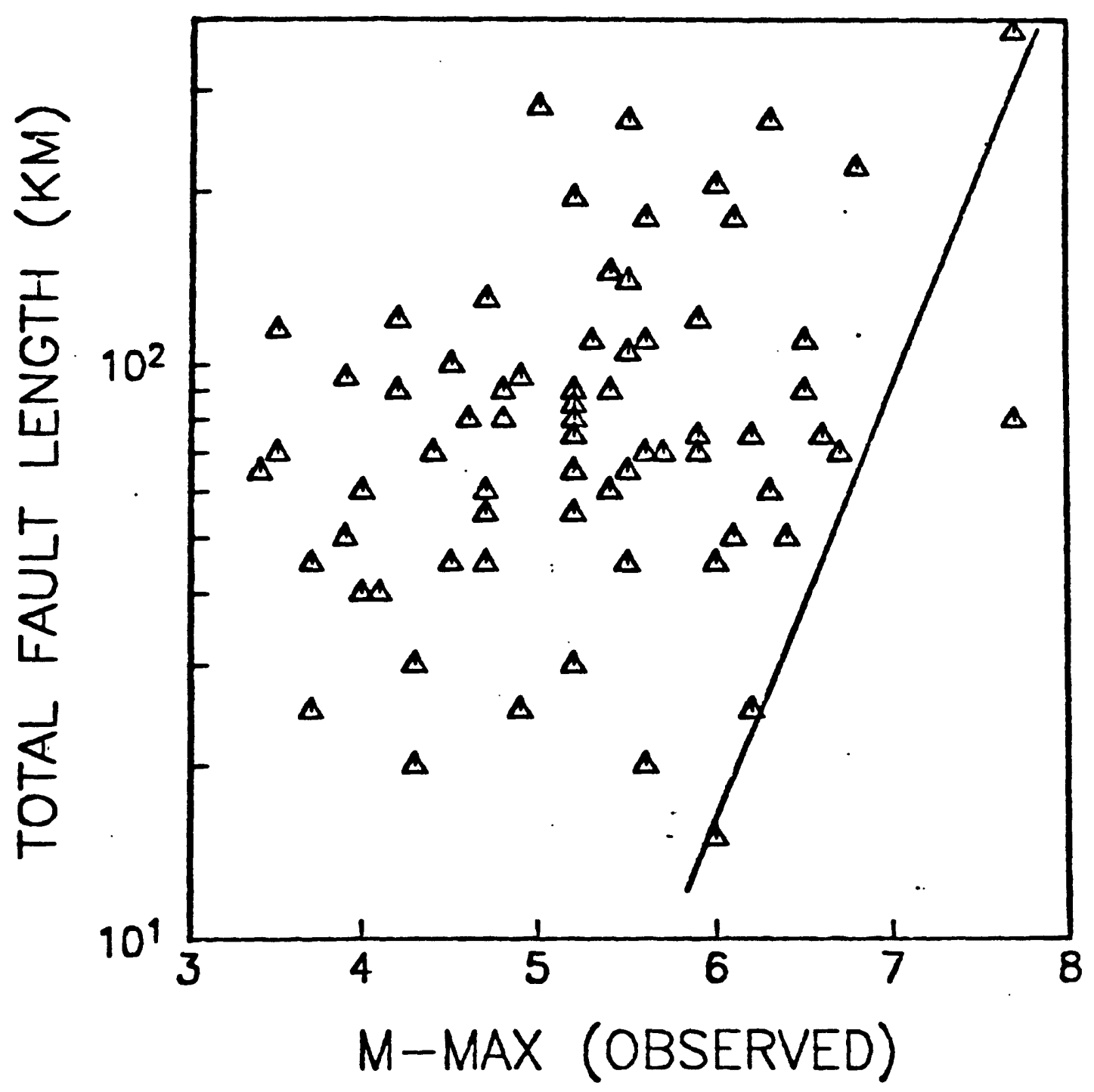

Figure 7. Naziman observed aagnitude earthquake on each fault, shora as - function of the length of the zone as dofined in Figure 2. The line is a theoretical relationsbip obtained based on a scaling relatlonsblp of Scholz (1982), and with one exception, appears to bo rood boond for these date. 
Append1x I

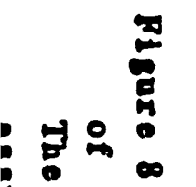

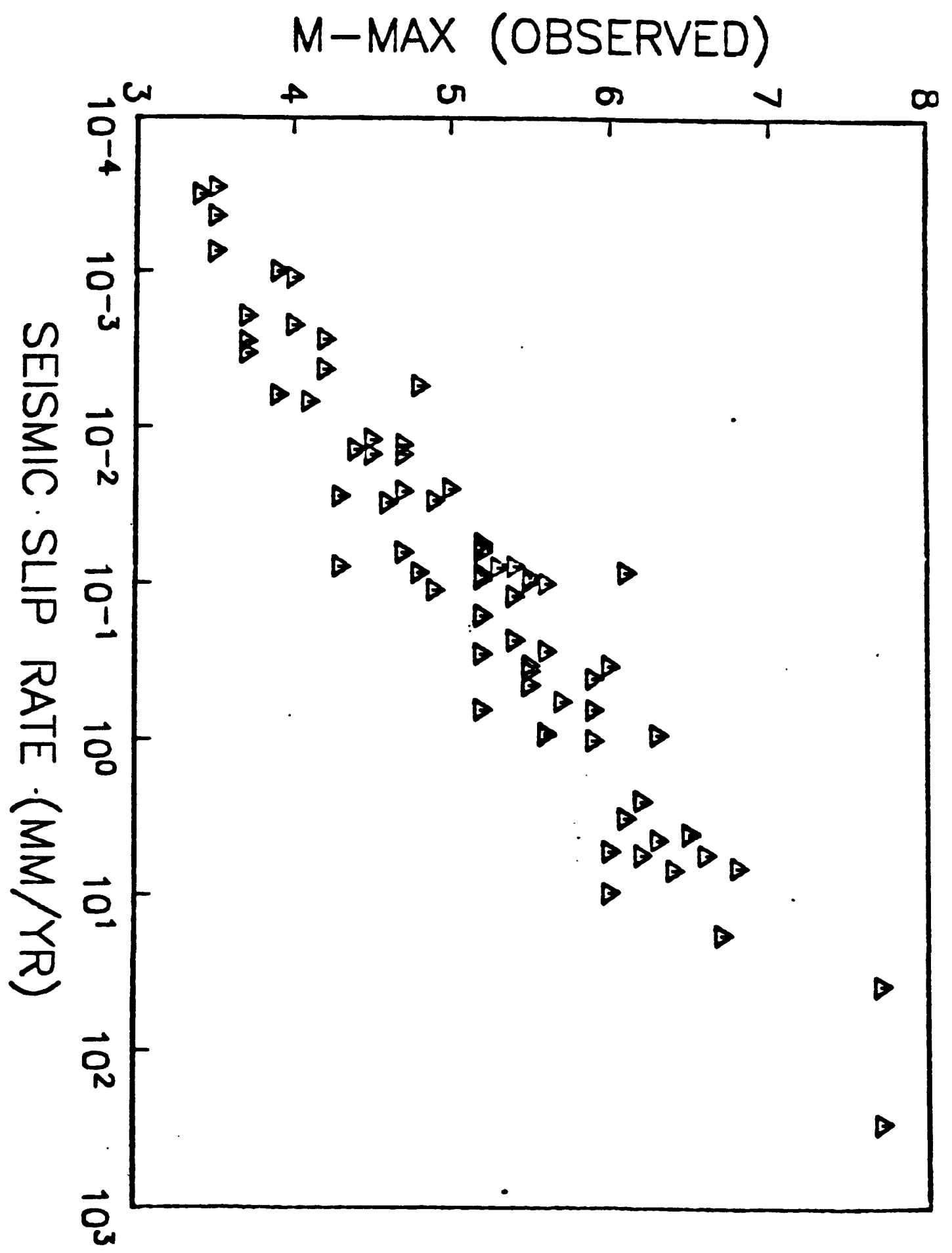


Append1x I

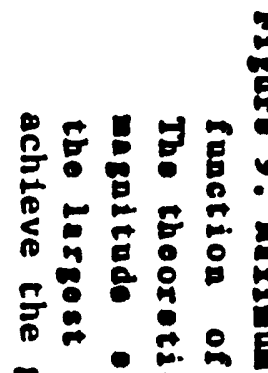

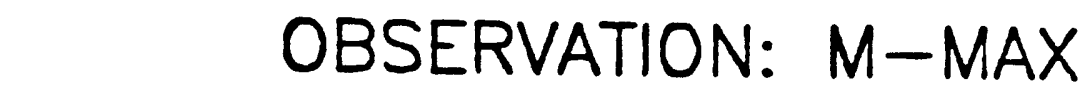

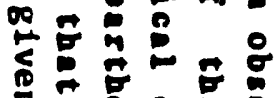

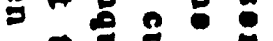

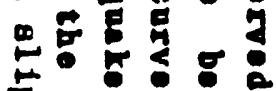

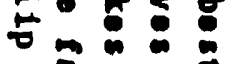

$\rightarrow 2$ क

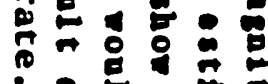

ะล

$\rightarrow=8$

둥응

-

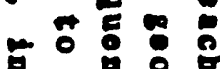

ด

웅

ำ 5

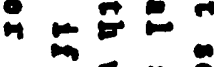

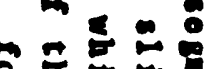

웅

- 6 -

불

웅요

-

$5 \%$

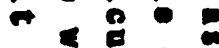

$-50$

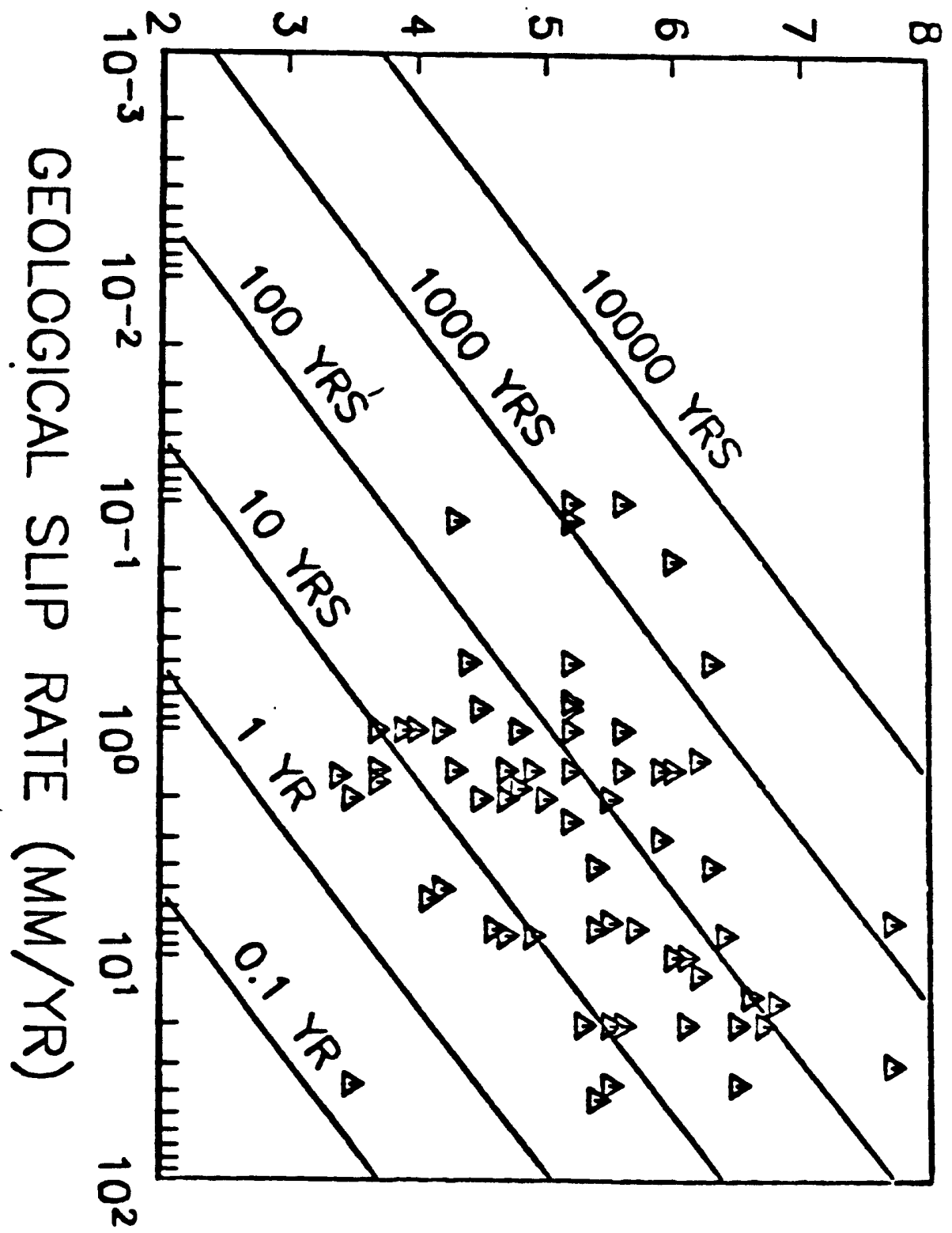




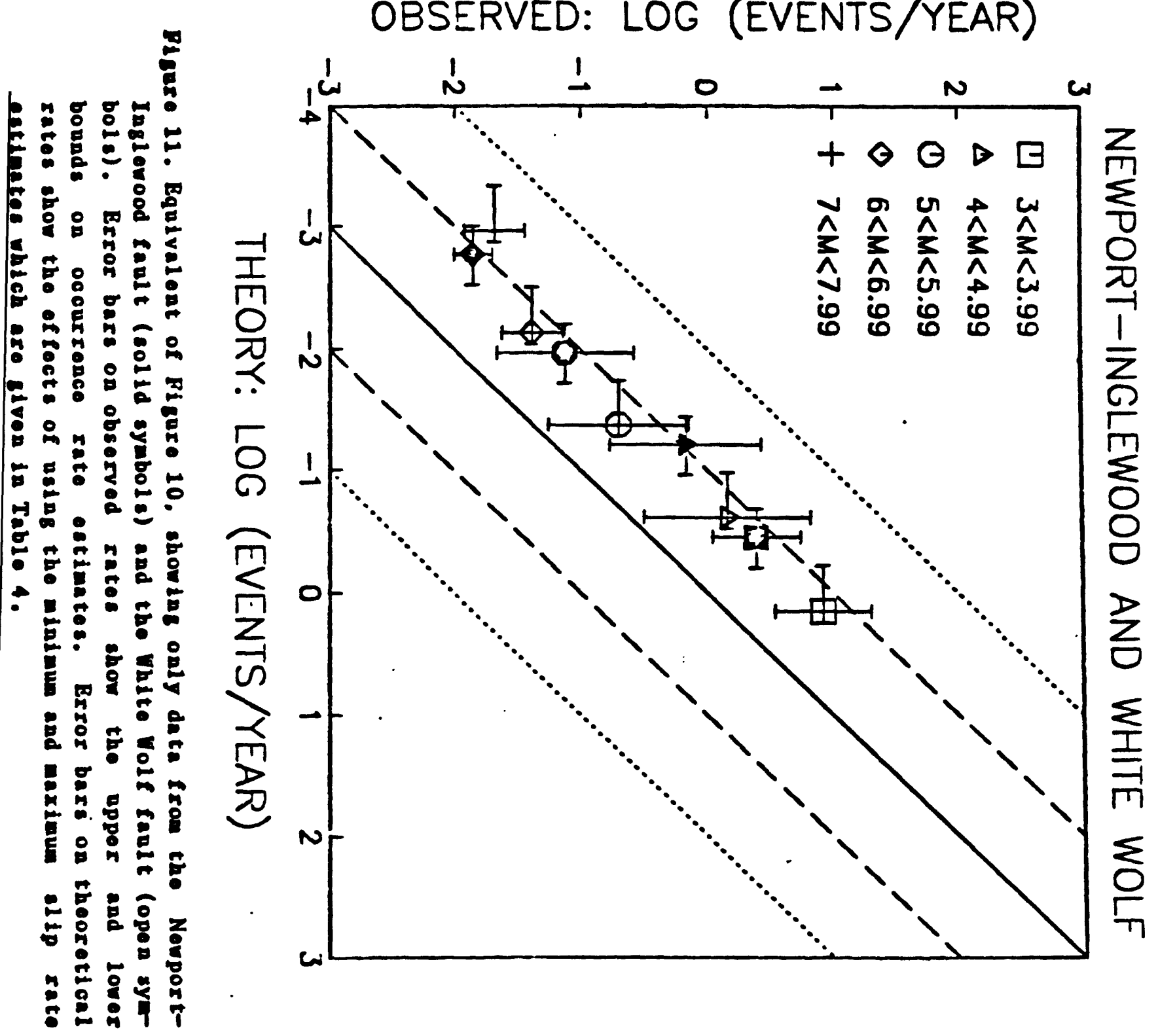


Append1X I

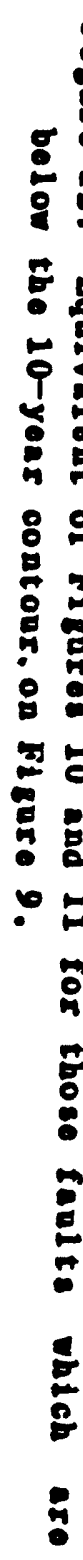

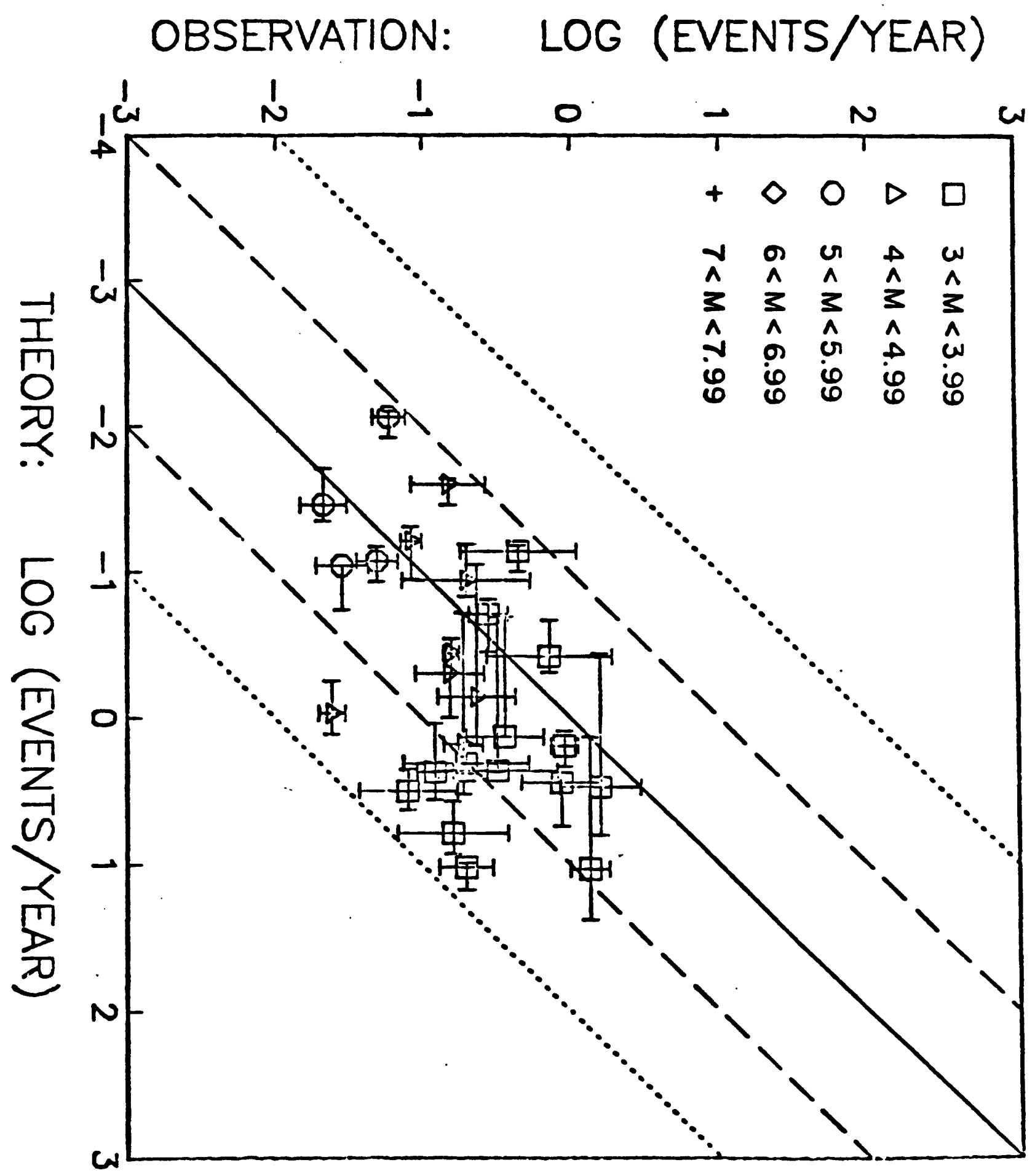


Append1x I

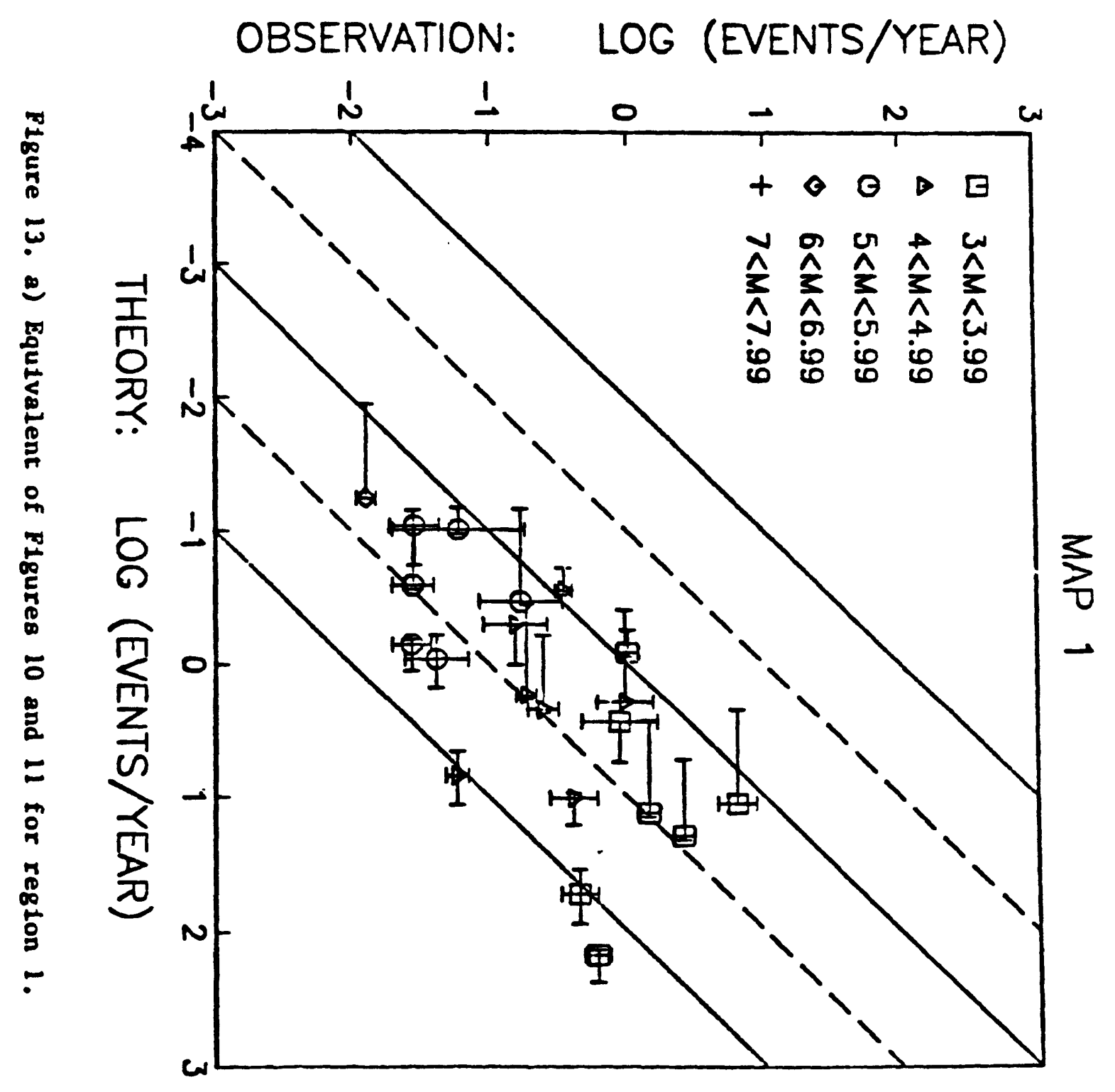


Appendix I

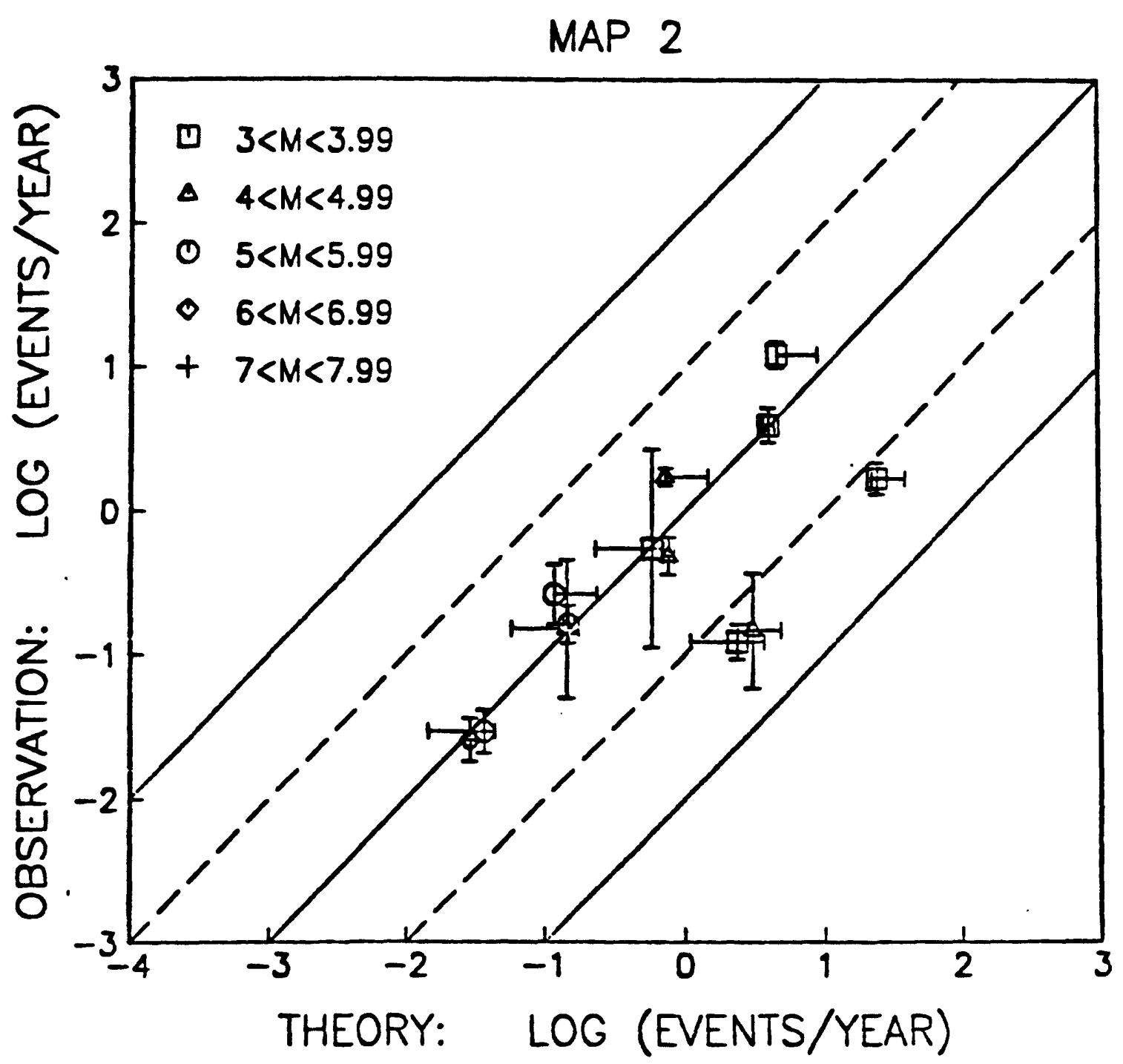

Figure 13. b) Equivalent of Figures 10 and 11 for region 2 . 


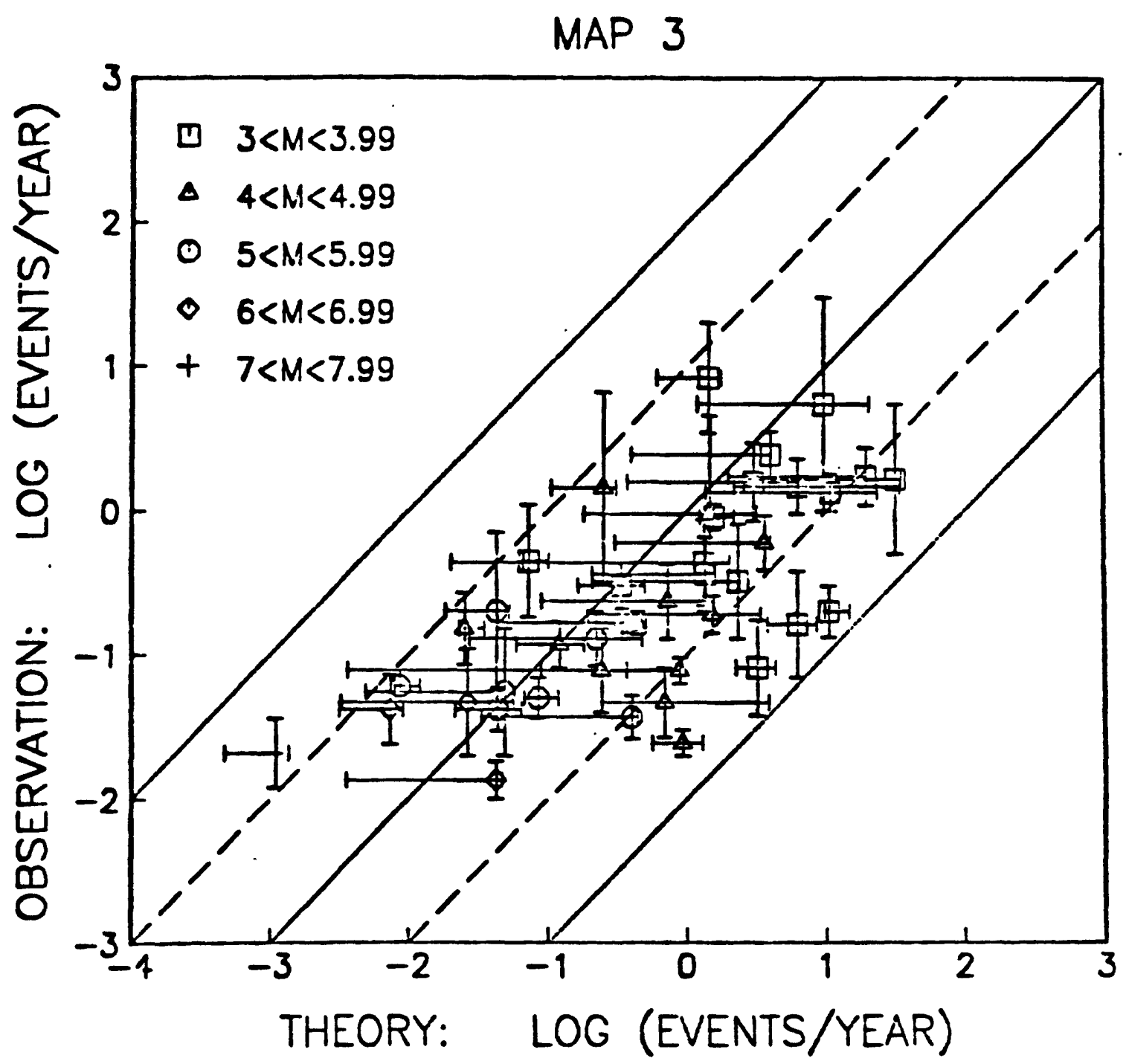

Figure 13. c) Equivalent of Figures 10 and 11 for region 3. 


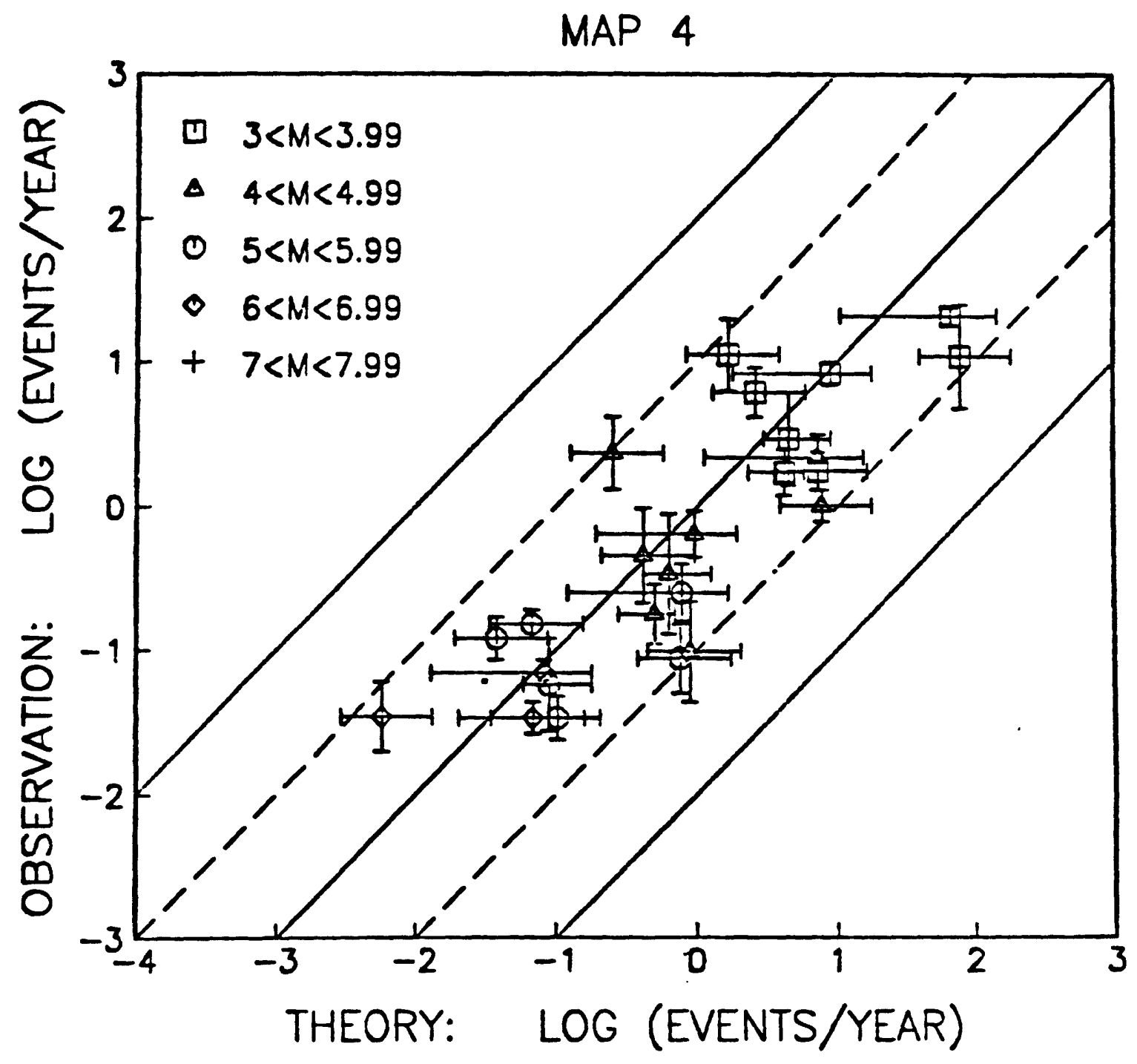

Figure 13. d) Equivalent of Figures 10 and 11 for region 4. 


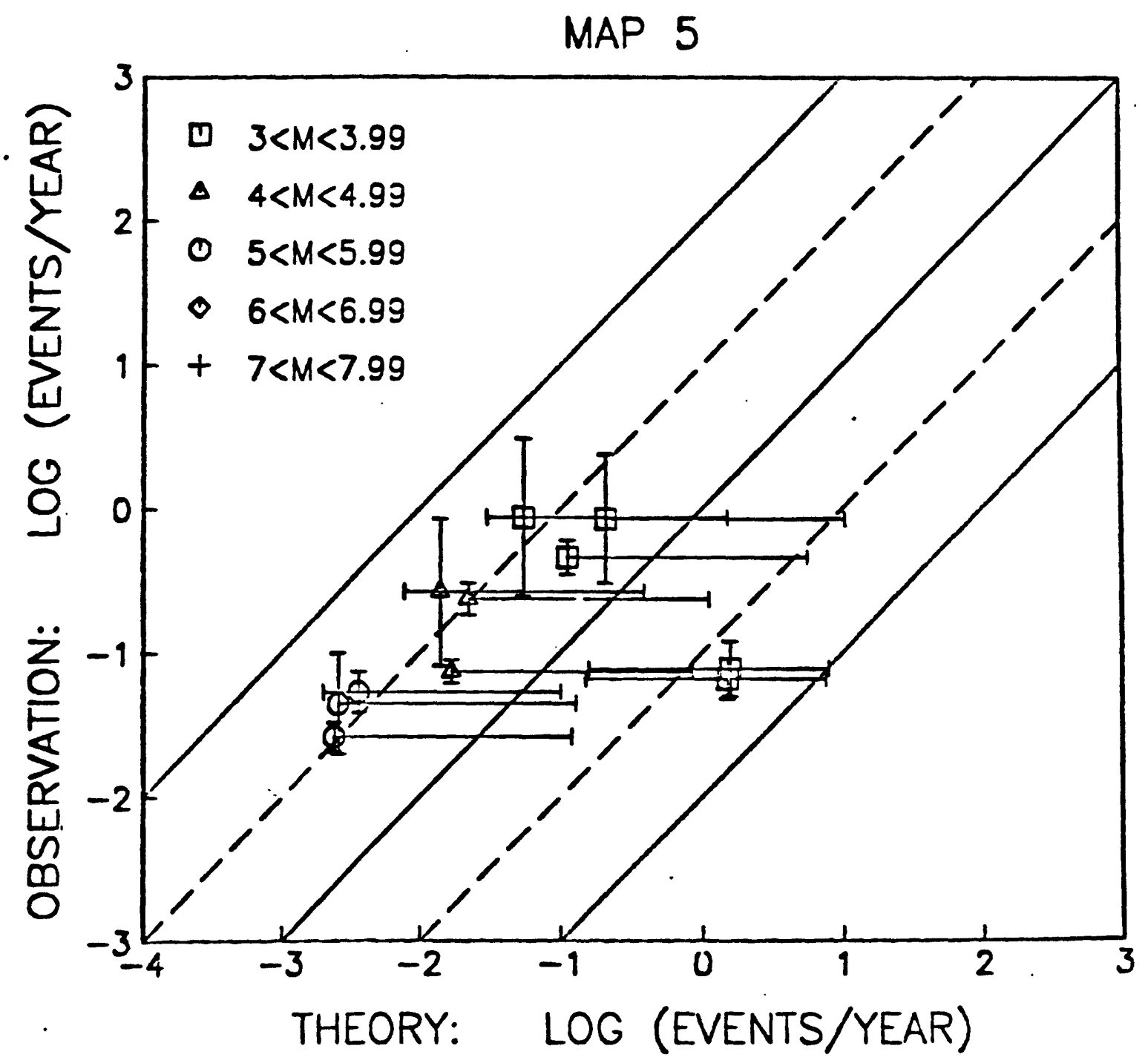

Figure 13. e) Equivalent of Figures 10 and 11 for region 5. 


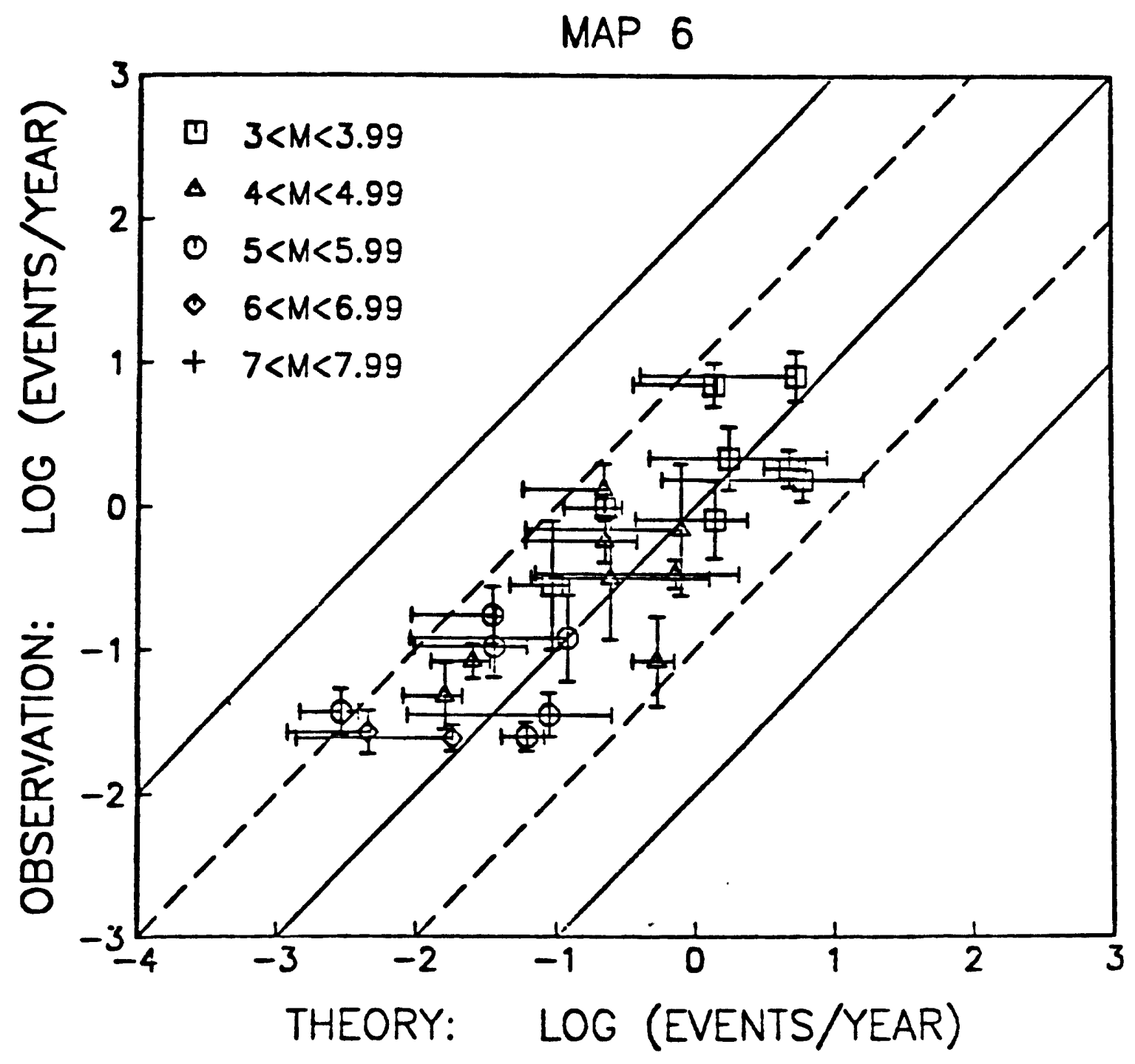

Figure 13. f) Equivalent of Figures 10 and 11 for region 6. 


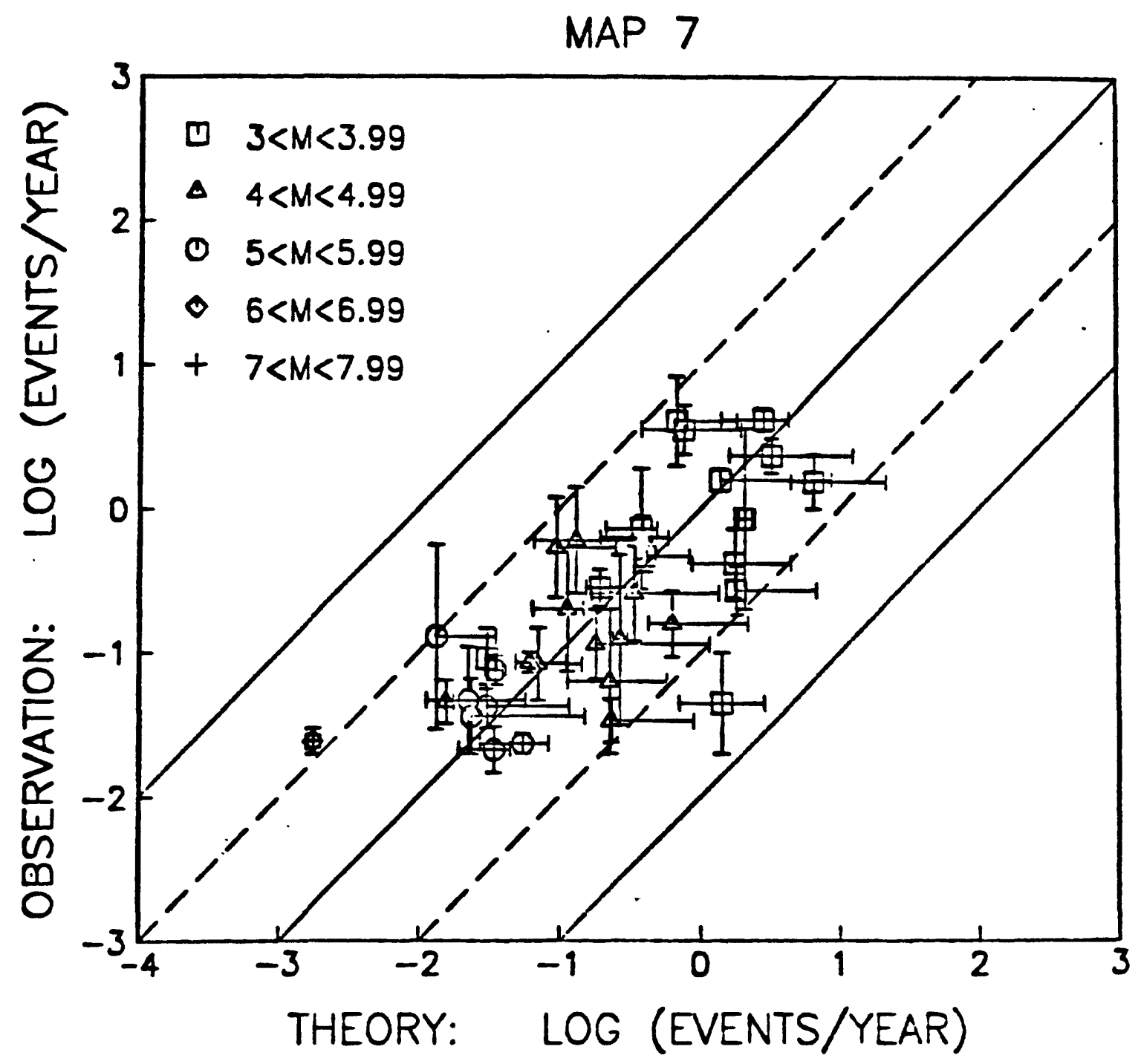

Figure 13. 8) Equivalent of Figures 10 and 11 for region 7. 


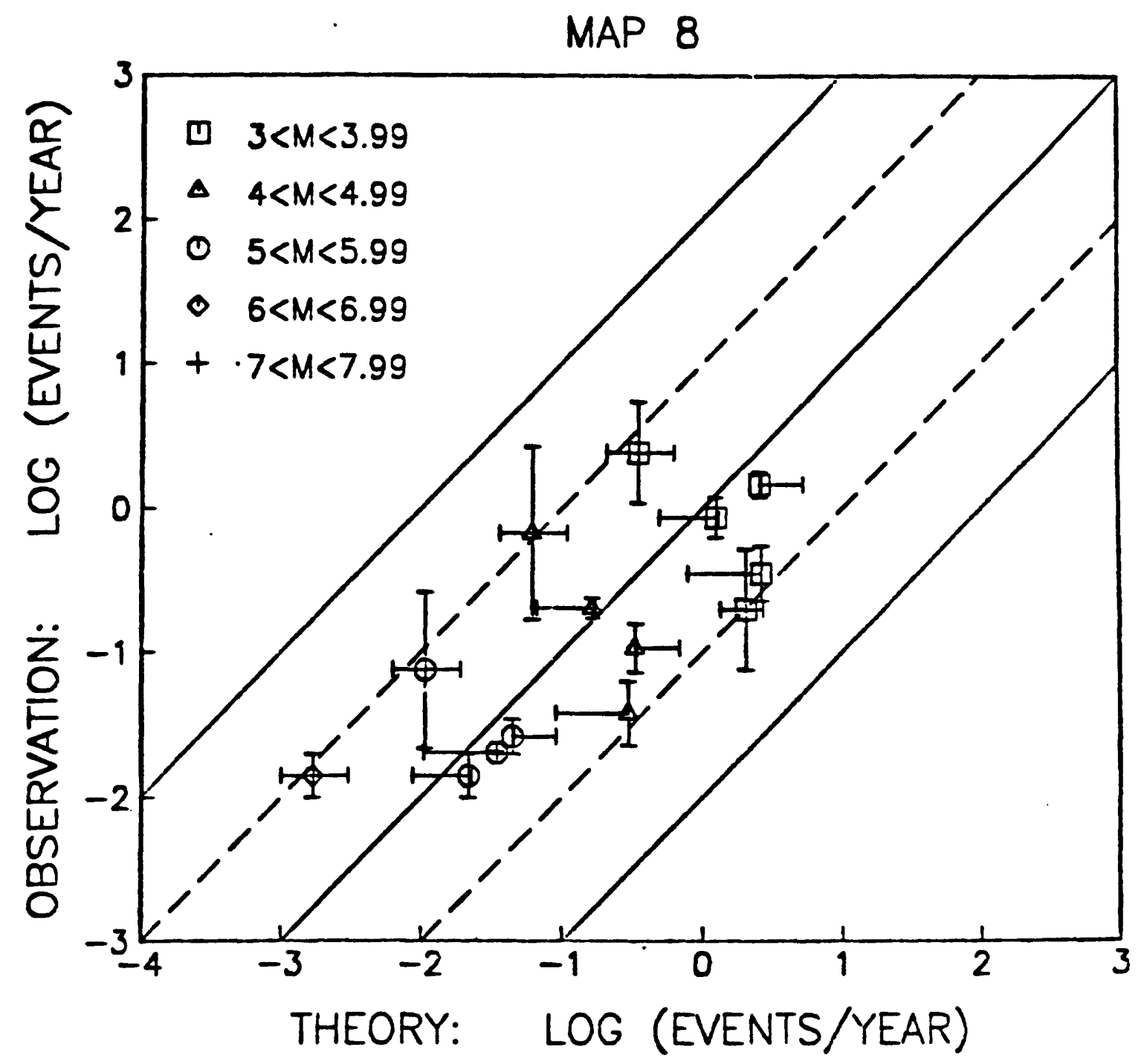

Figure 13. h) Equivalent of Figures 10 and 11 for region 8 . 


\section{APPENDIX I-1}

Plots of average occurrence rates of earthquakes as a function of length of the time period over wich the average is defined. All time periods end December 31, 1979.

Symbols correspond to the following magnitude ranges:
$\square \quad 3.0 \leq M \leq 3.99$
$\triangle 4.0 \leq M \leq 4.99$
O $5.0 \leq M \leq 5.99$
$06.0 \leq M \leq 6.99$
$+7.0 \leq M \leq 7.99$ 


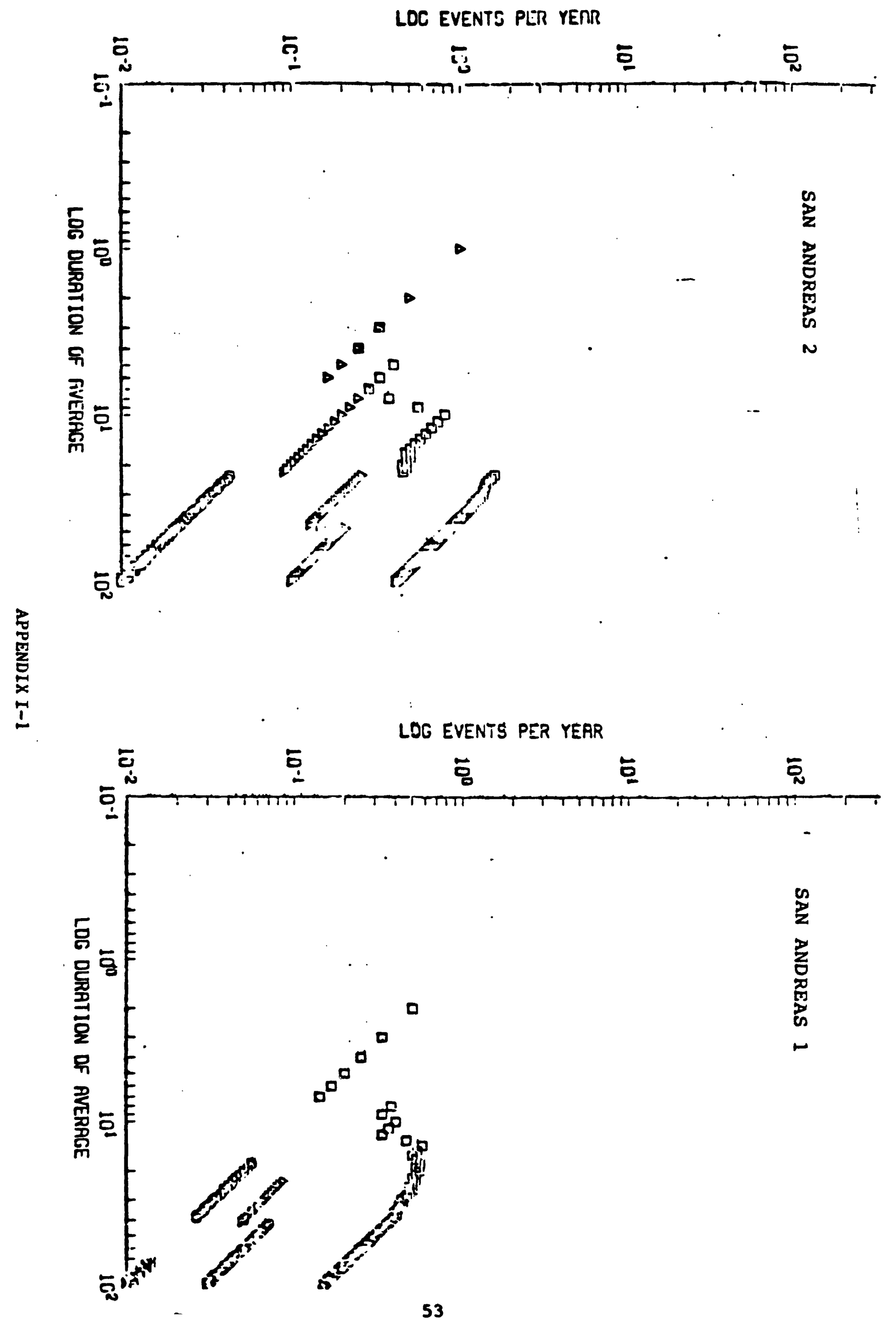




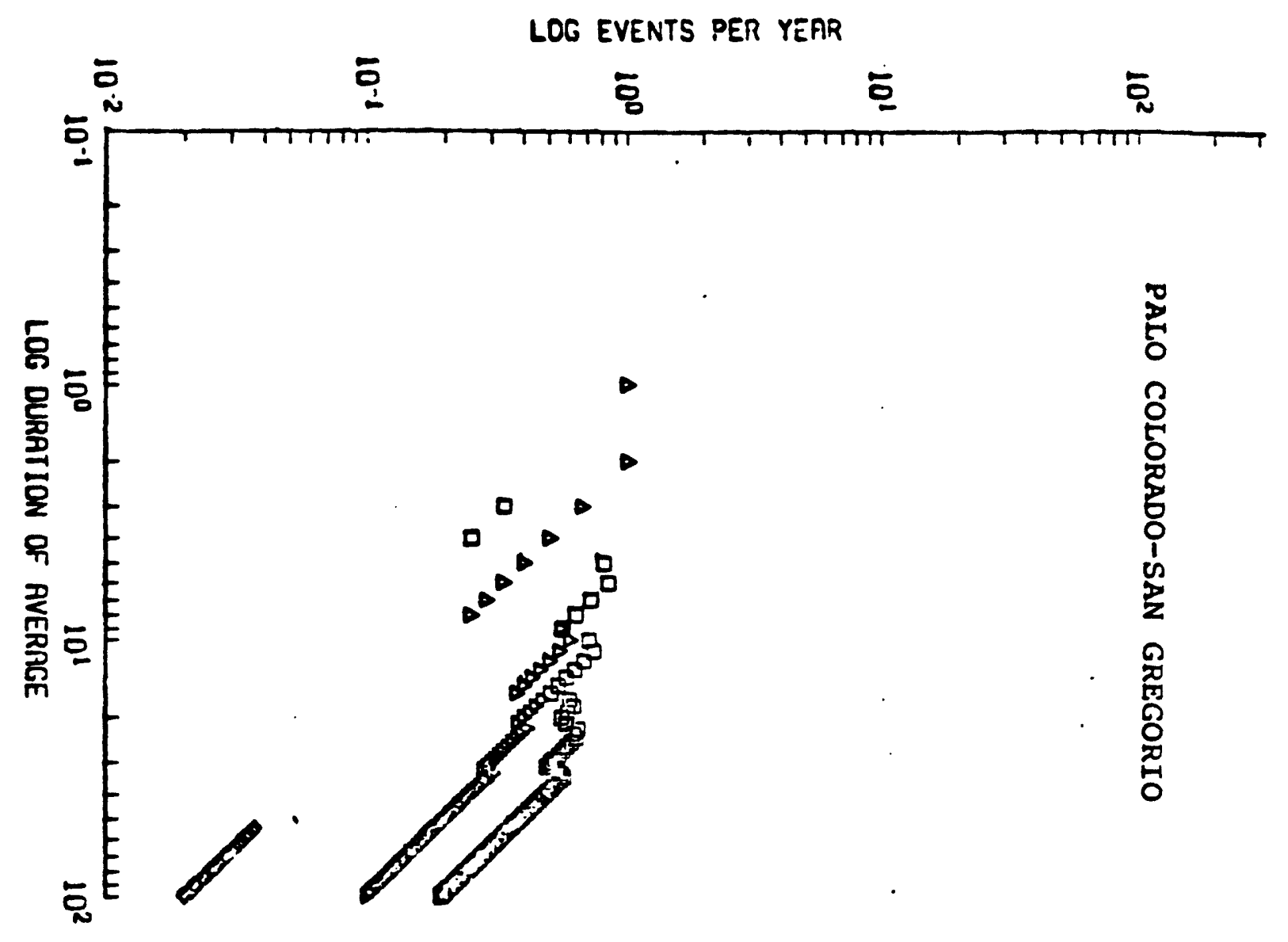

苟

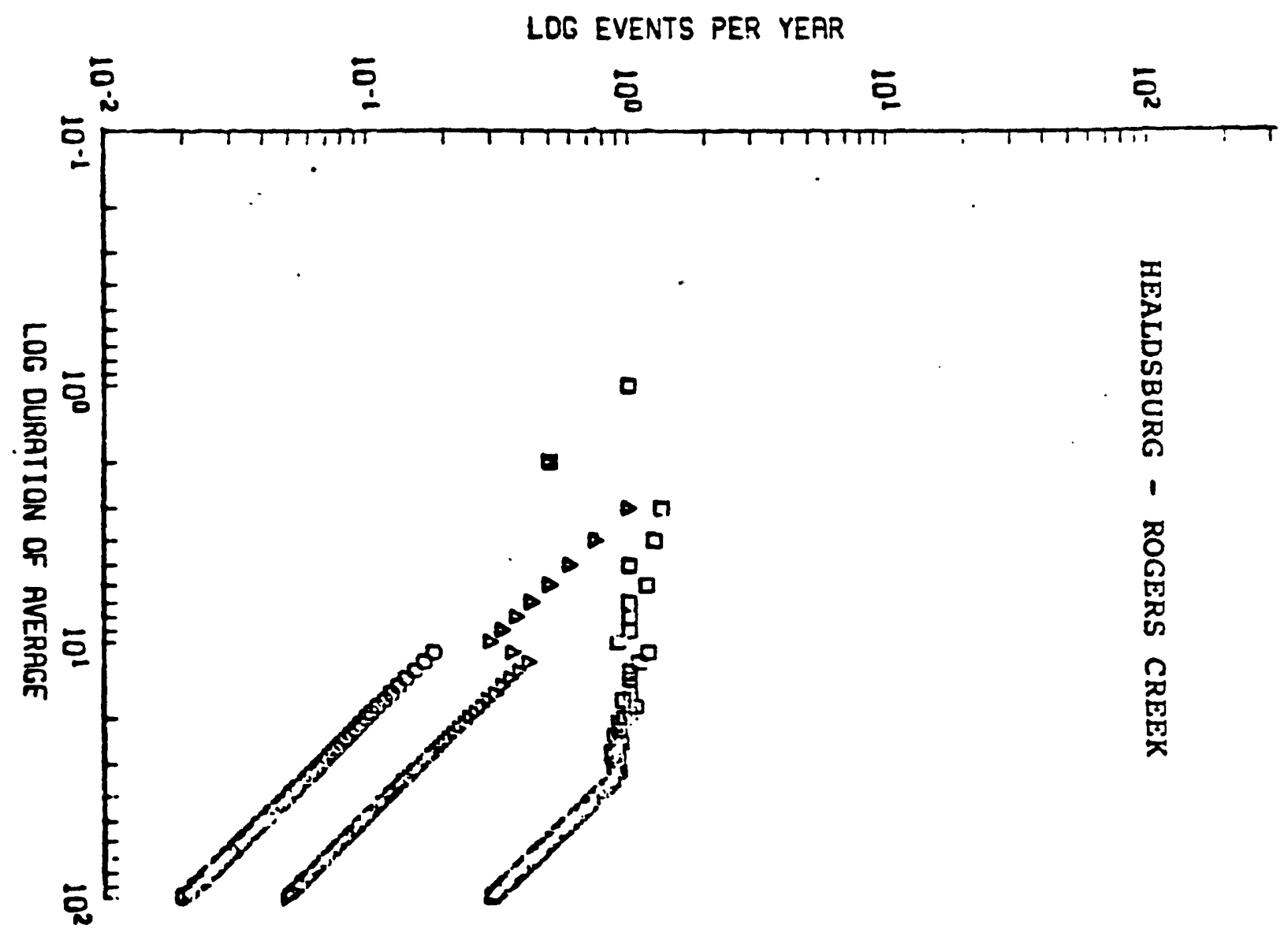

54 


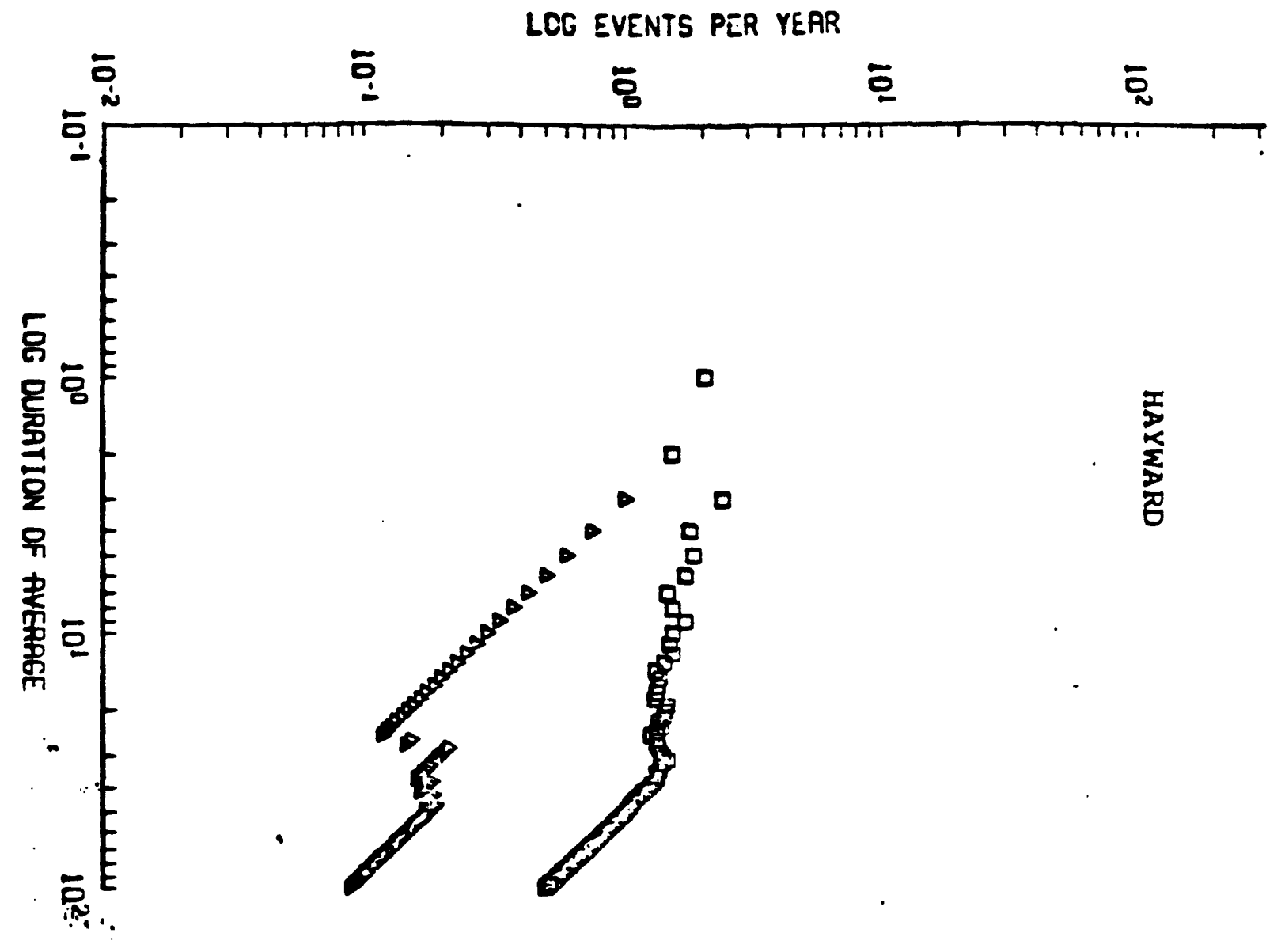

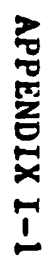

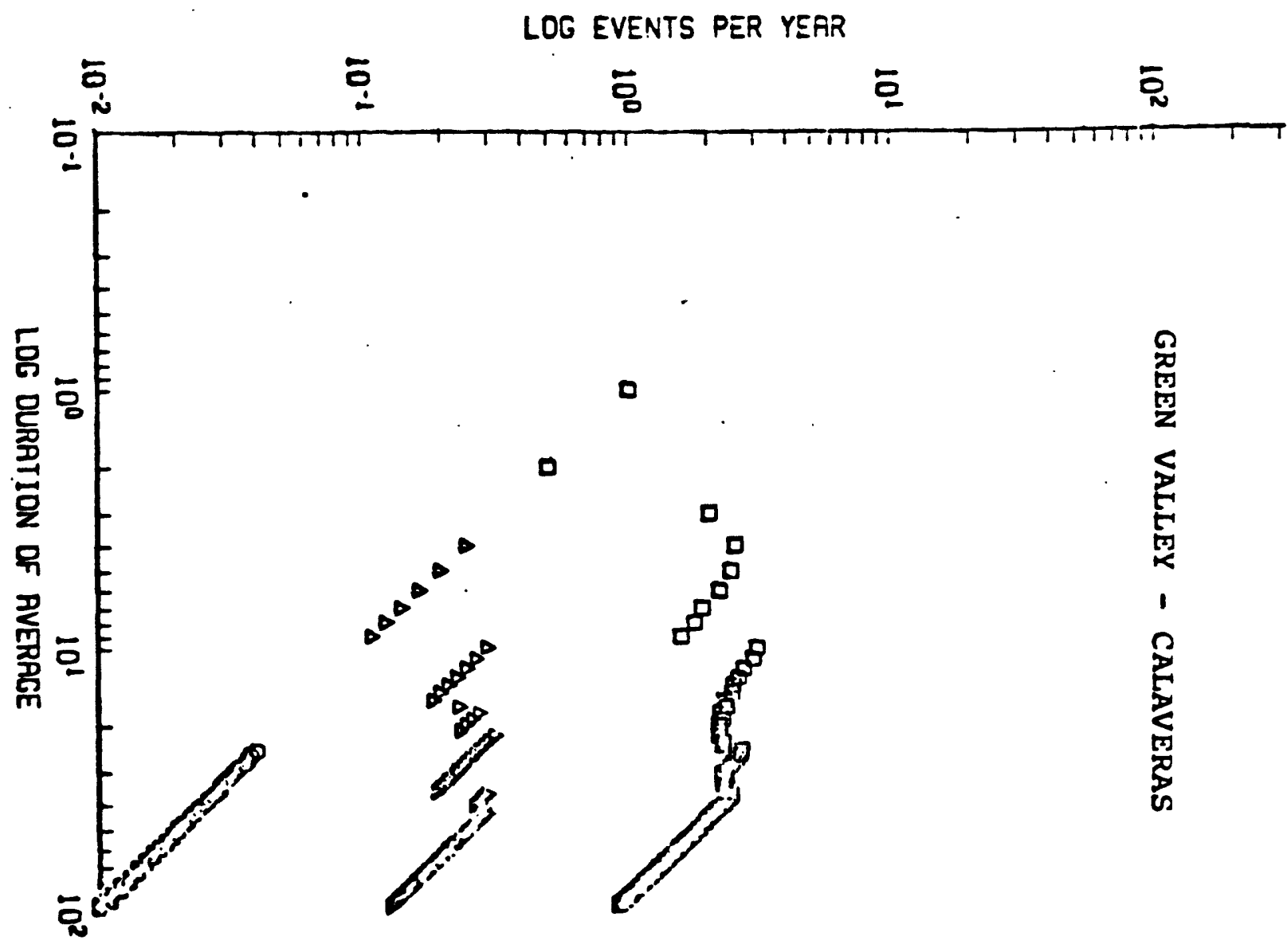




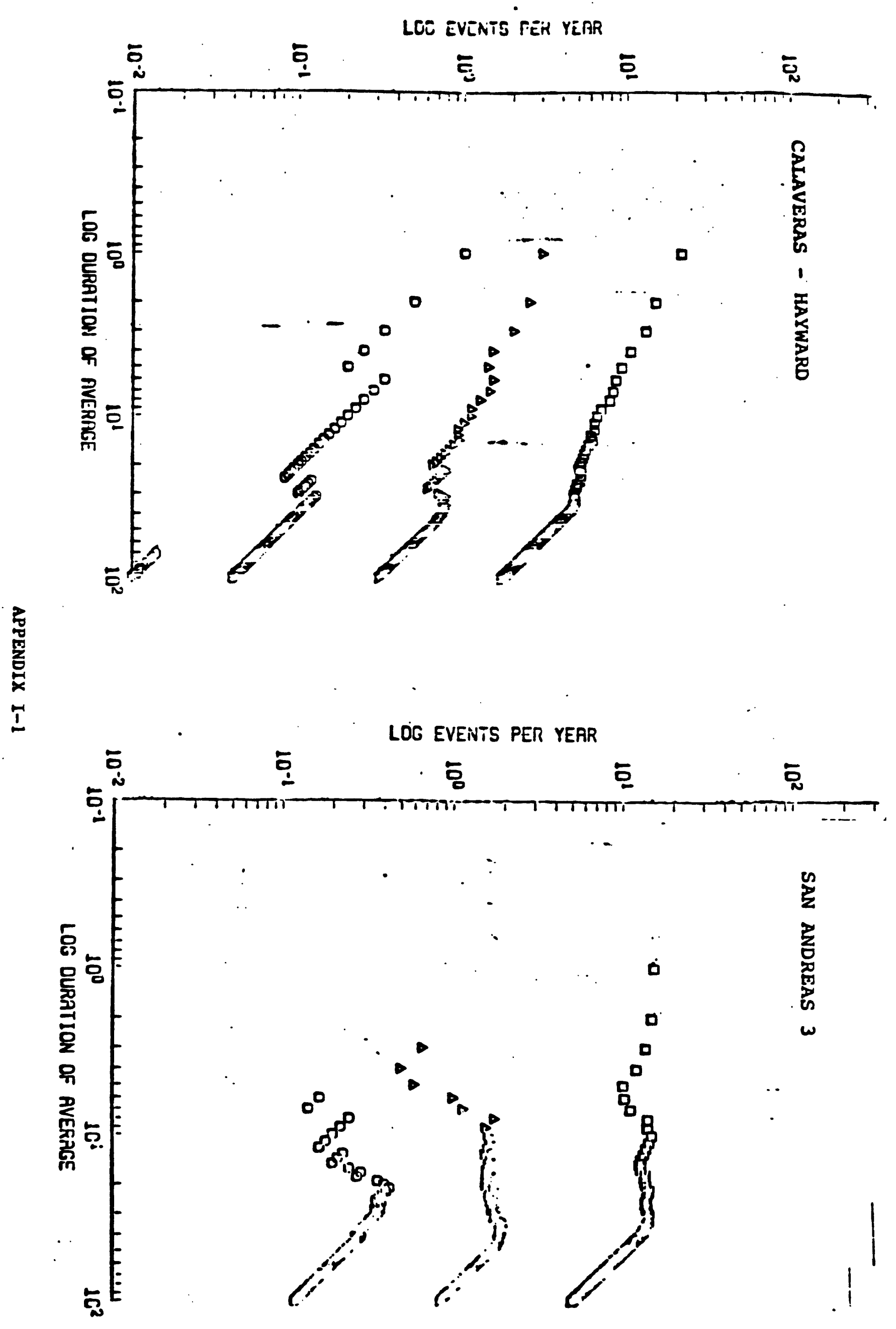




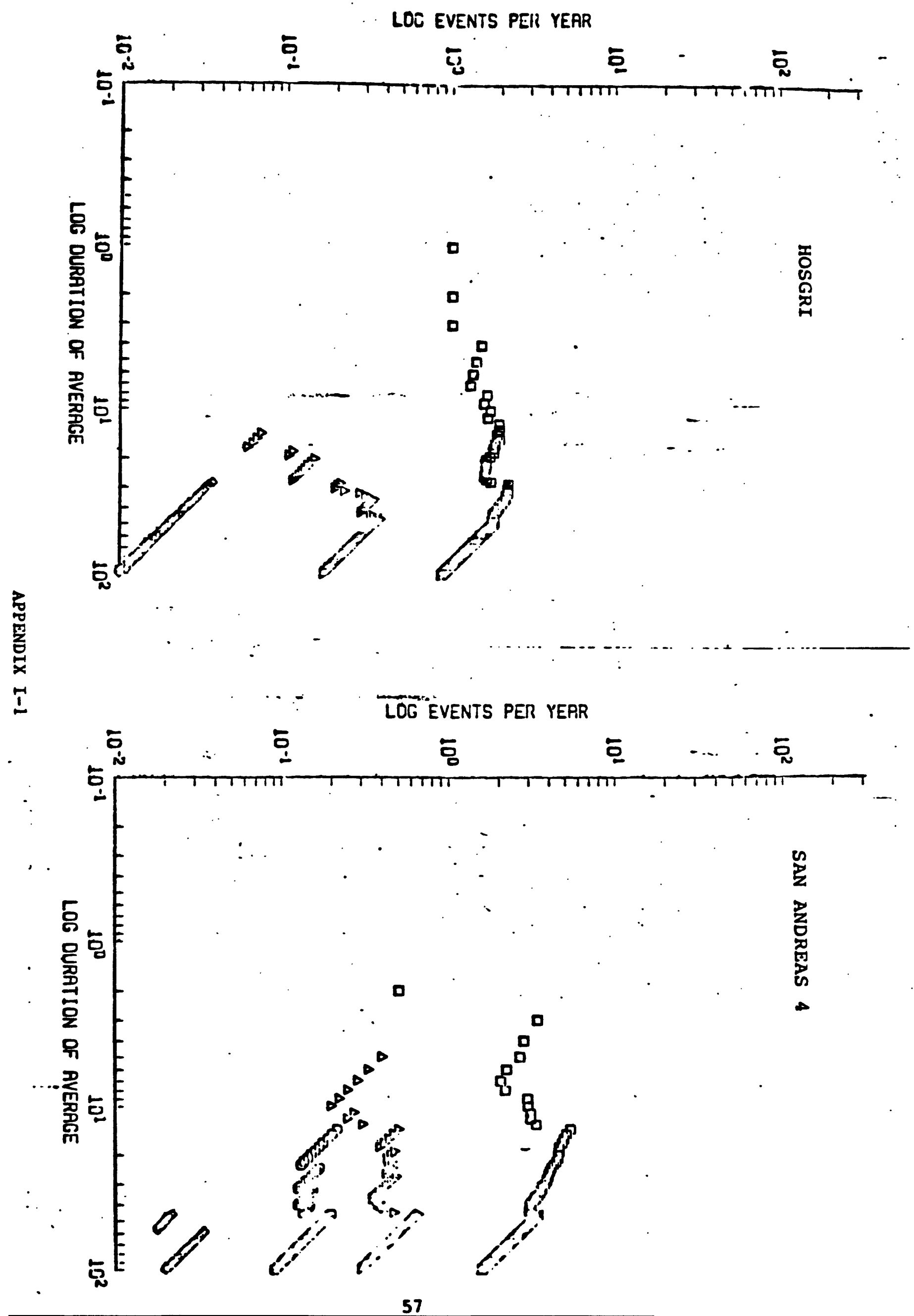




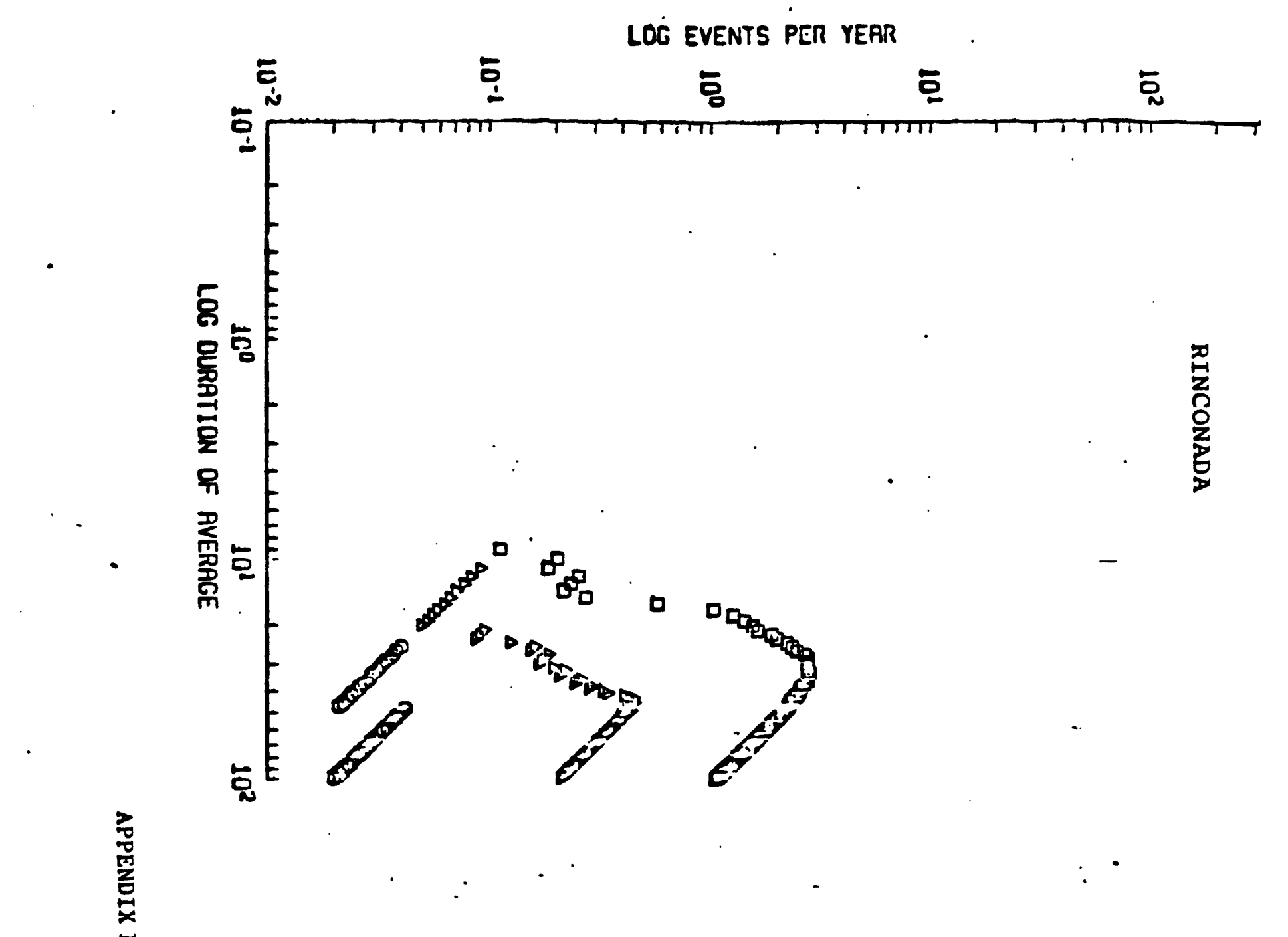

.15

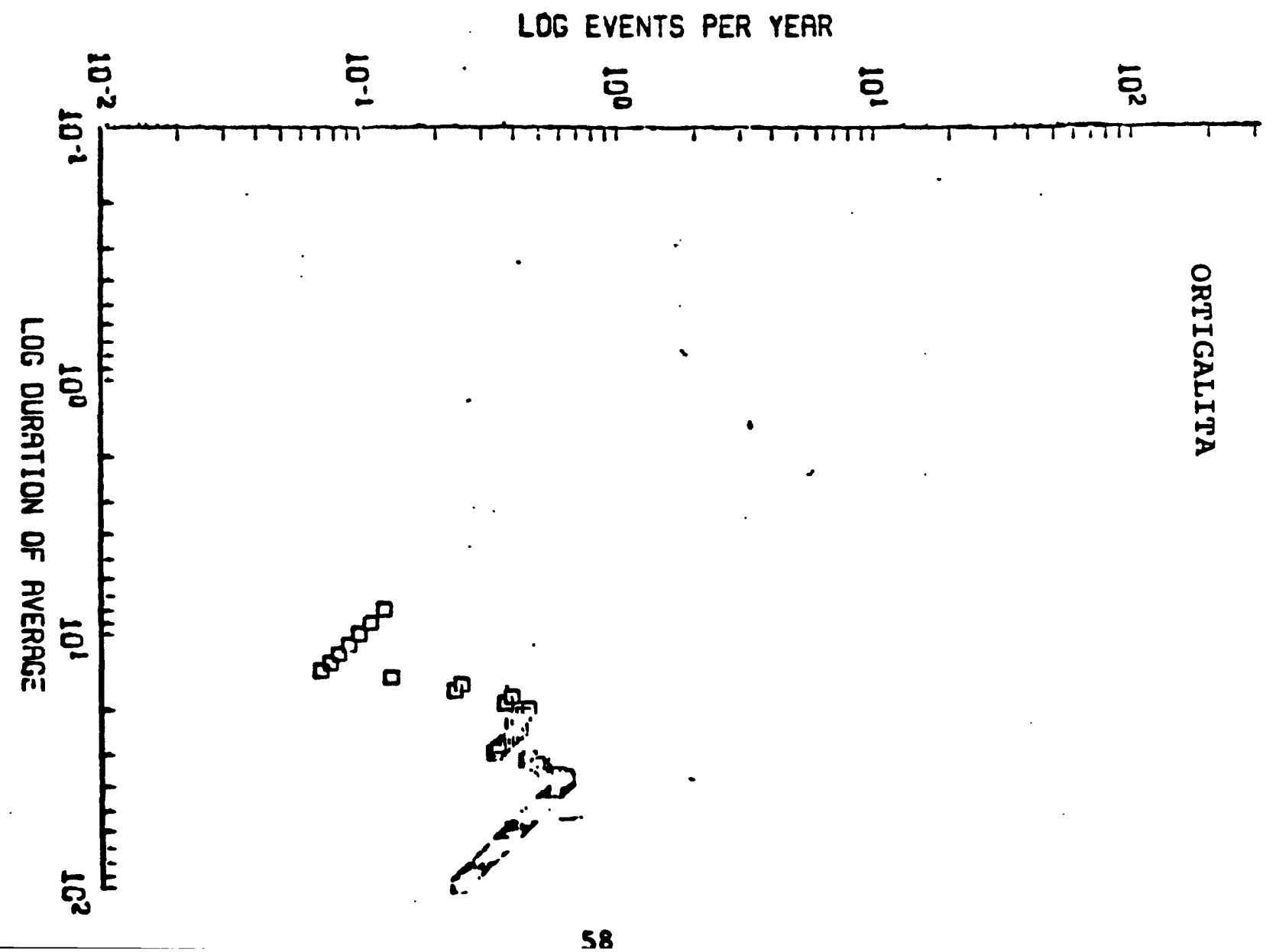




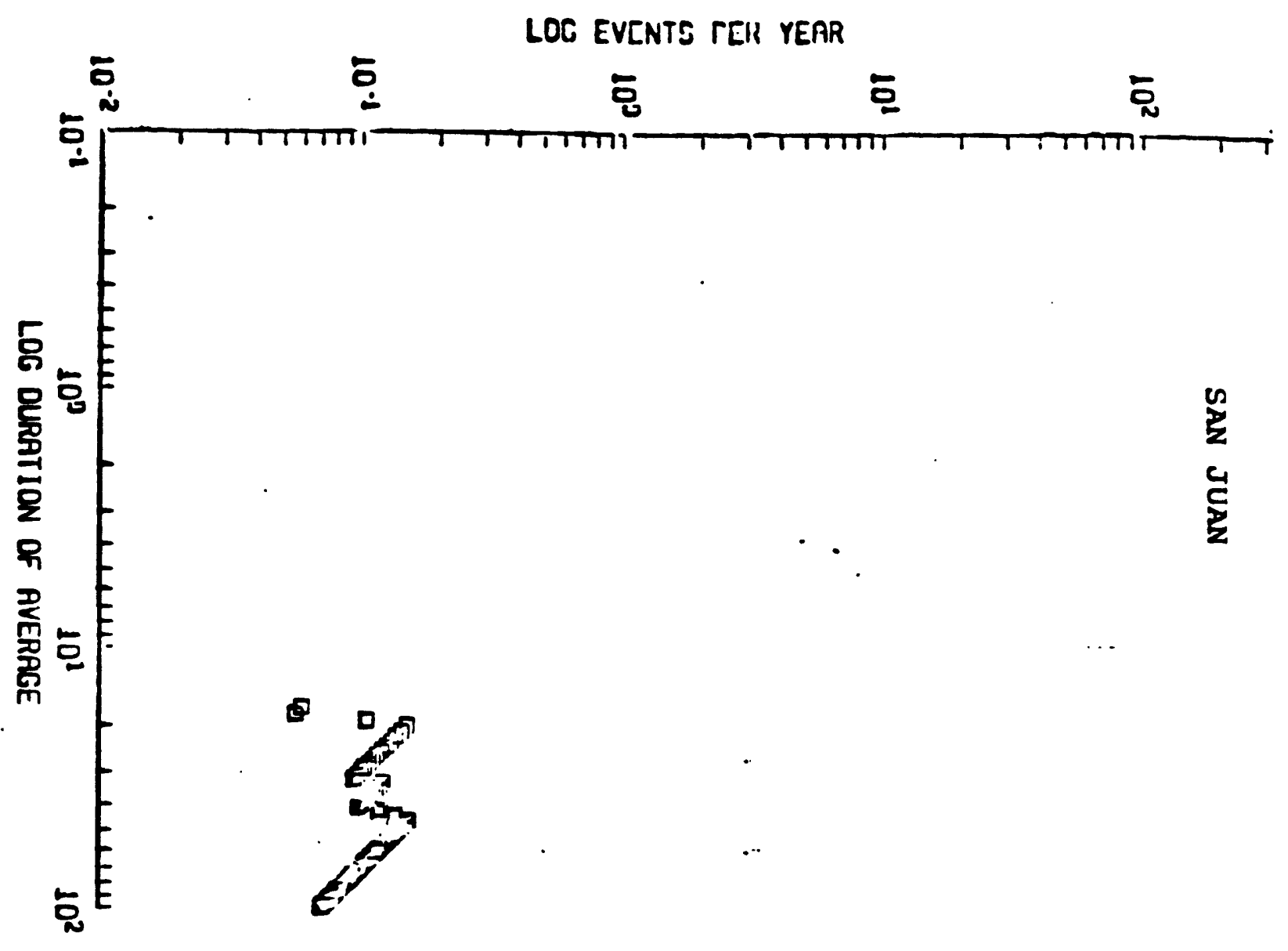

范

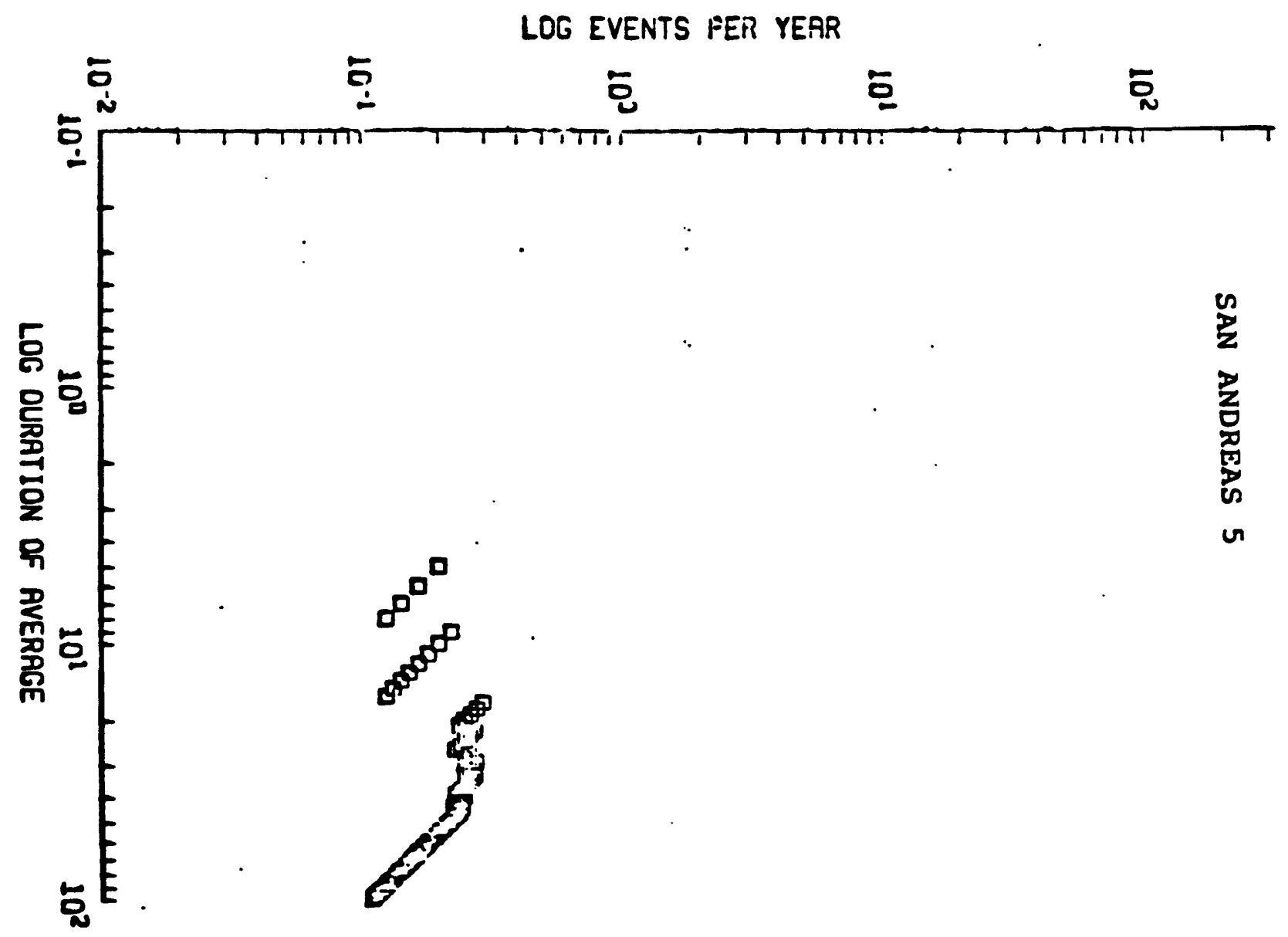




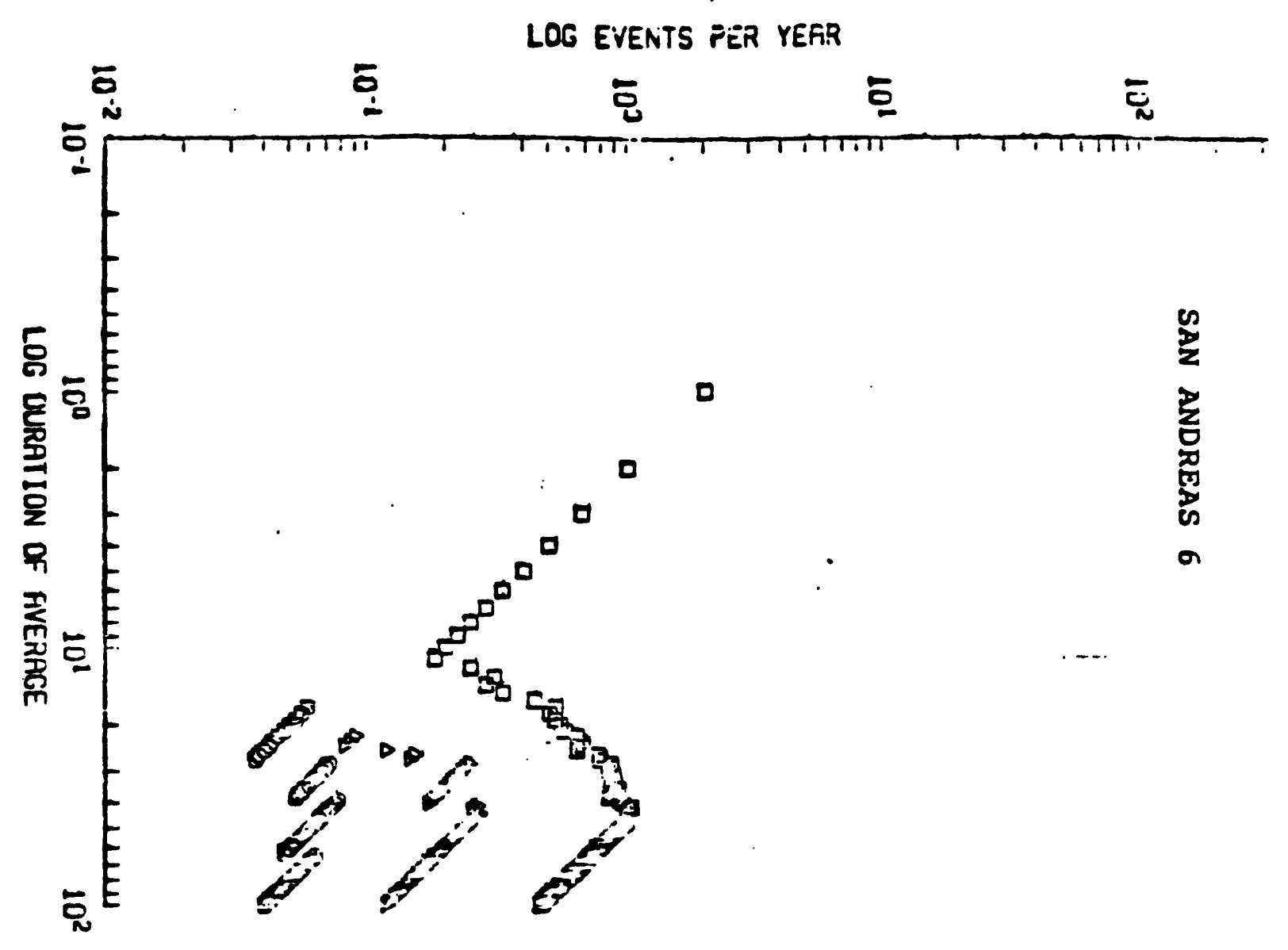

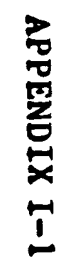

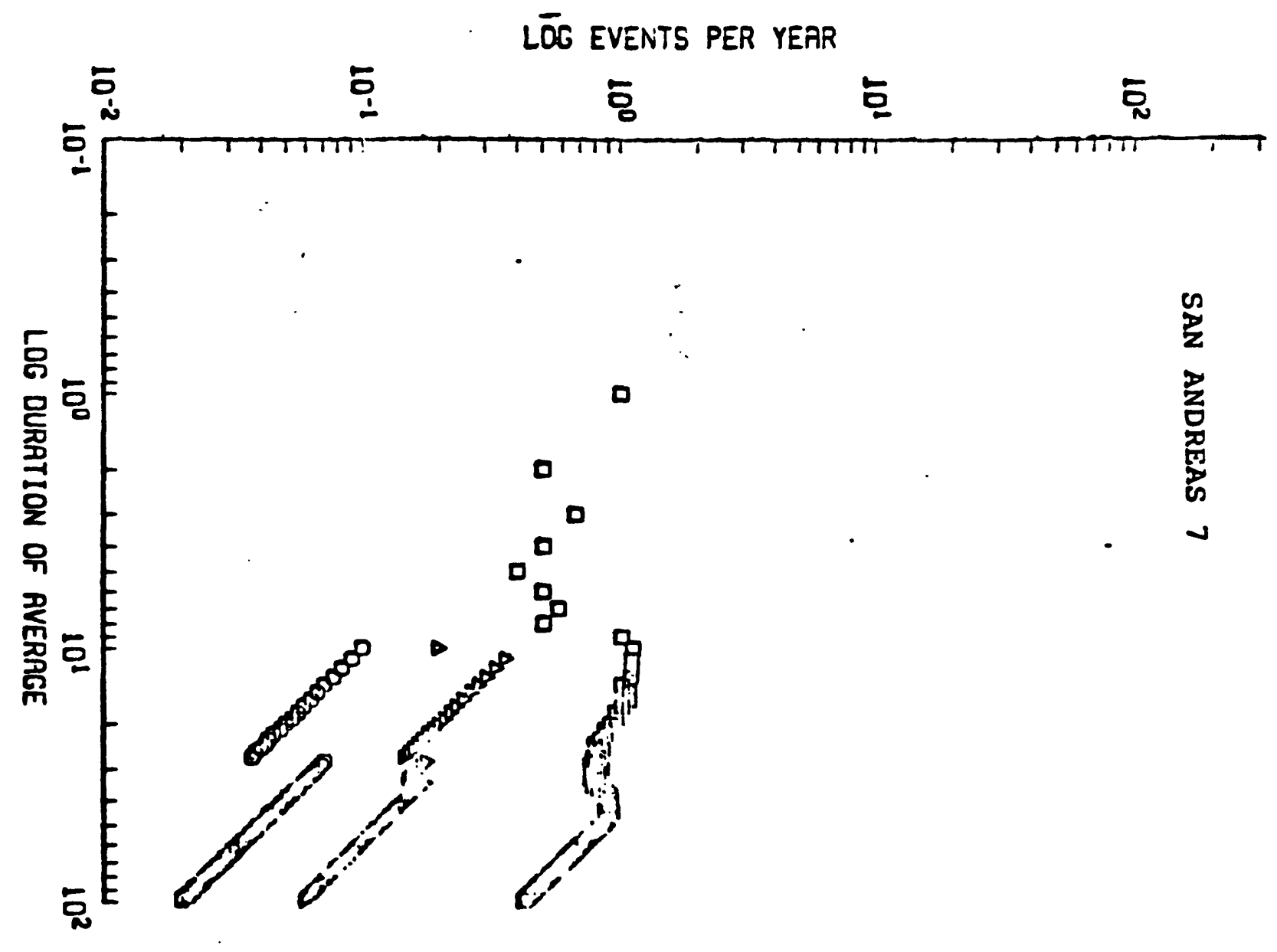




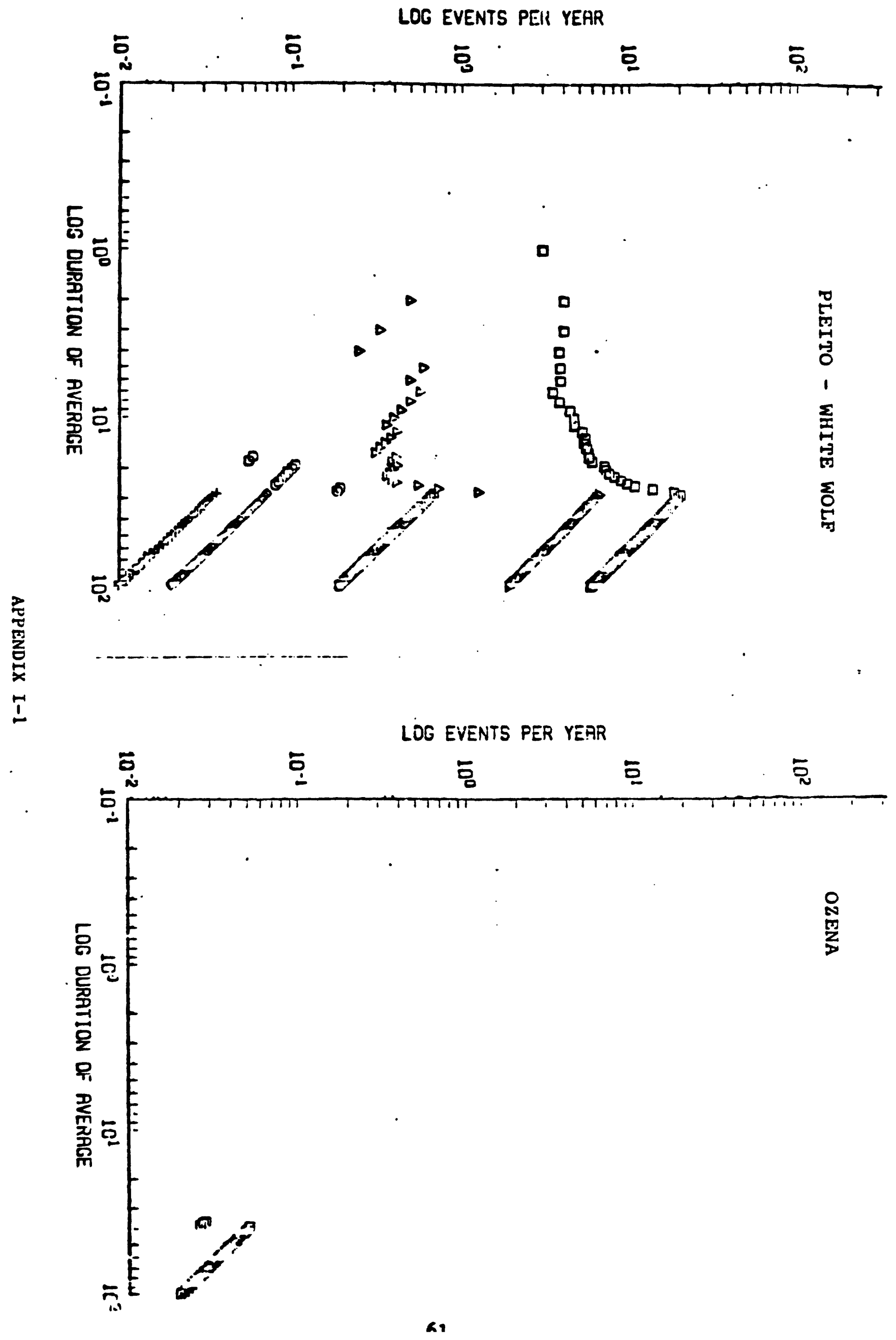




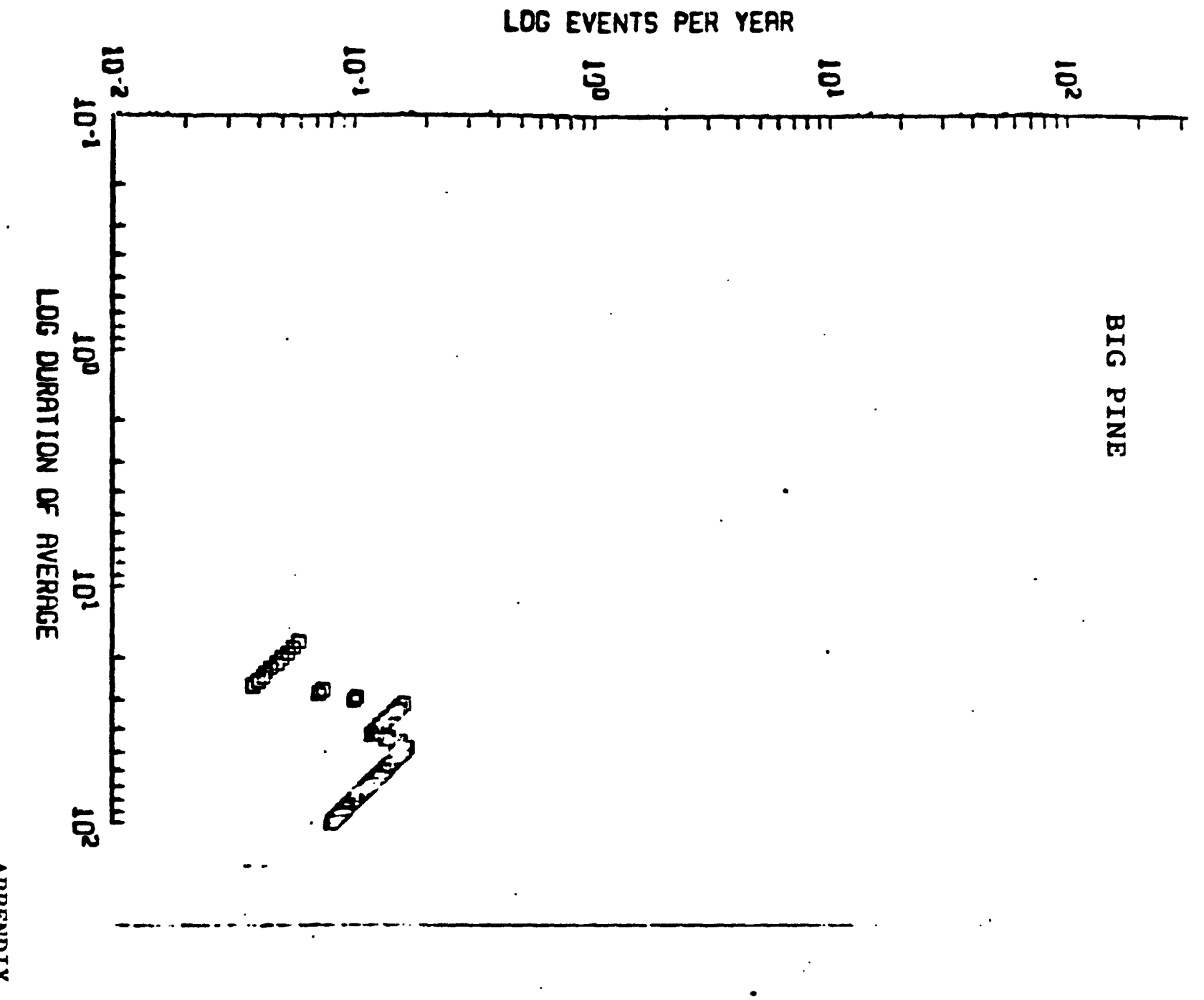

I

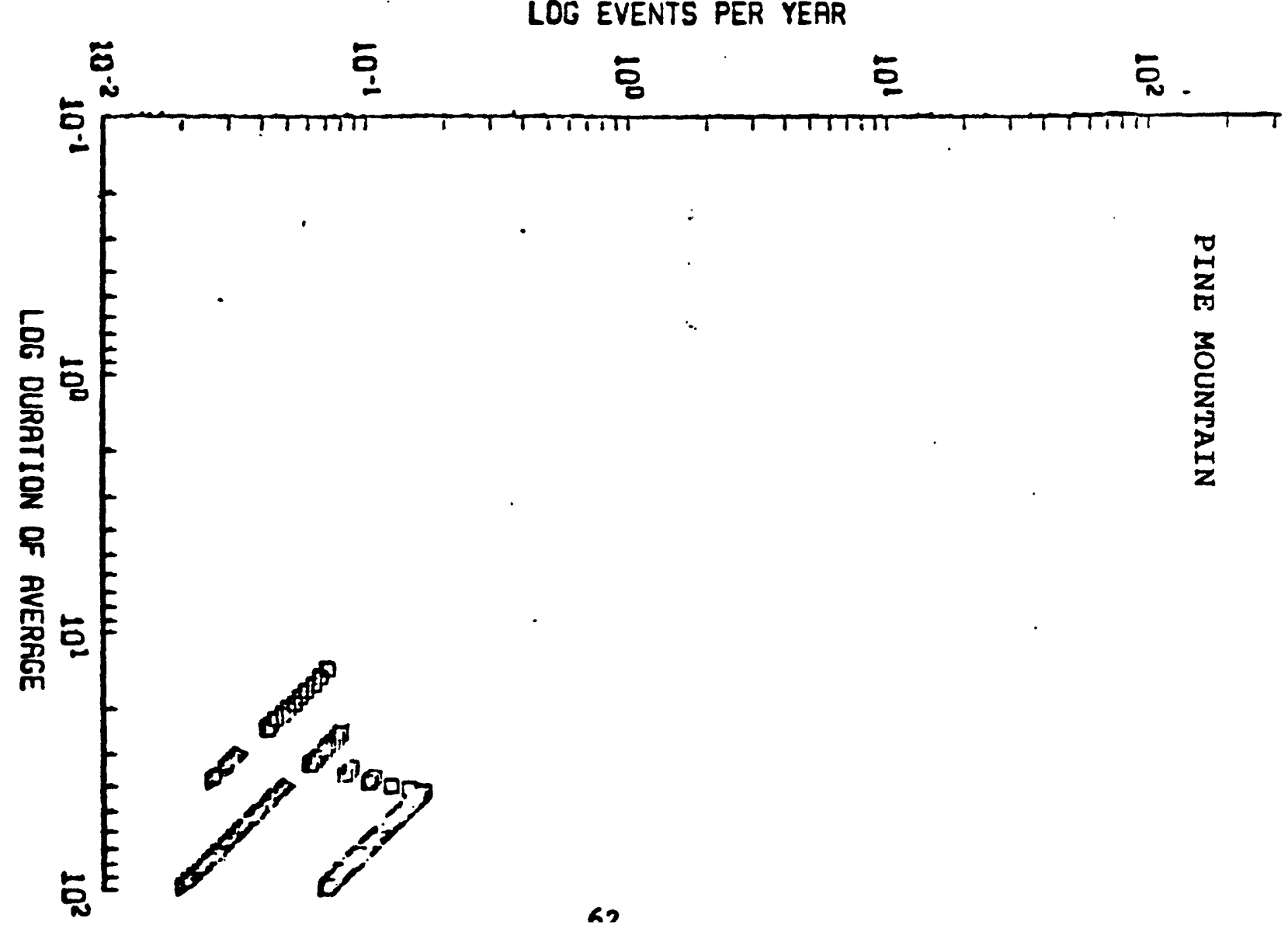




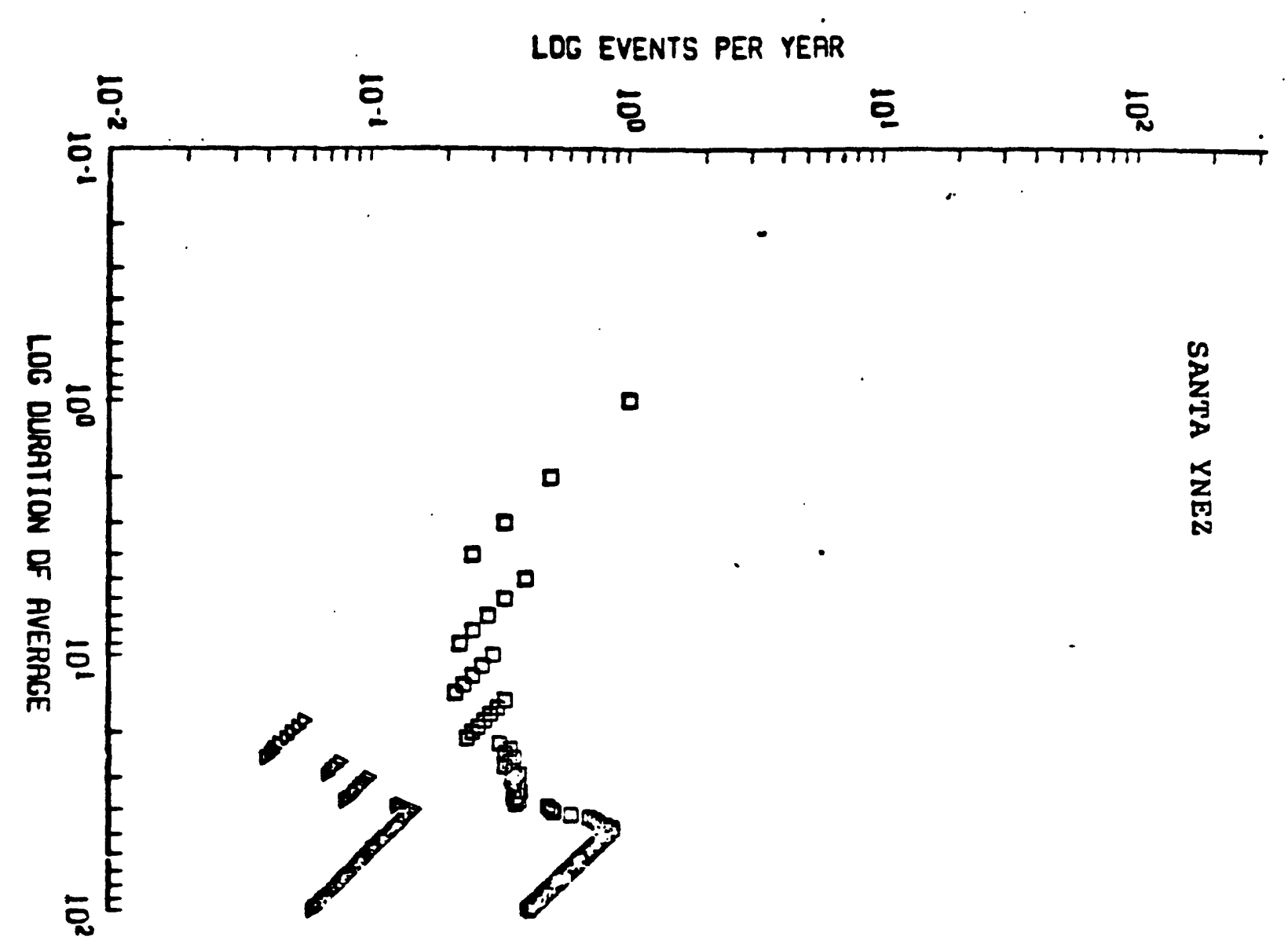

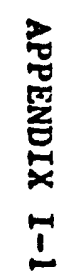

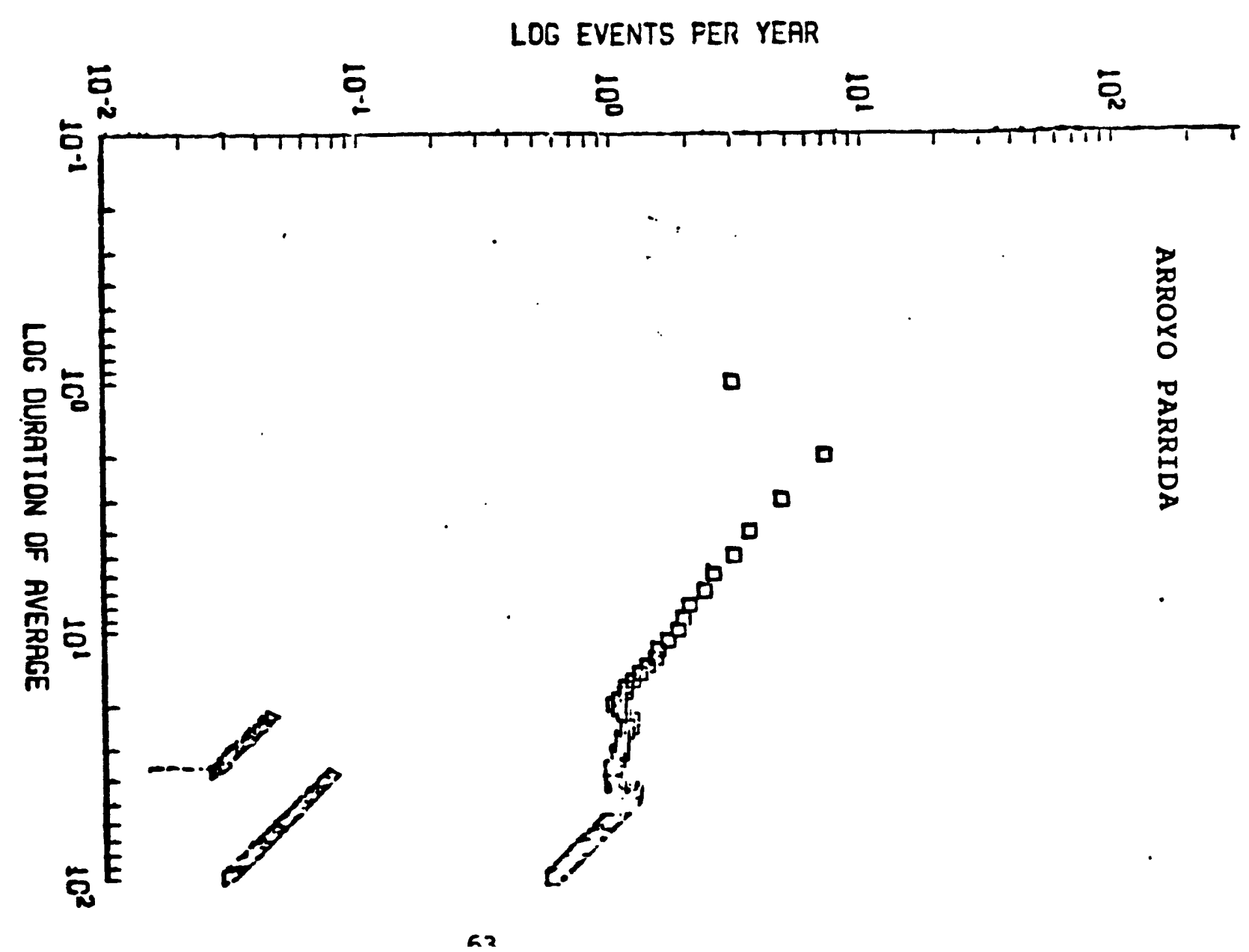




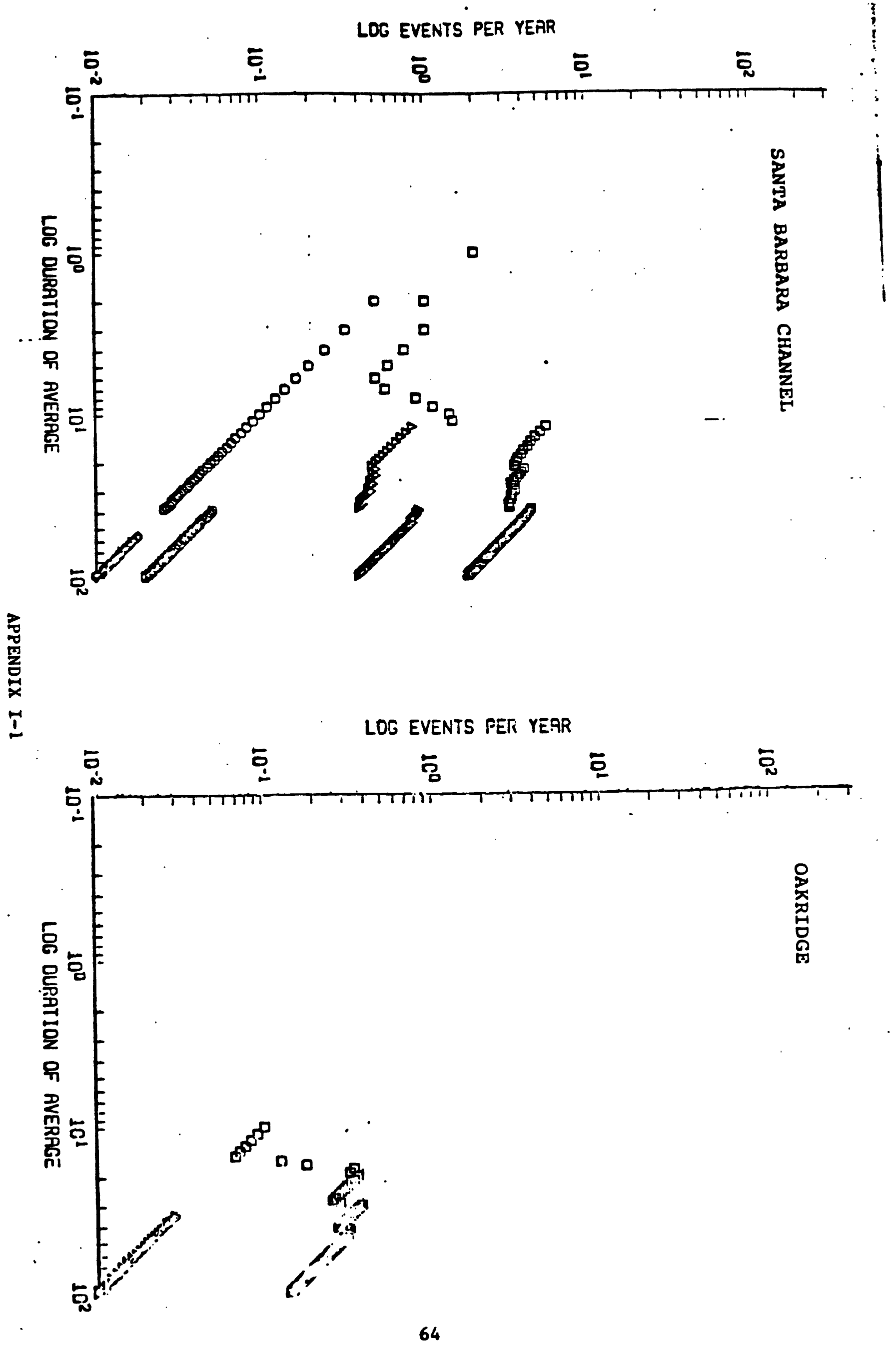




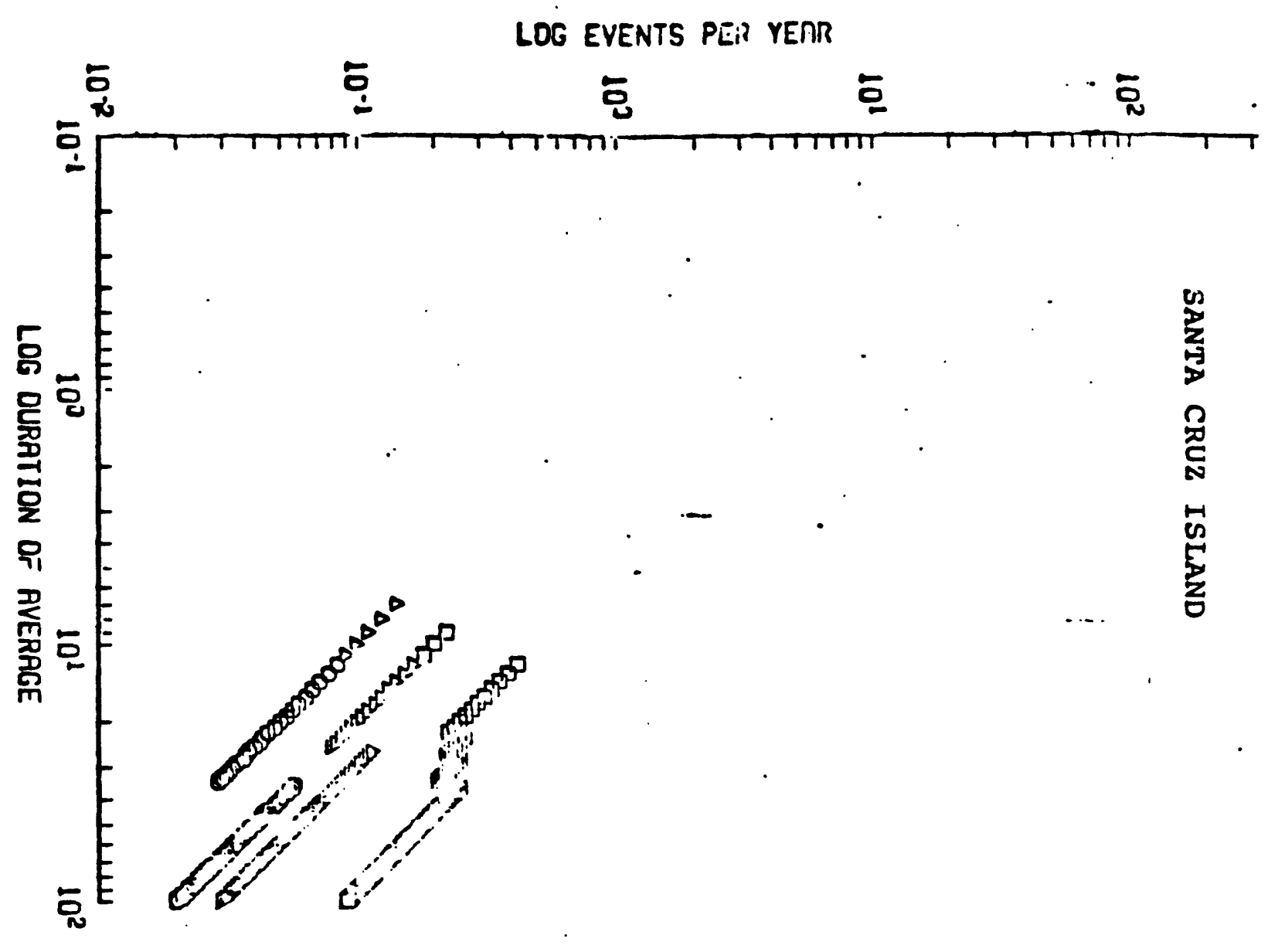

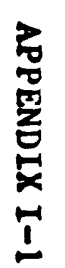

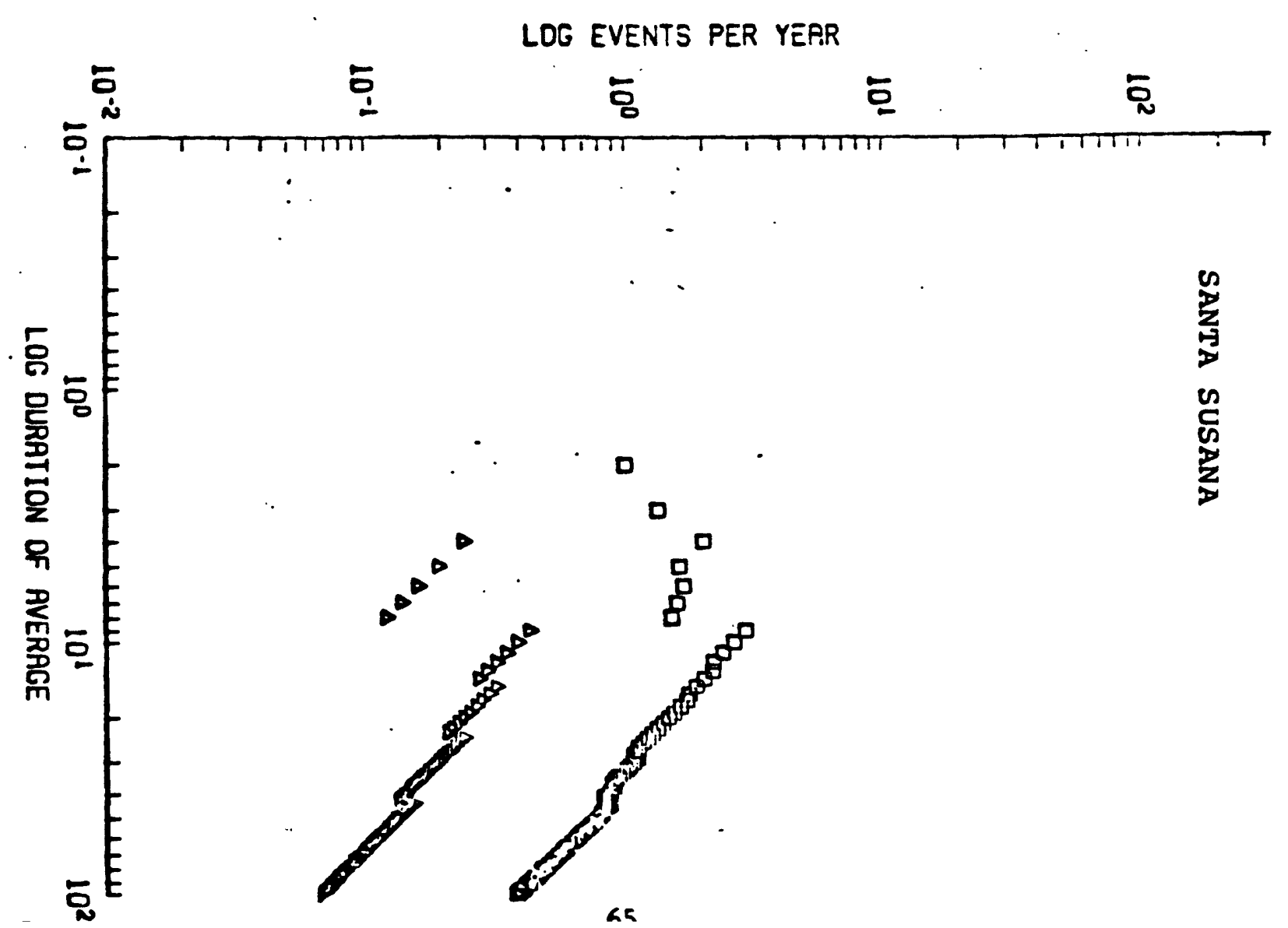




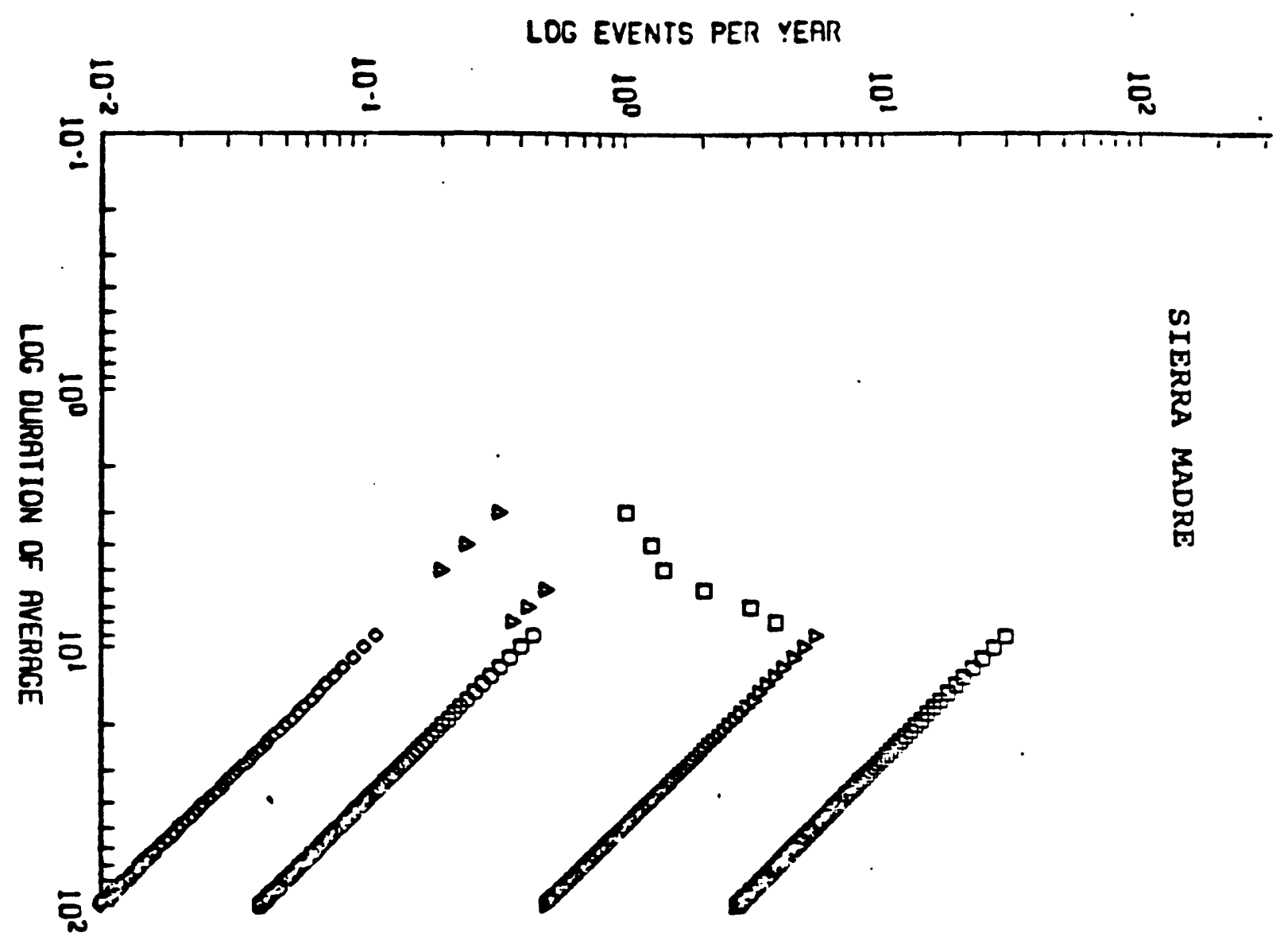

雚

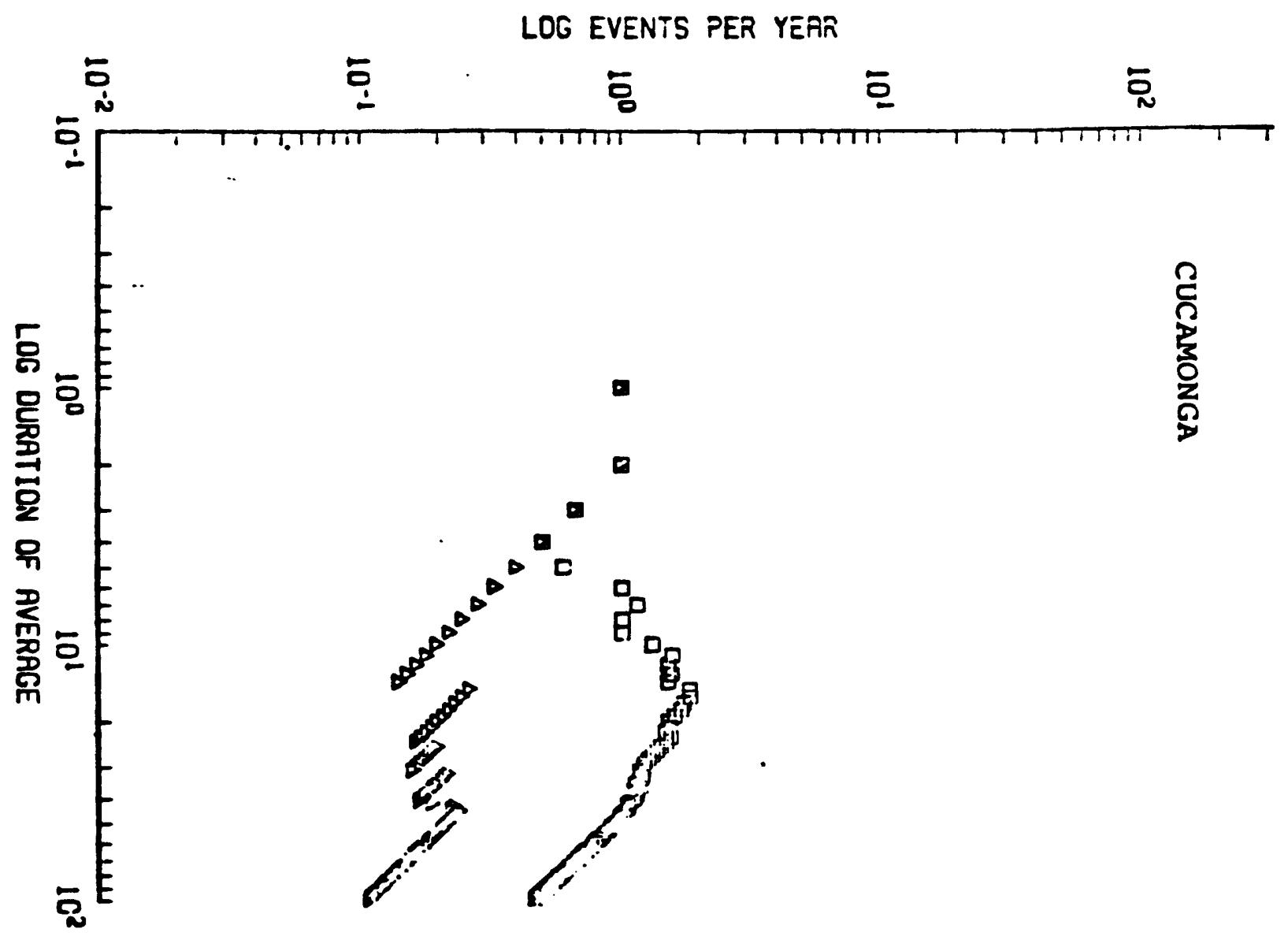




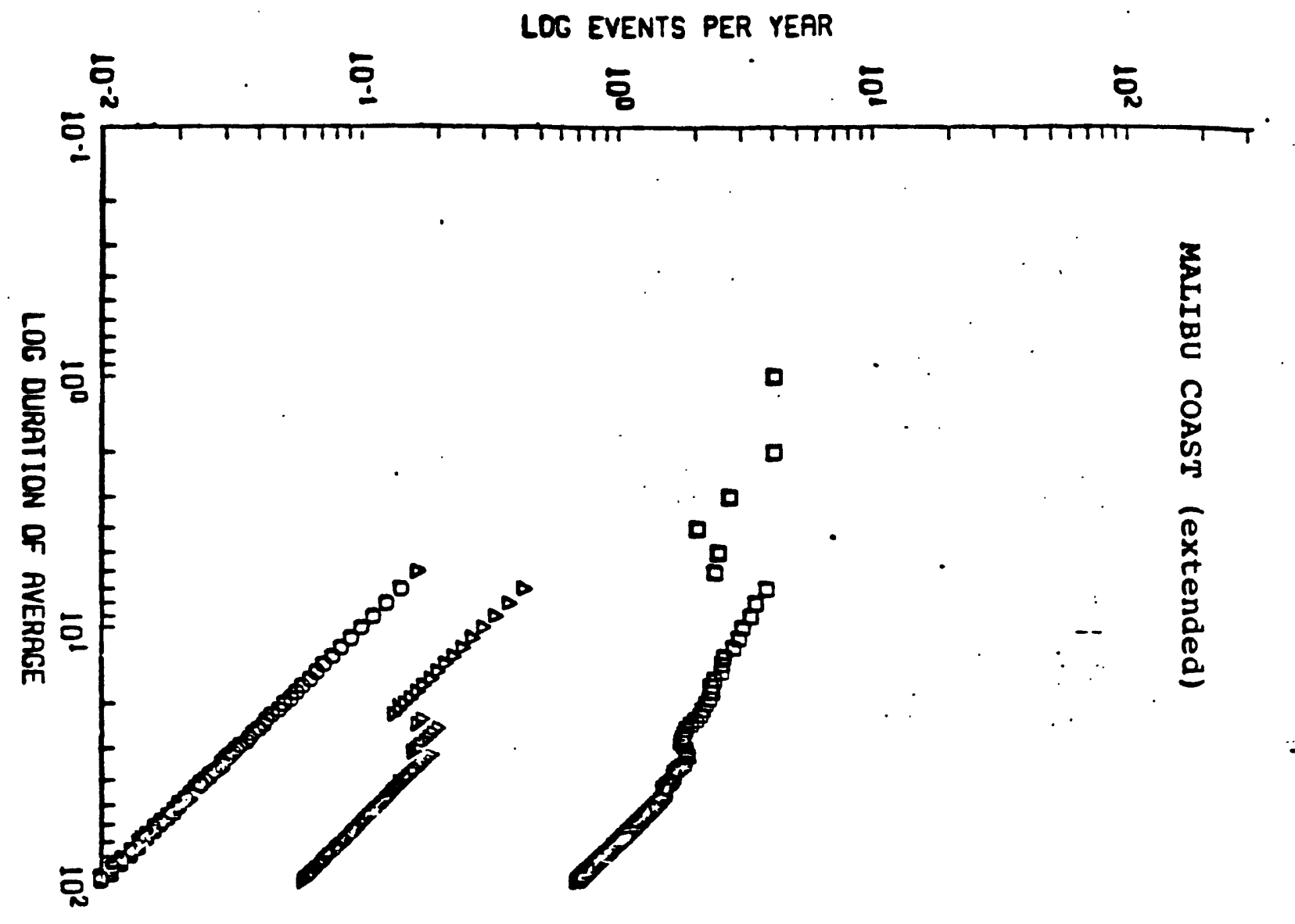

疍

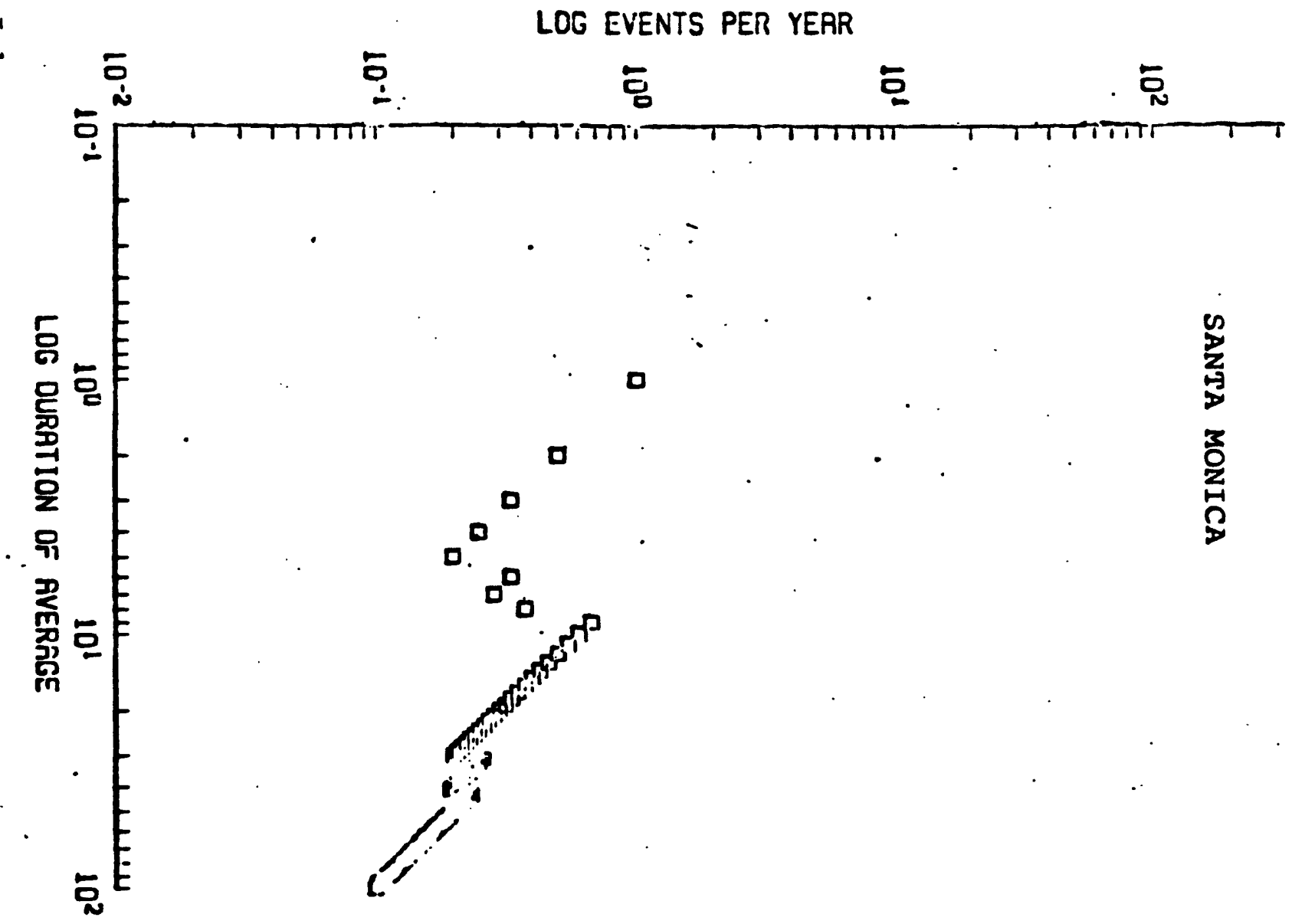



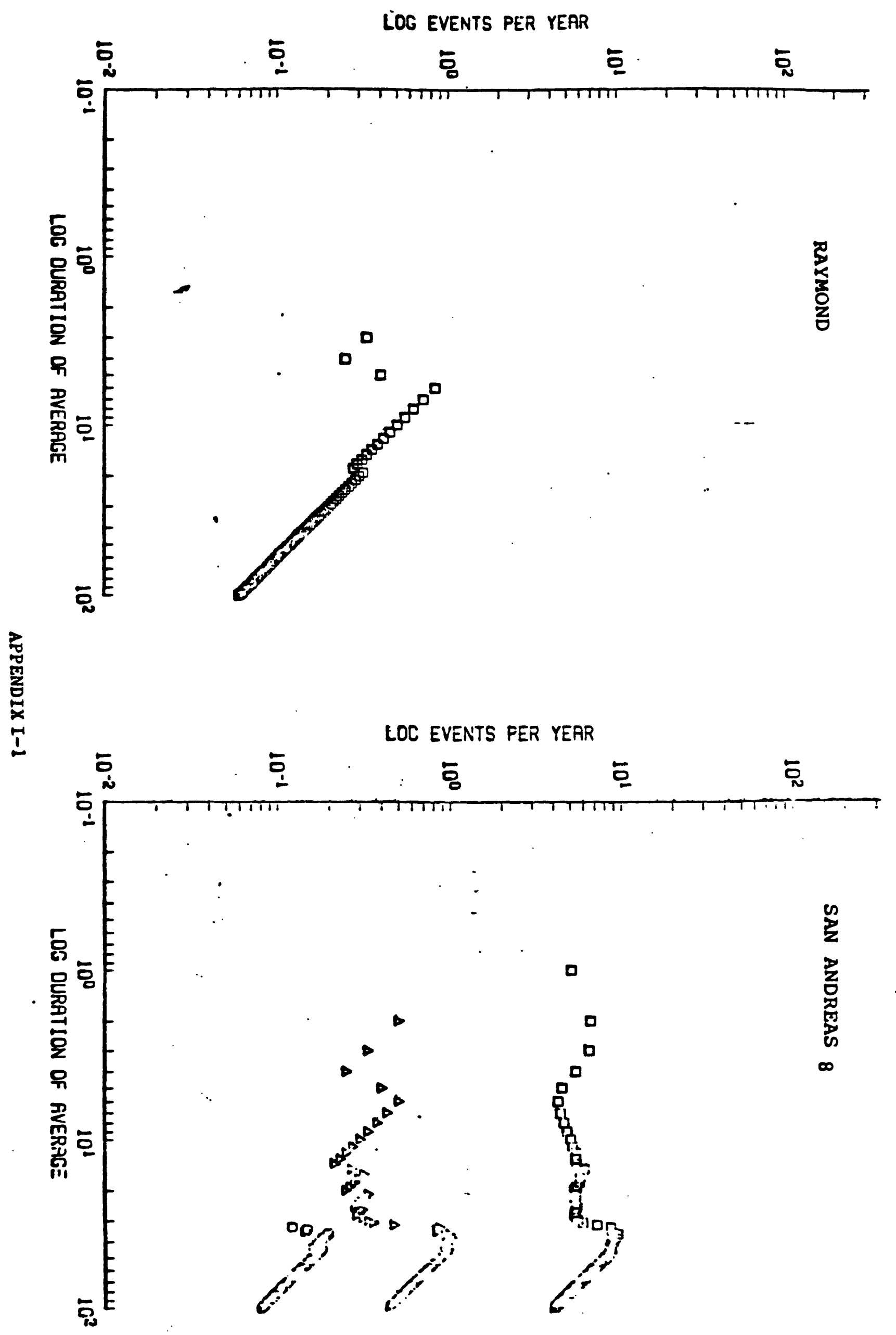


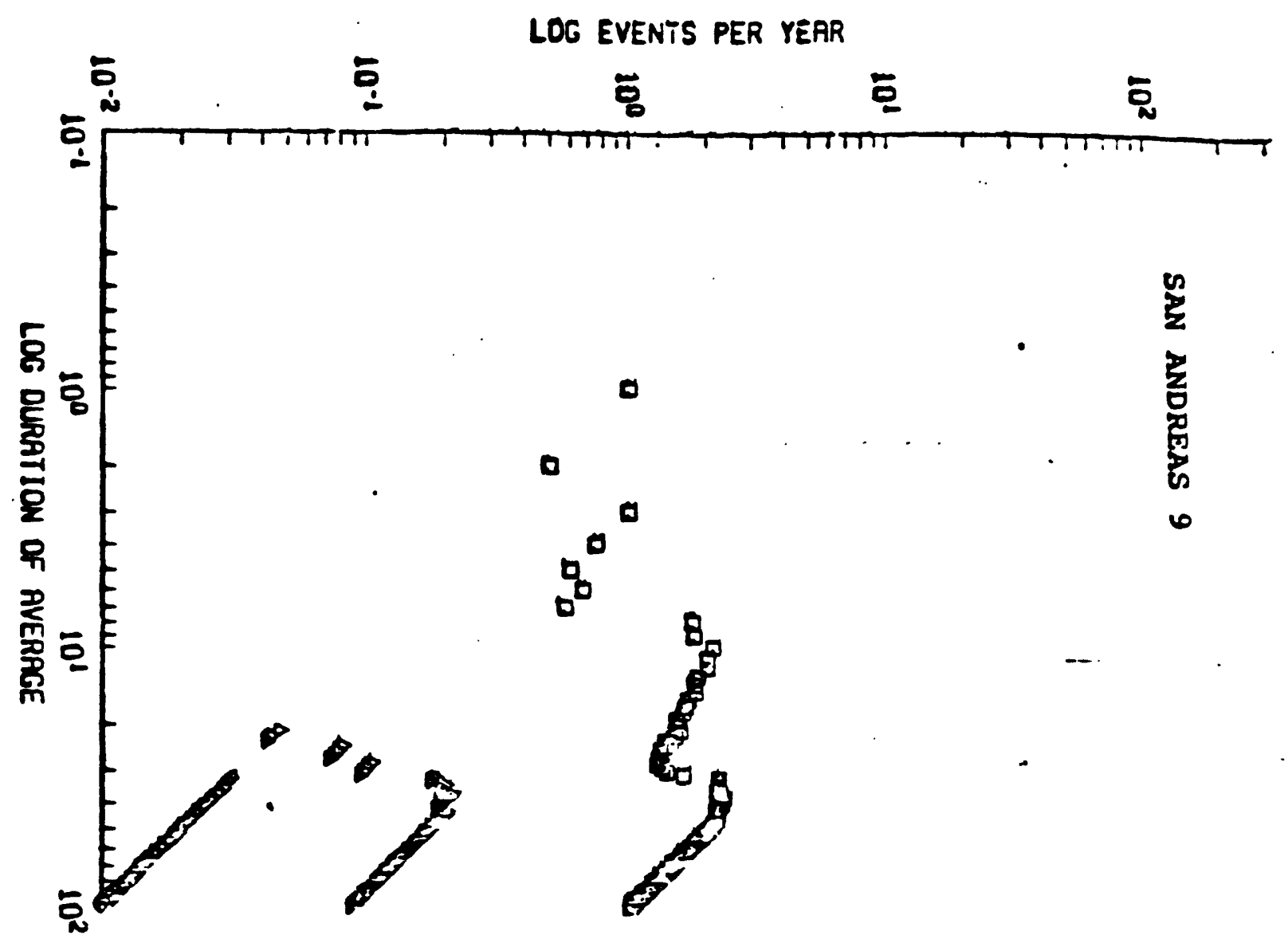

总

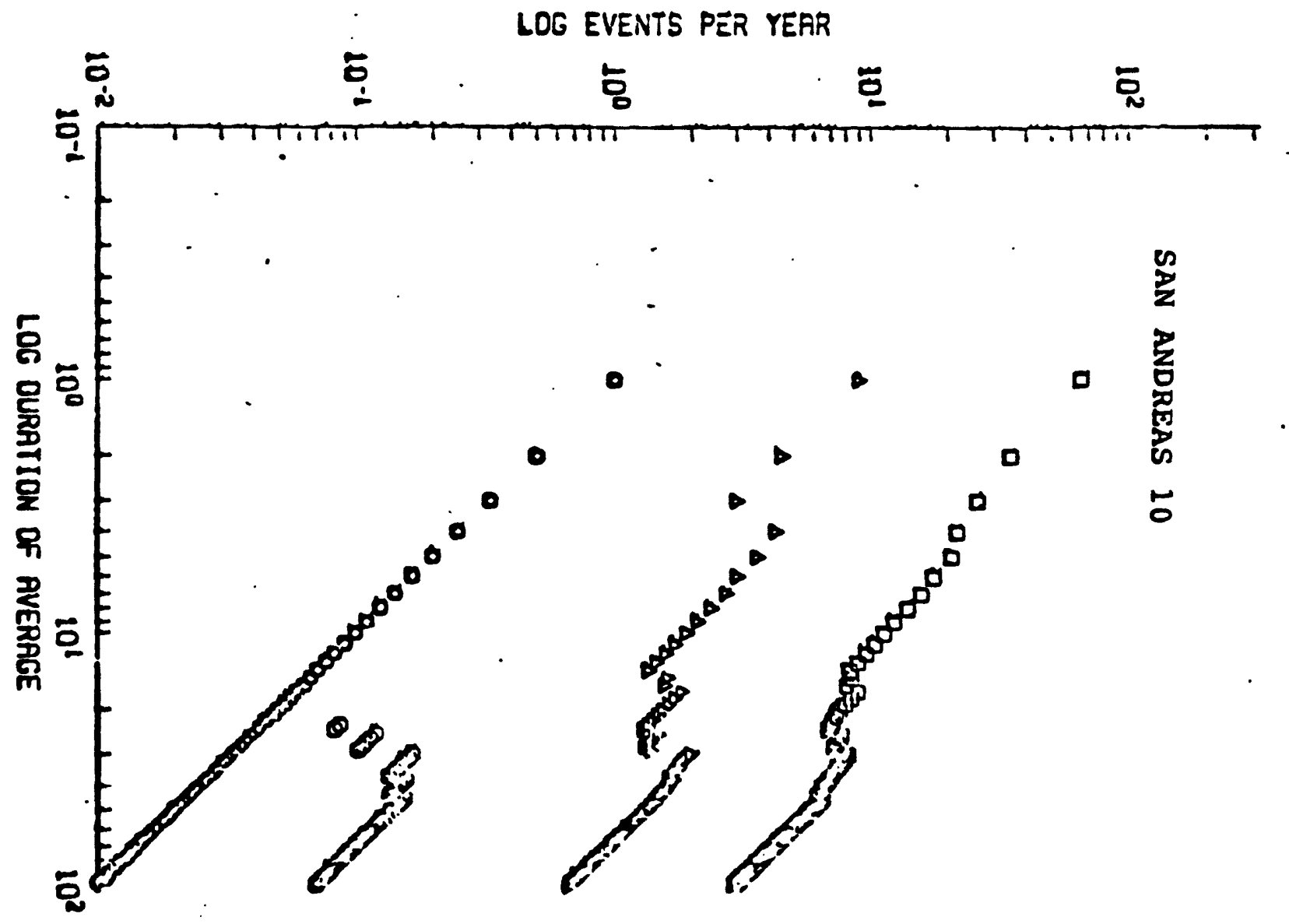




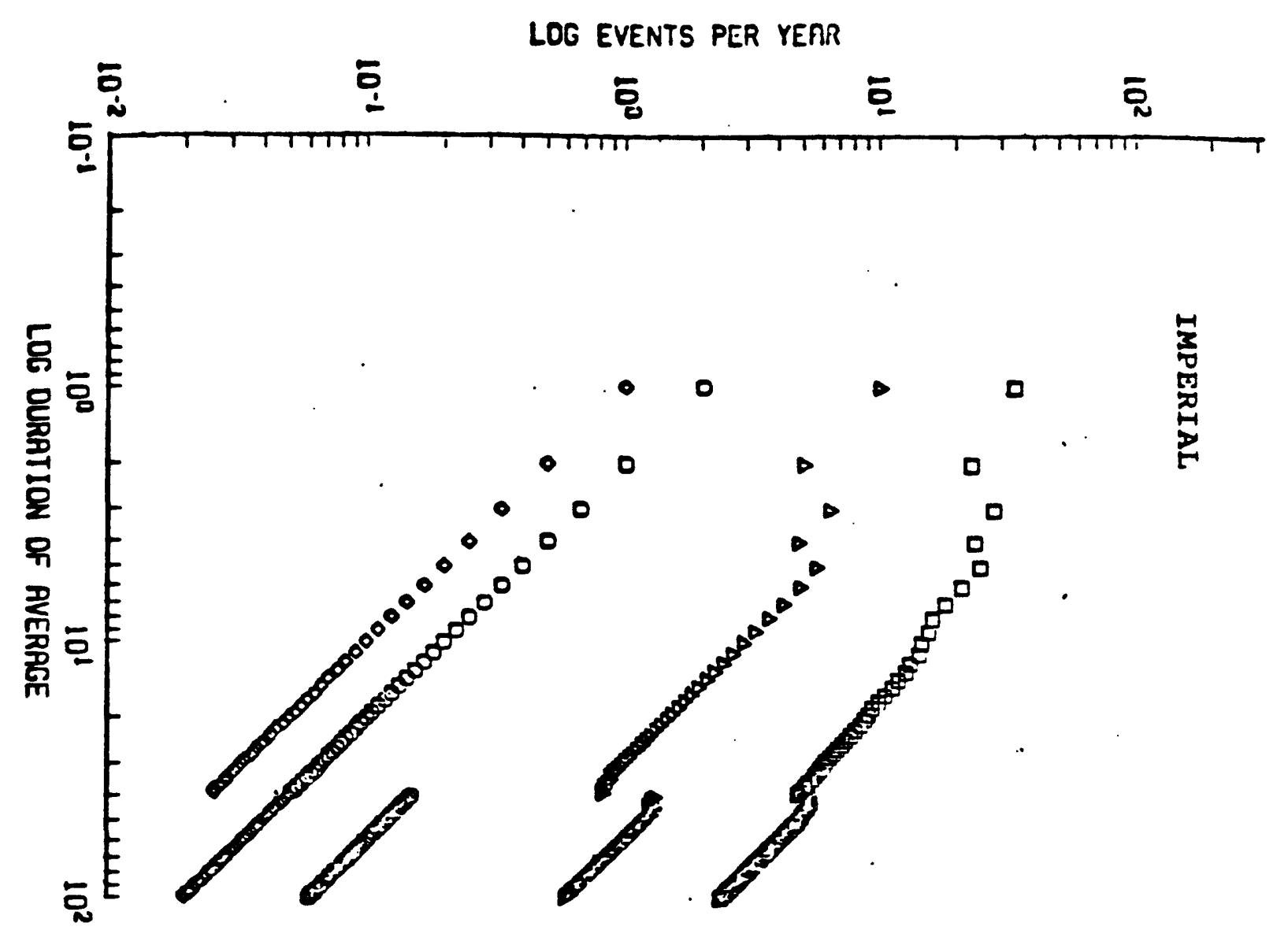

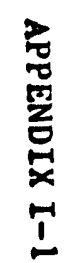

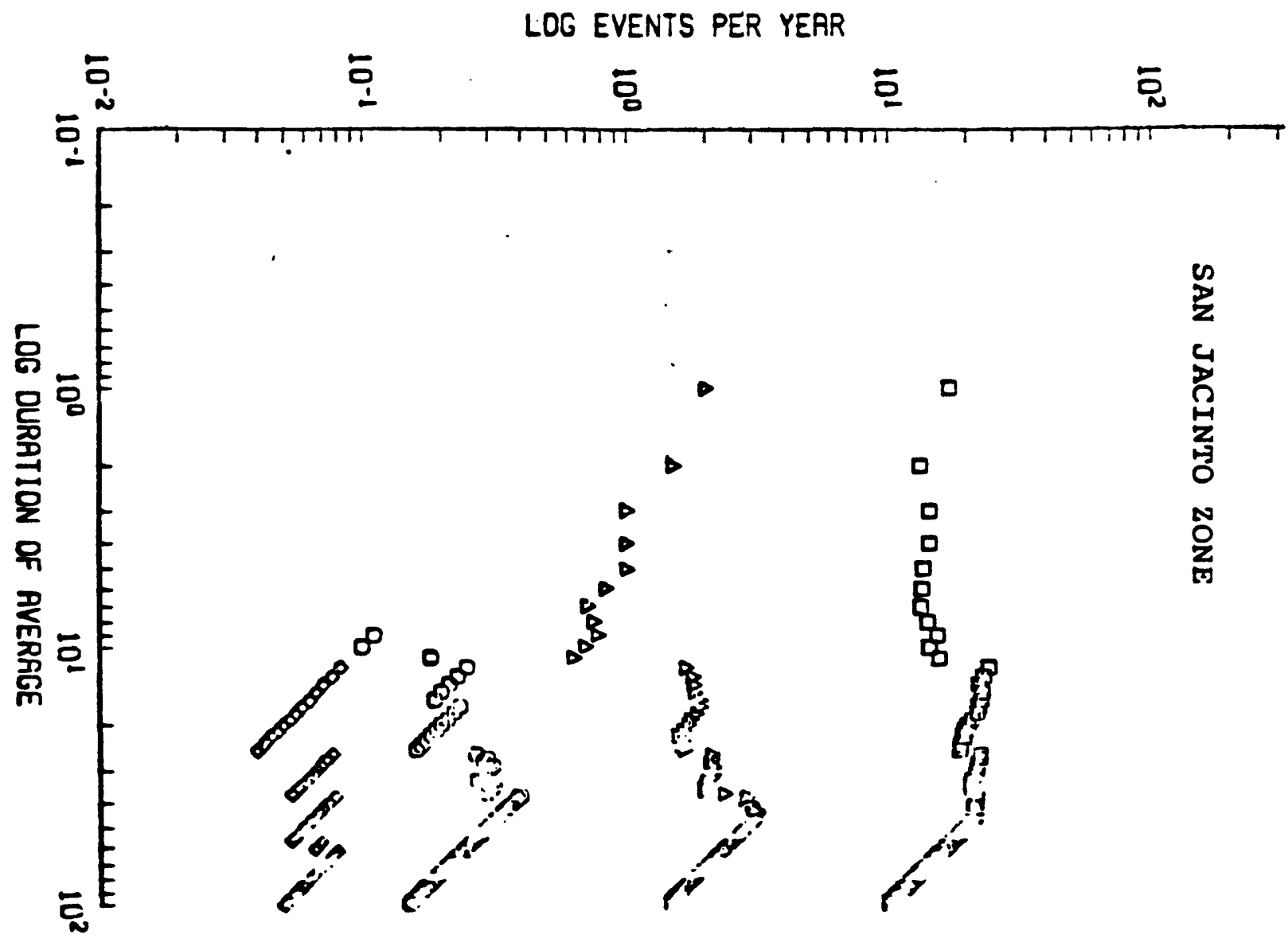




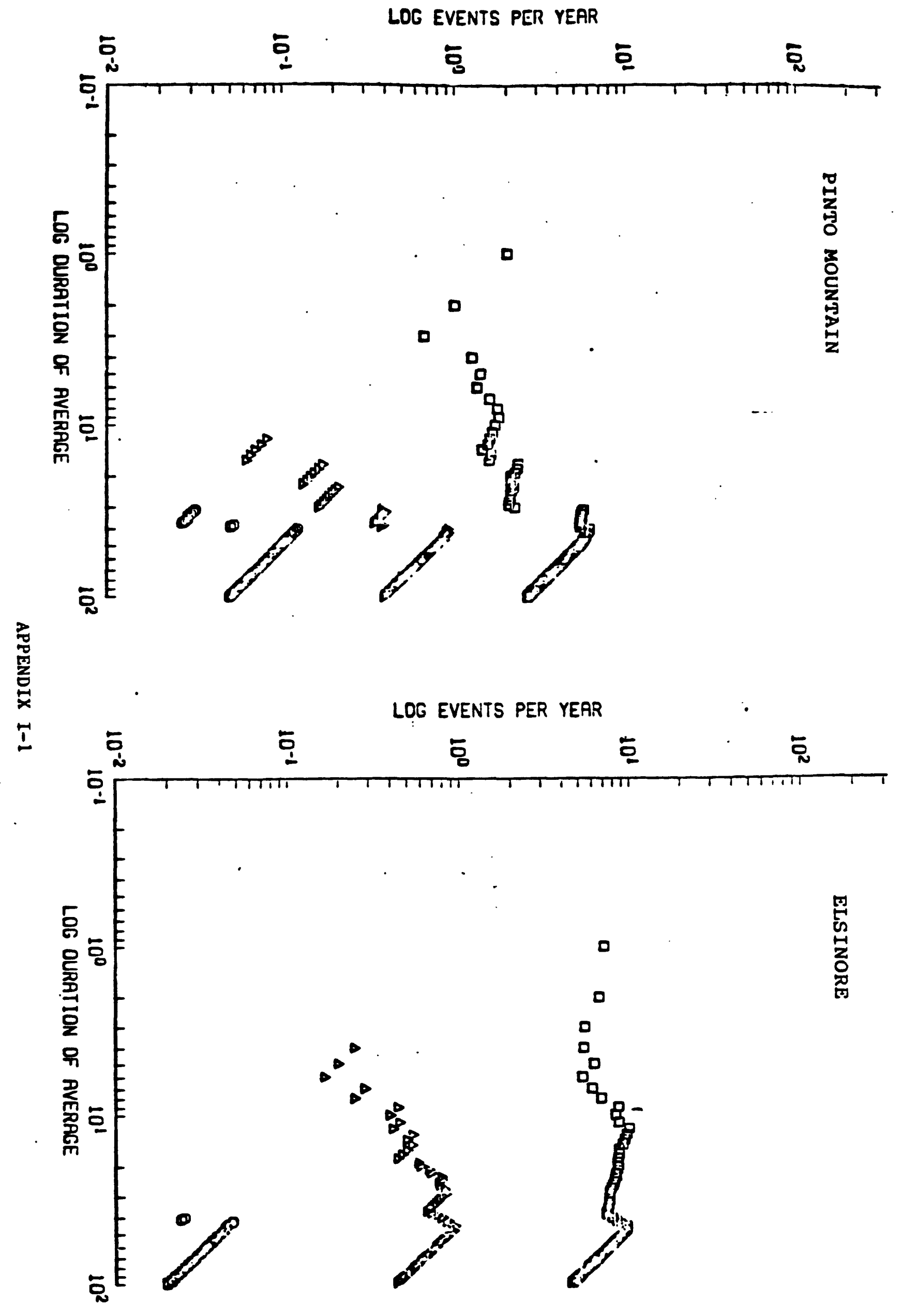




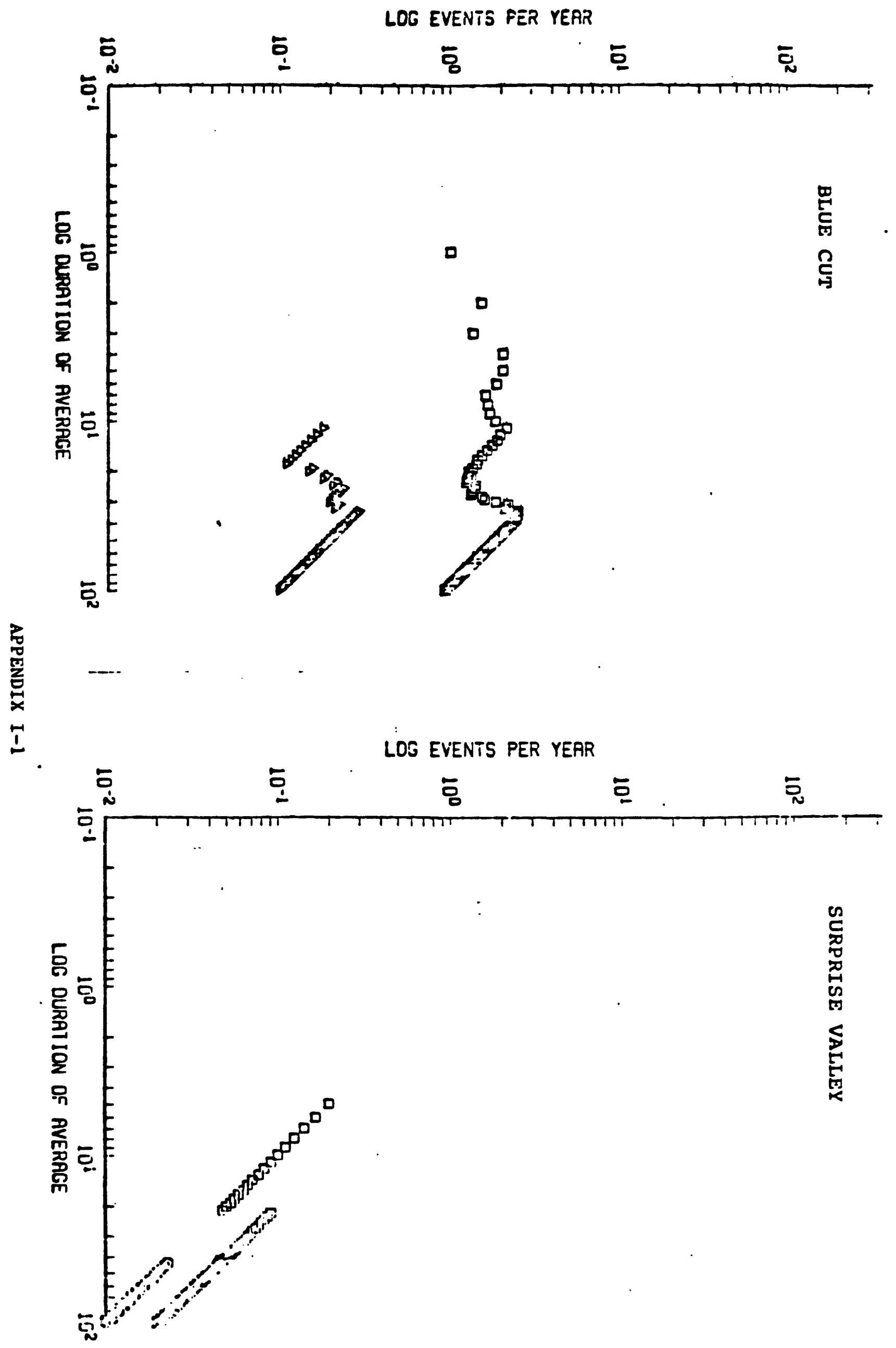




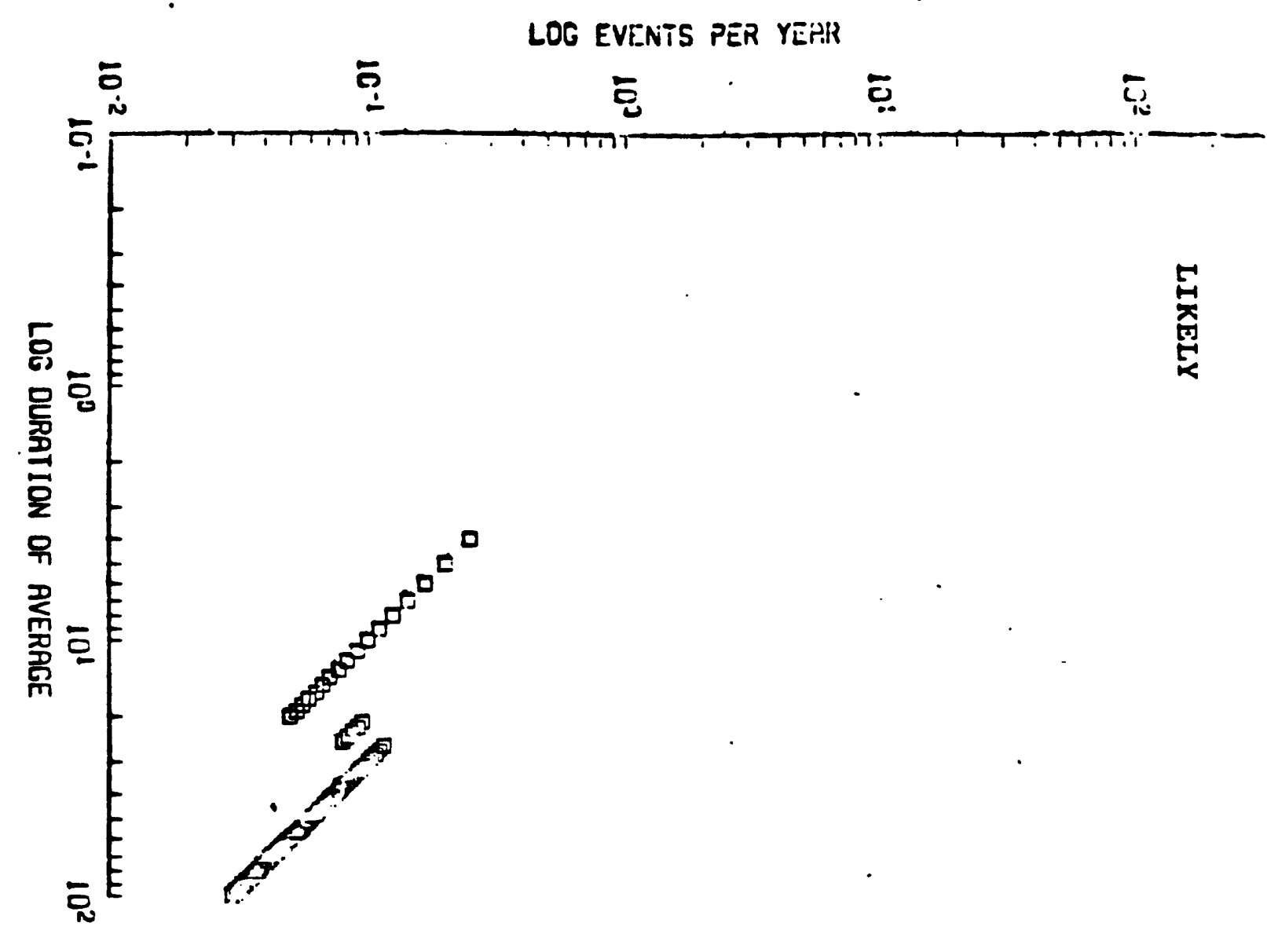

旁

I

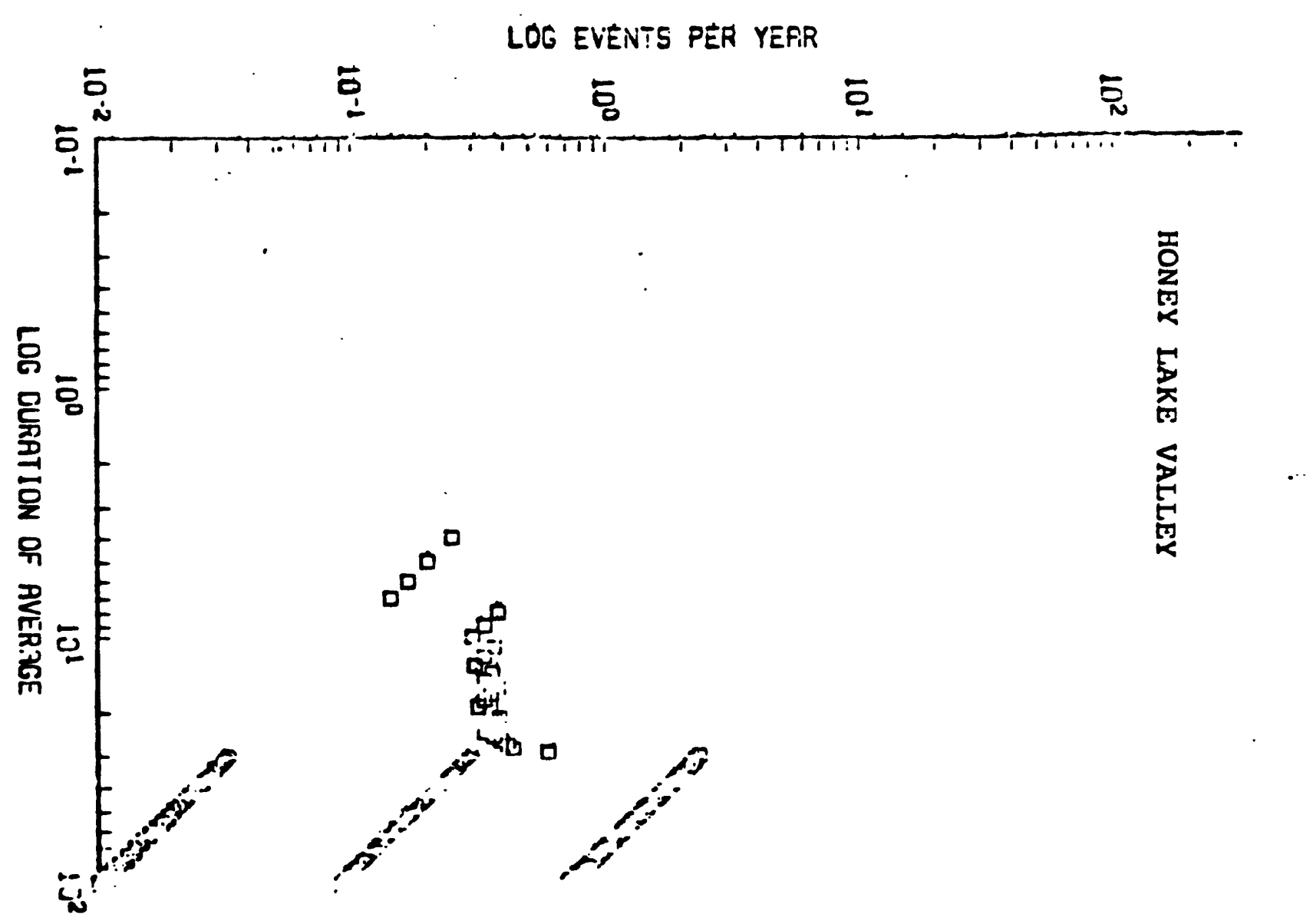




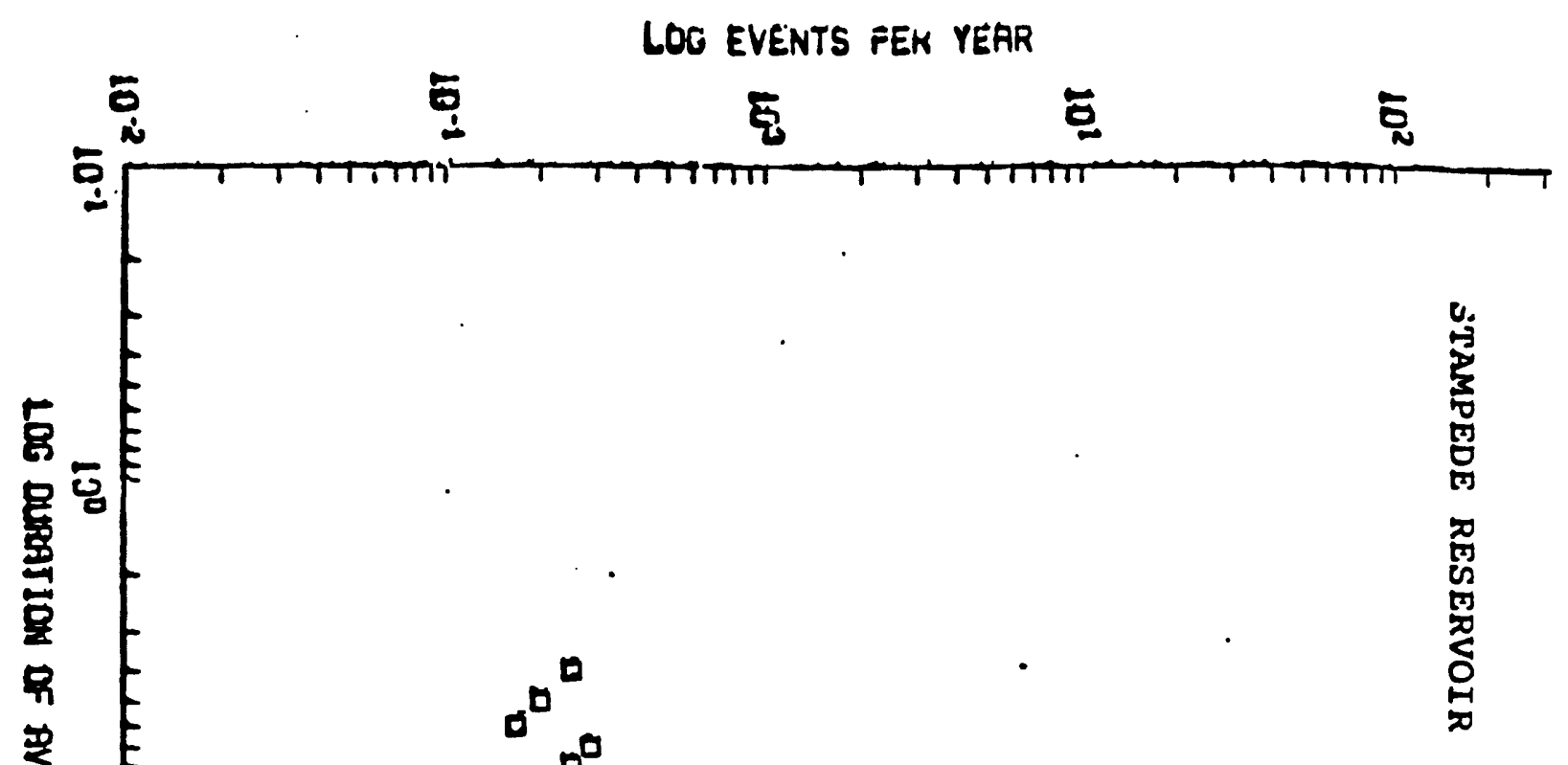

,

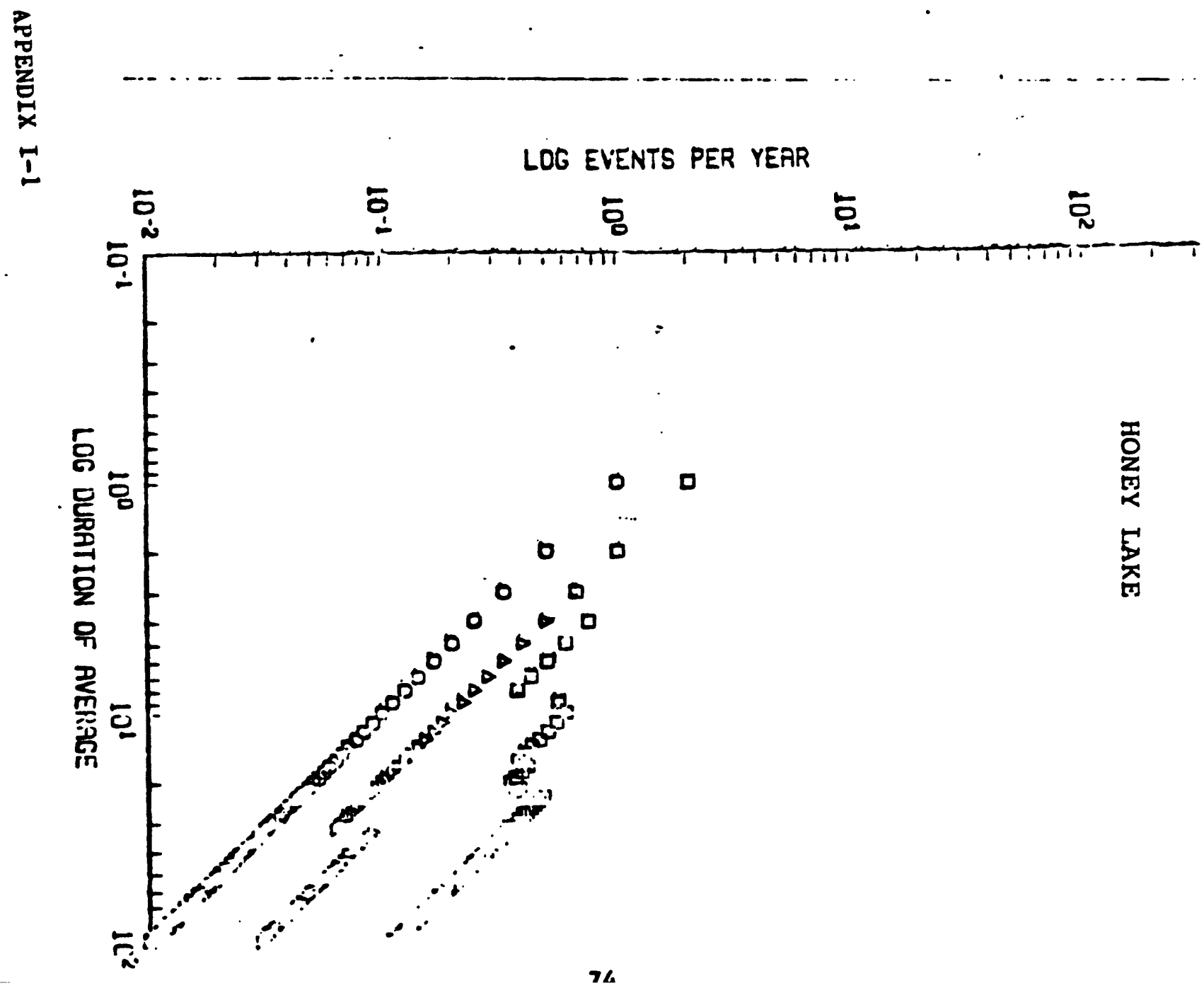




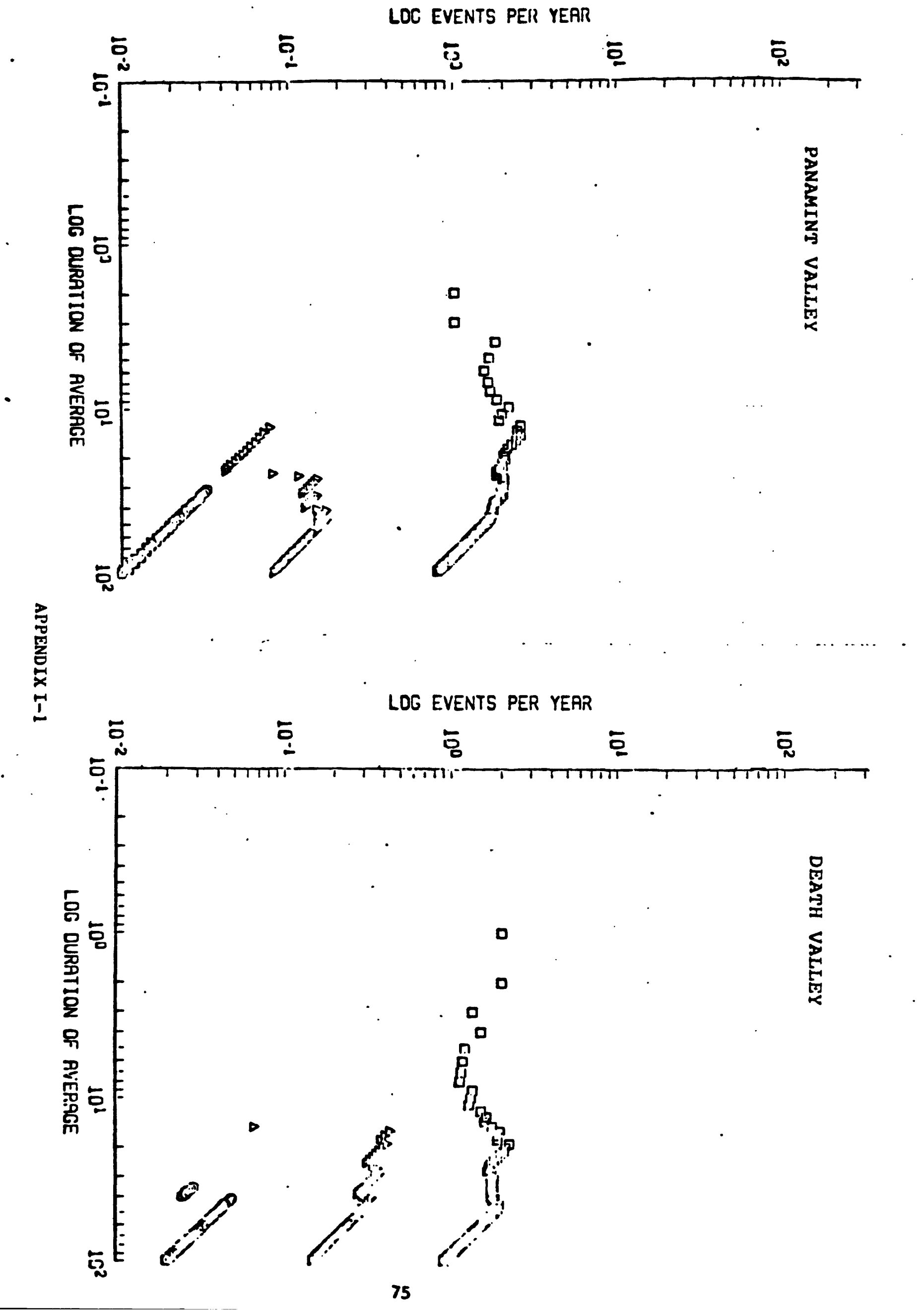




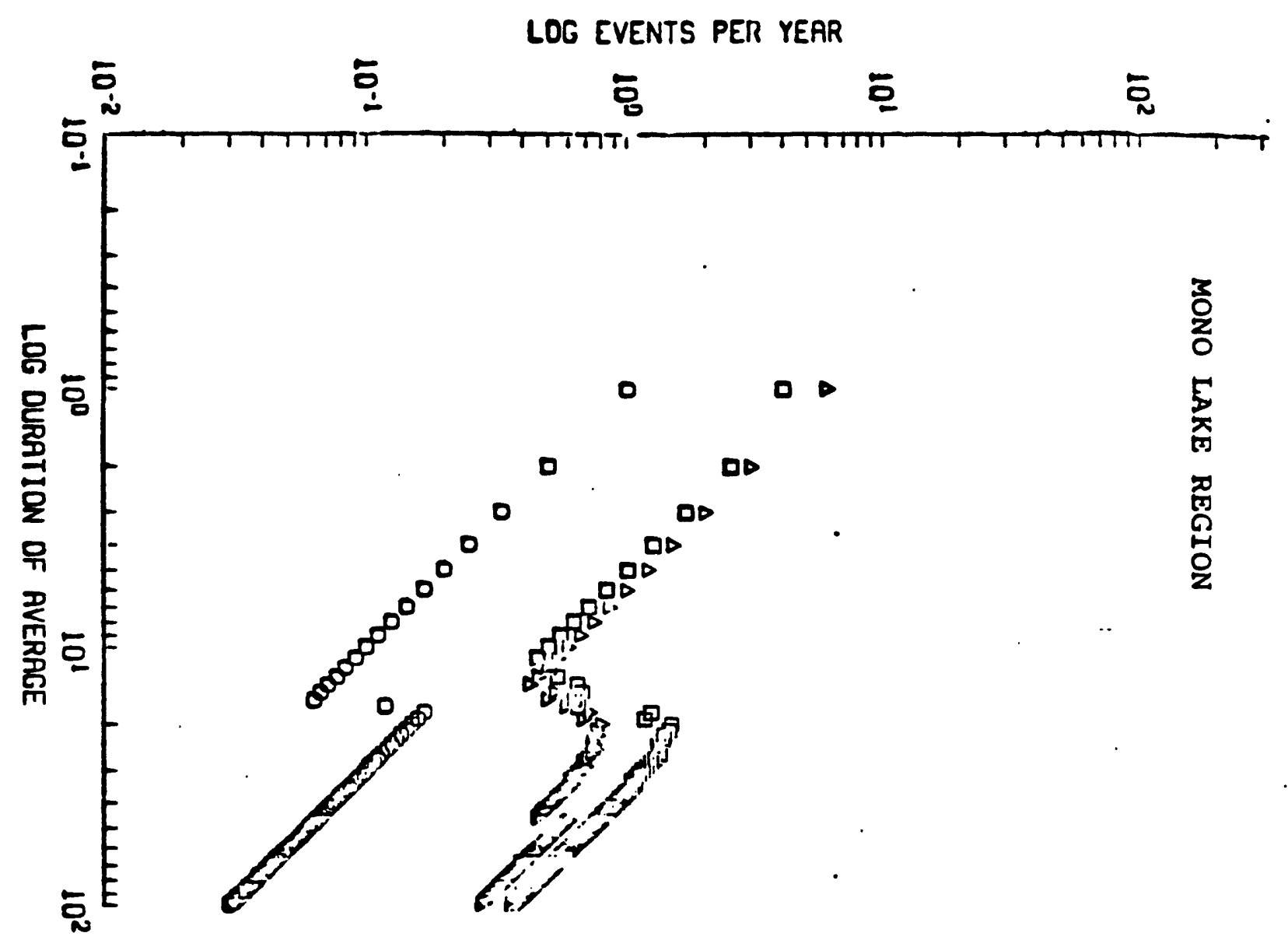

.1
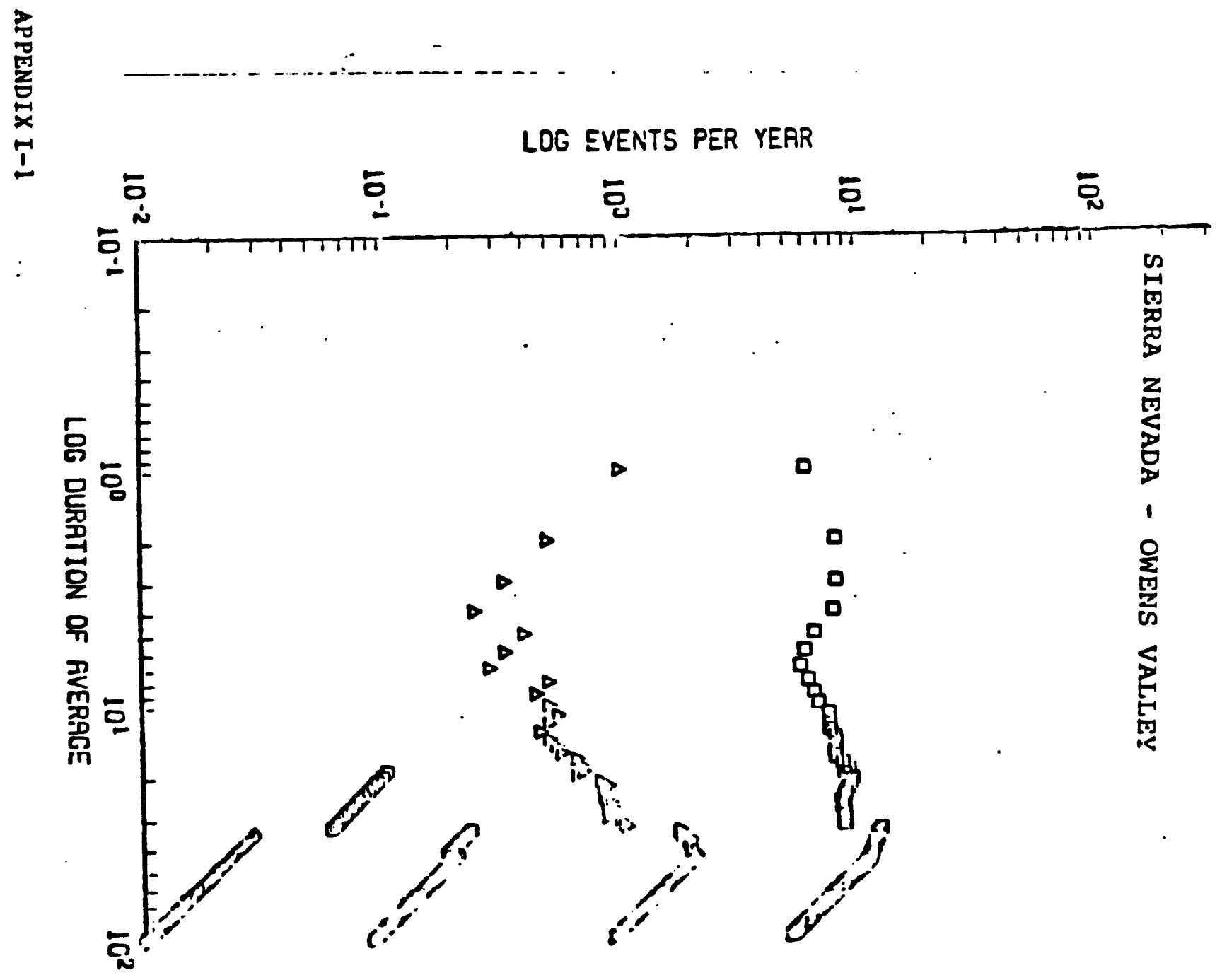


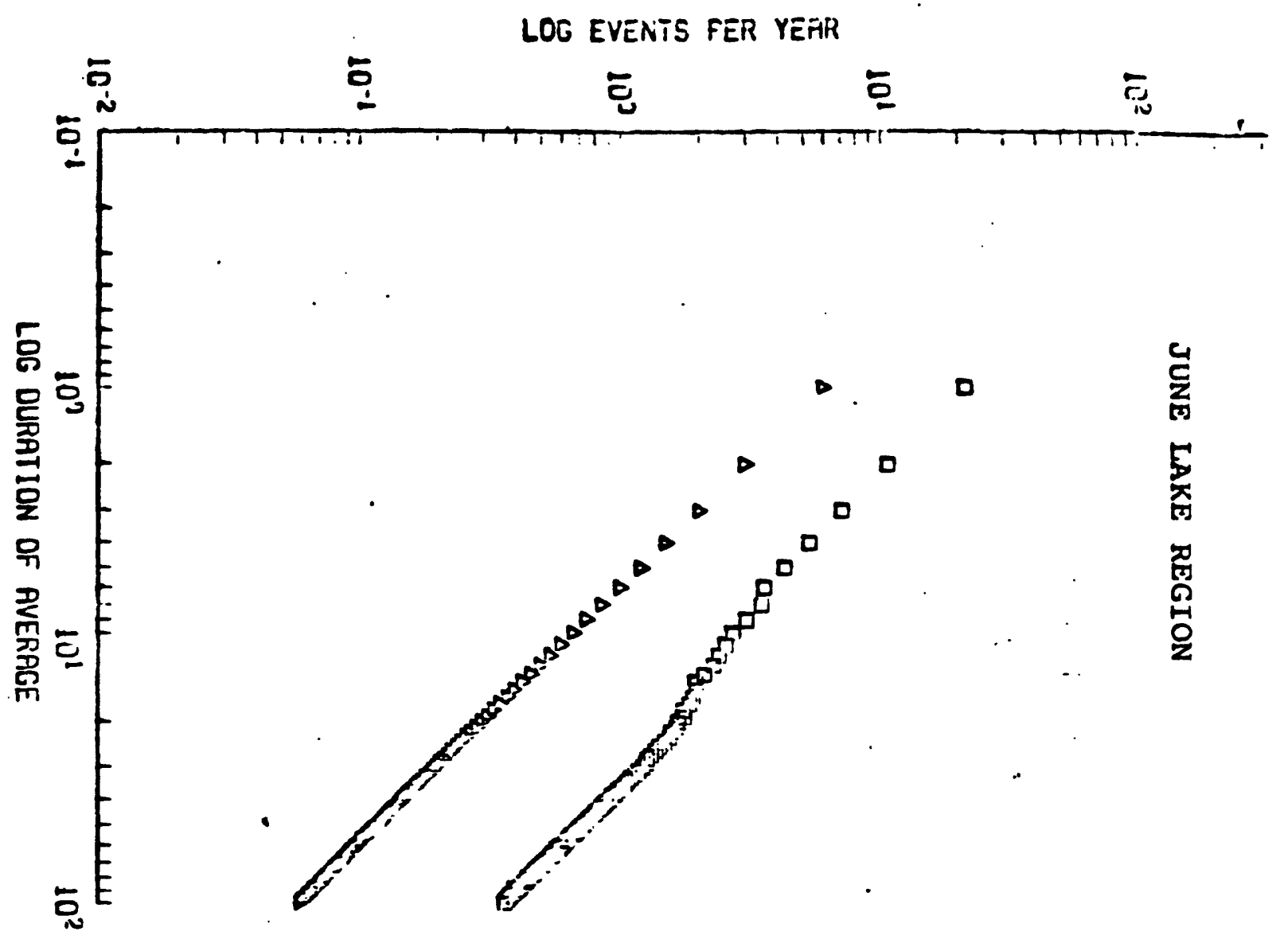

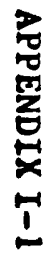

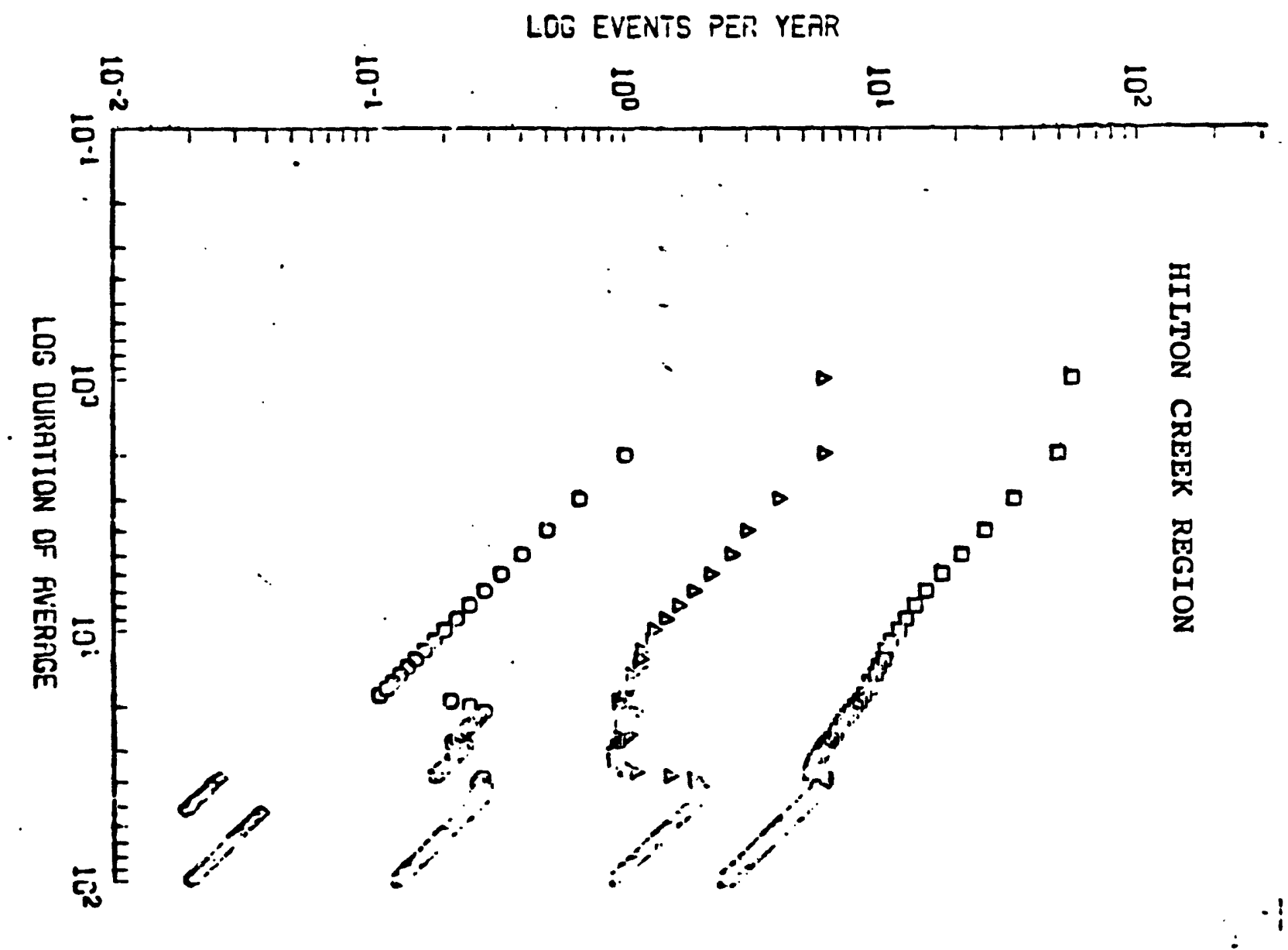




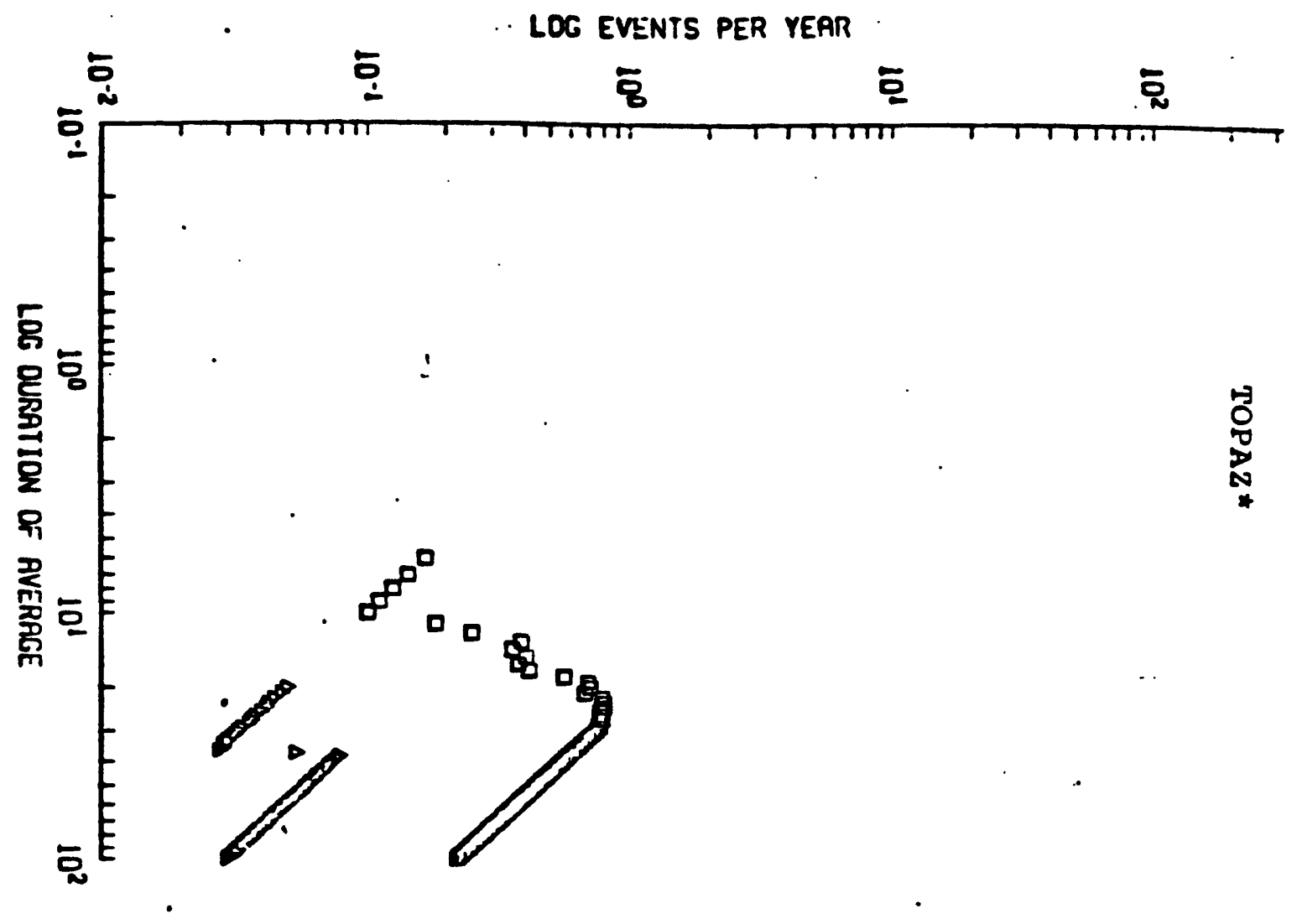

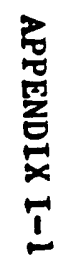

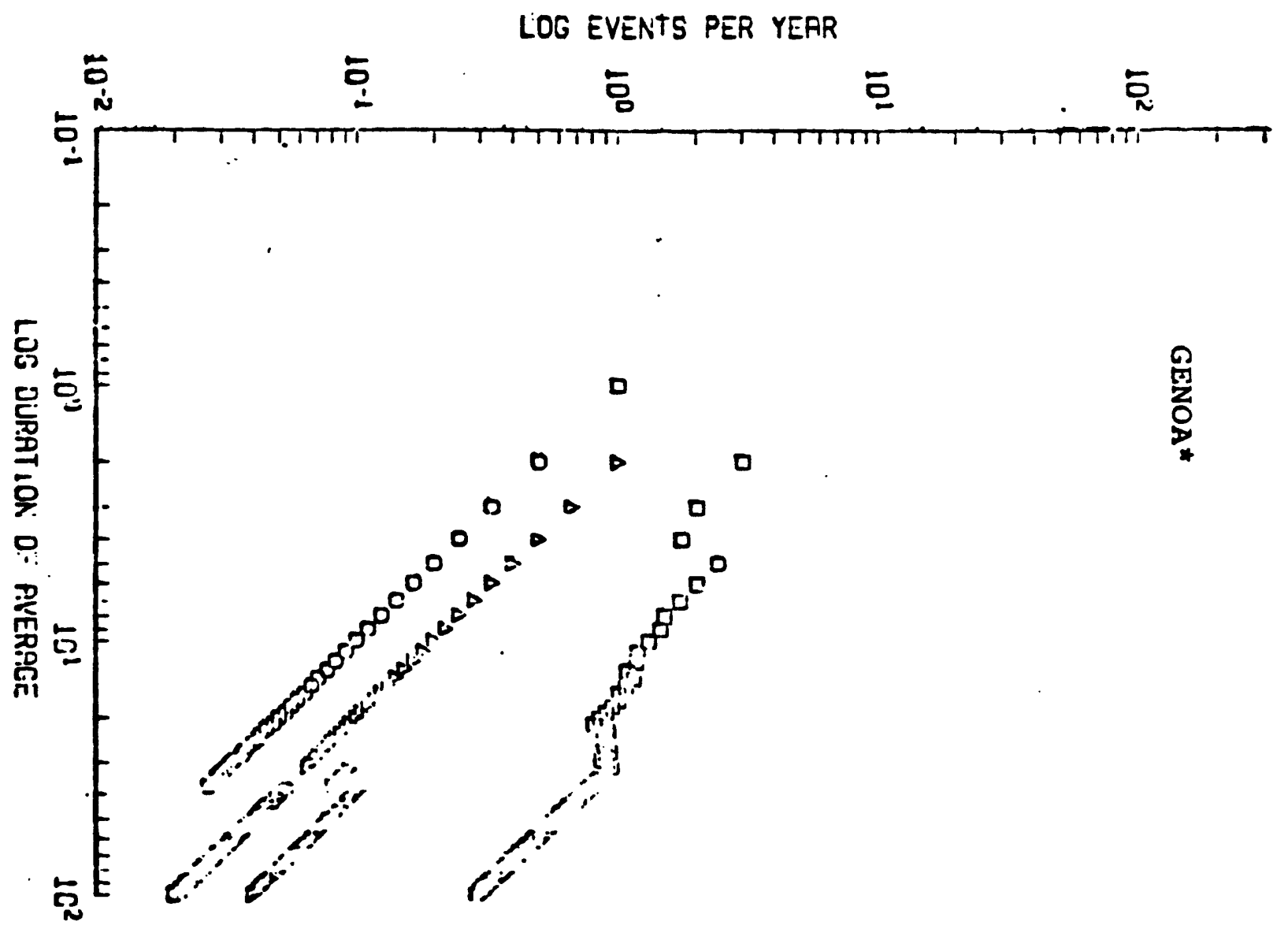




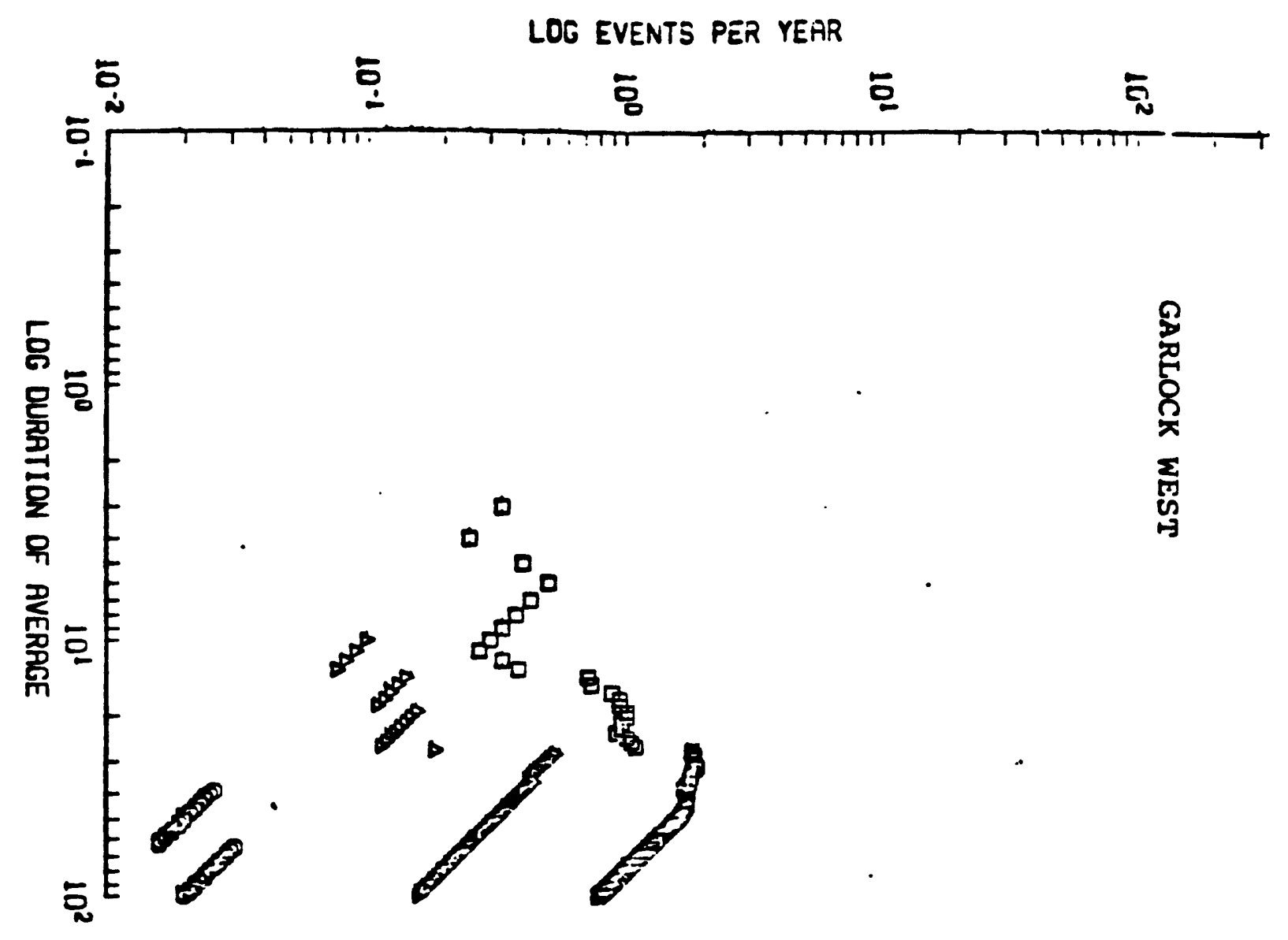

恶

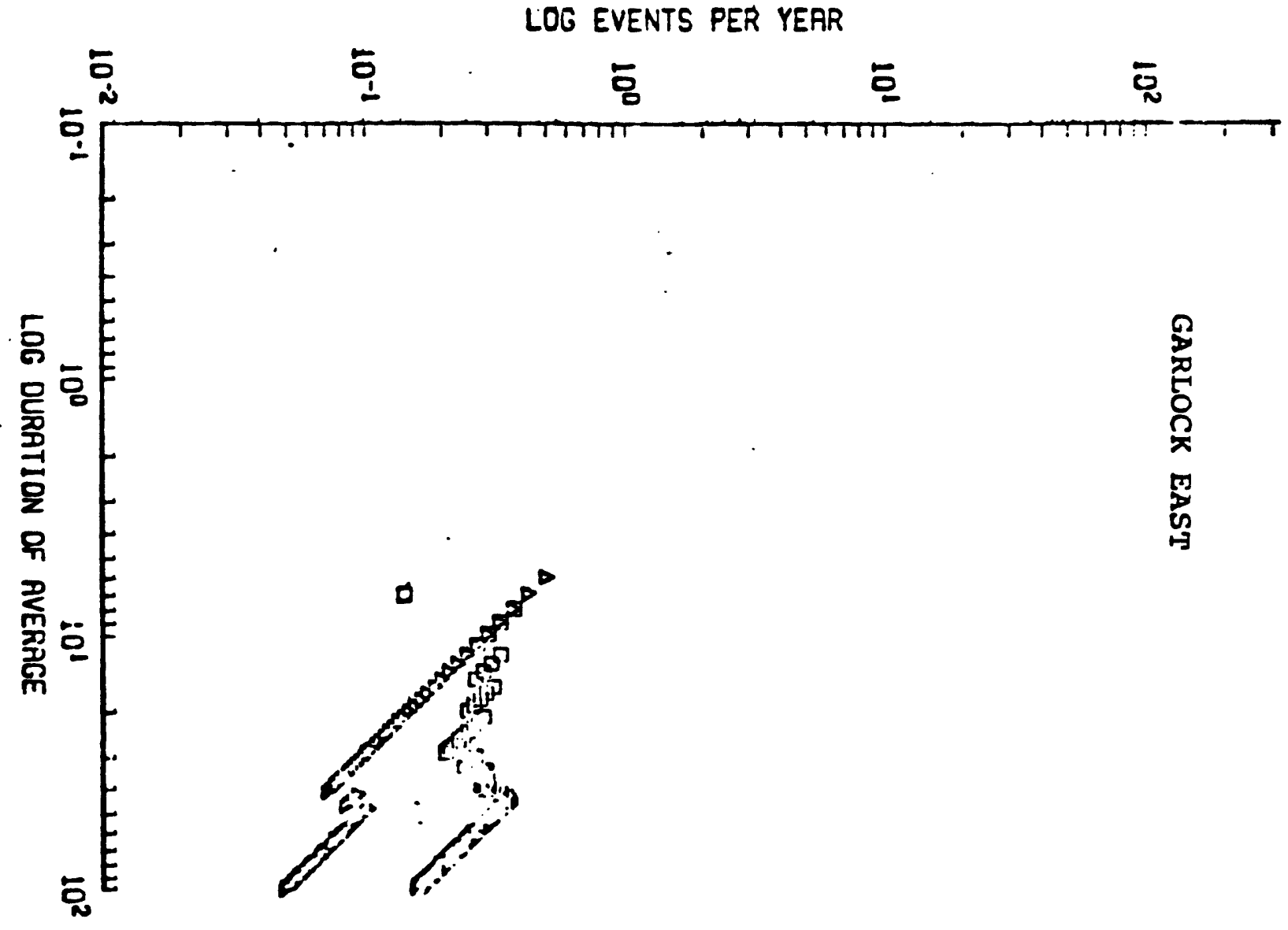




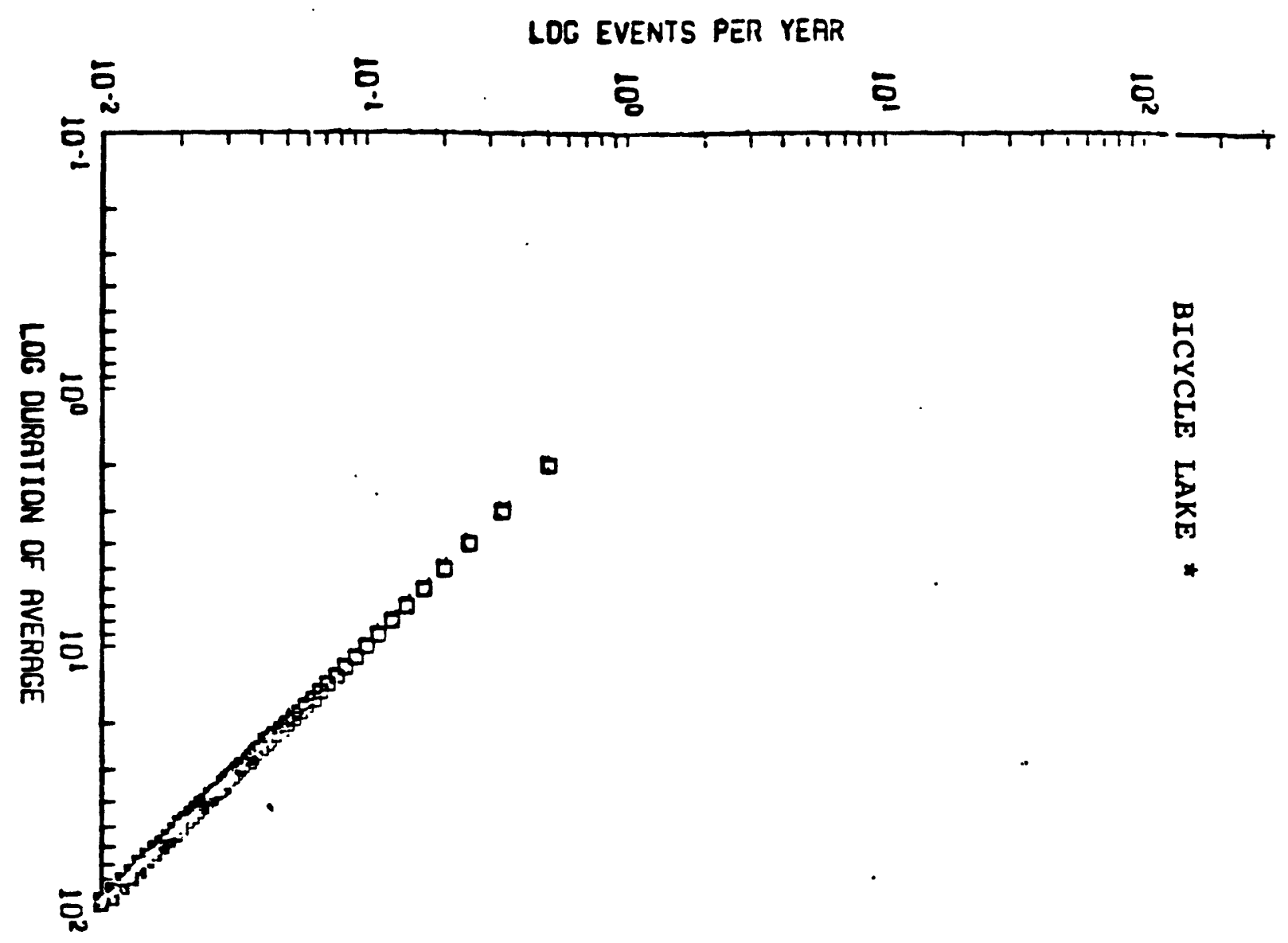

兽

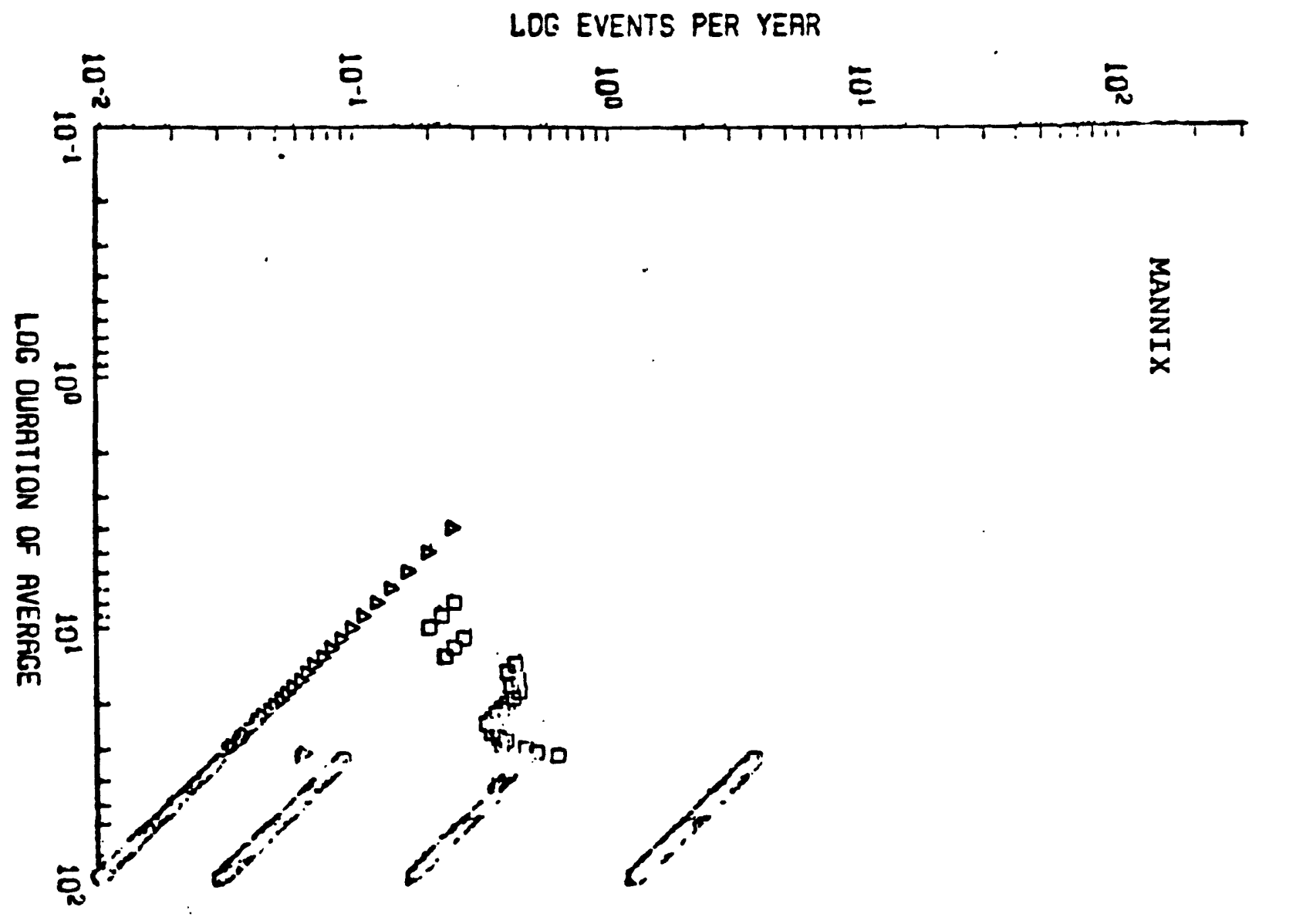




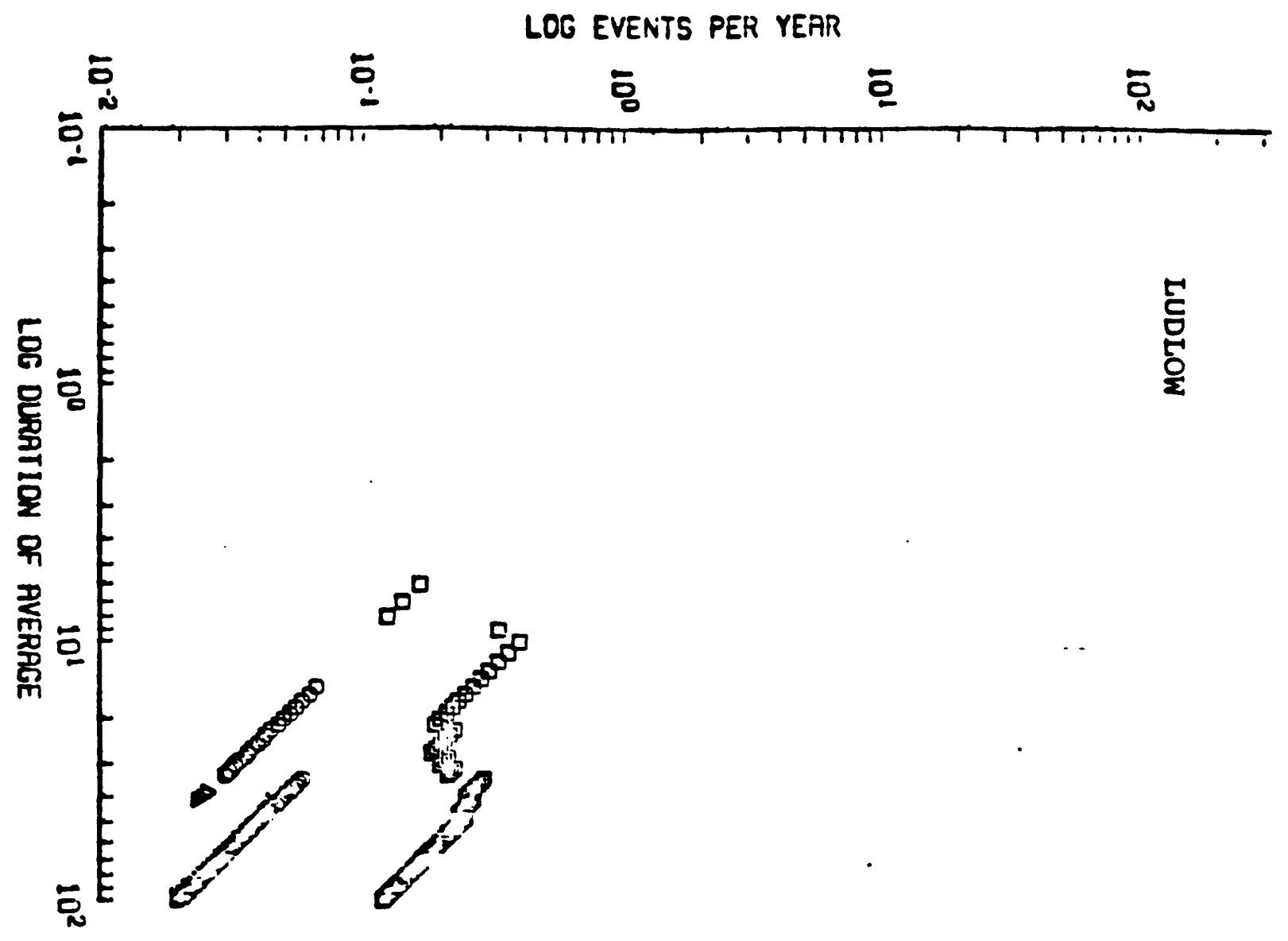

总

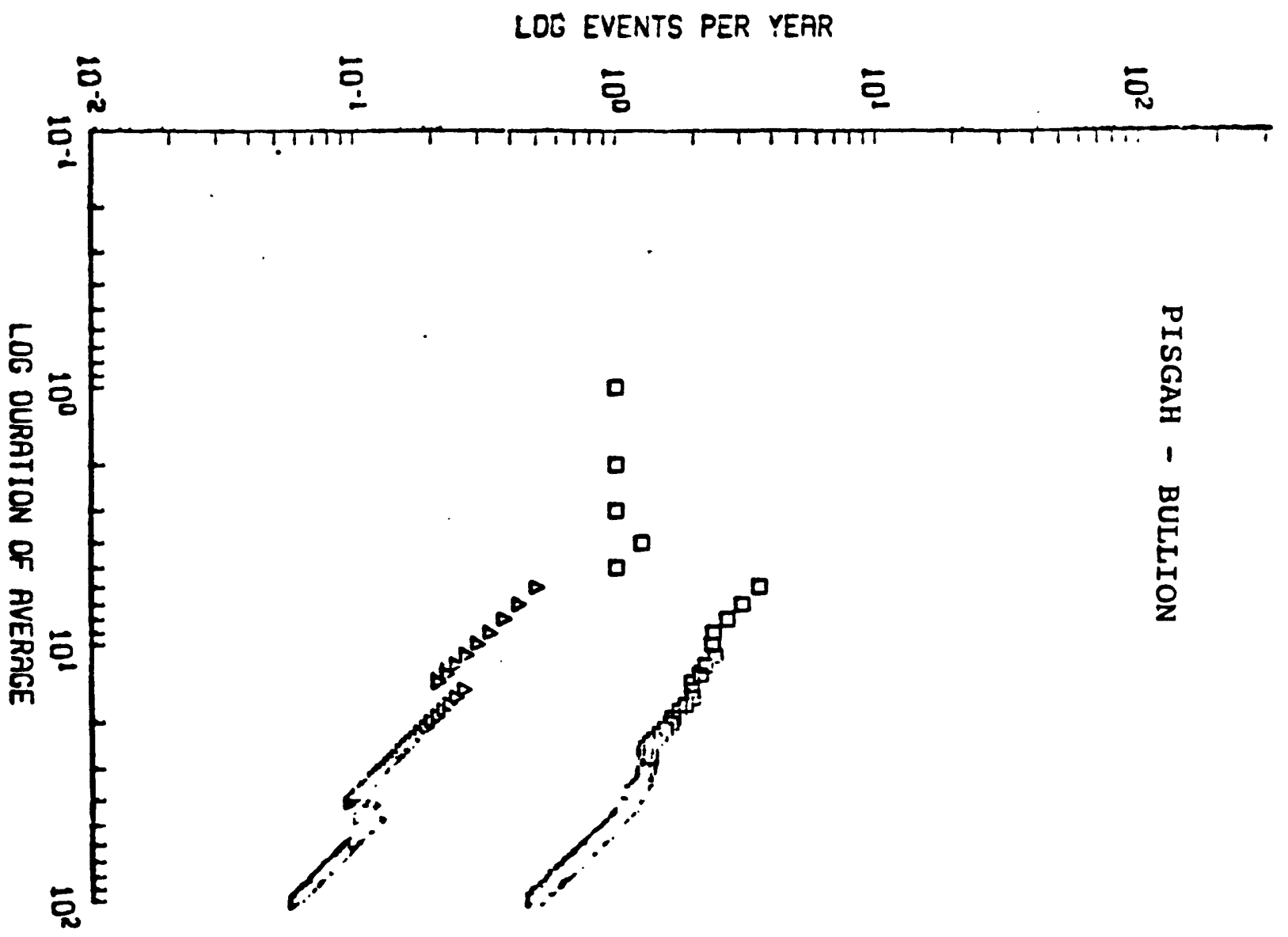

81 


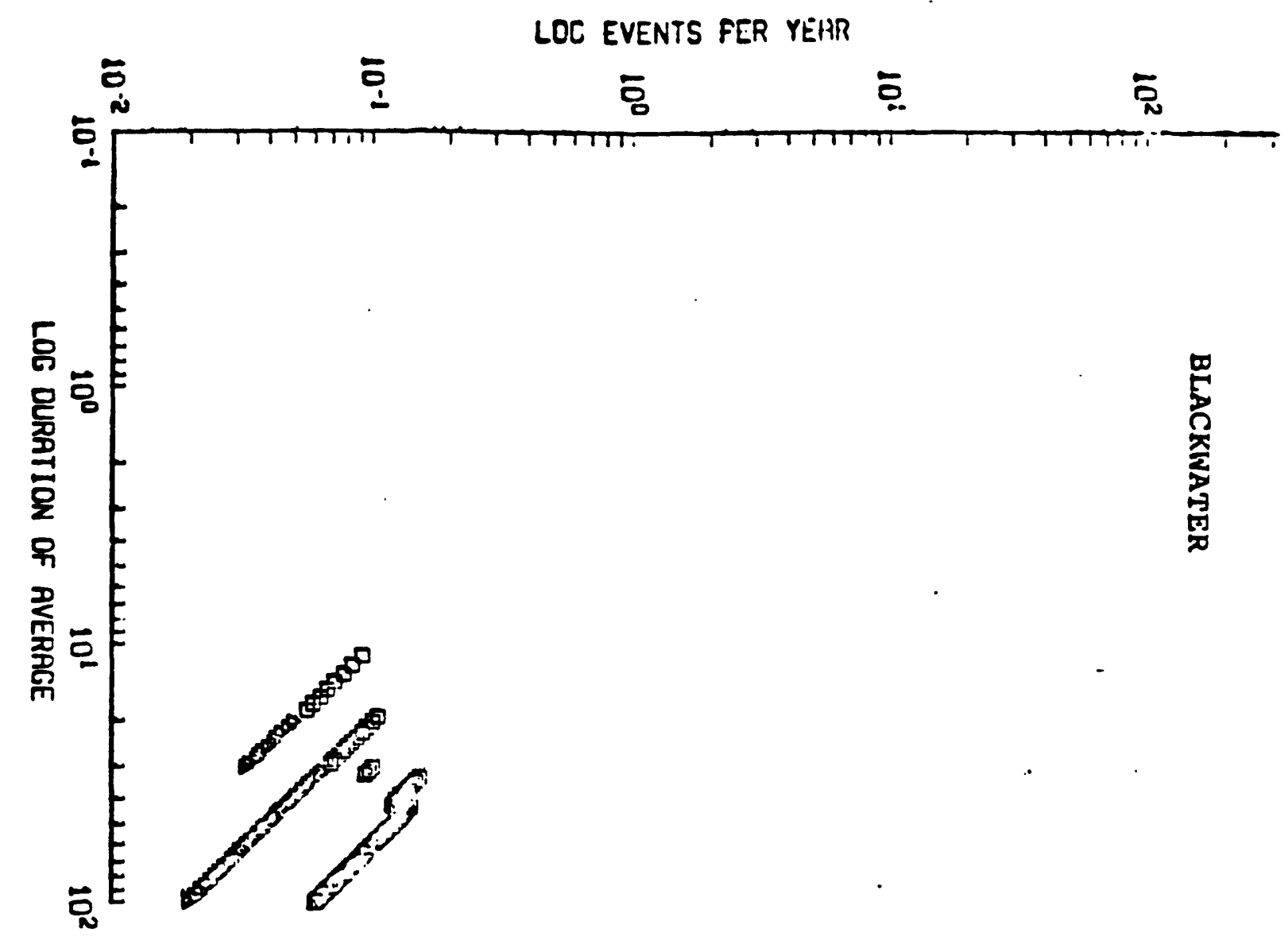

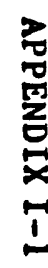

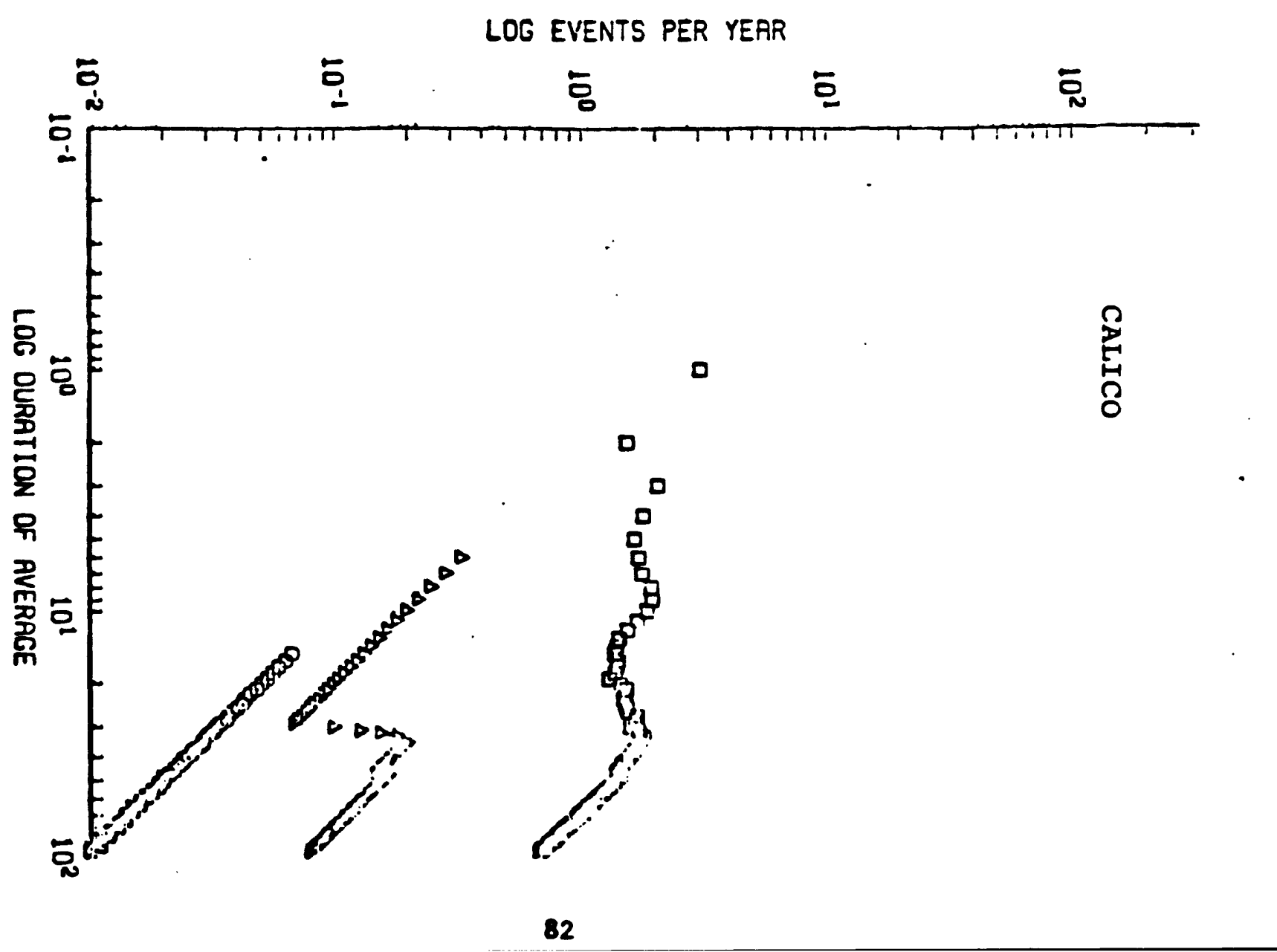




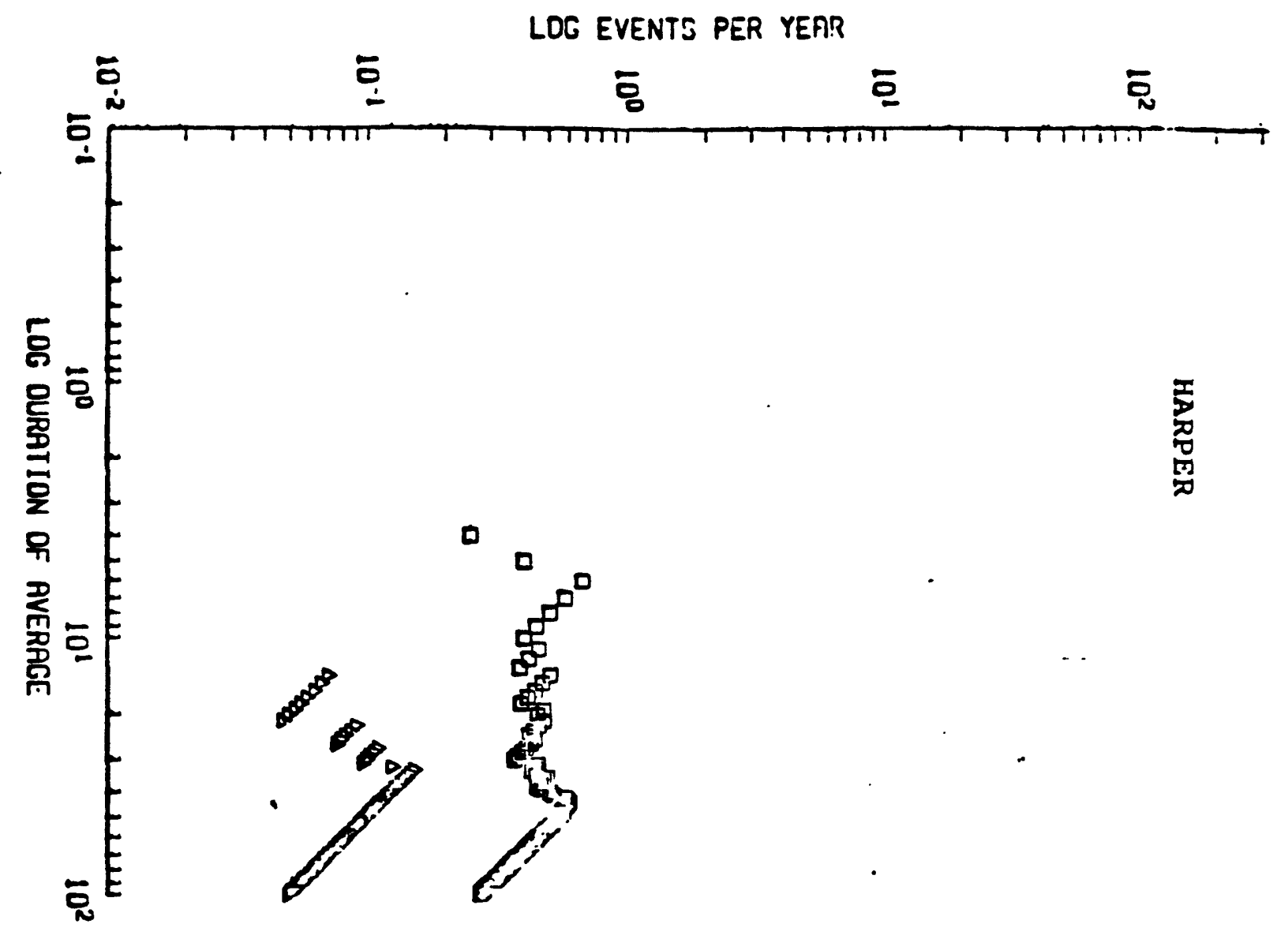

疍
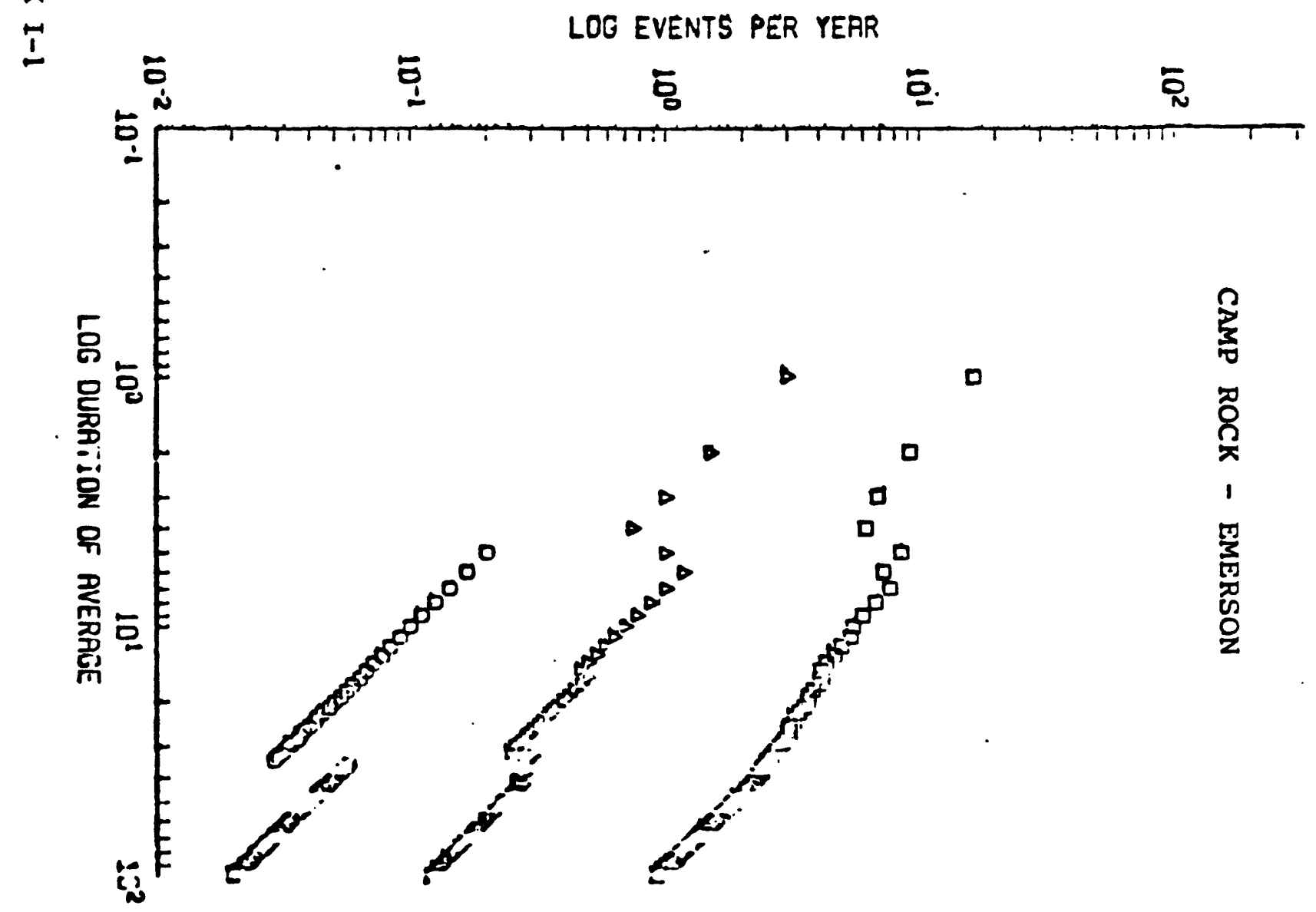


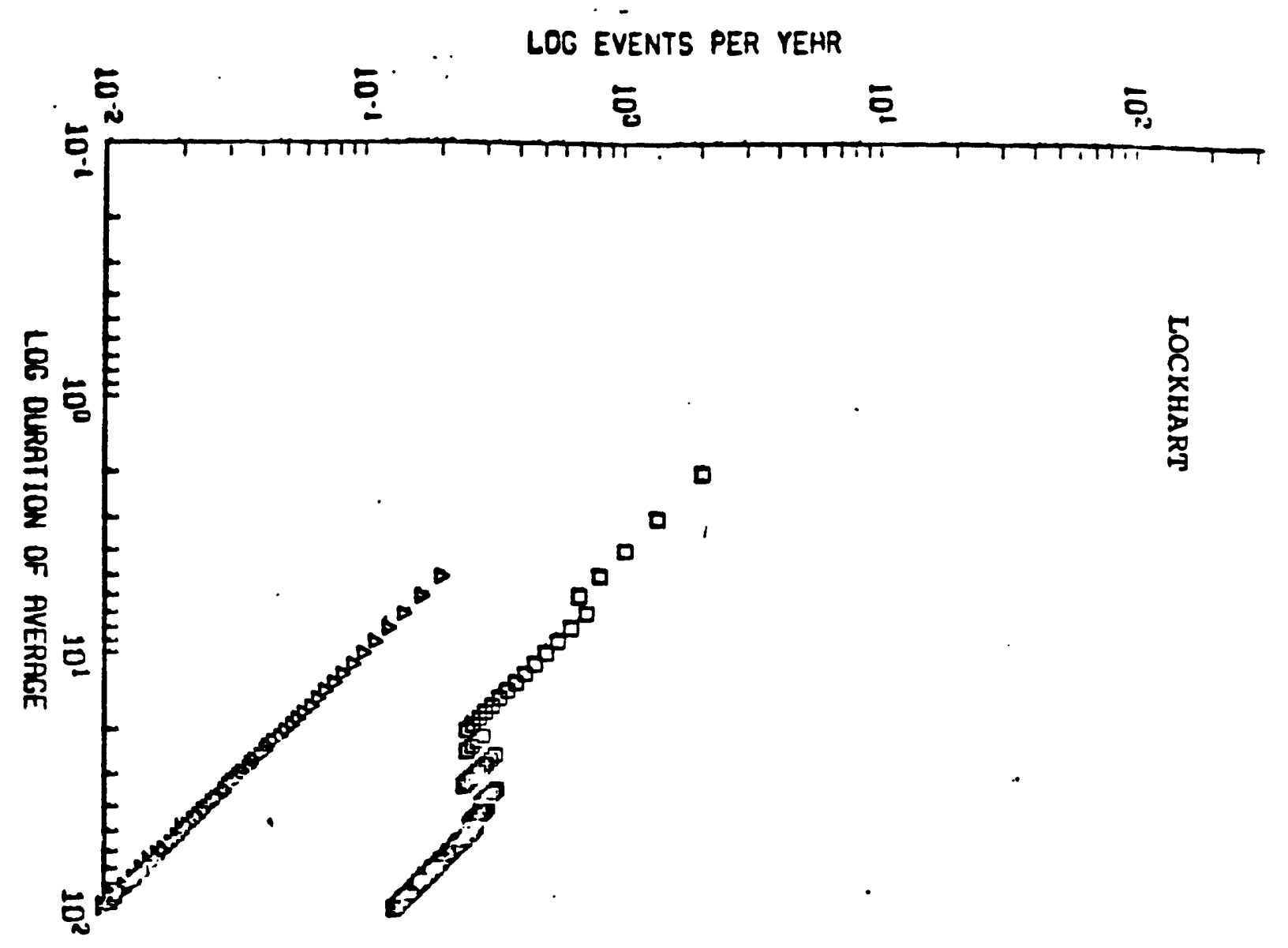

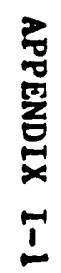

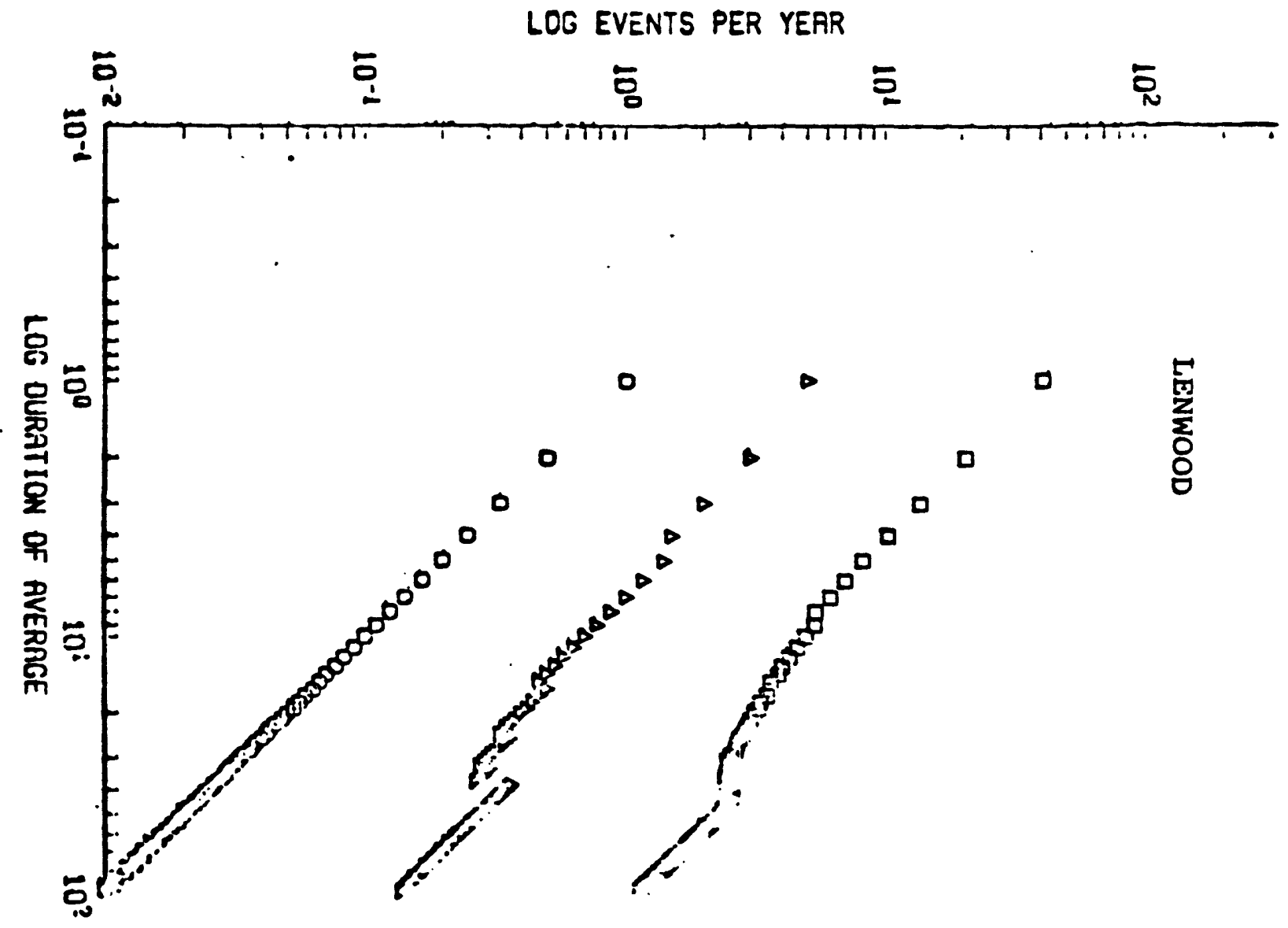




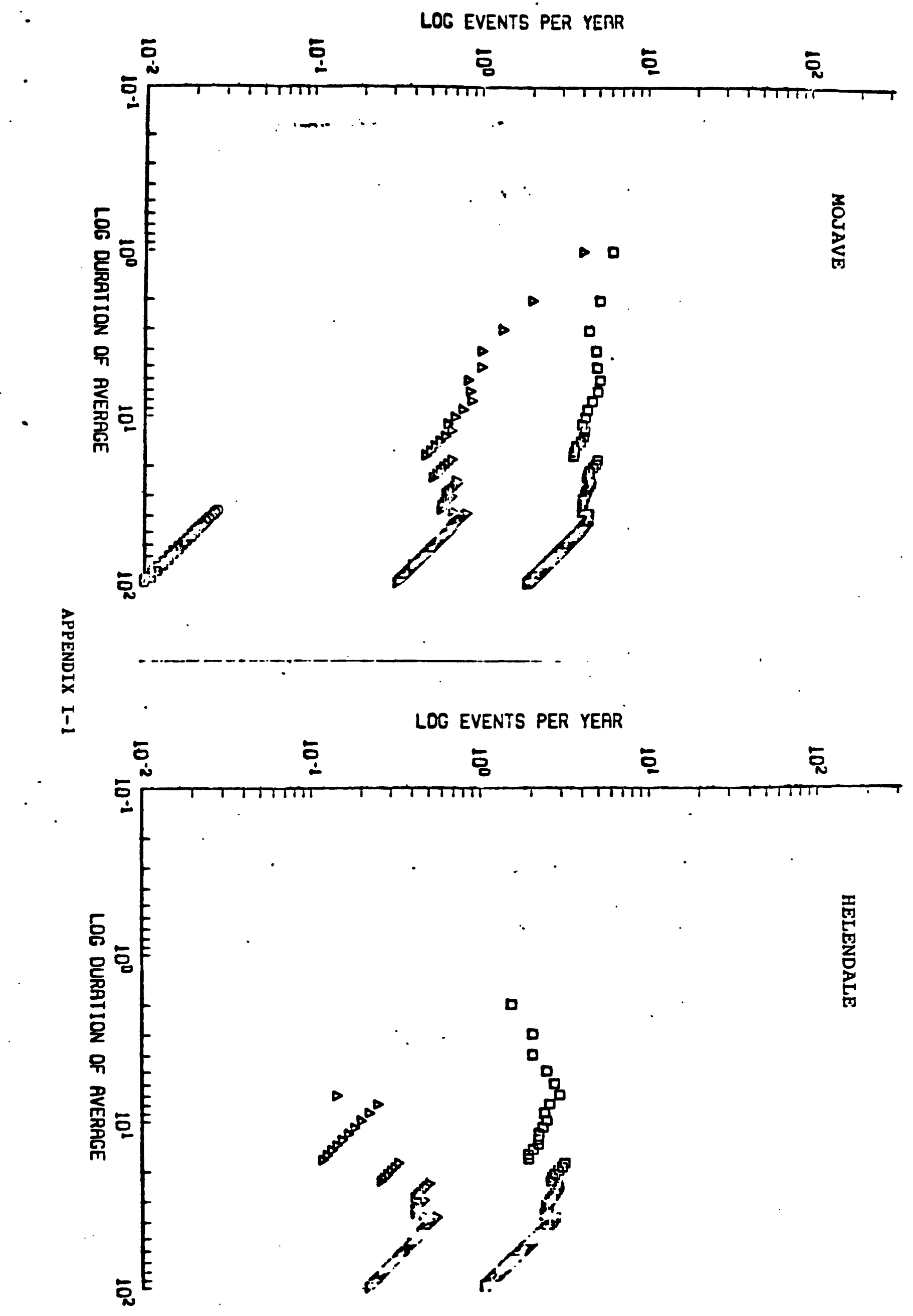




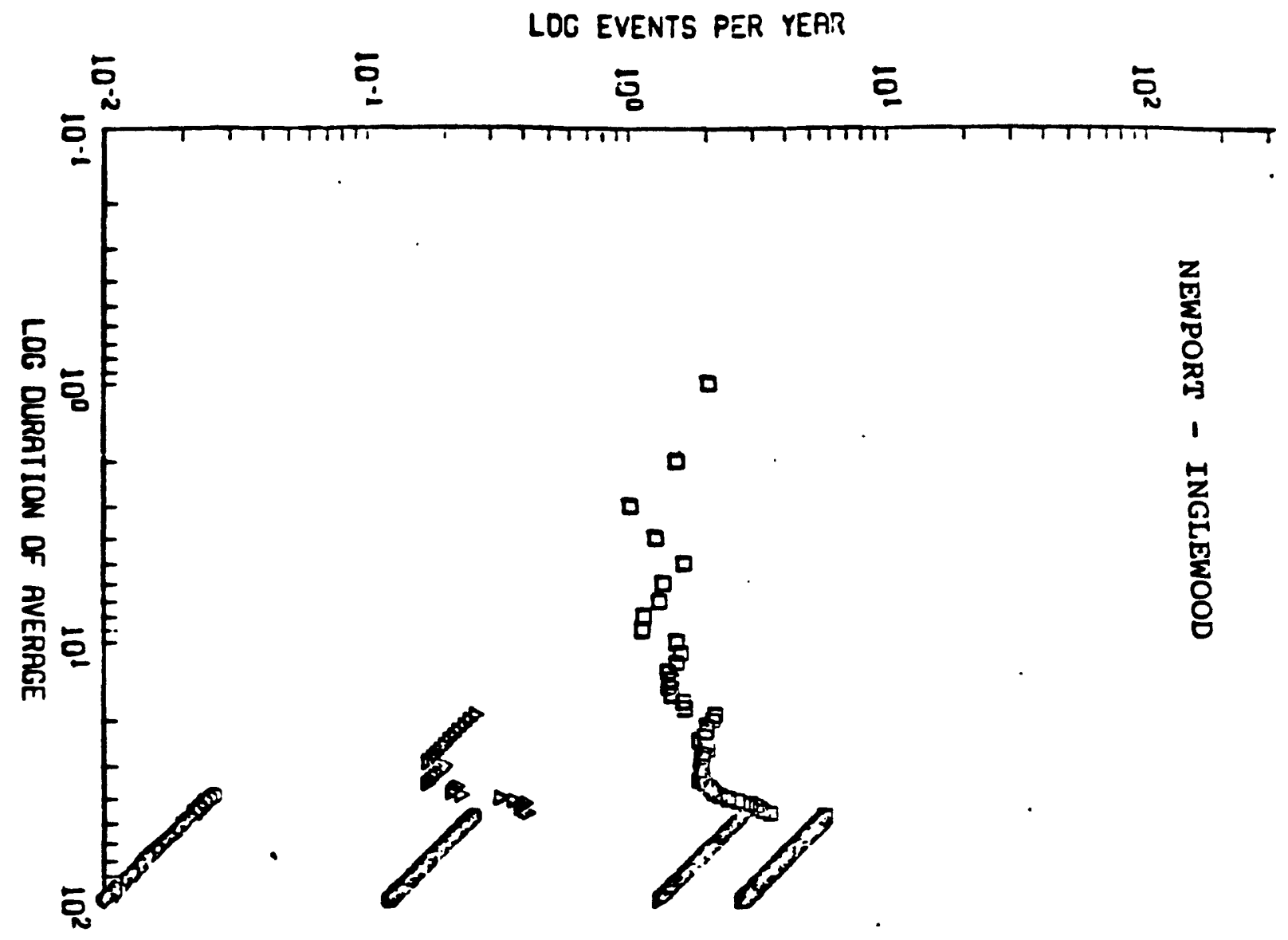

总

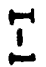

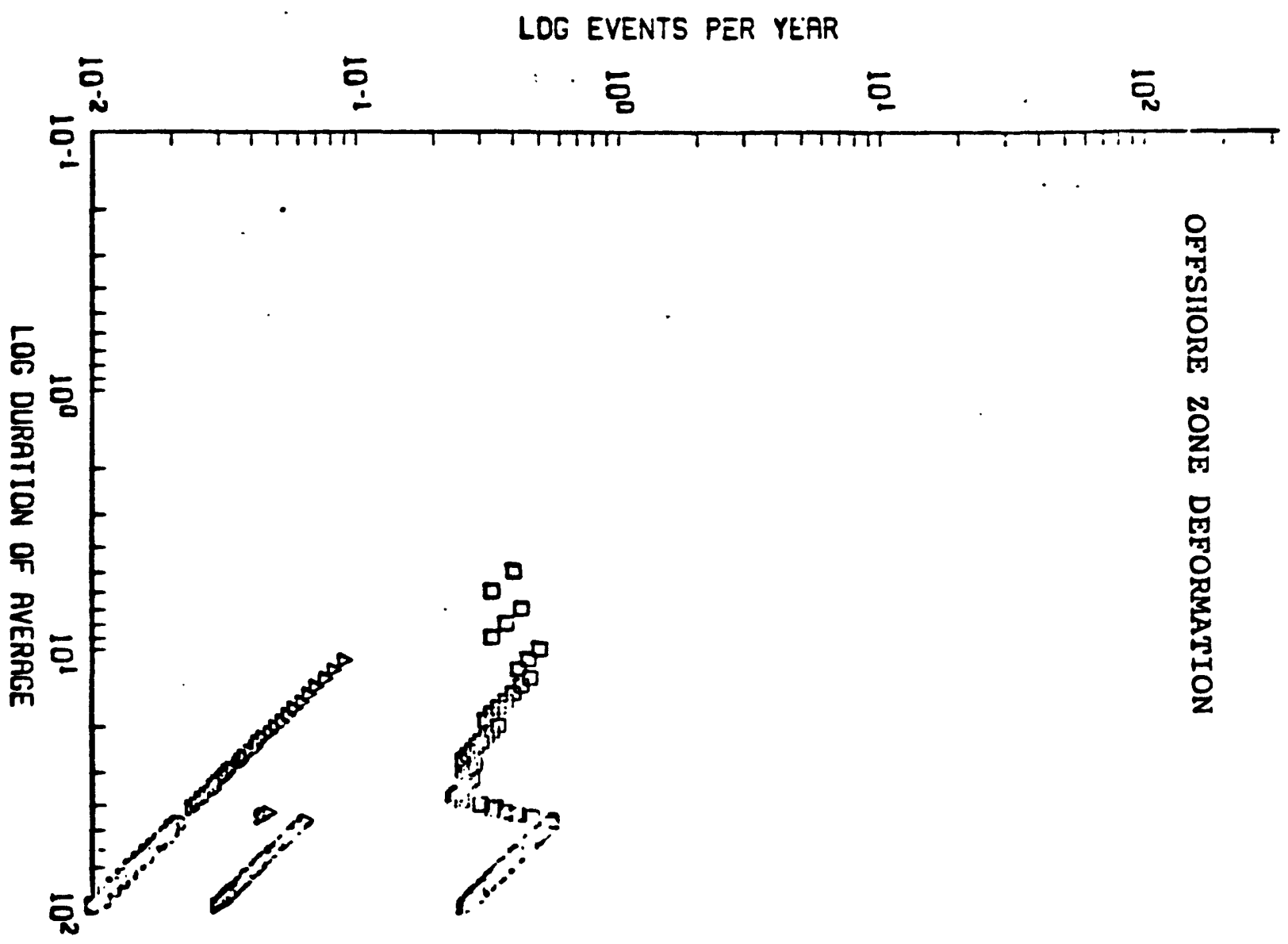




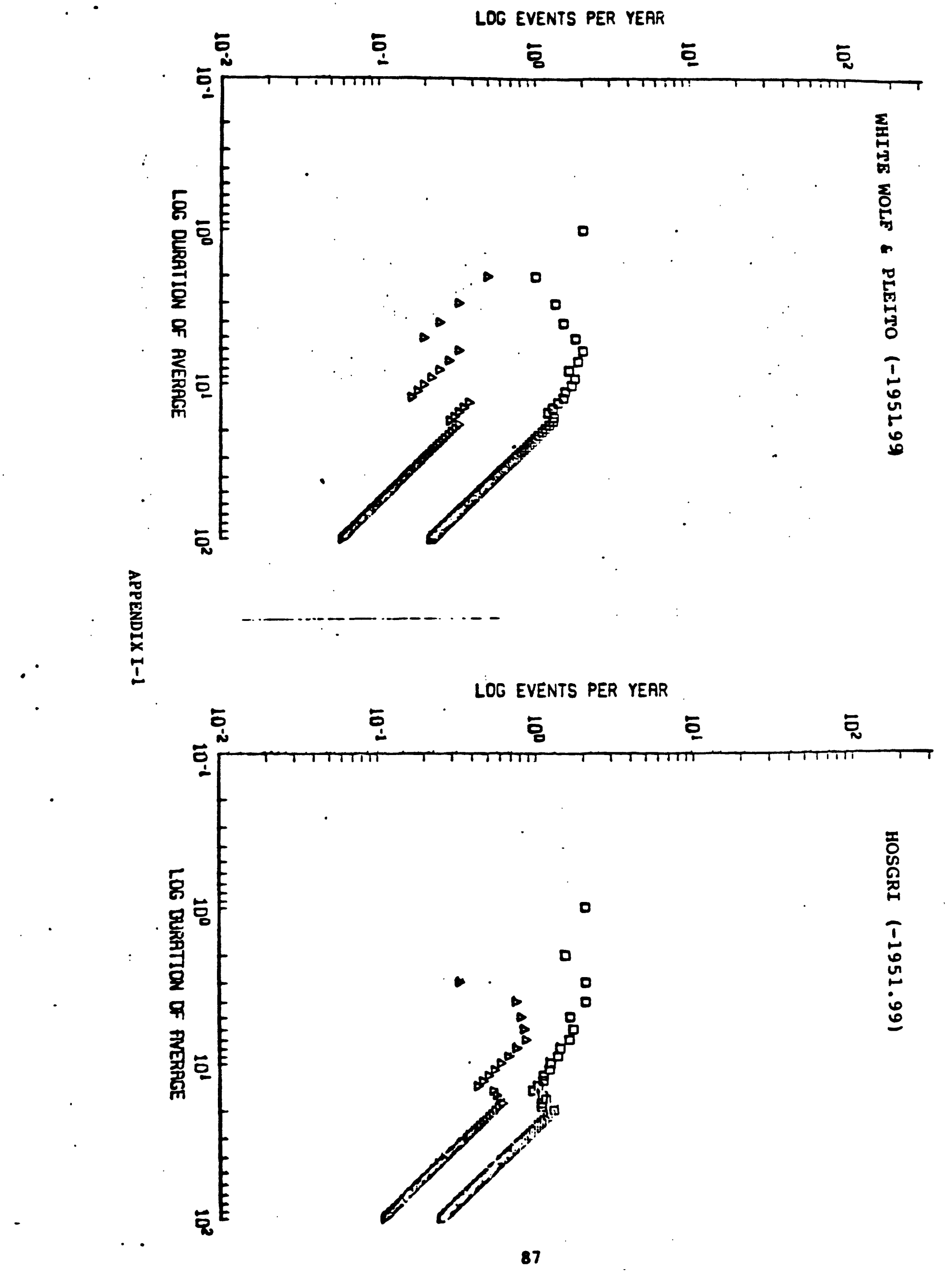




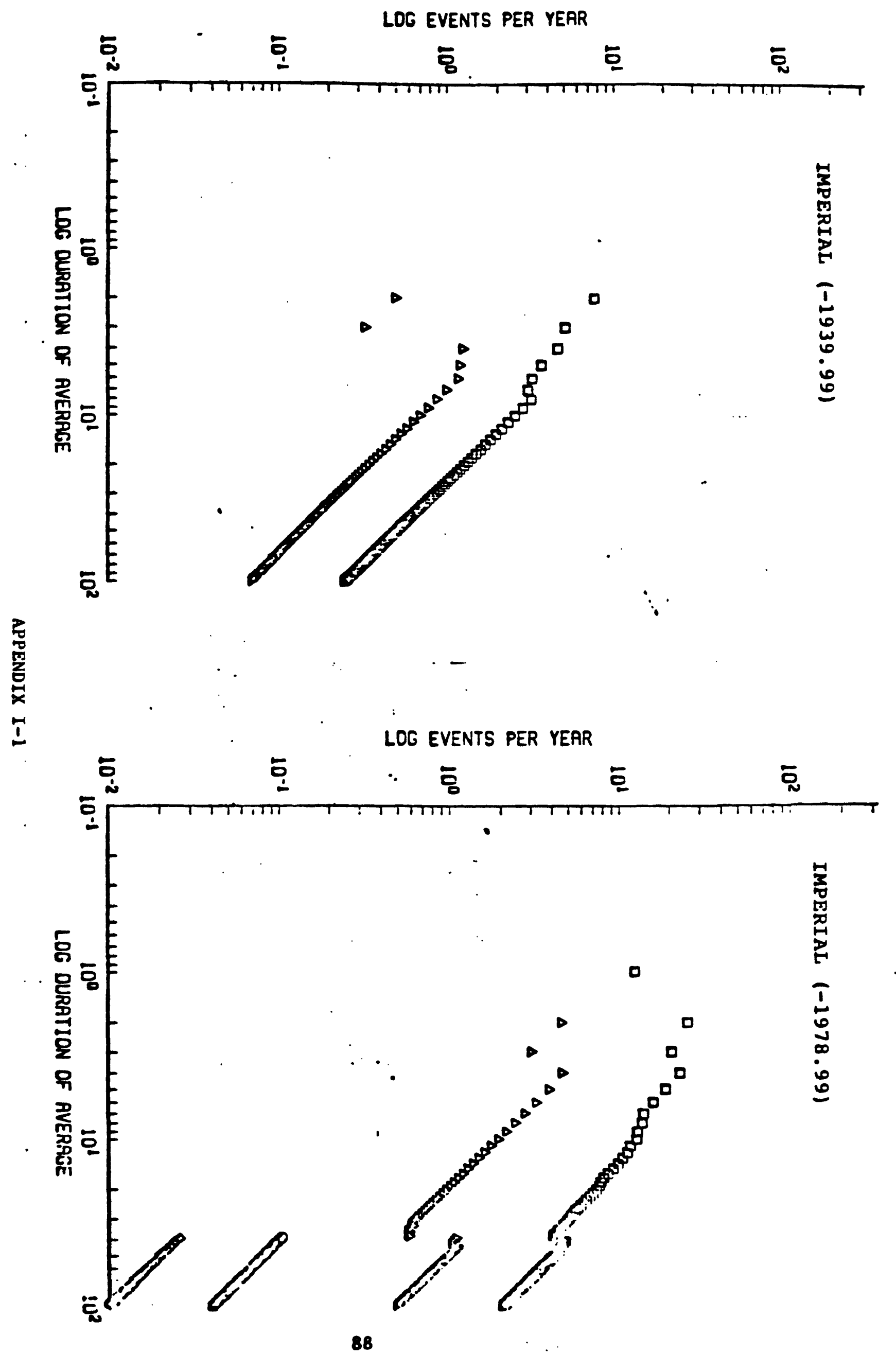




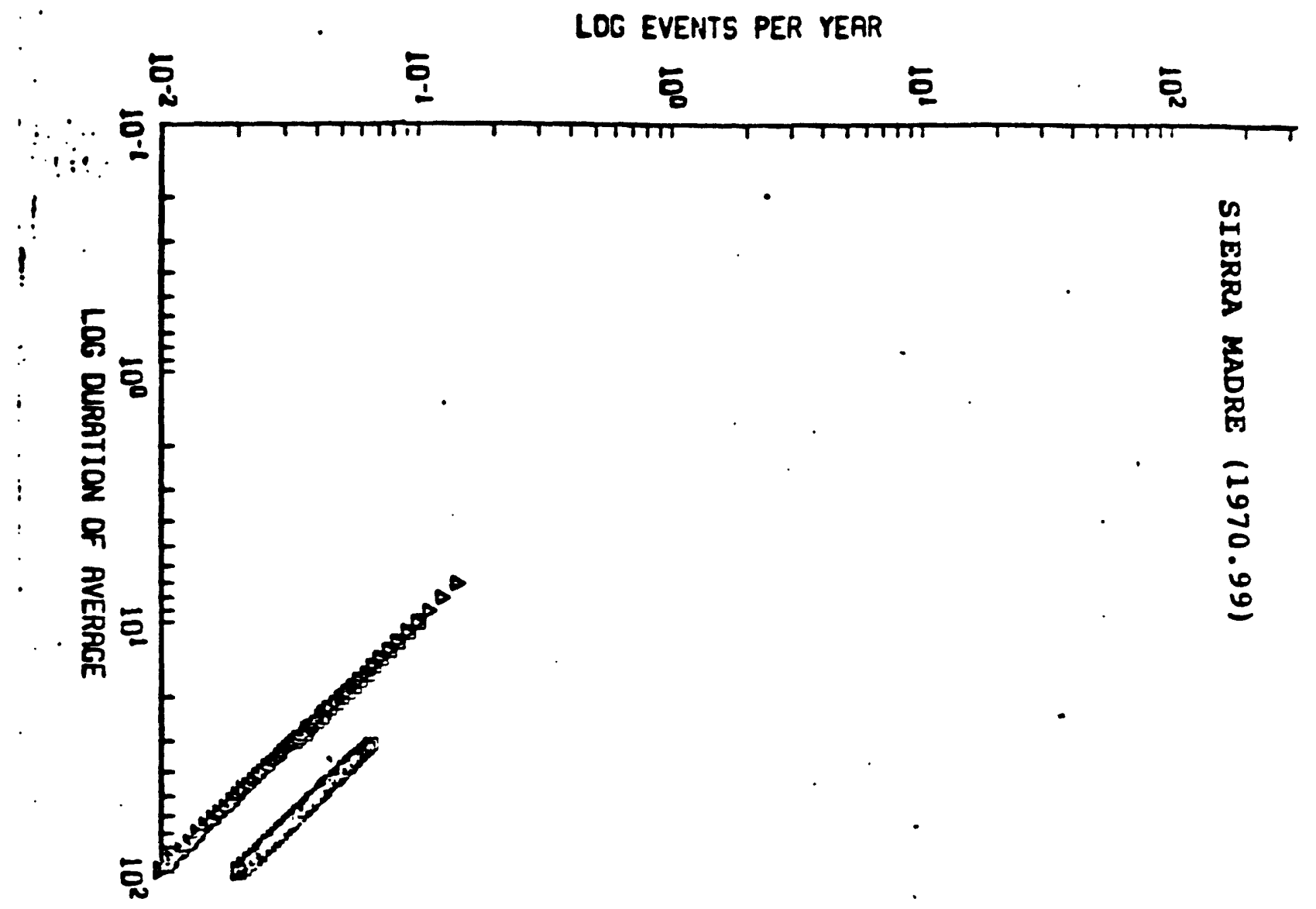

总

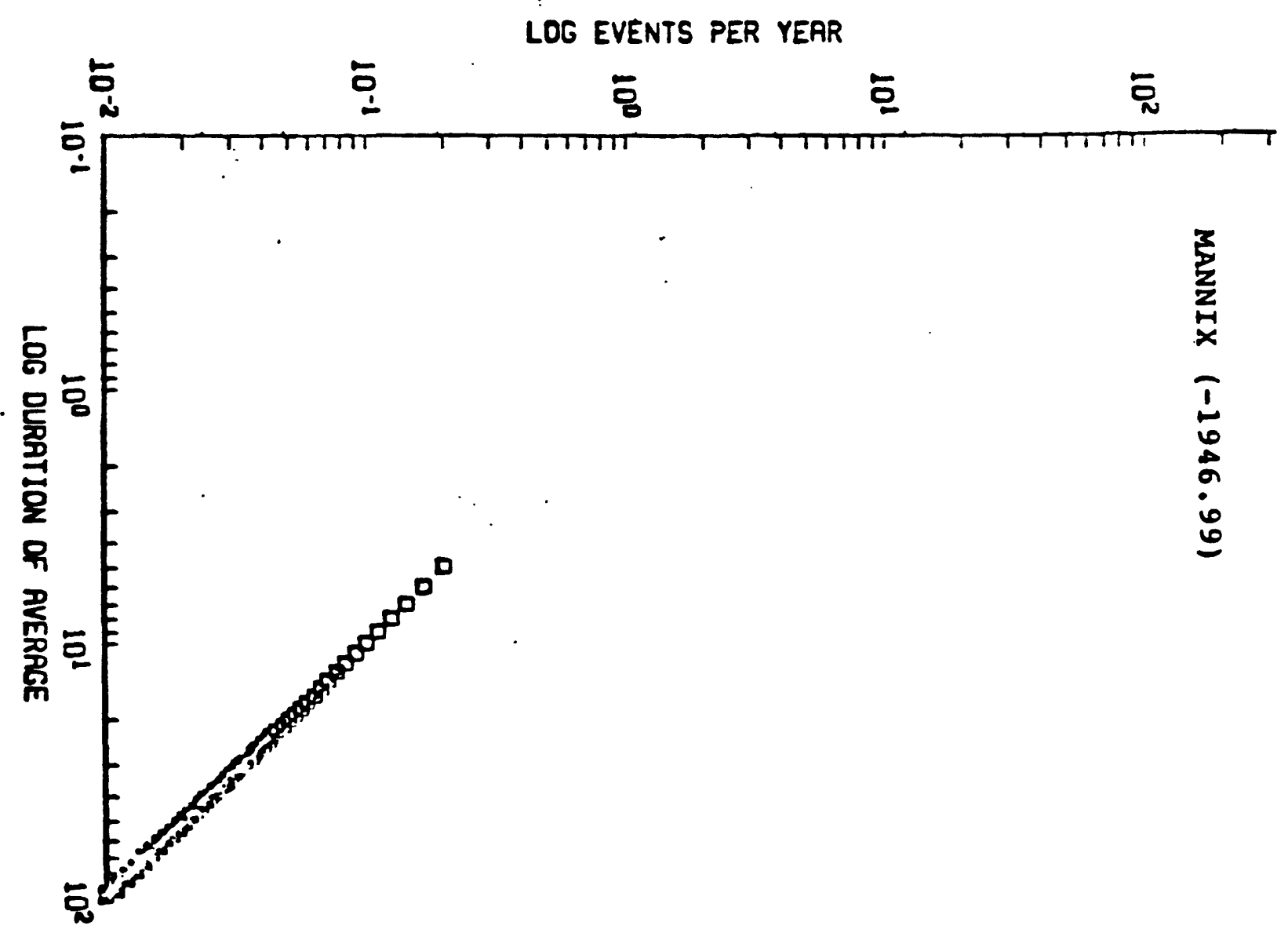




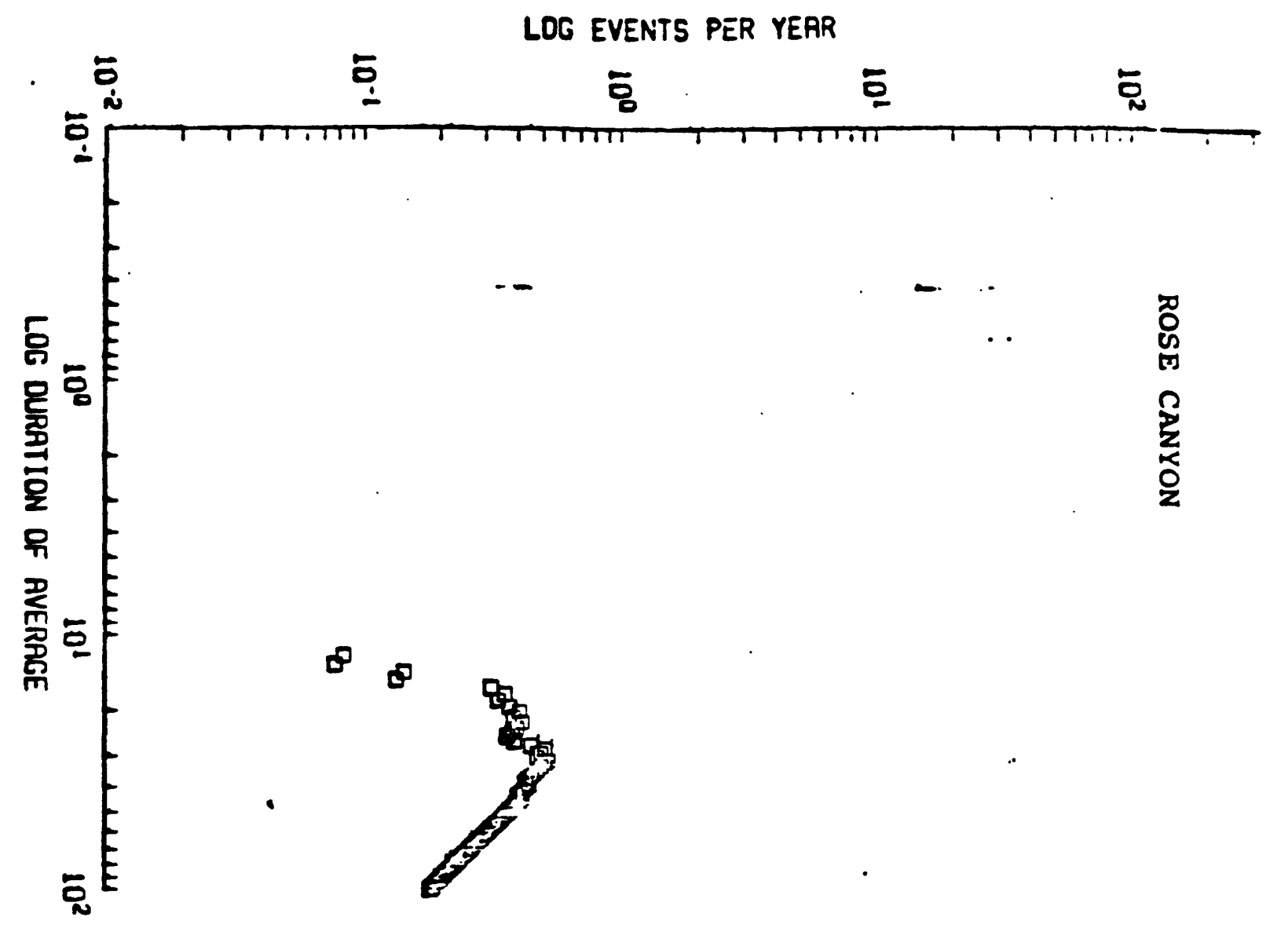

泀

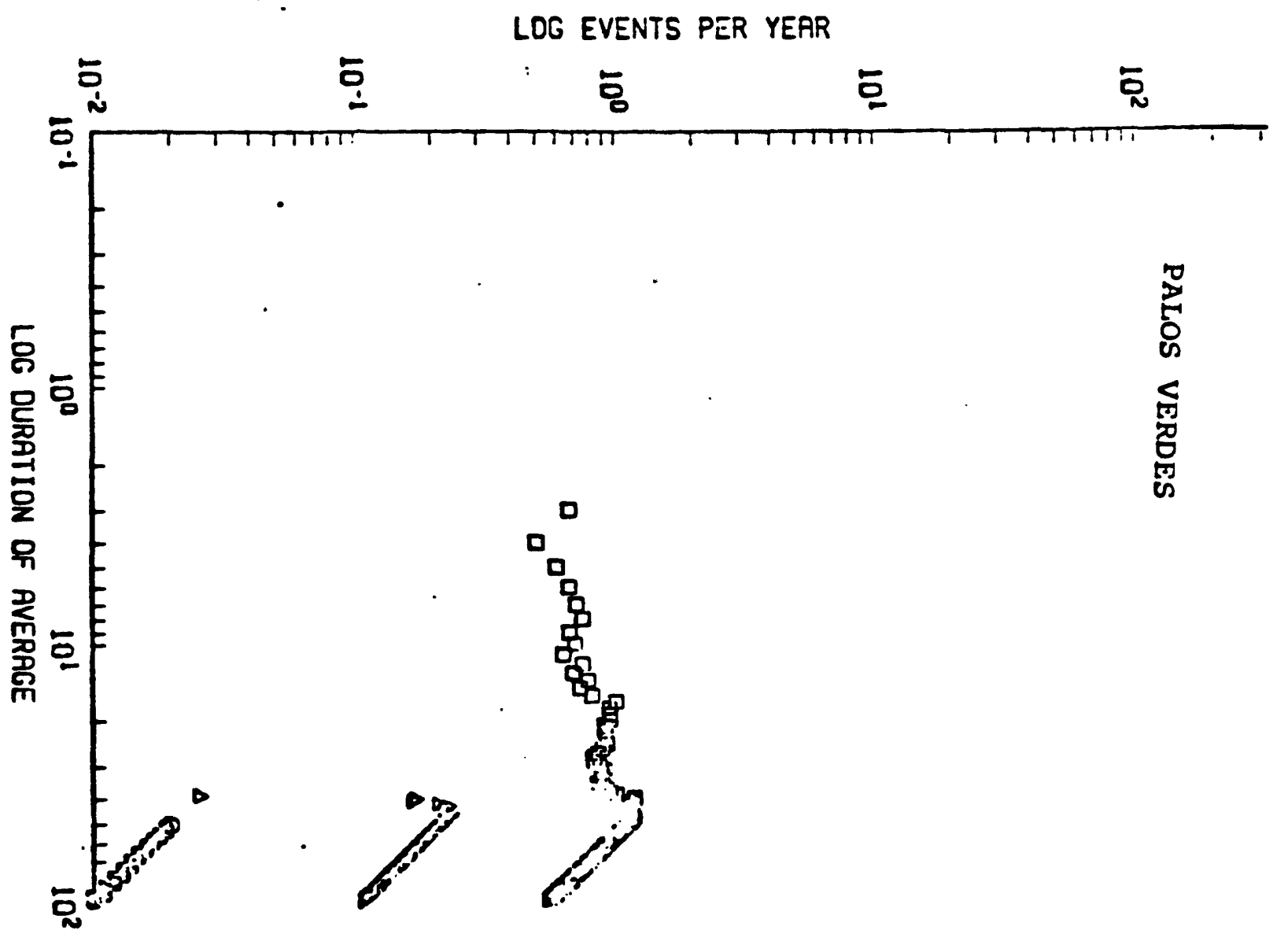




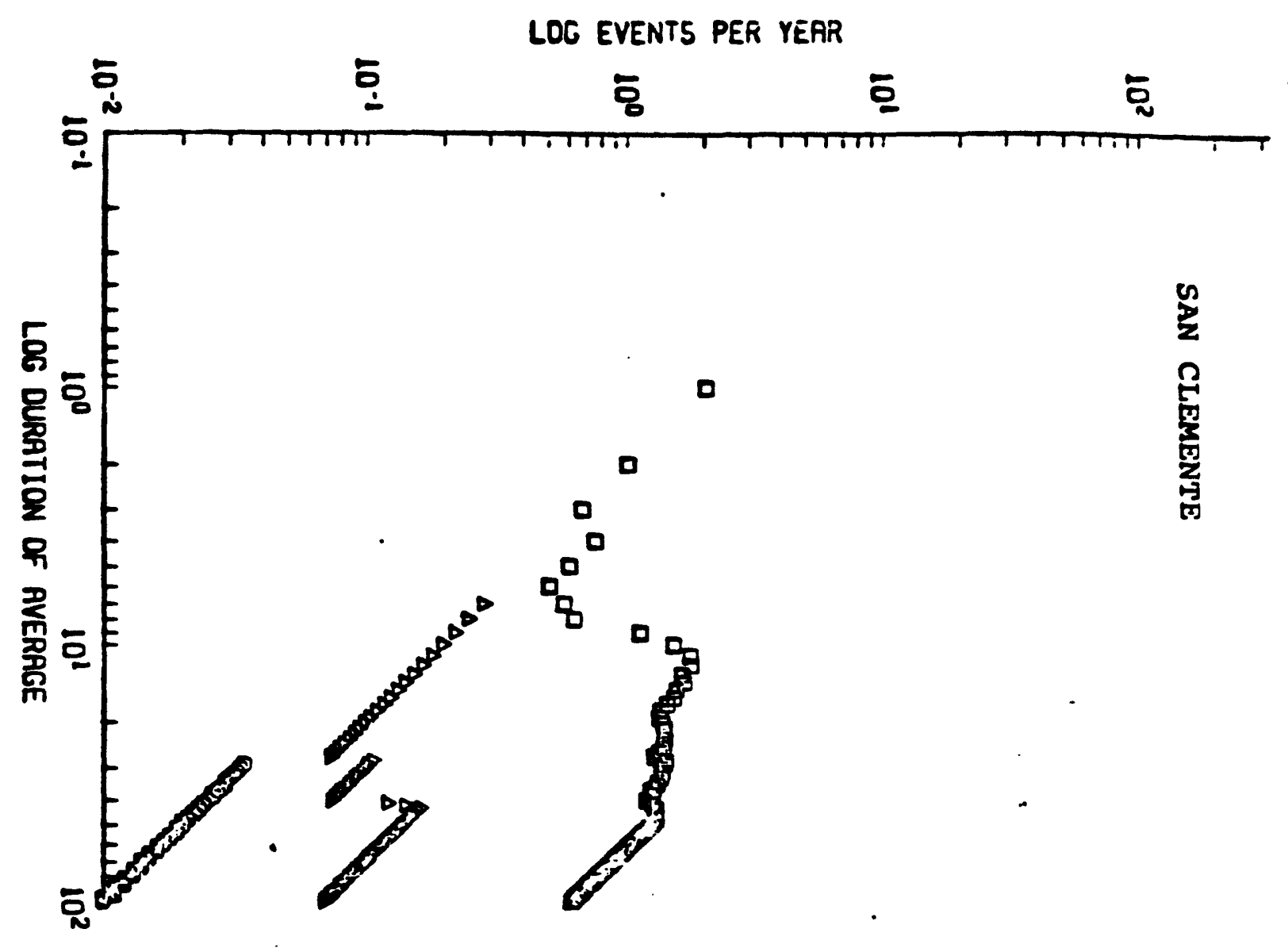

?
寒
$\vdots$
$\vdots$

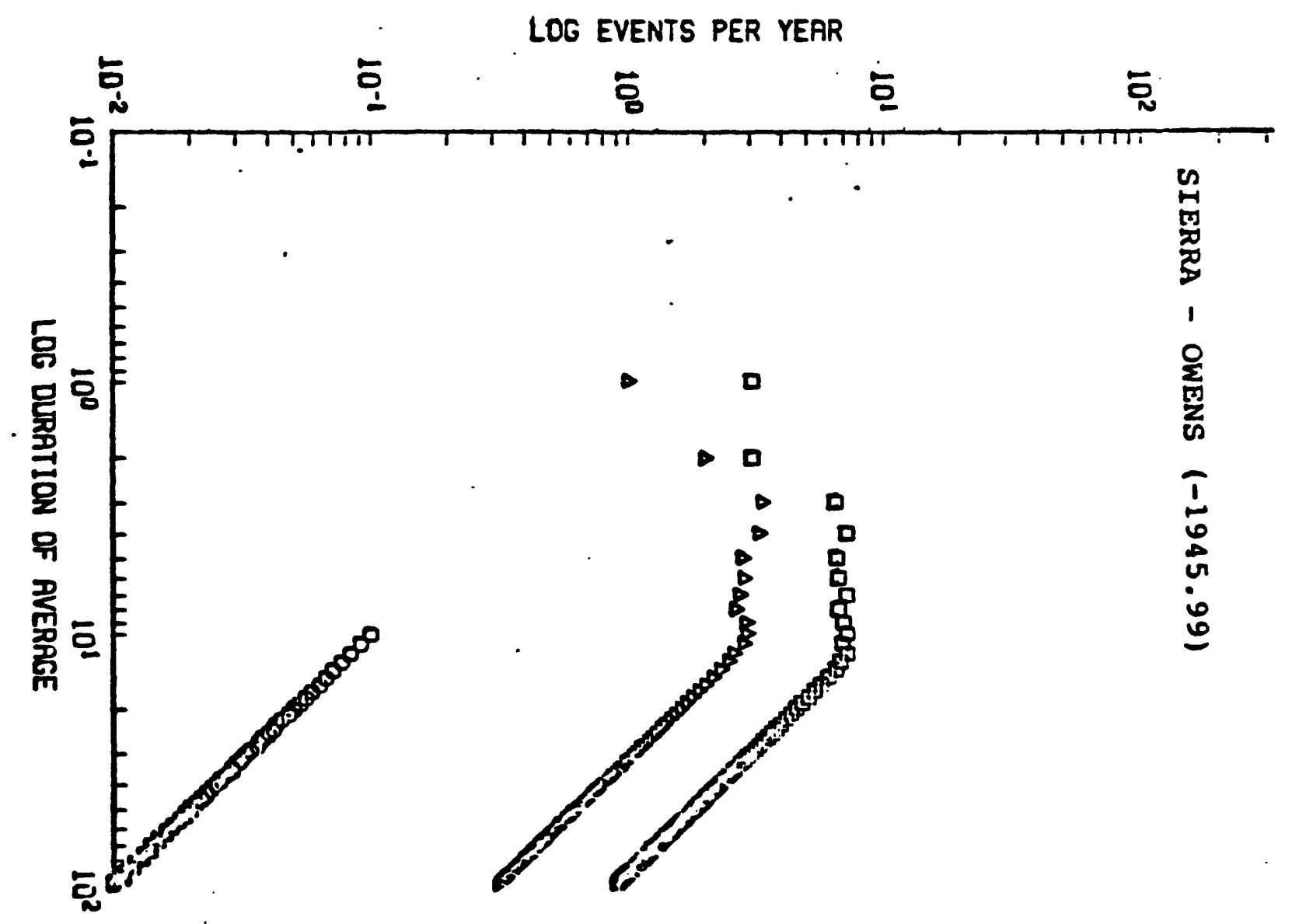




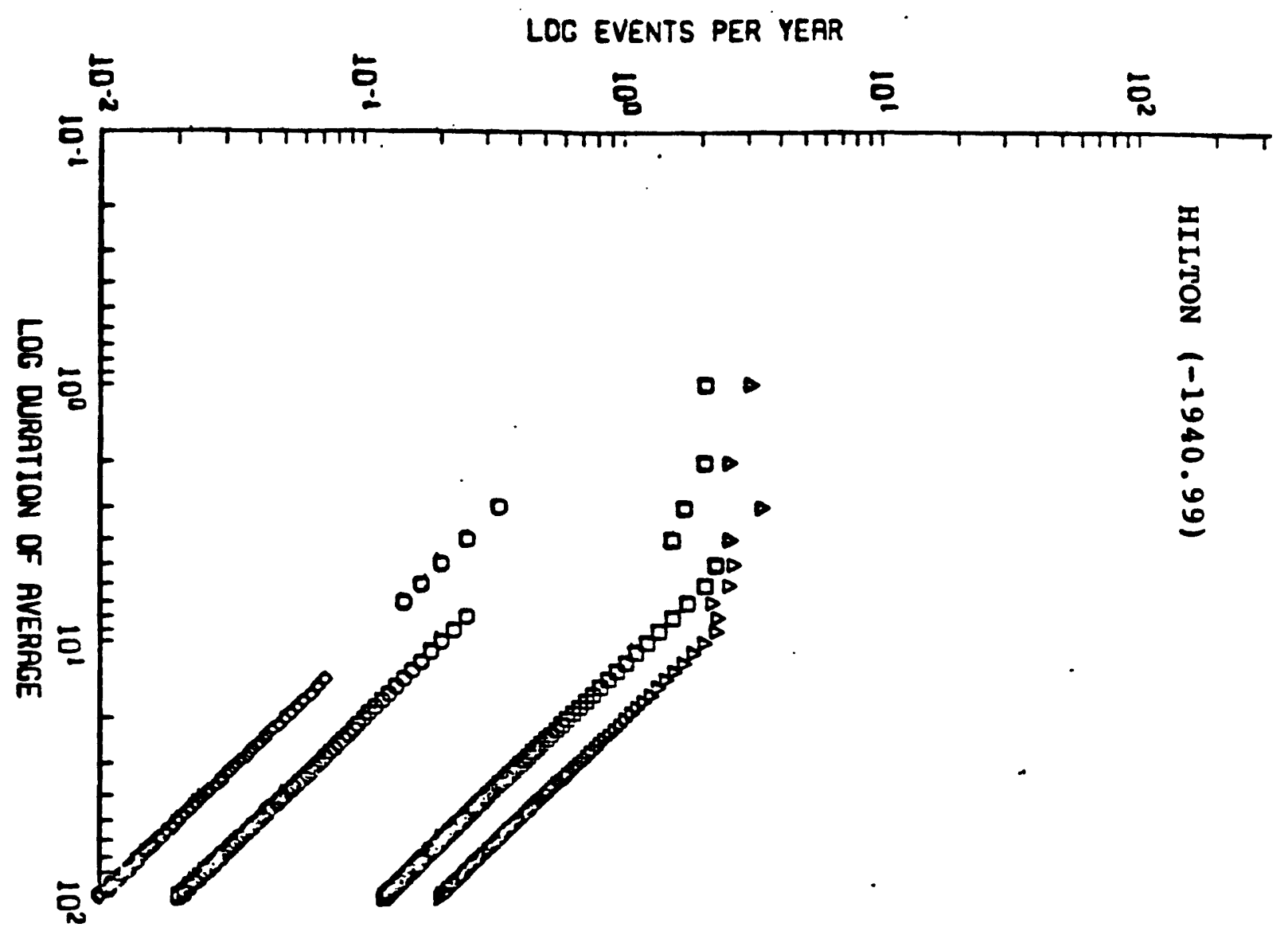

疍

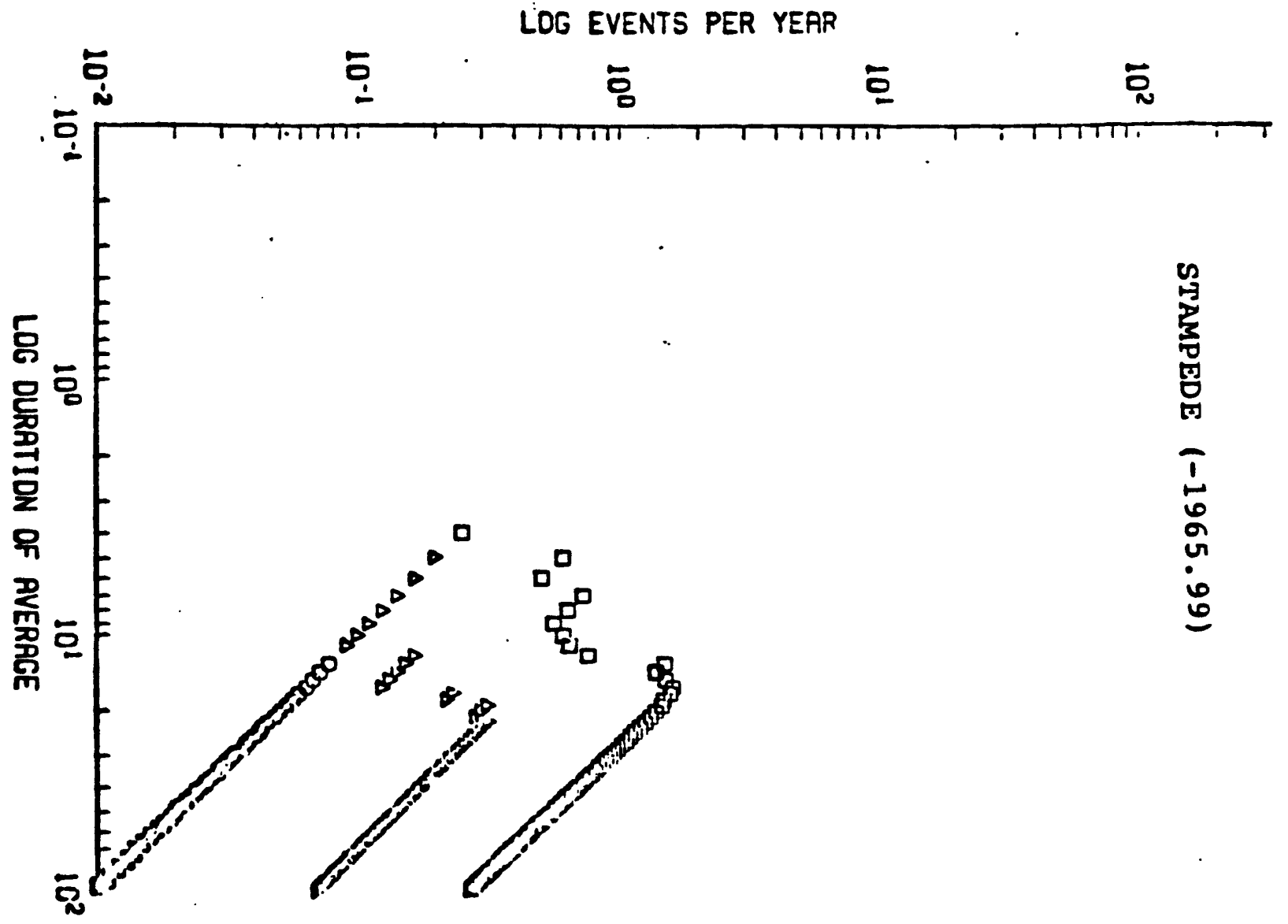

92 


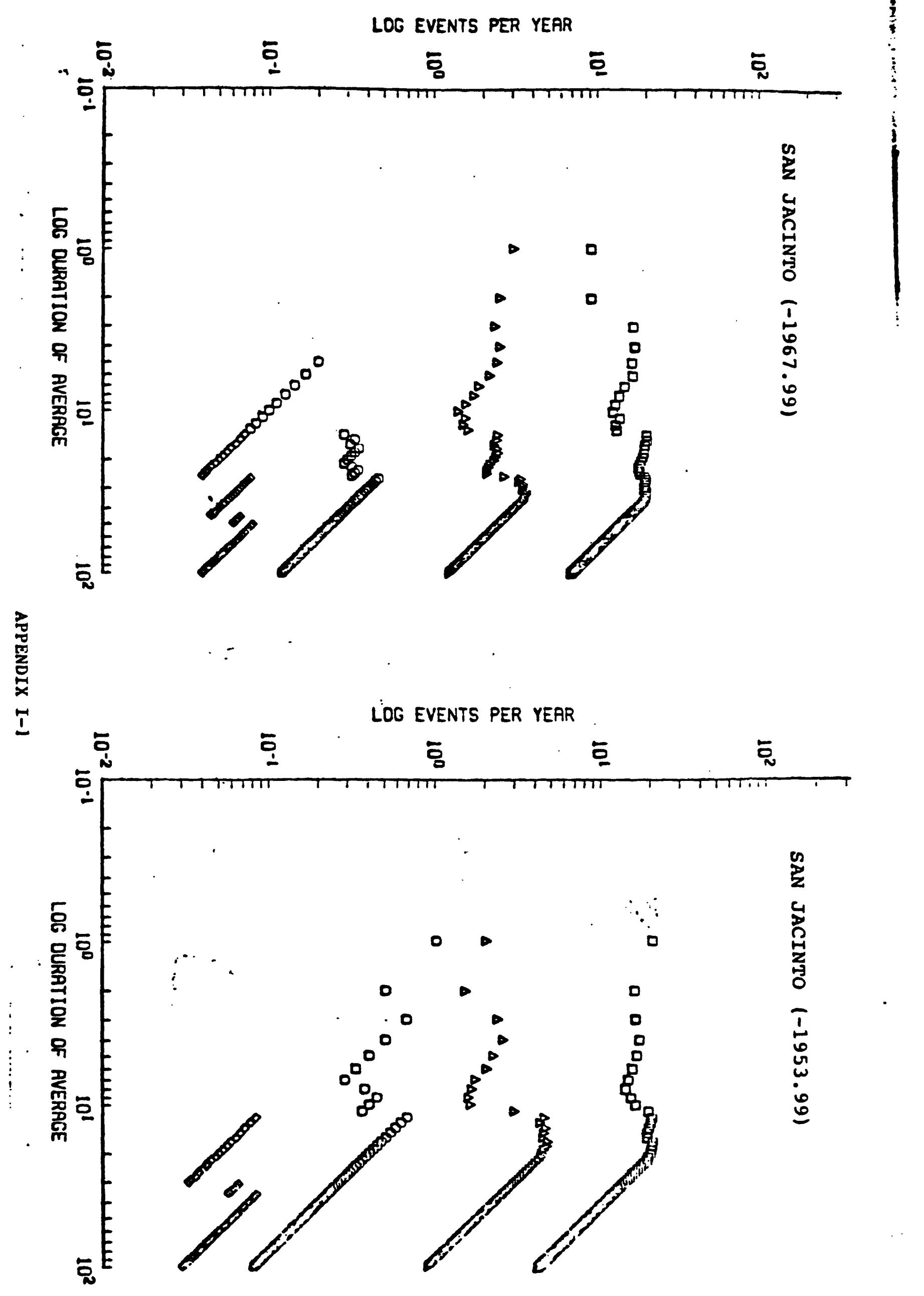




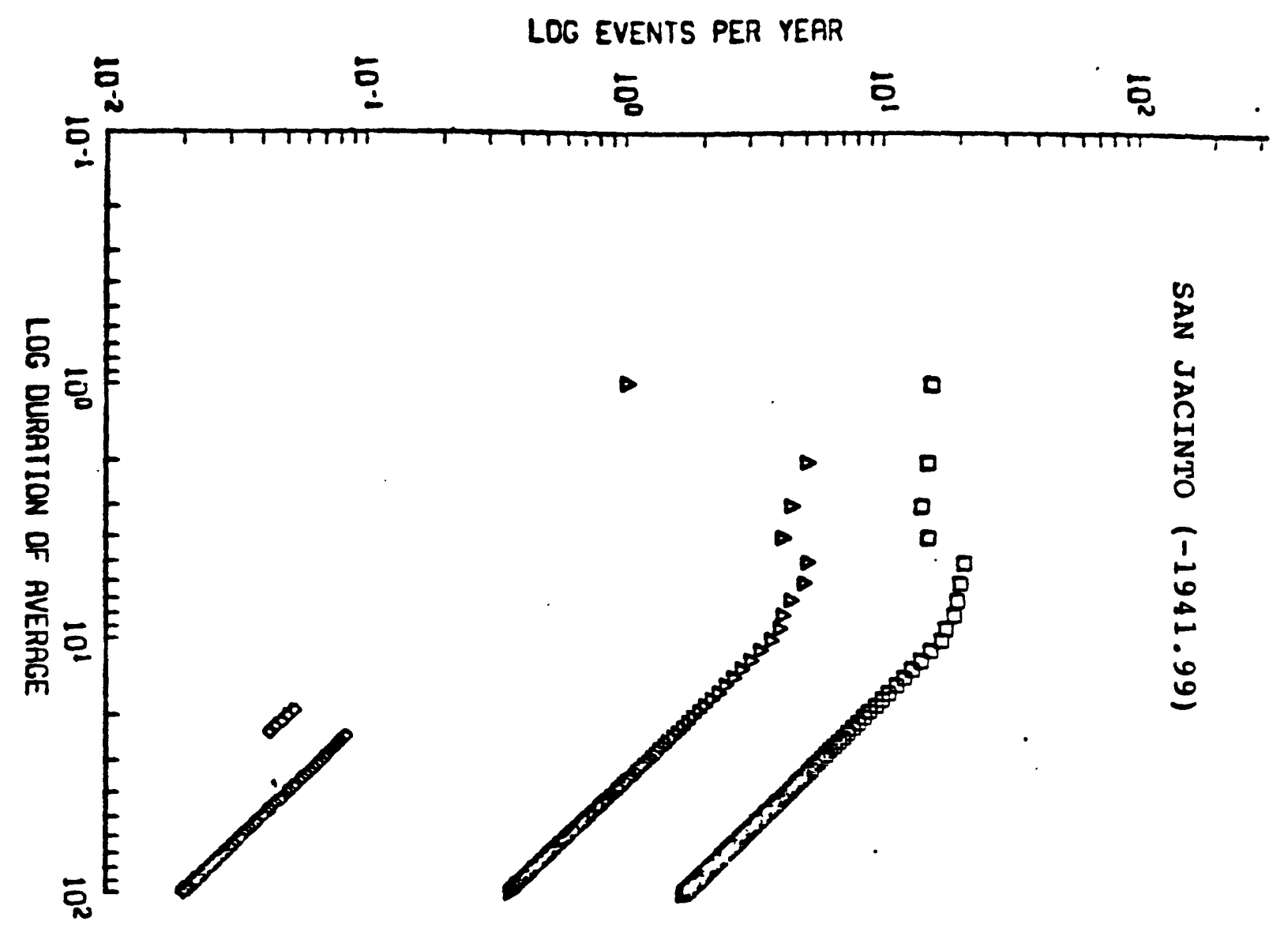

总

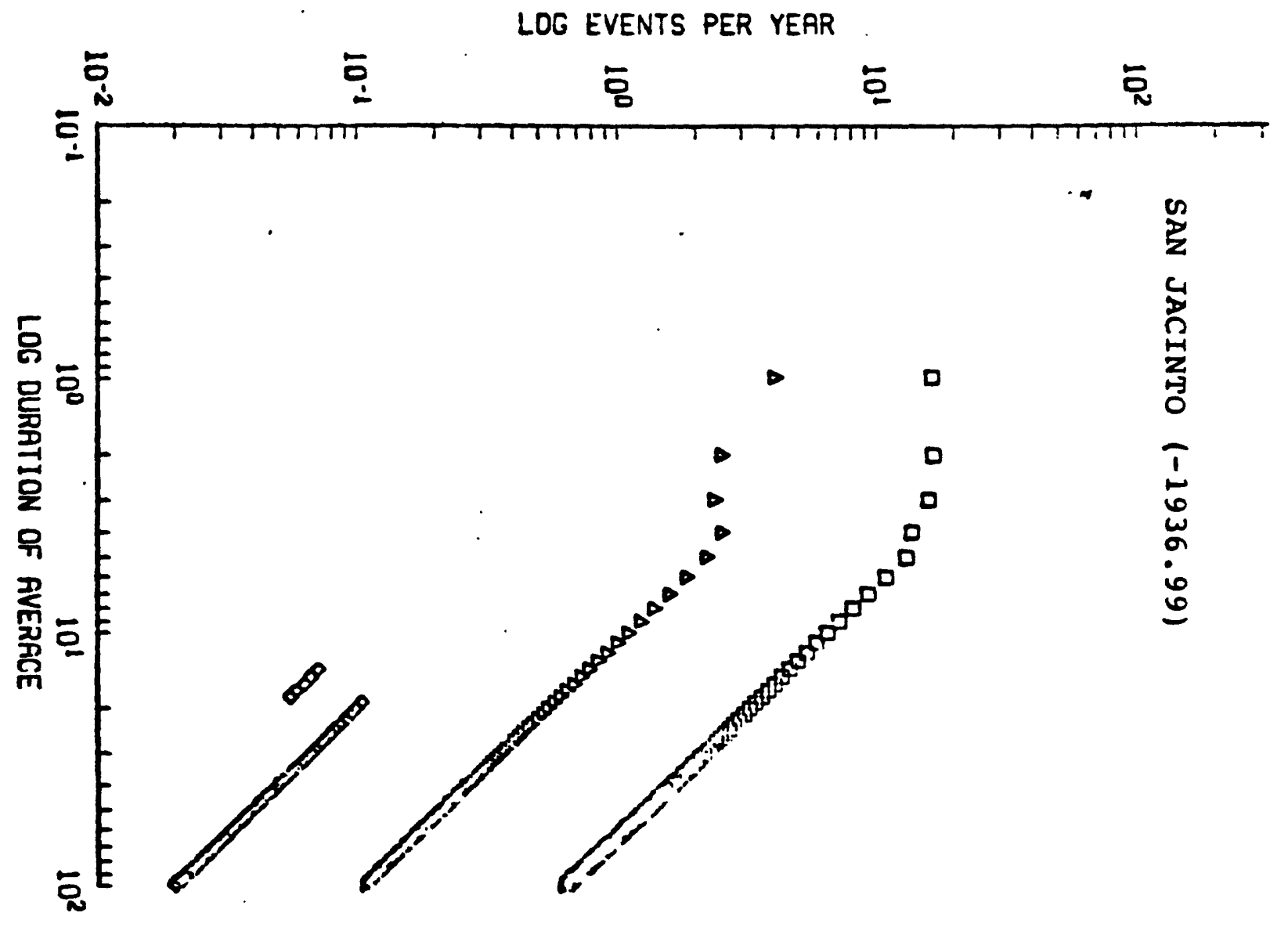




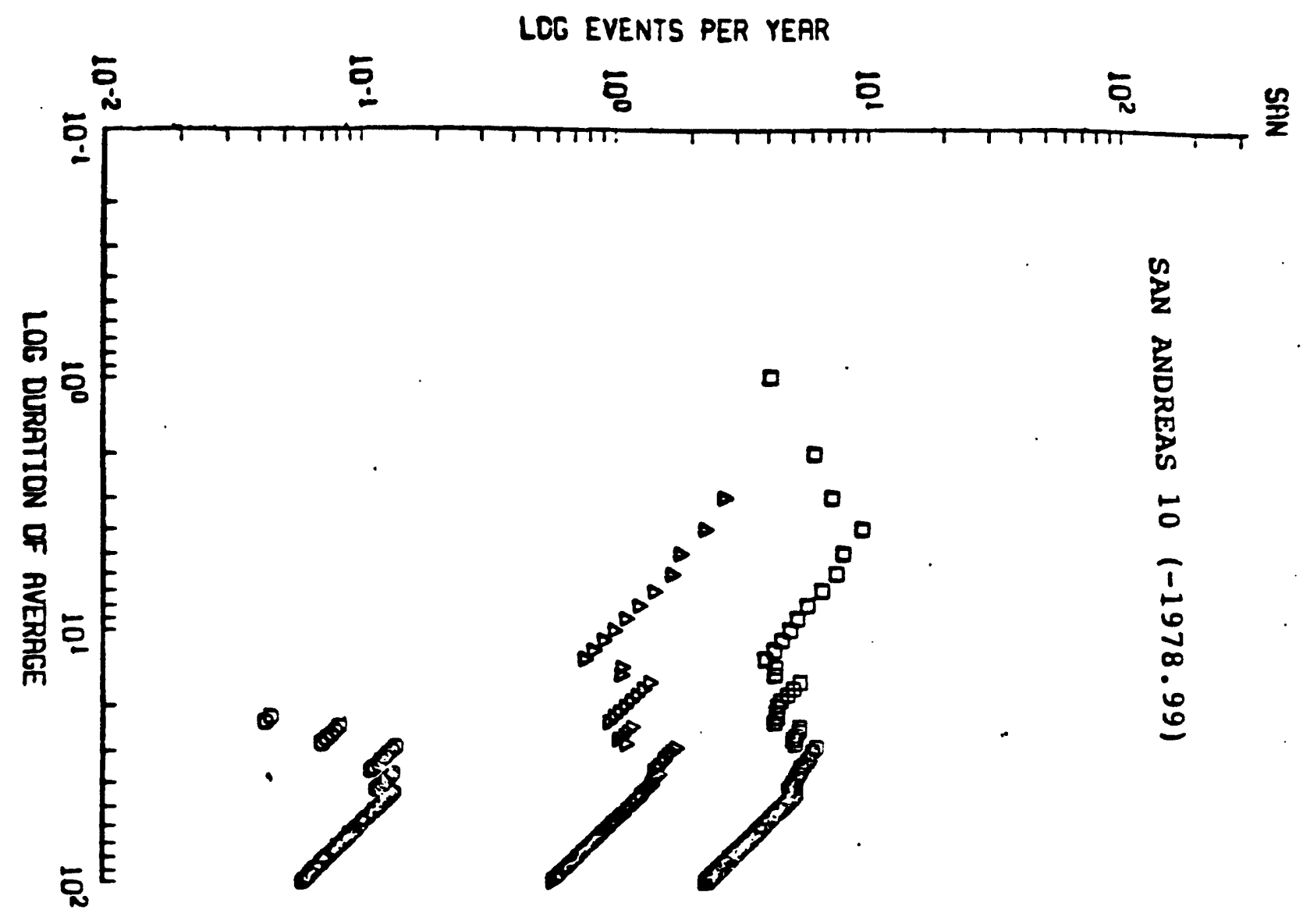

总

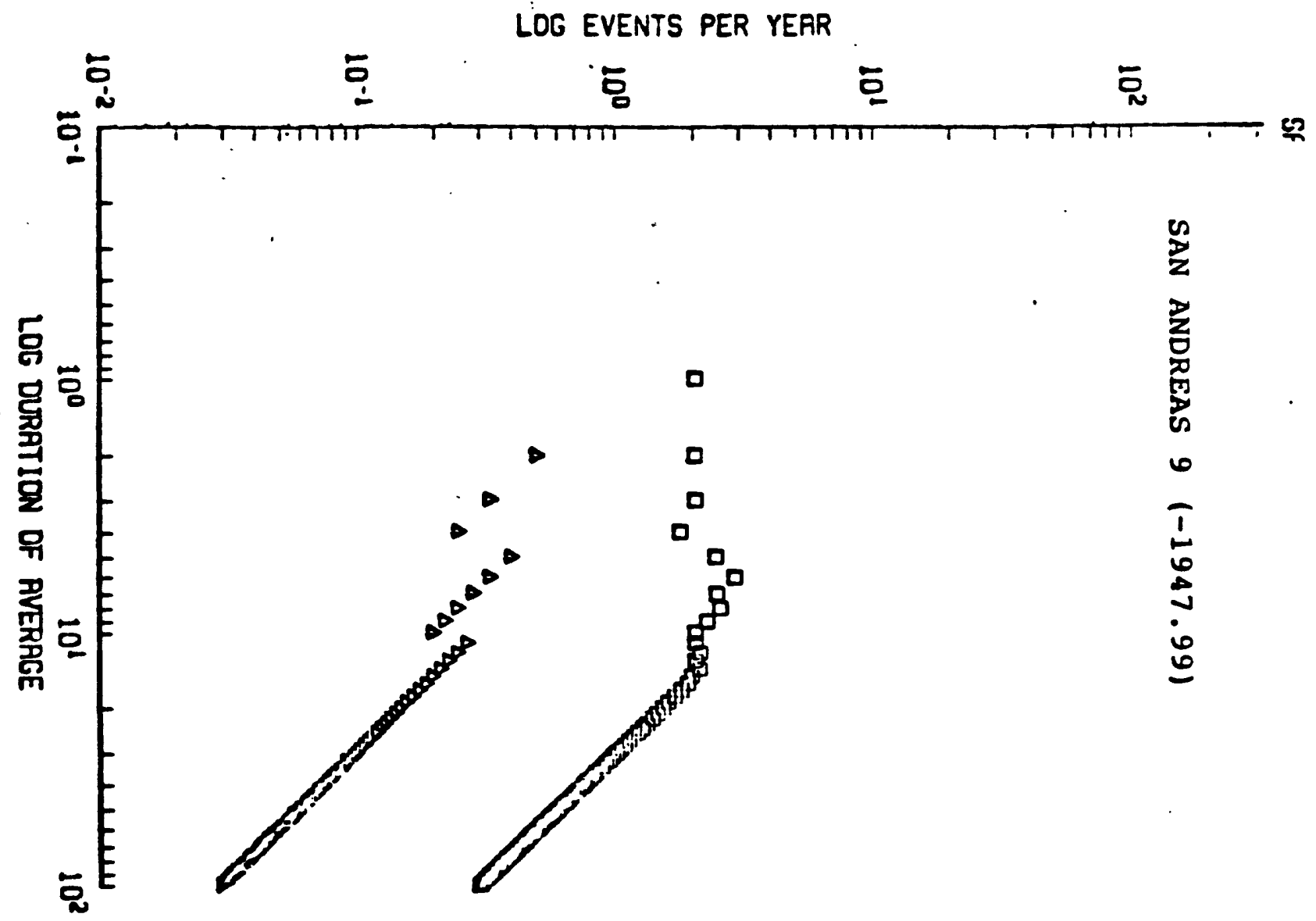




\section{APPENDIX I-2}

Plots of observed incremental occurrence rates of earthquakes (sol1d trlangle) and of predicted occurrence rates based on the ellp rates. Large open symbols give best slip rate estimate; smaller symbols correspond to estimates for extreme ranges of proposed slip rates in Table 4, and to estimates for best 811 p rate but with a 0.5 magnitude unit Increase or decrease in theoretical maximum magnitude from the values isted in Table 4. 

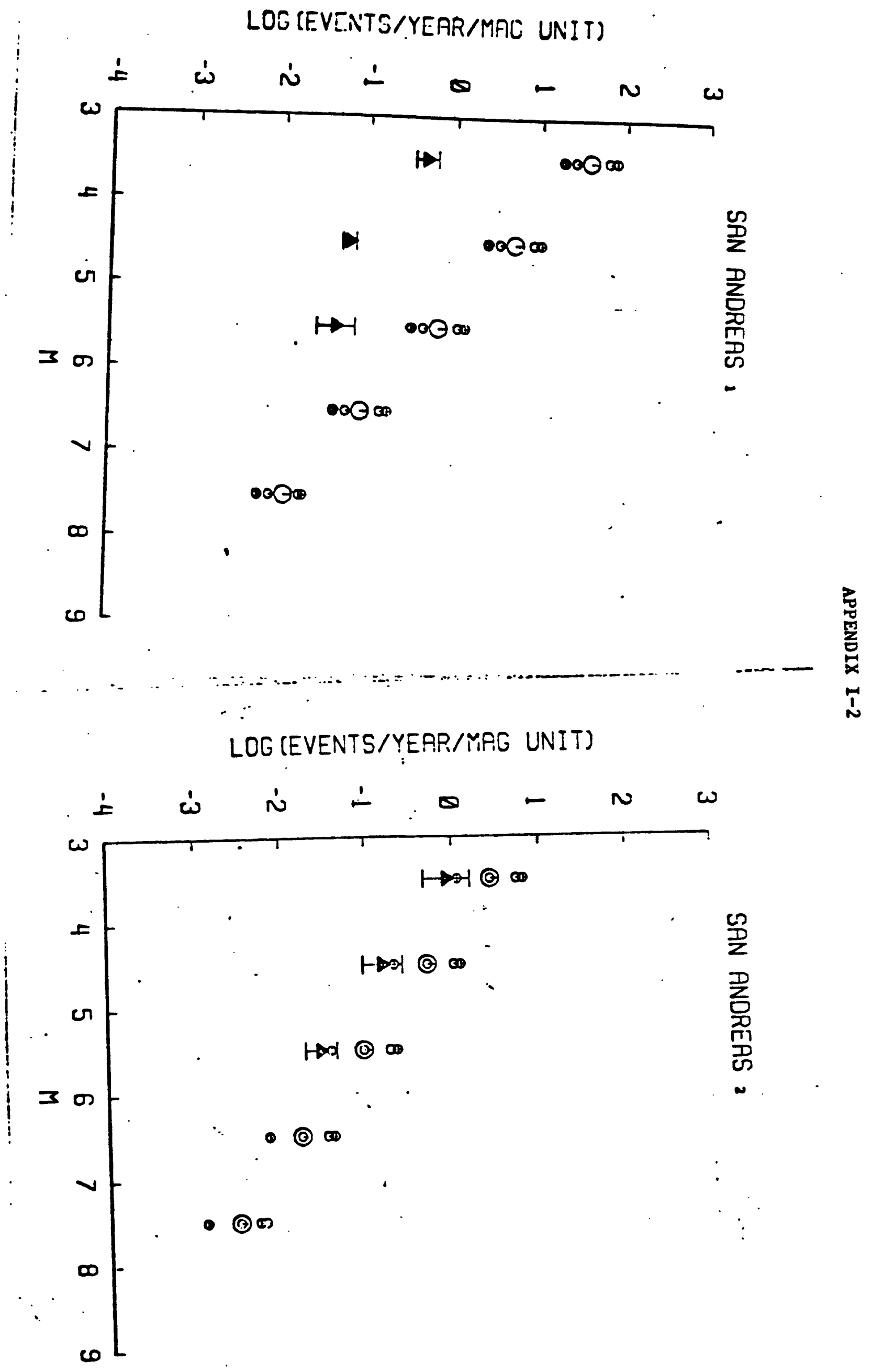

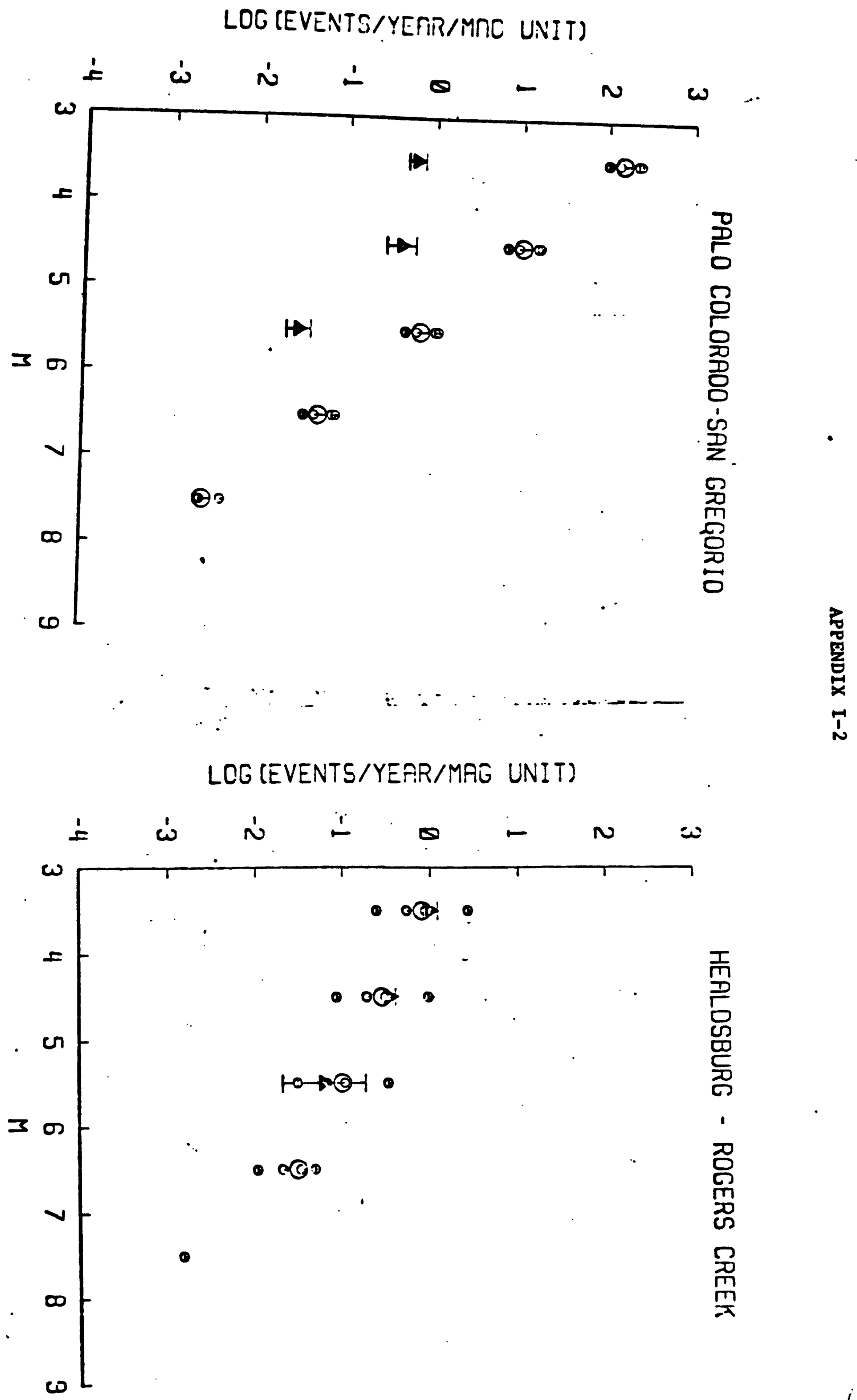
$\therefore \quad$ LOG (EVENTS/YERR/MAC UNIT)
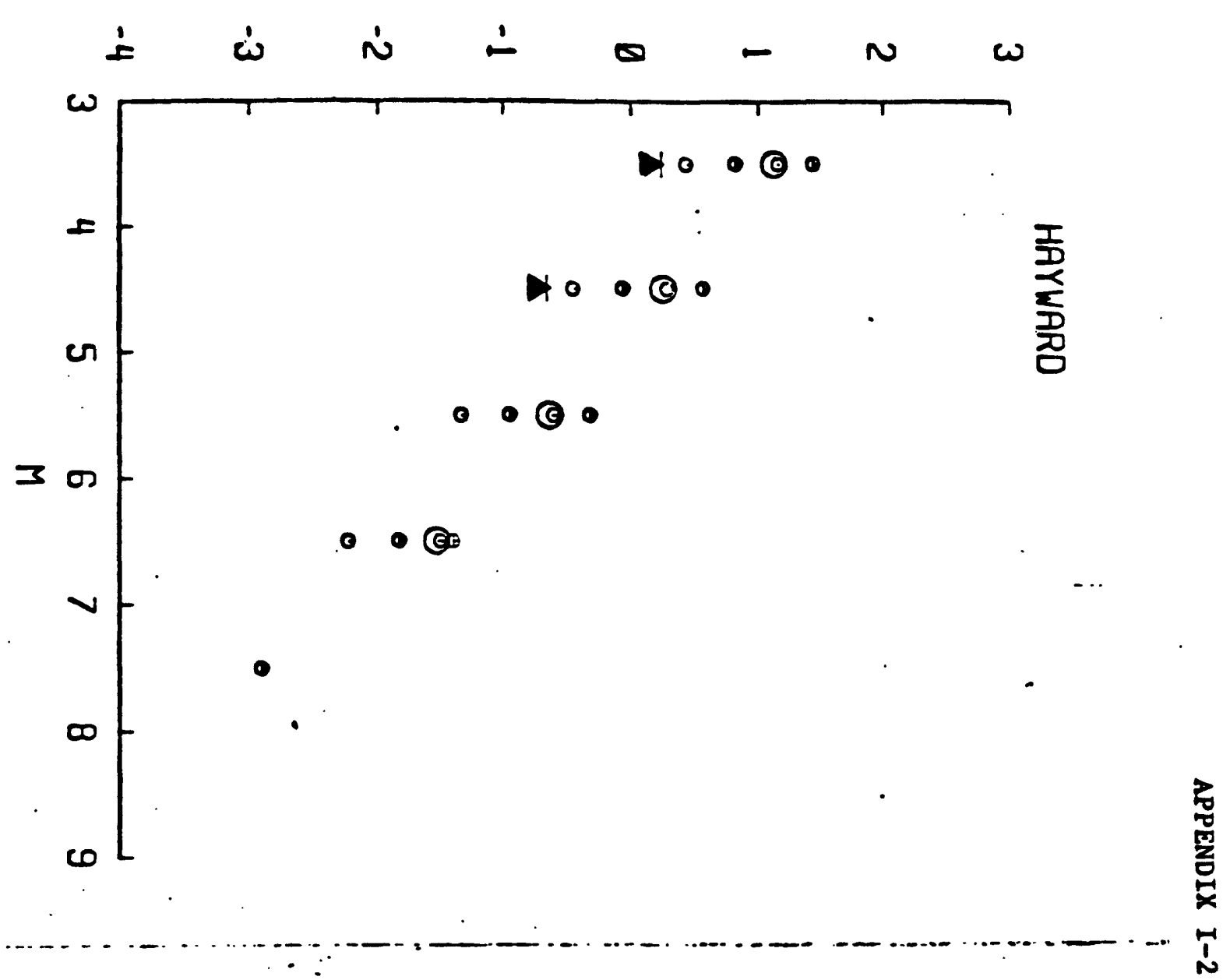

LOG (EVENTS/YEAR/MIAG UNIT)

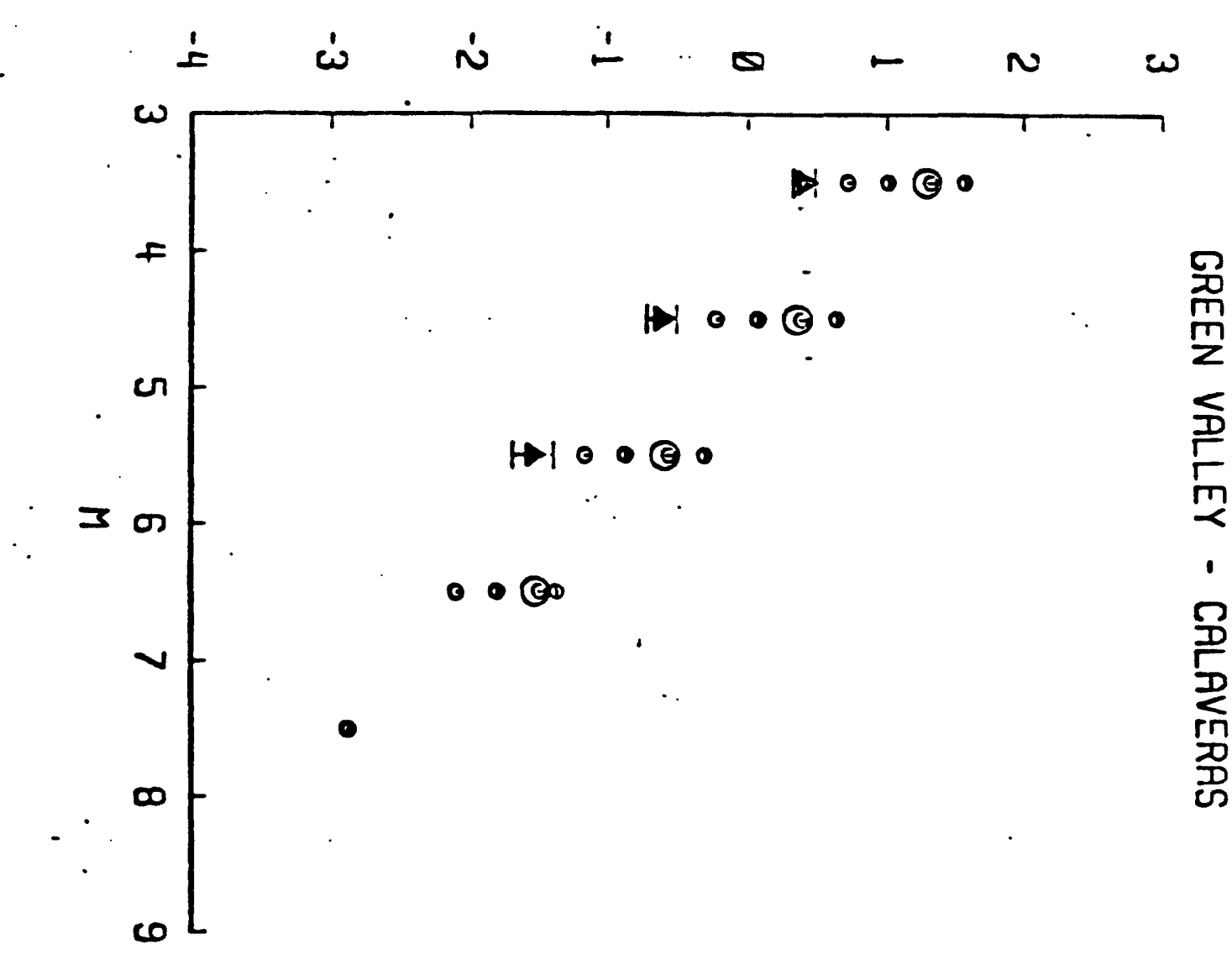

99 


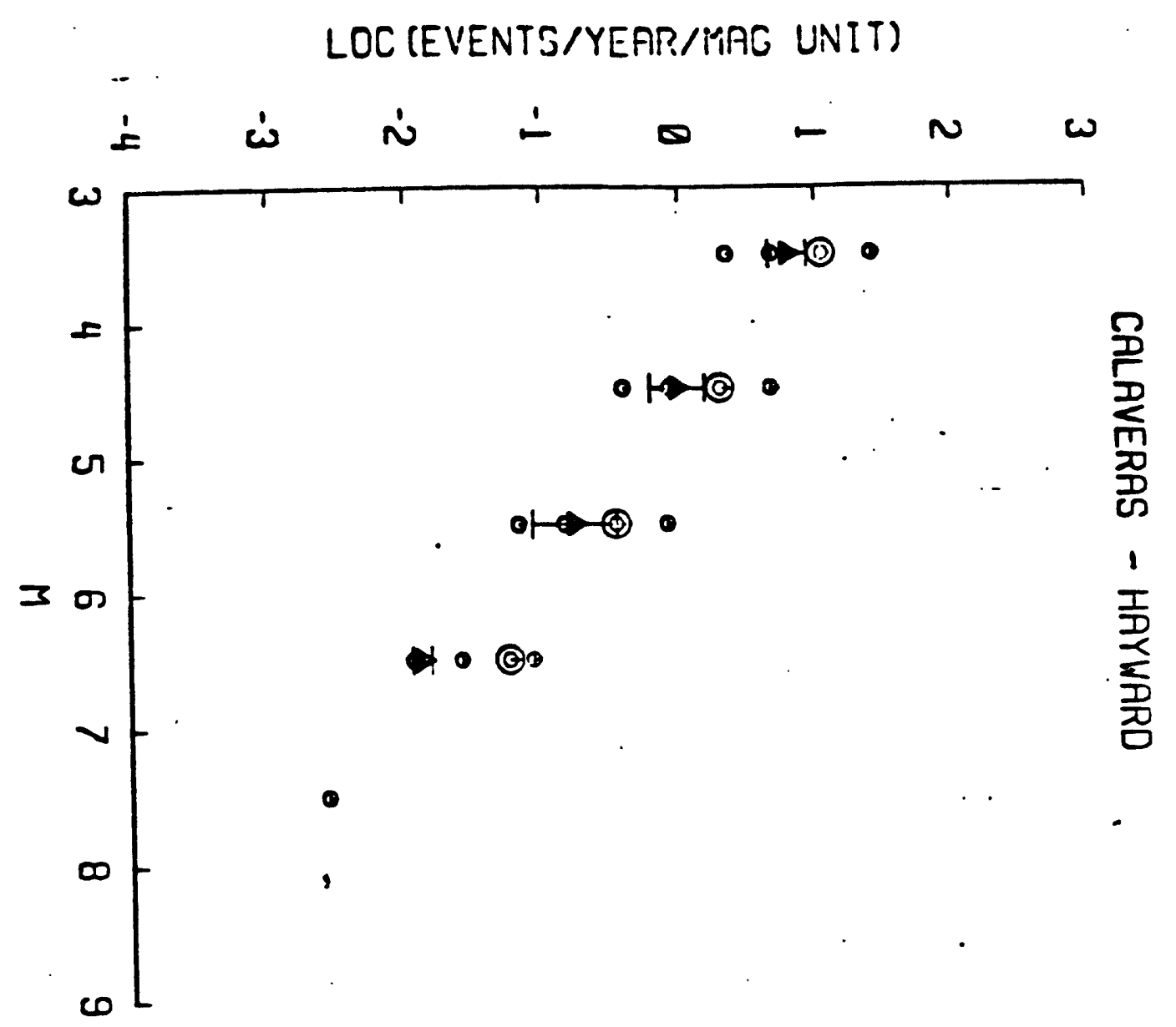

-

LOG (EVENTS/YEAR/MPG UNIT)

总

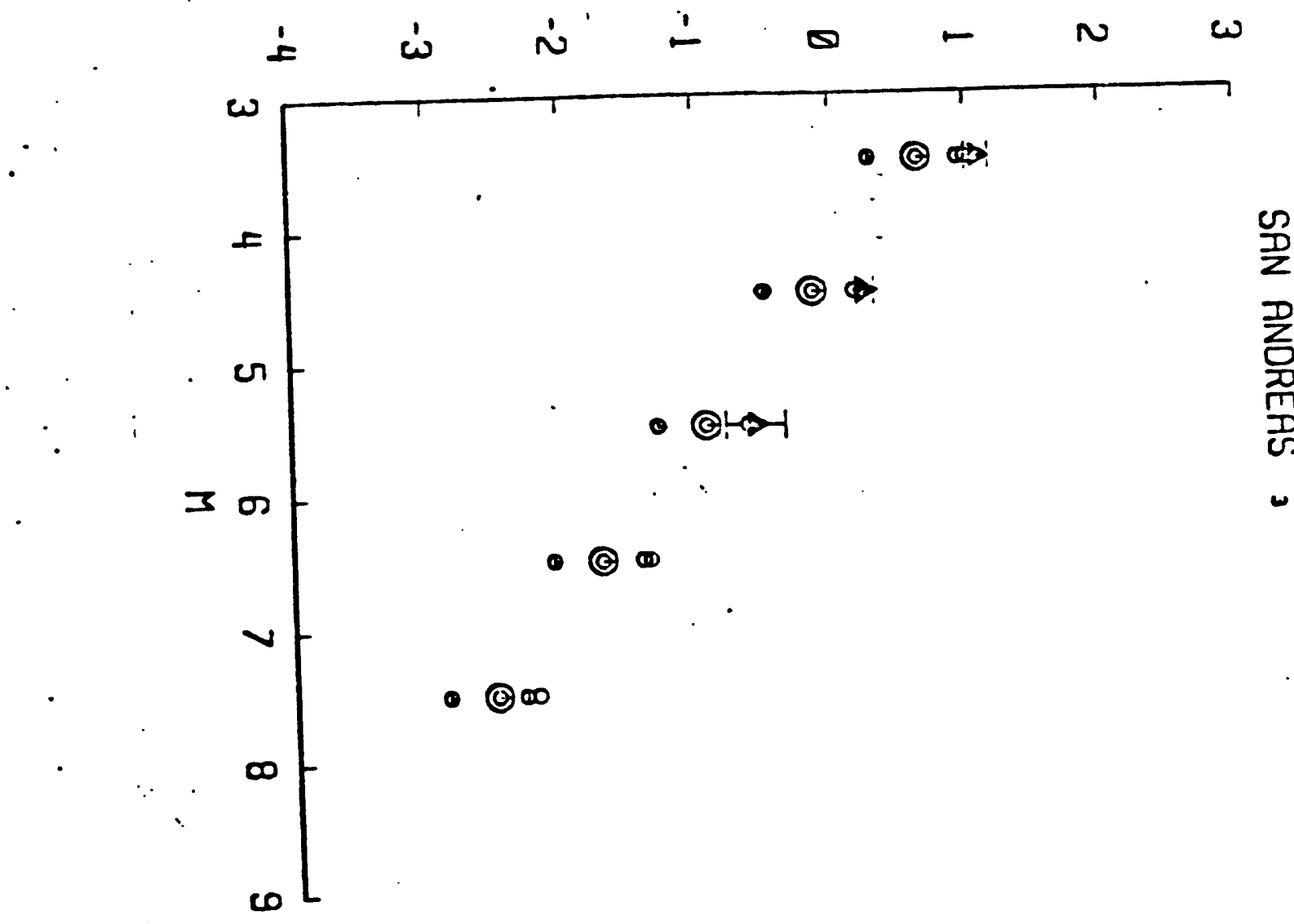


LOC (EVENTS/YEAR/MAC UNIT)

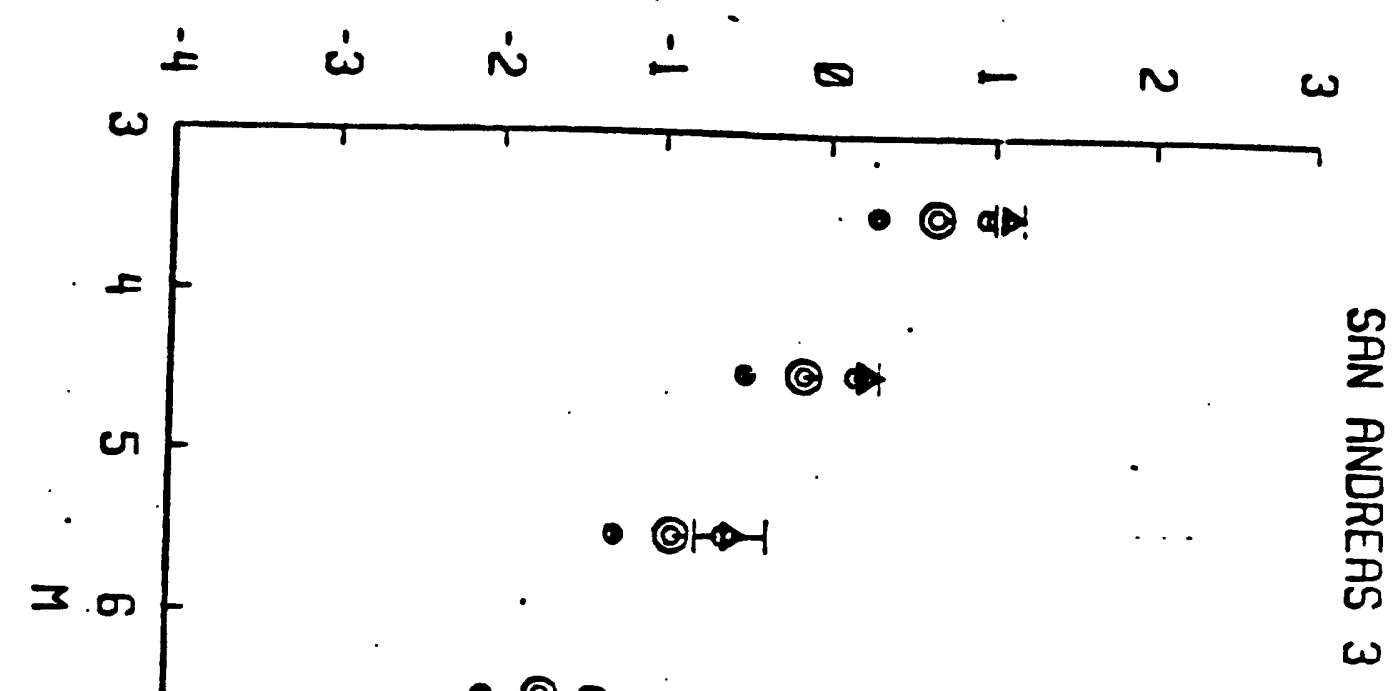

- 우

- ()心

$\infty$
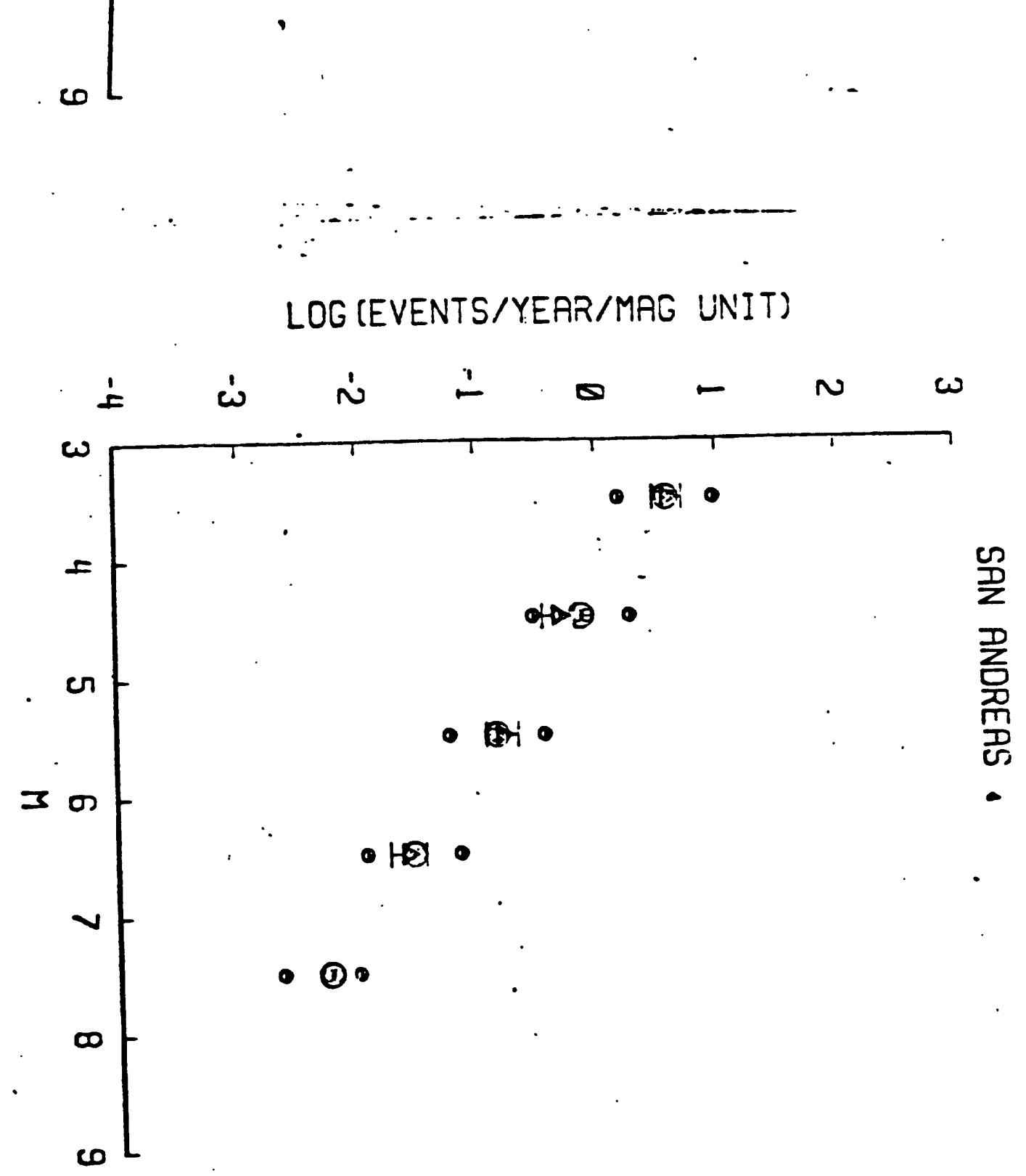

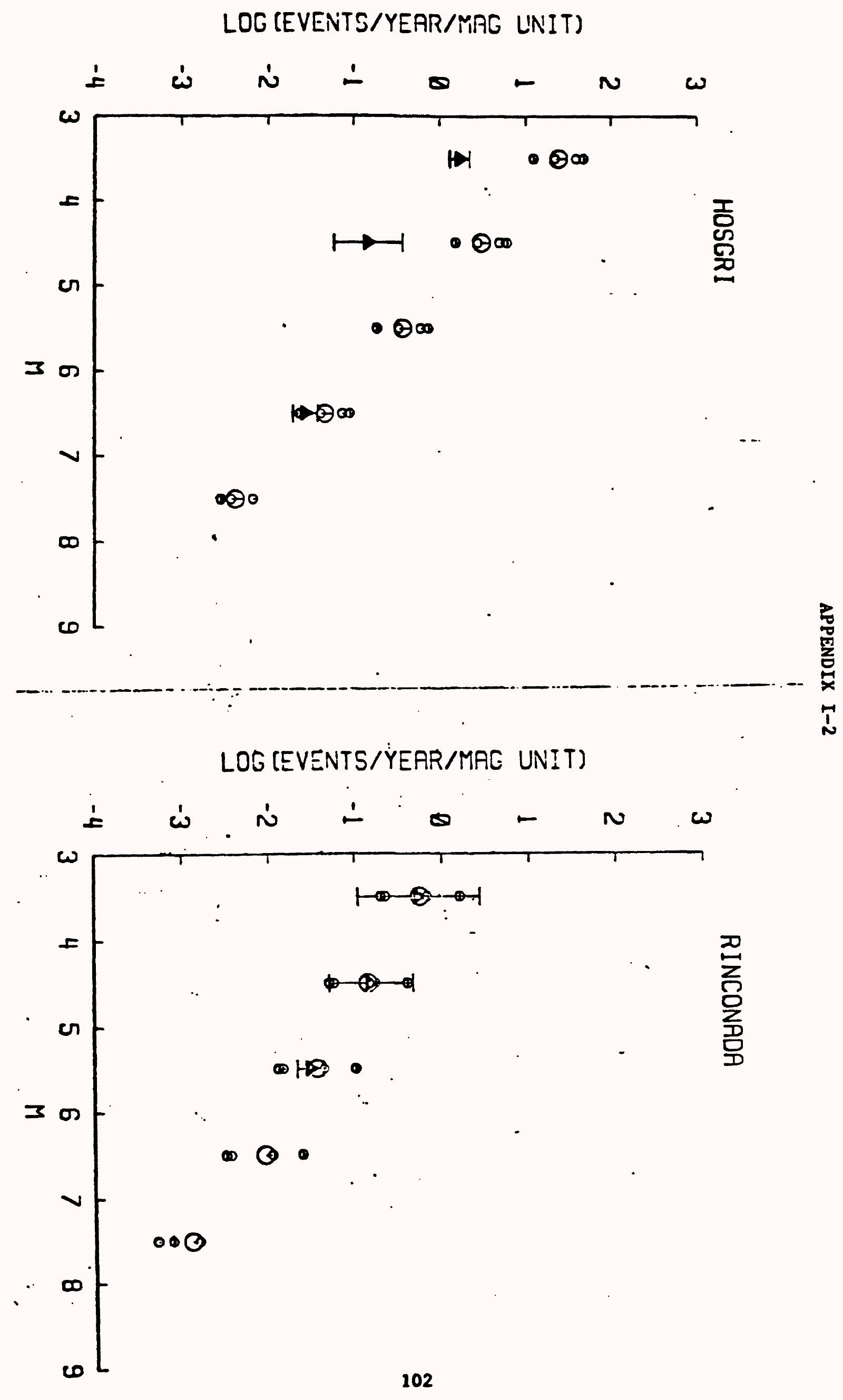
LOG (EVENTS/YEAR/MFC UNIT)
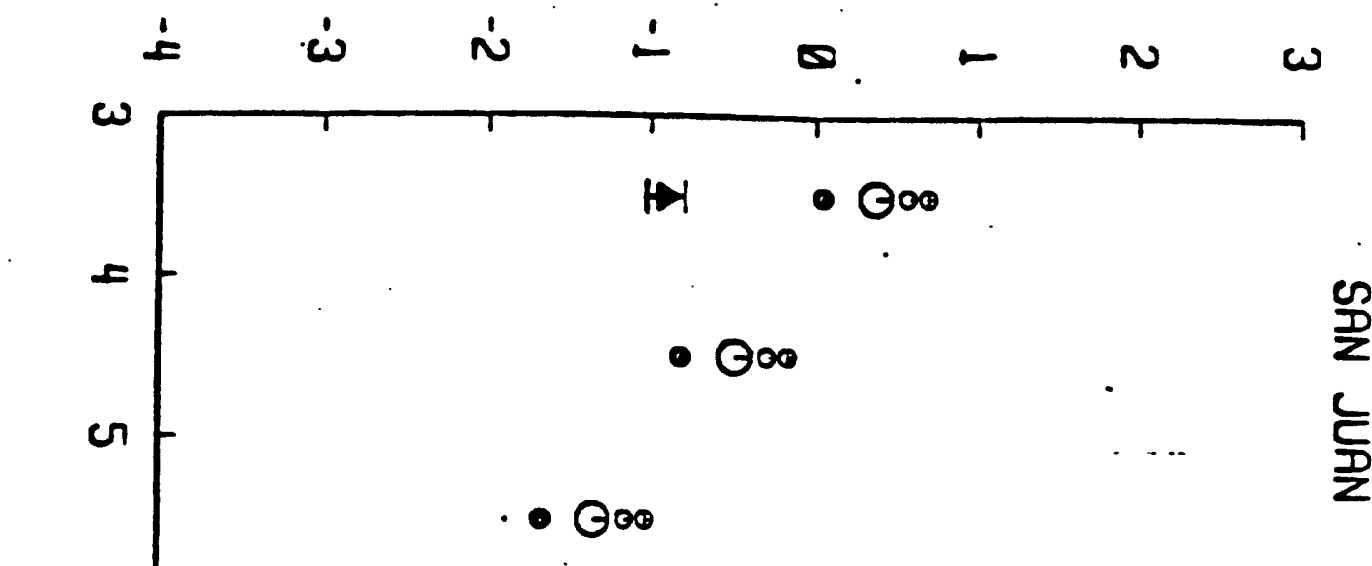

3 os

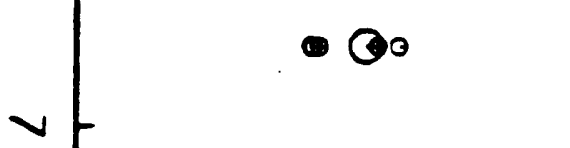

LOG (EVENTS/YEAR/MAG UNIT)

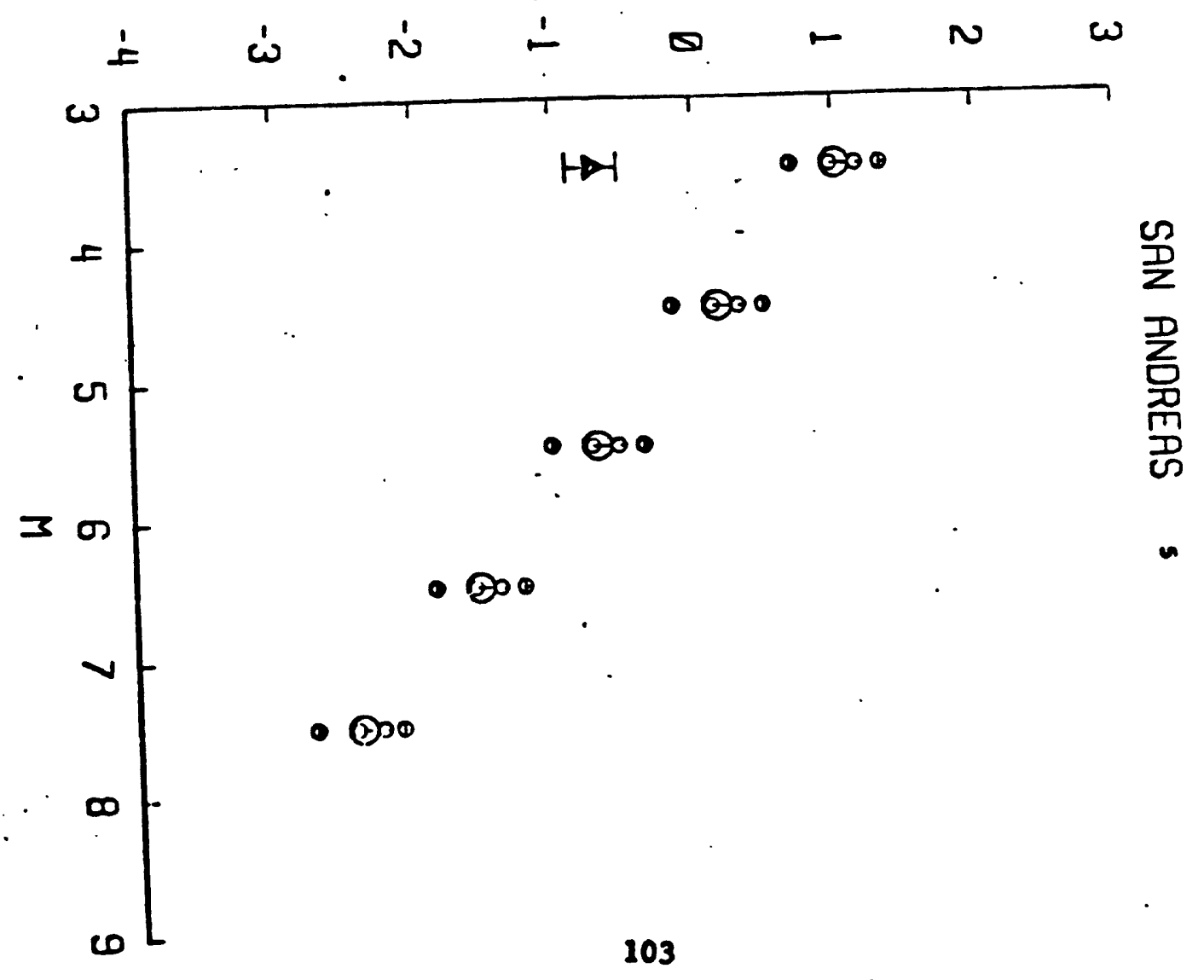



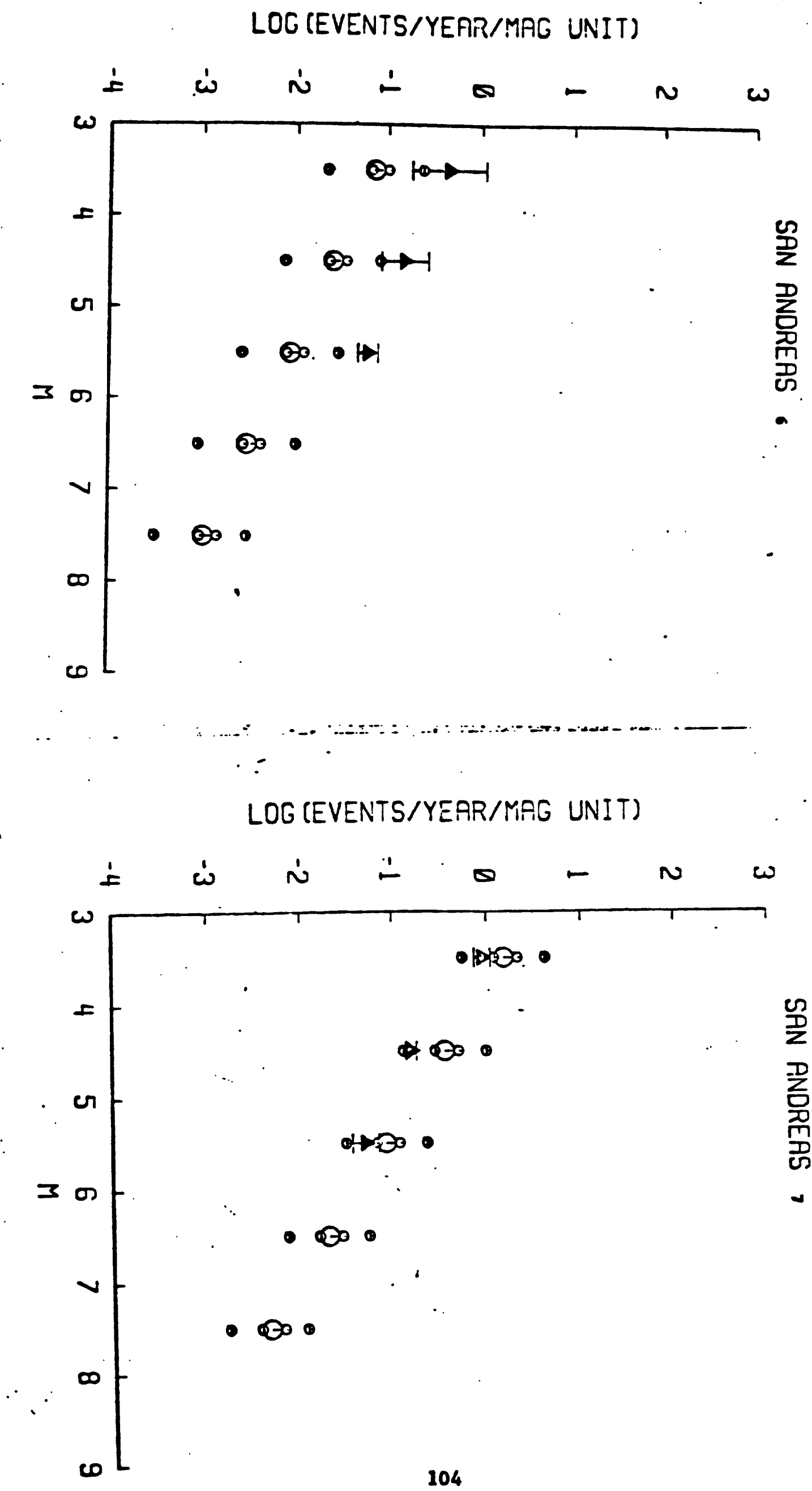


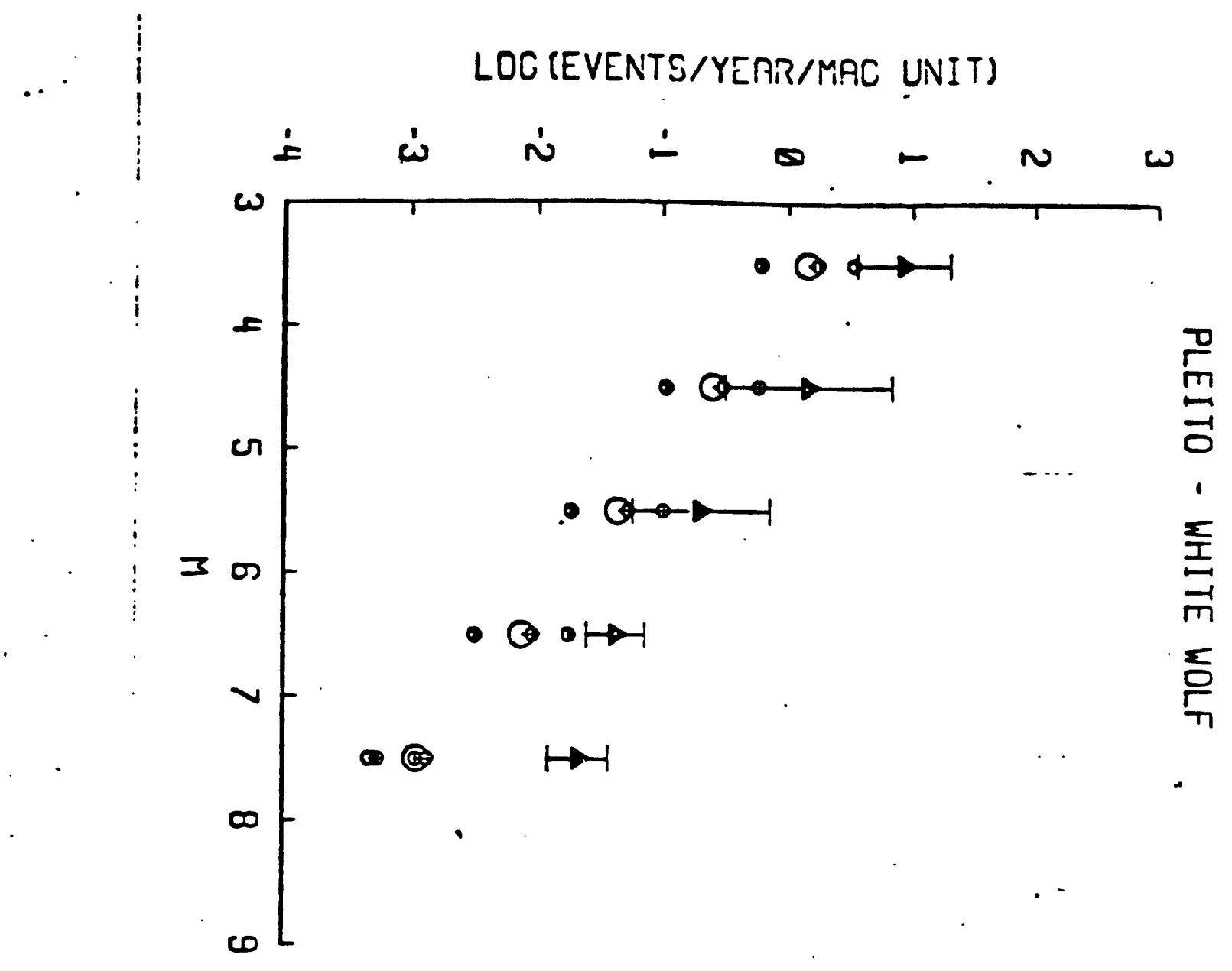

$\because \vdots-\quad-\ldots+\therefore \cdot$

LOG (EVENTS/YERR/MF.G UNIT)

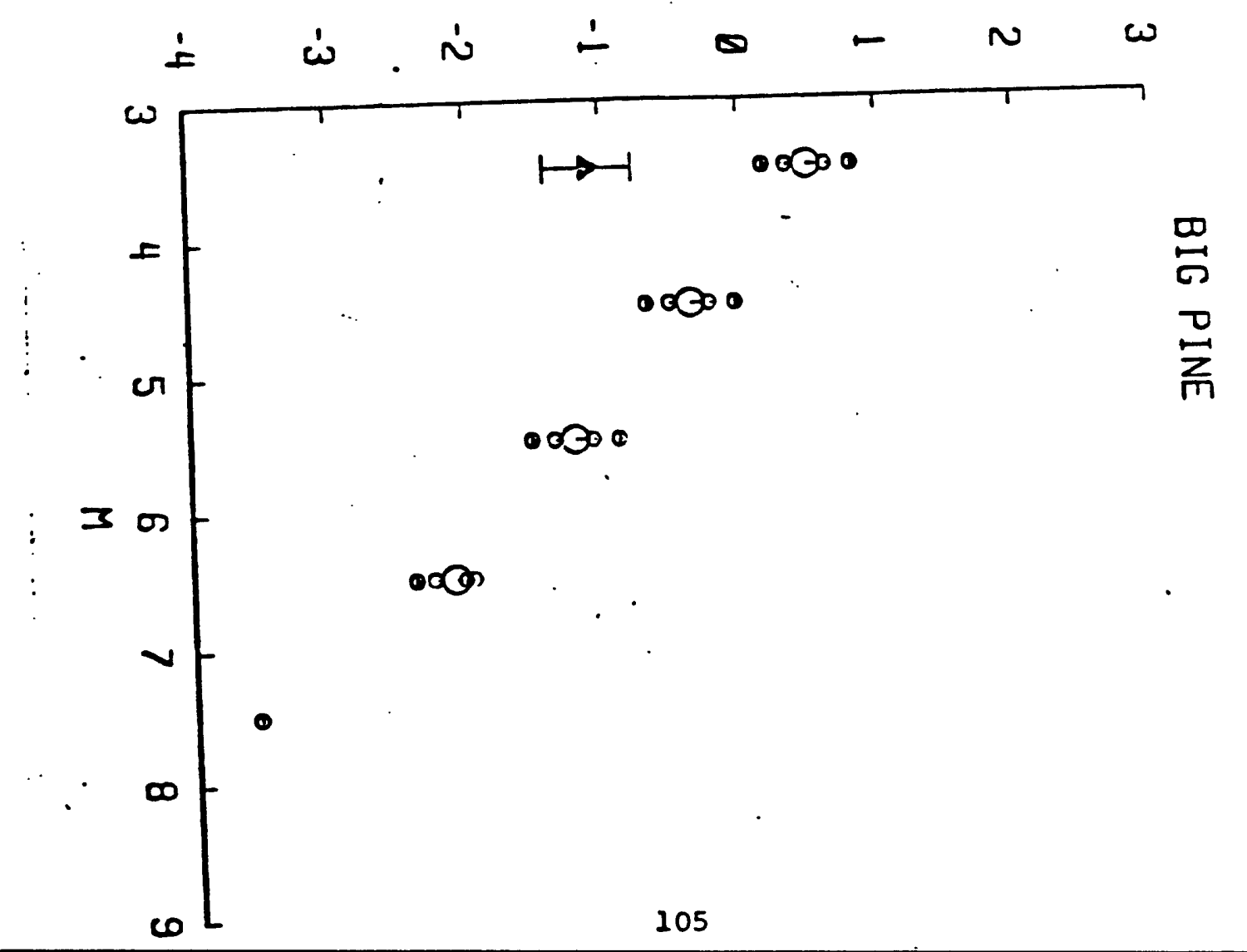


LOG (EVENTS/YEAR/MAC LNIT)
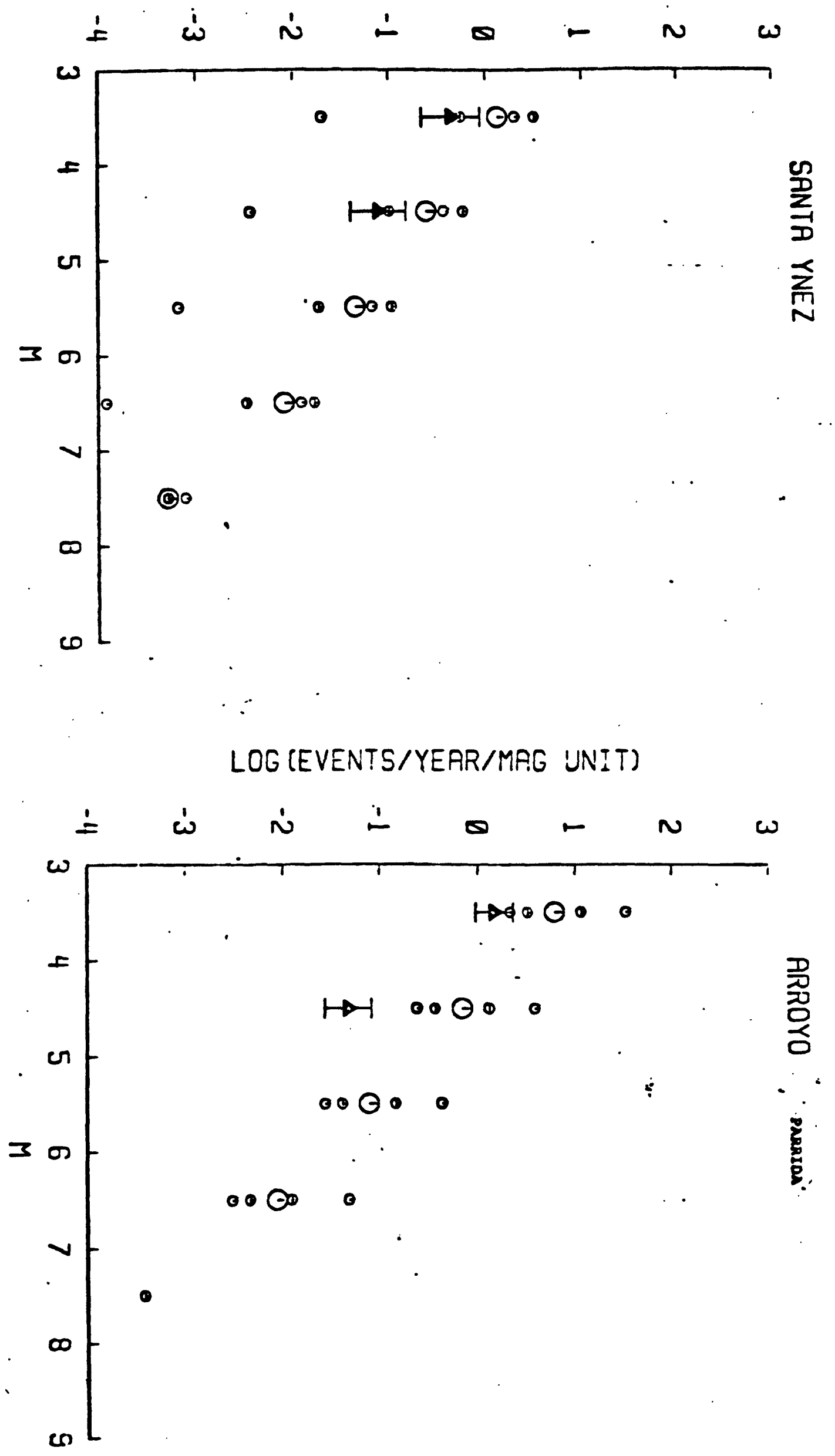
LOG (EVENTS/YEAR/MAG UNIT)

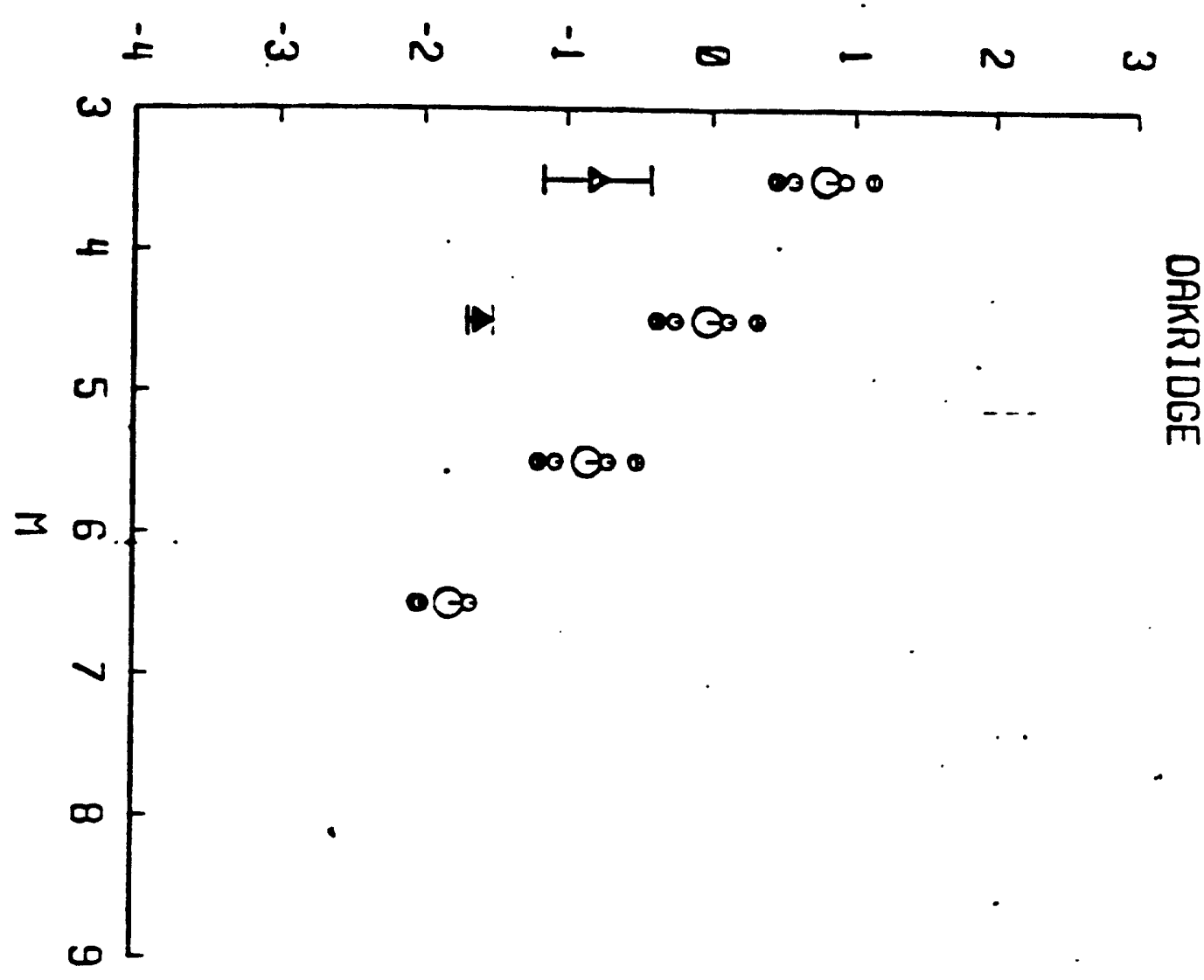

$\therefore \quad$ LOG (EVENTS/YERR/MAG LNIT)

$\stackrel{1}{\sim}$

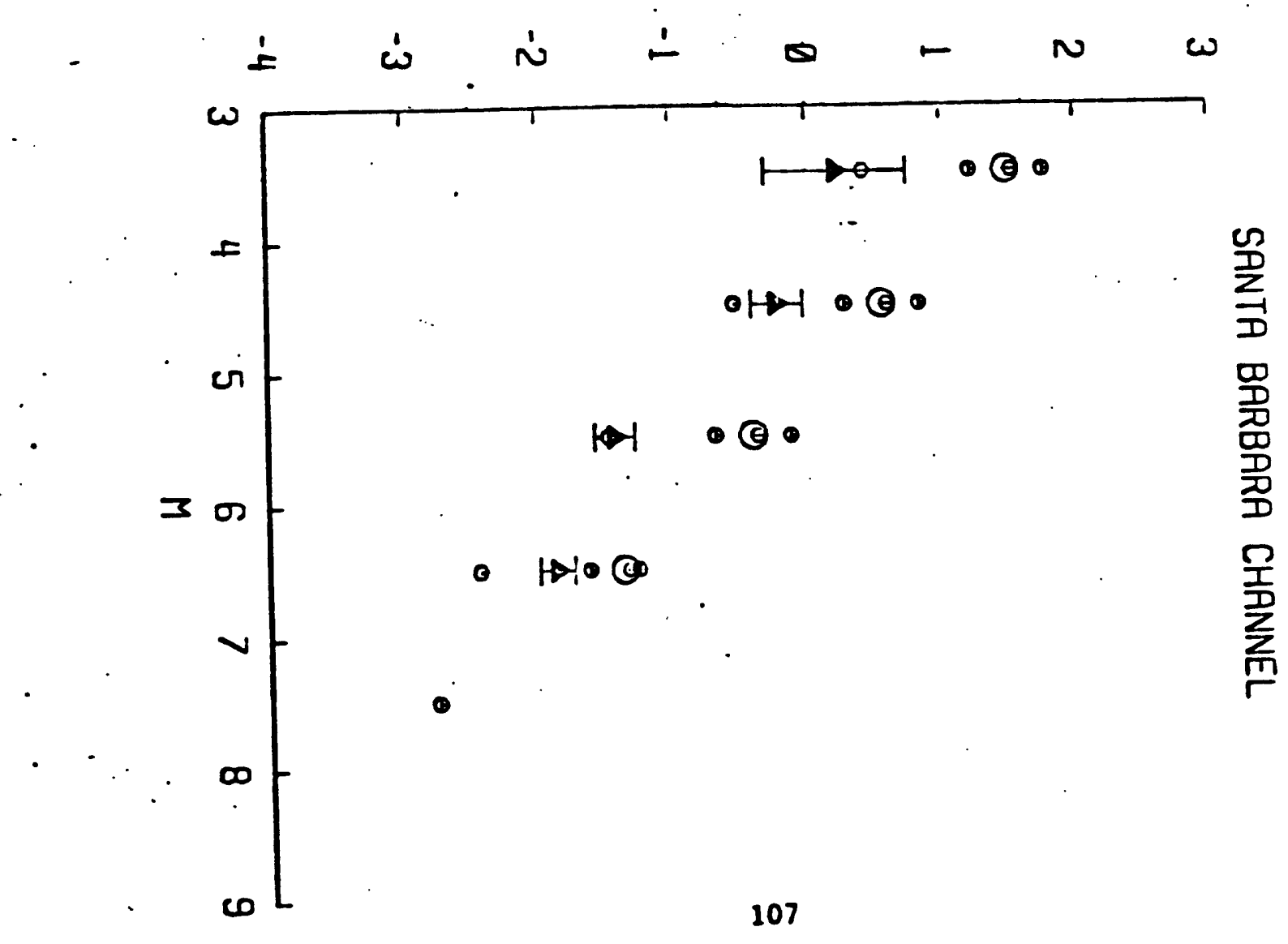


LOC (EVENTS/YEAR/MIEG UNIT)
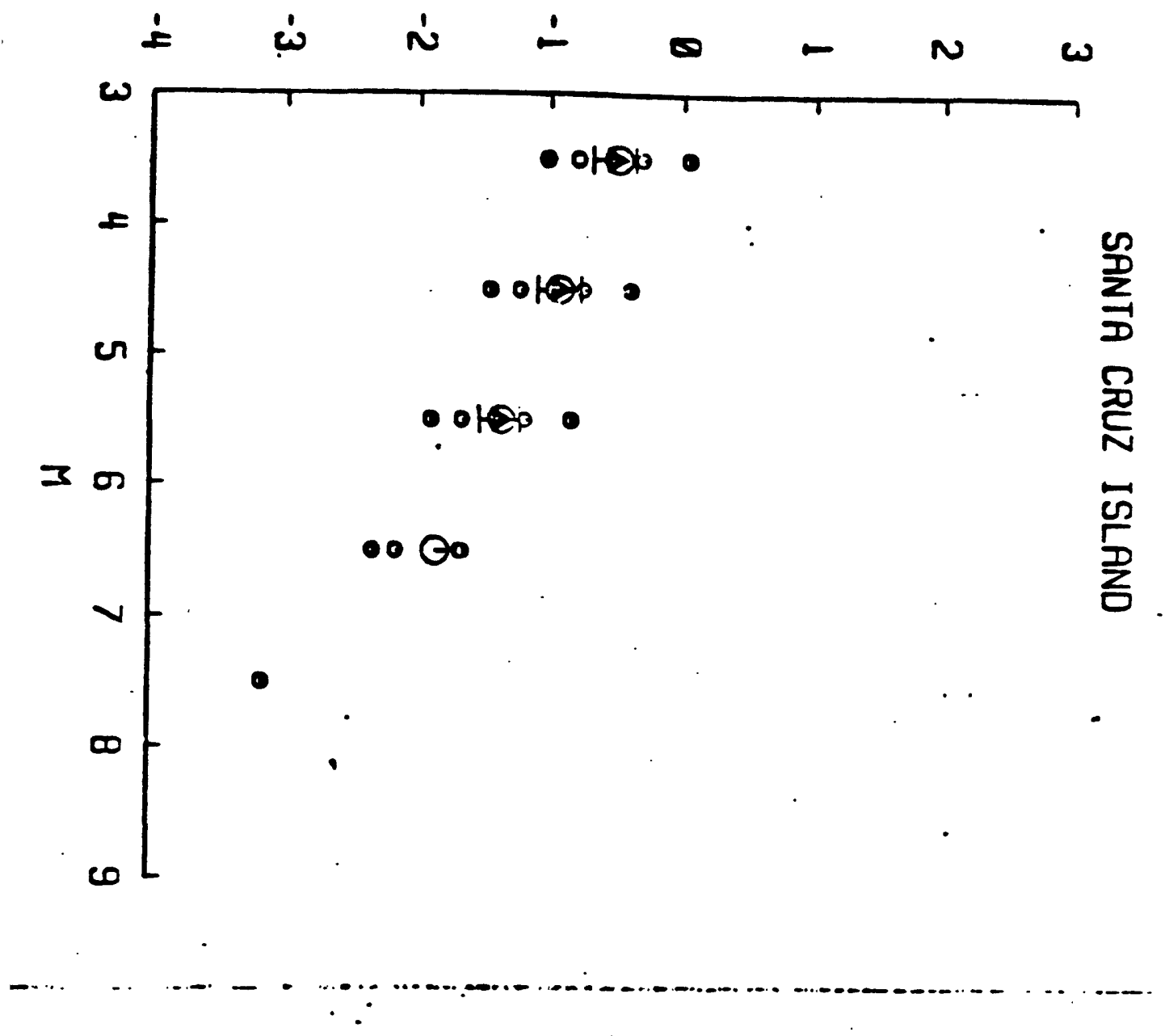

LOG (EVENTS/YEAR/MAG UNIT)

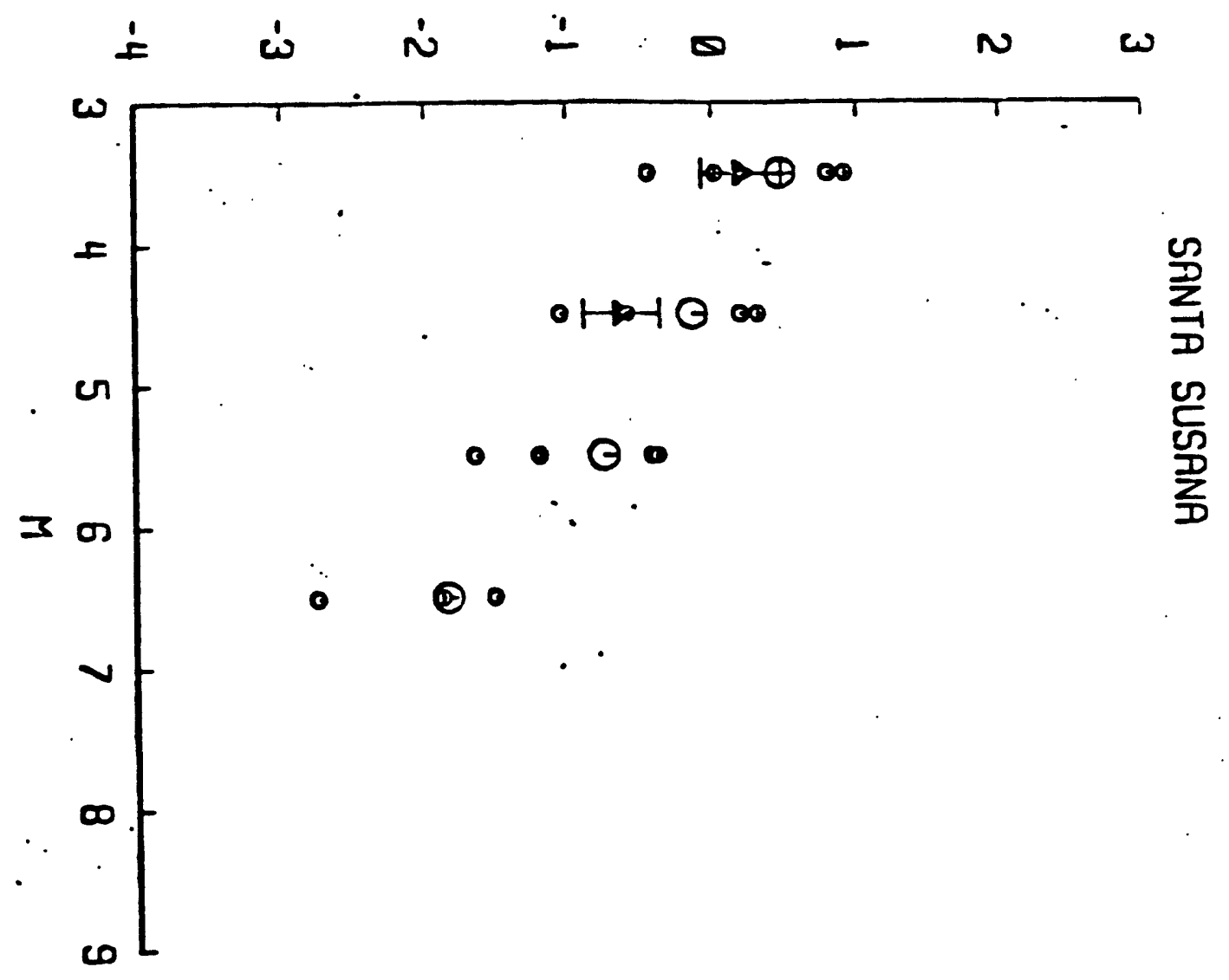


LOG (EVENTS/YERR/MIIG UNIT)

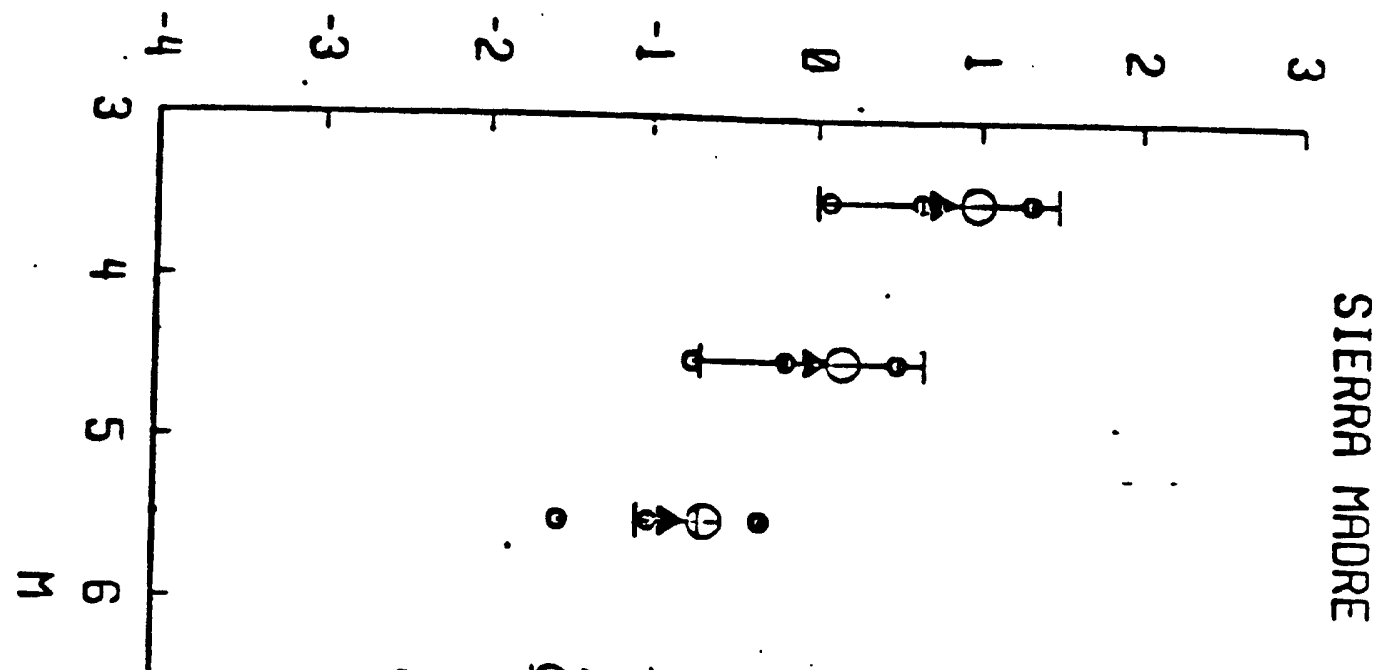

- $D=1$

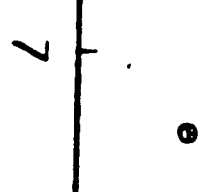

[ع

$\therefore$

LOG (EVENTS/YEAR/MPE UNIT)

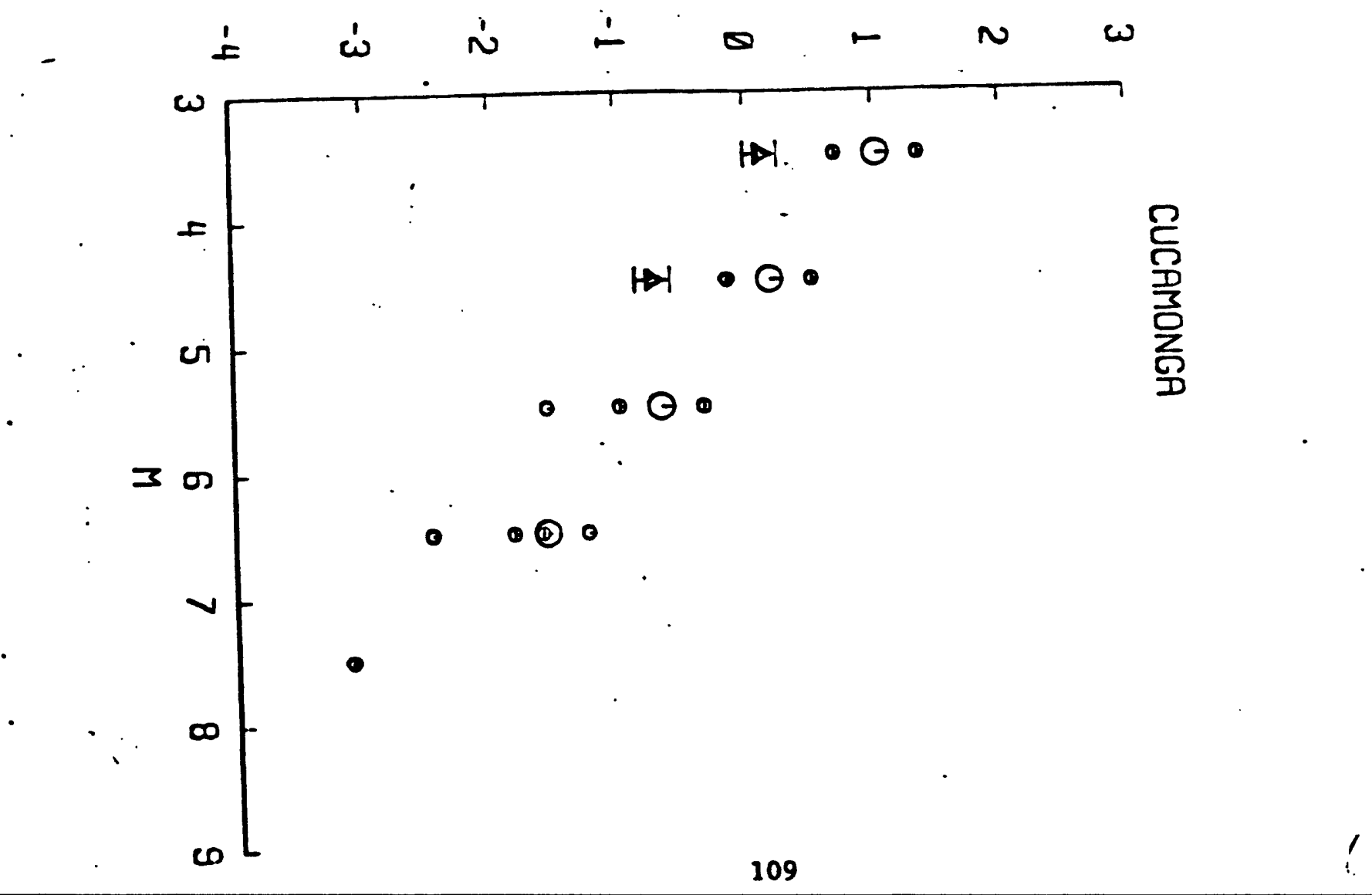

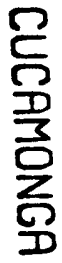

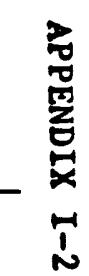


LOG (EVENTS/YEF:R/MFIC UNIT)

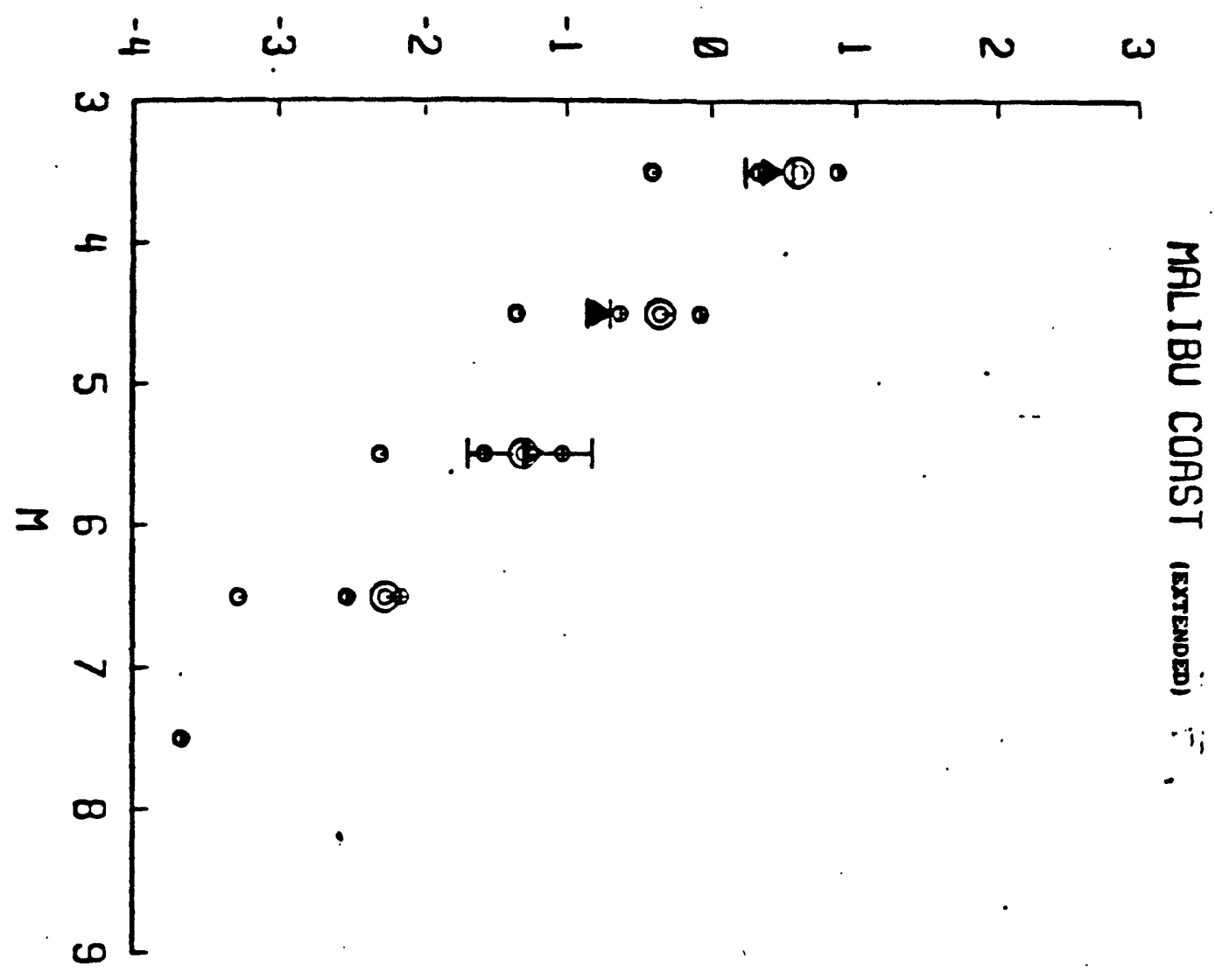

-

LOG (EVENTS/YEAR/MAG UNIT)

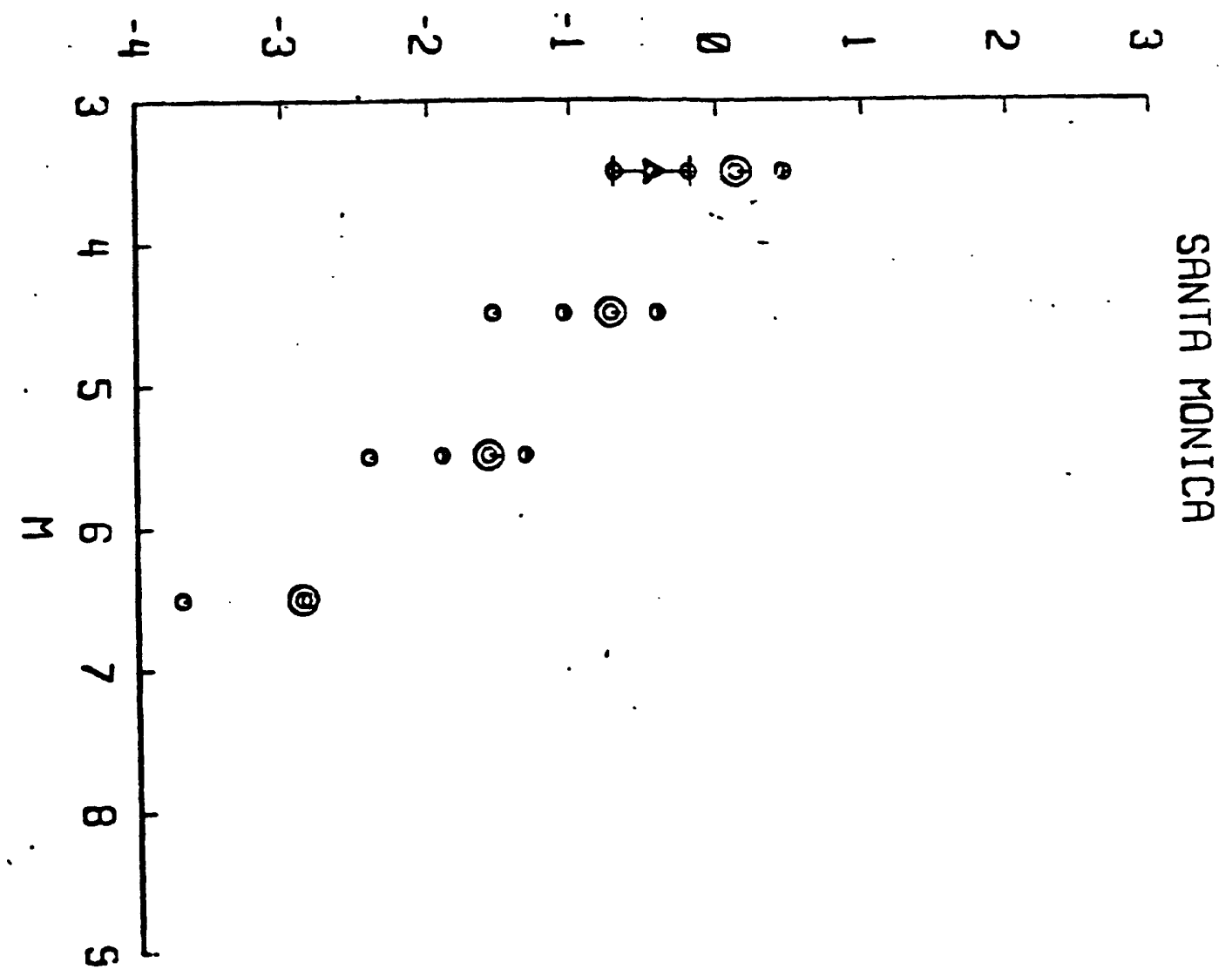


LOC (EVENTS/YEAR/MAG UNIT)

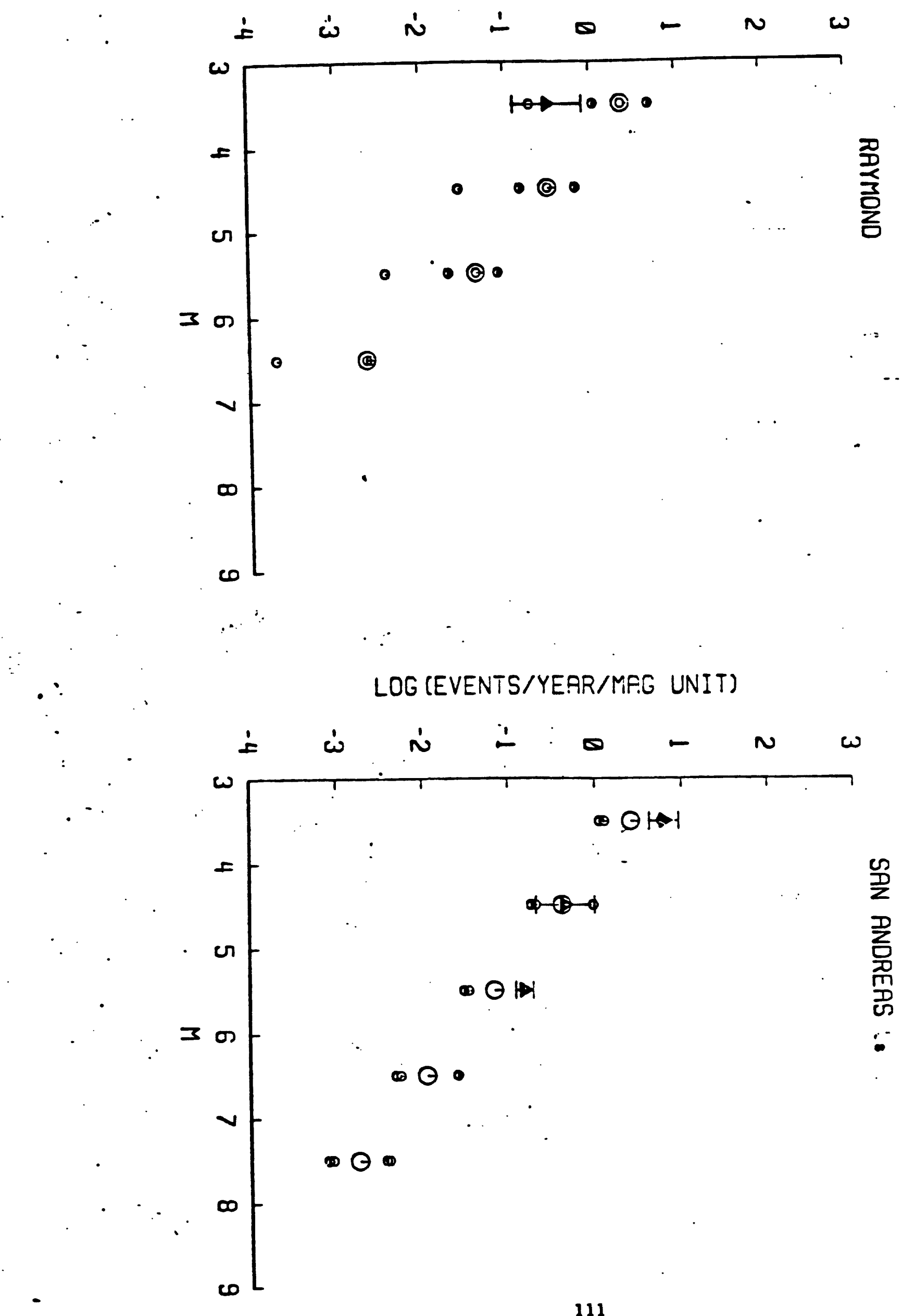


-

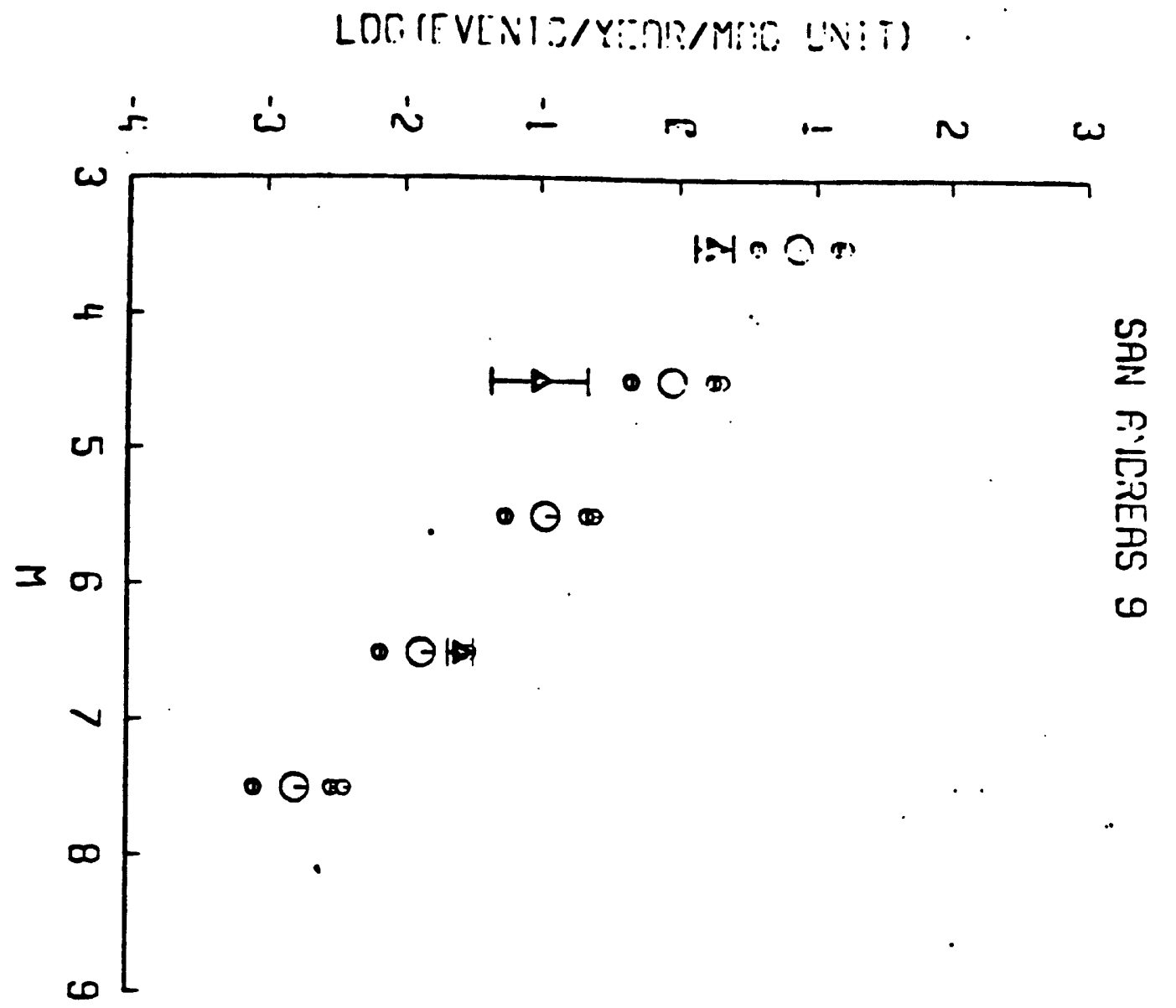

LOG (EVENTS/YEFR/MAG LNIT)

旁

.

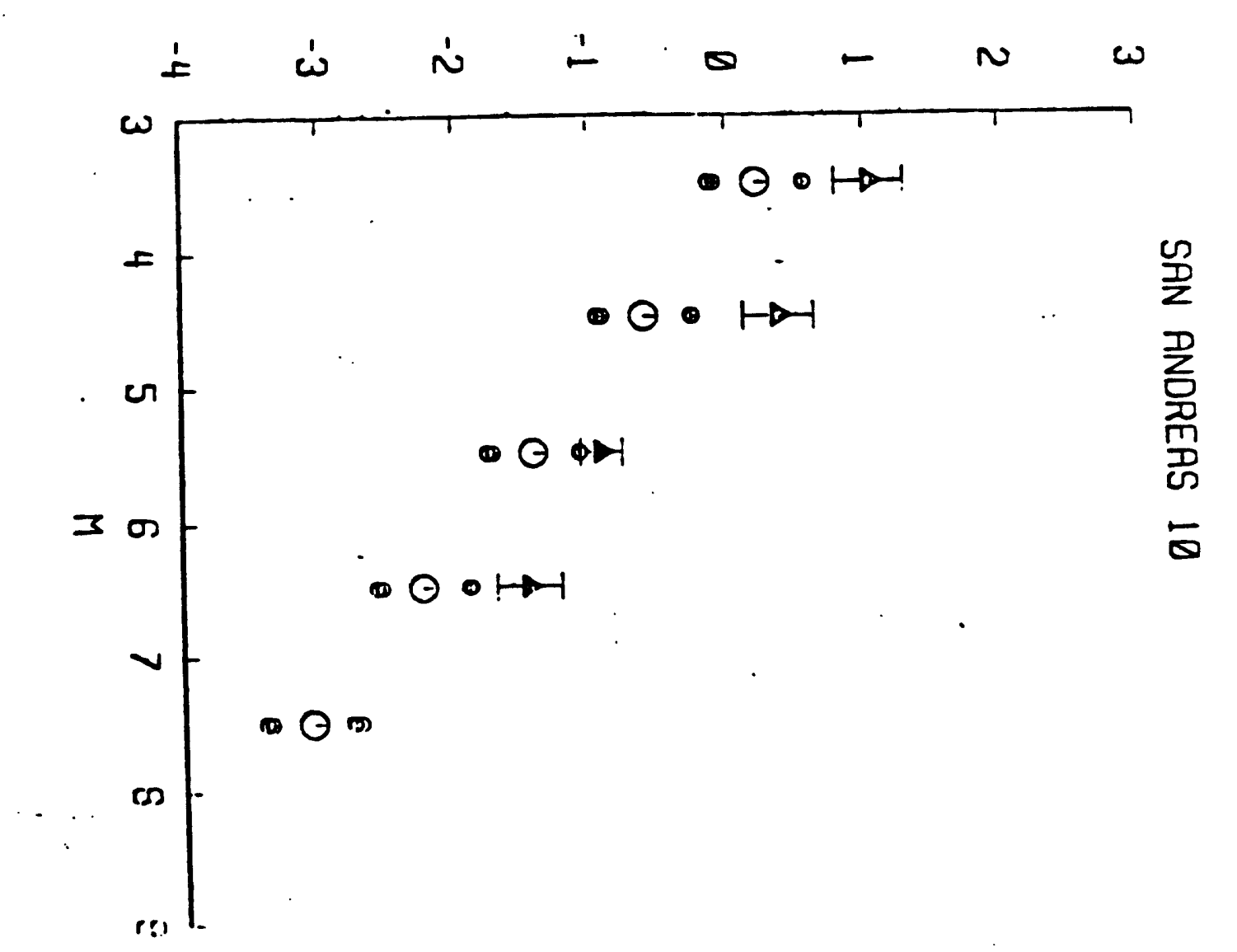

112 
. LOG (EVENTS/YEAR/MAC UNIT)
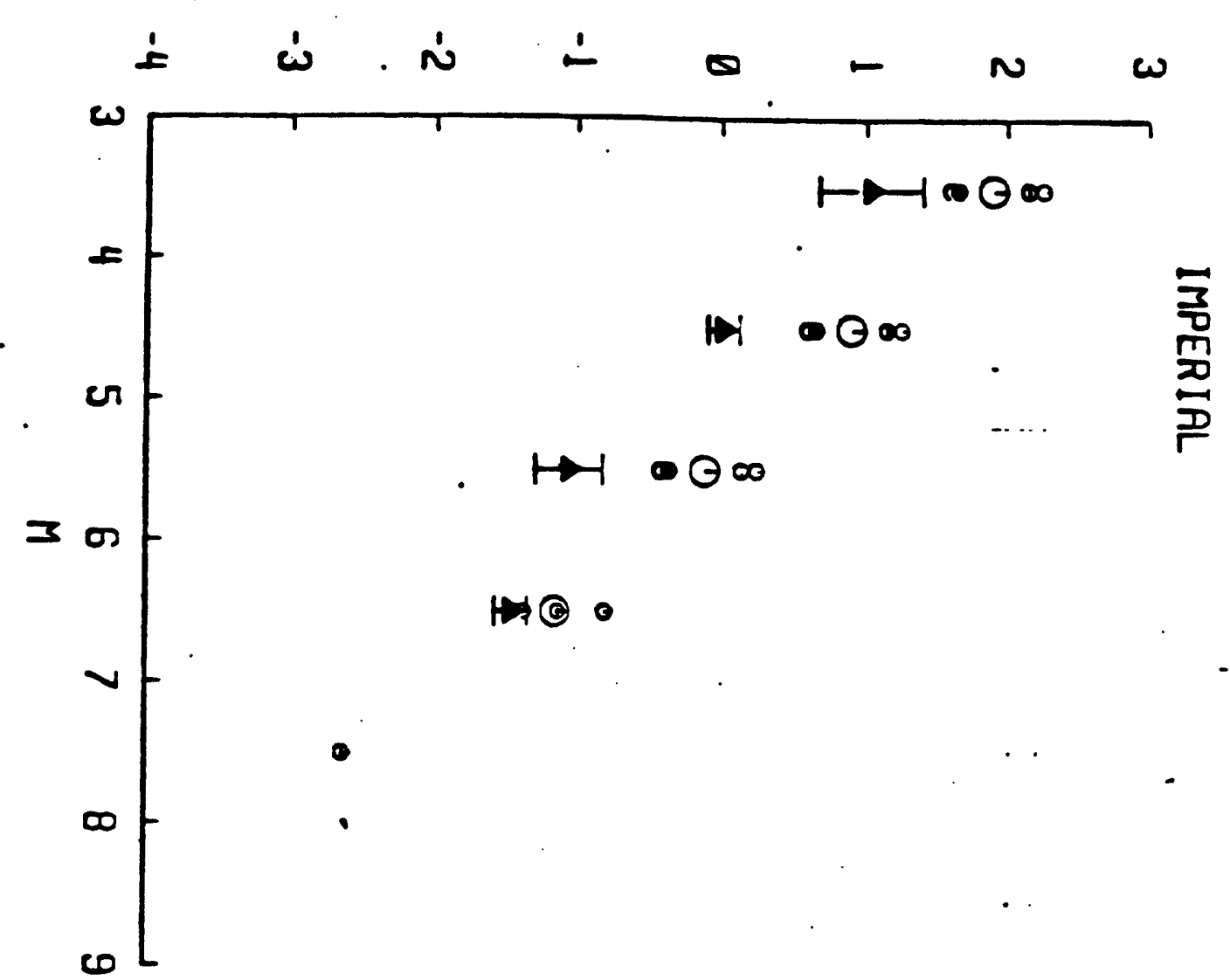

$\therefore \quad$ LOG (EVENTS/YEAR/MAG UNIT)

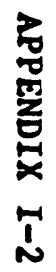

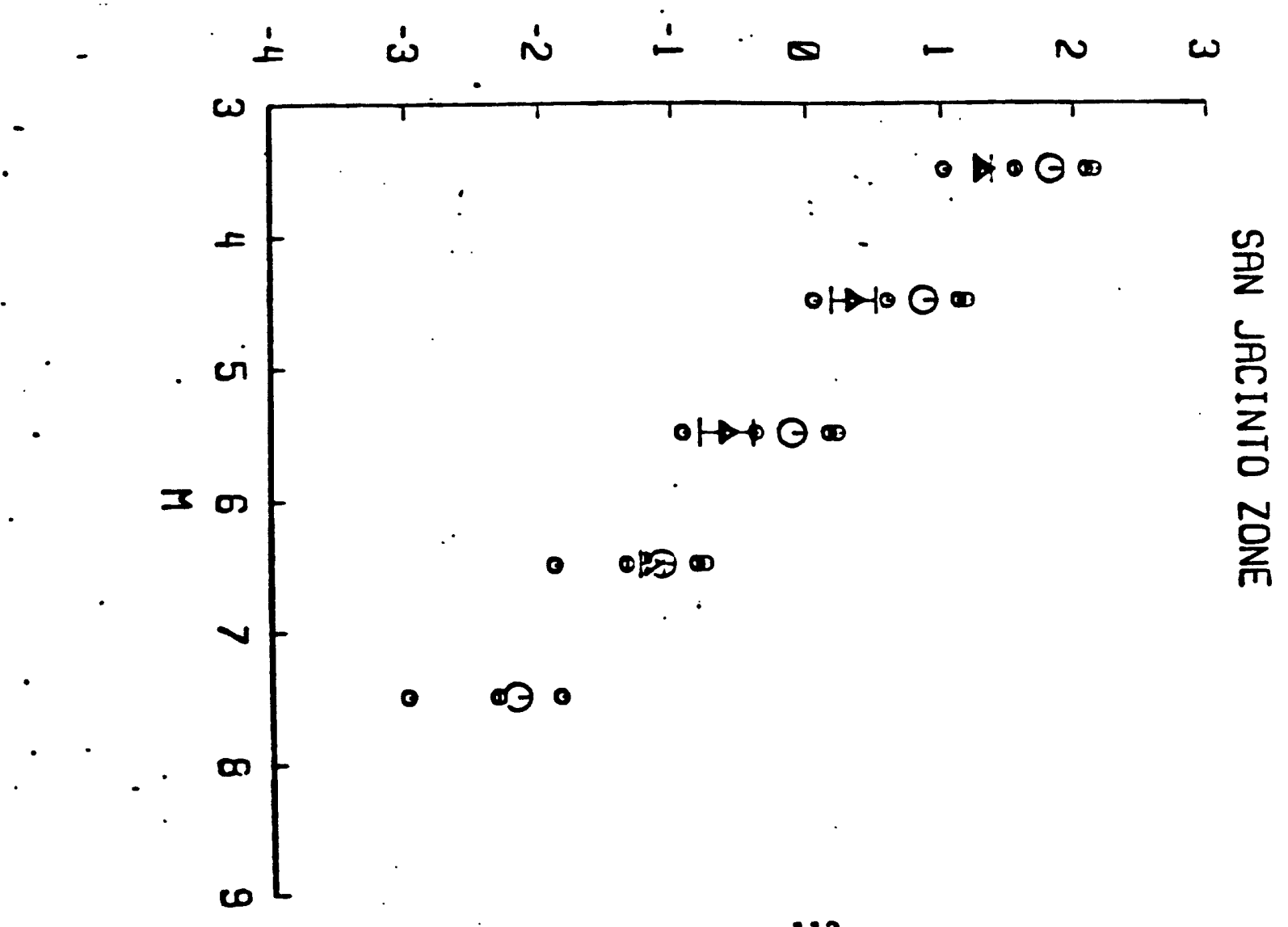

113 
LOG (EVENTS/YEAR/MAG UNIT)
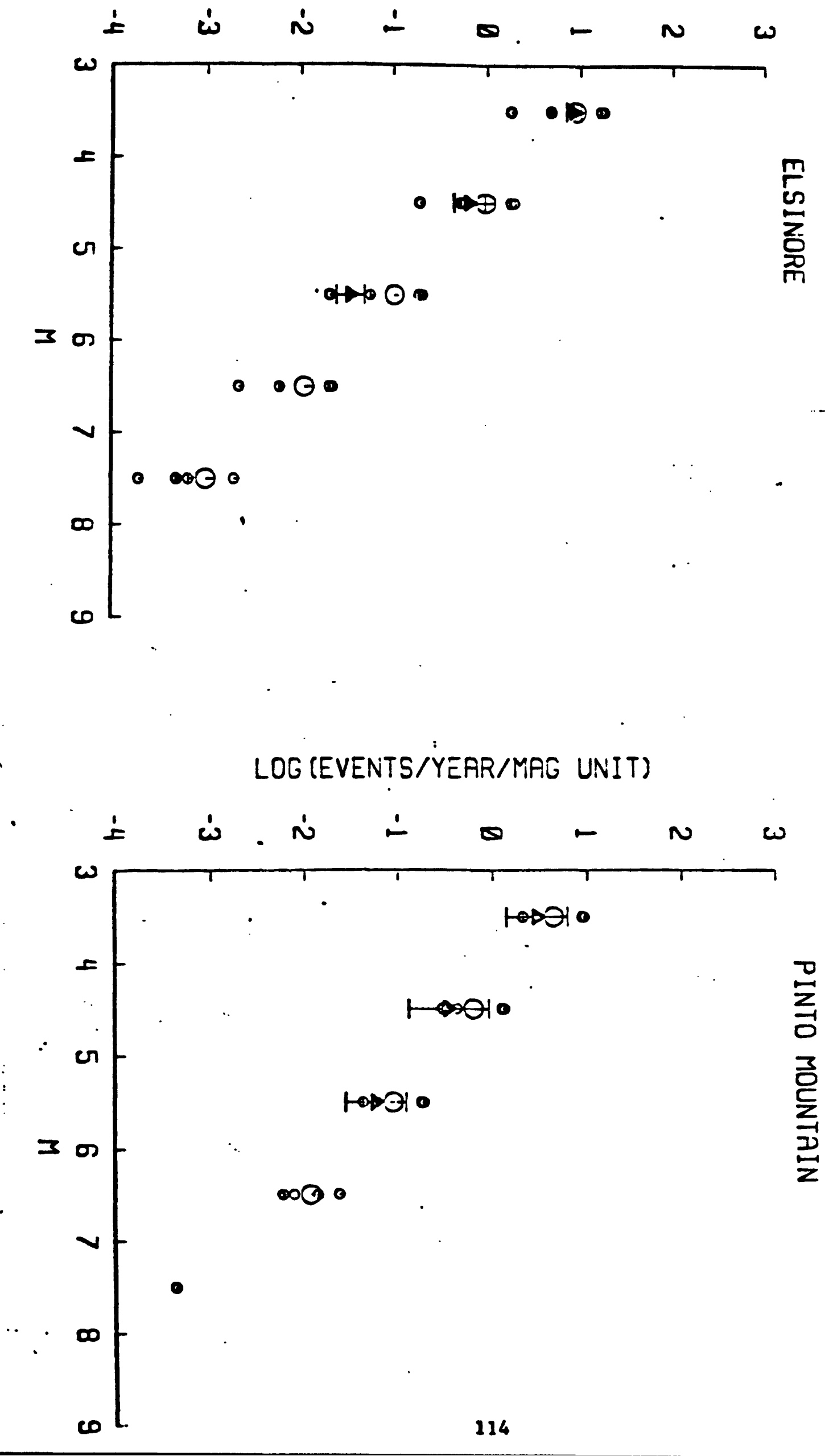
LOG (EVENTS/YERIR/MIIC UNIT)

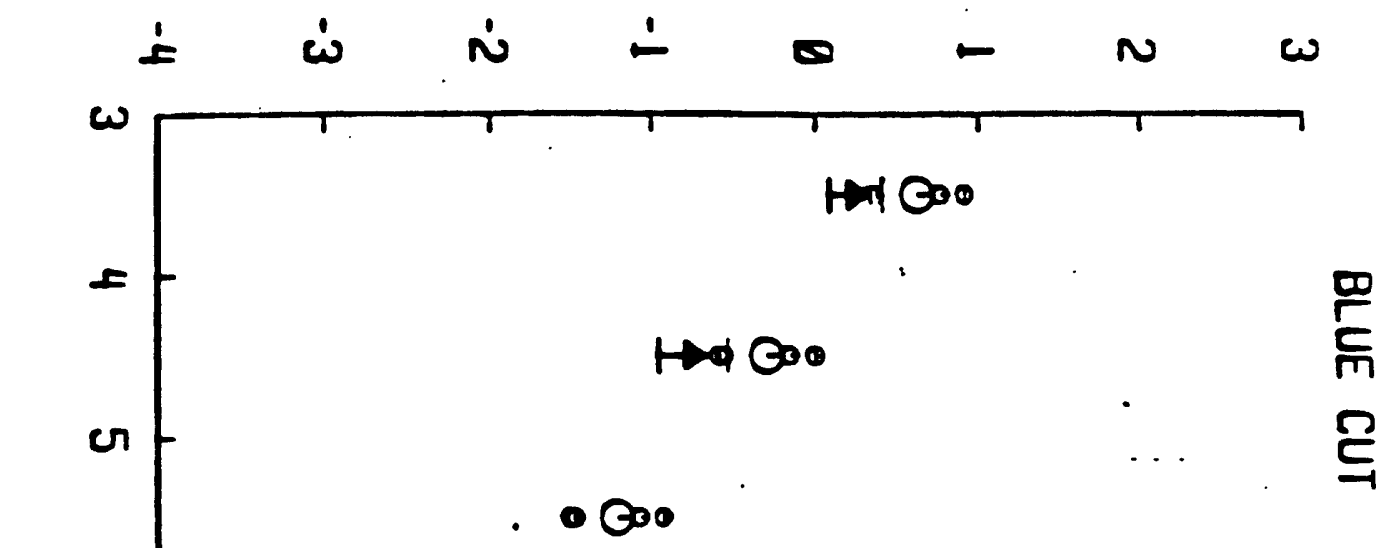

$\therefore \quad$.. LOG (EVENTS/YERR/MPG UNIT)

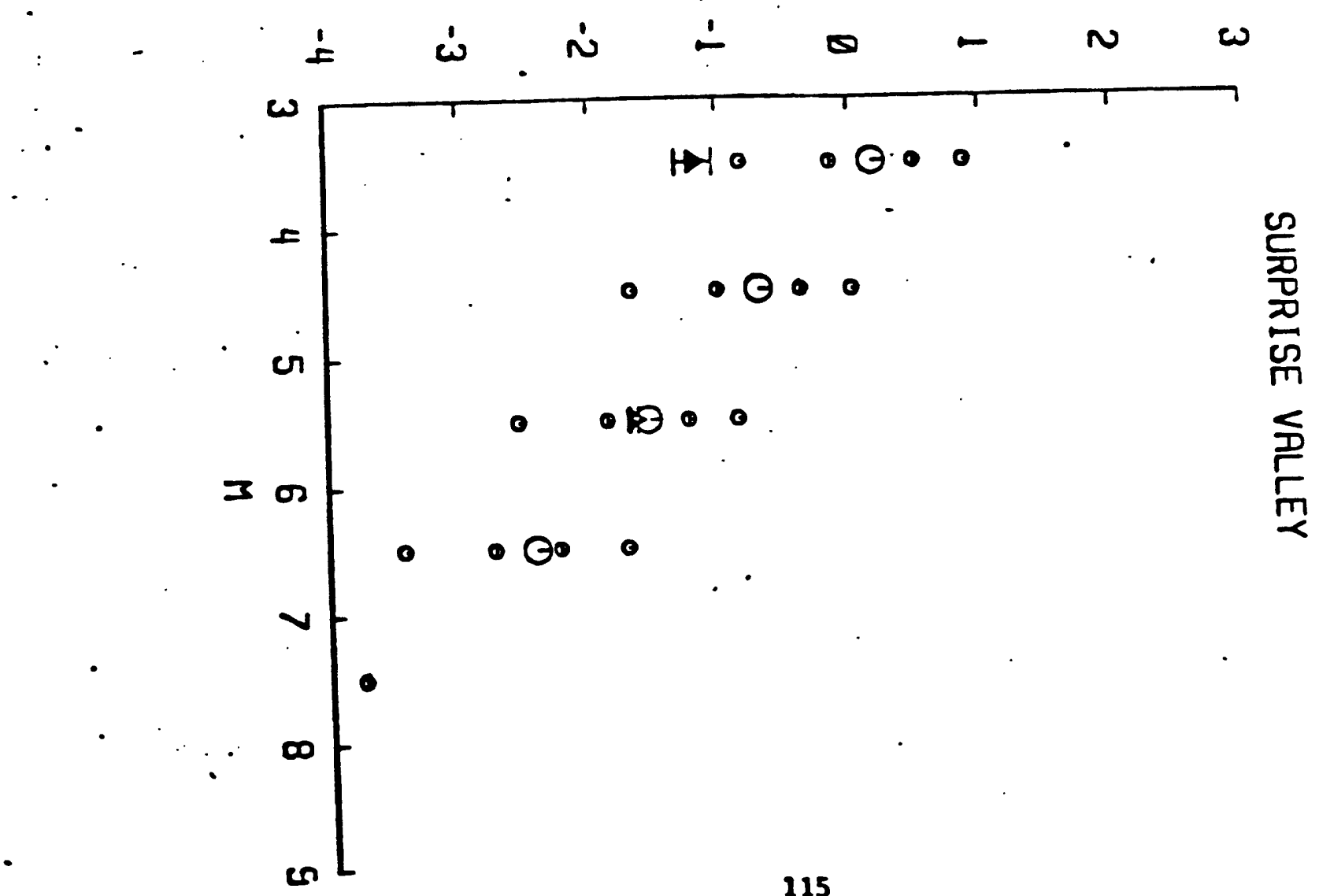


LOG (EVENTS/YEAR/MAG UNIT)

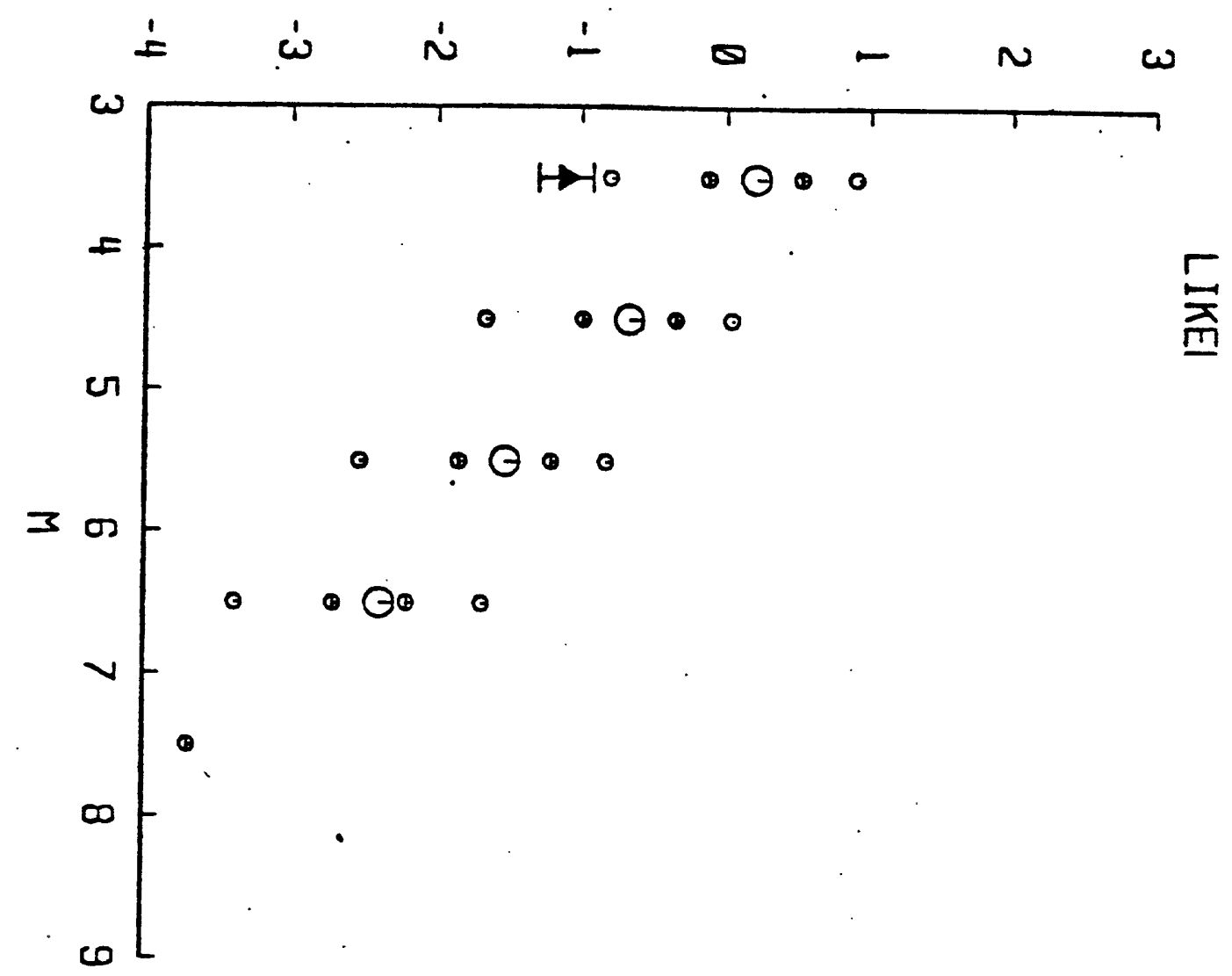

LOG (EVENTS/YERR/MAG UNIT)

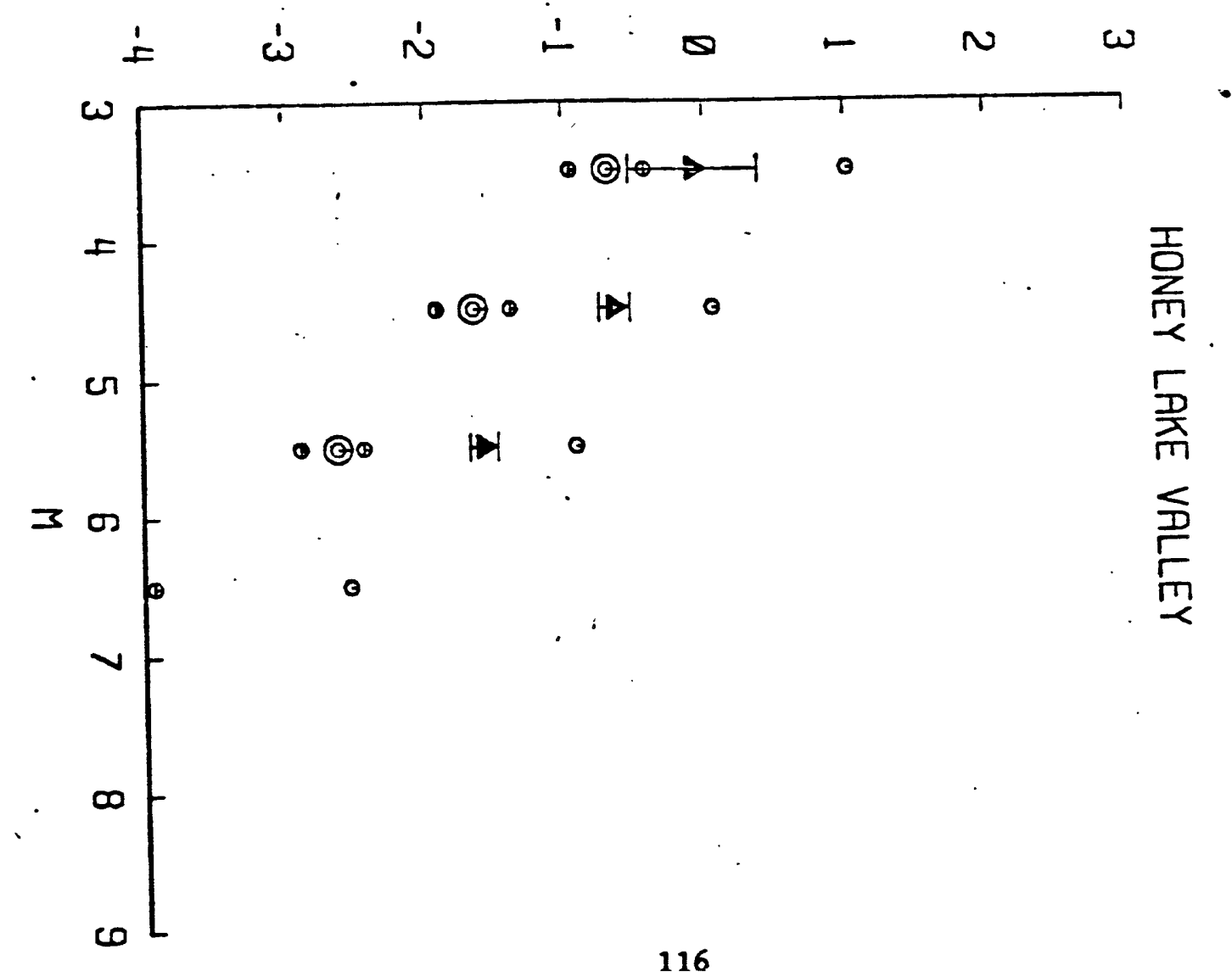




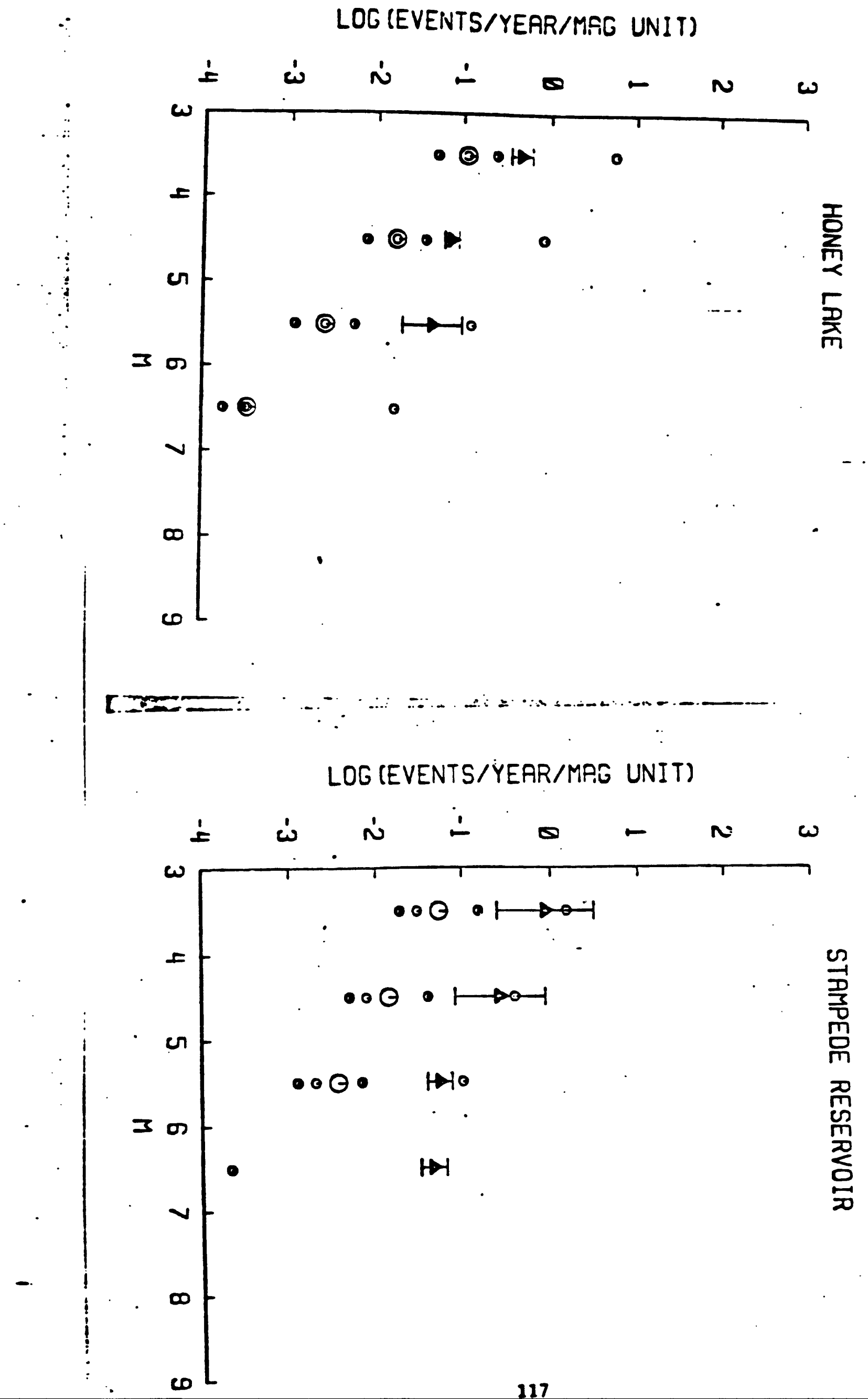


LOC LEVENTS/YERR/MTIL UNIT)
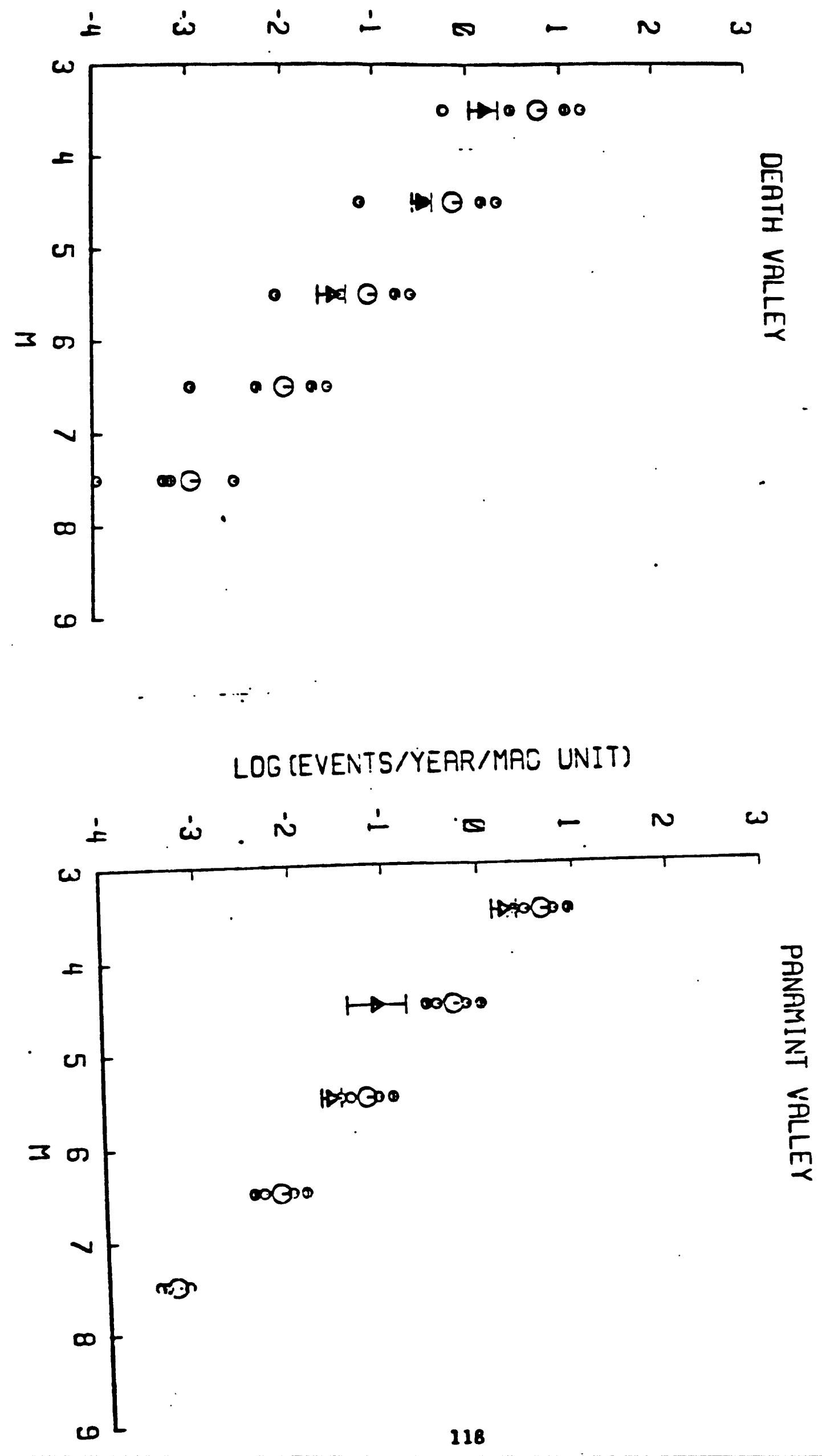


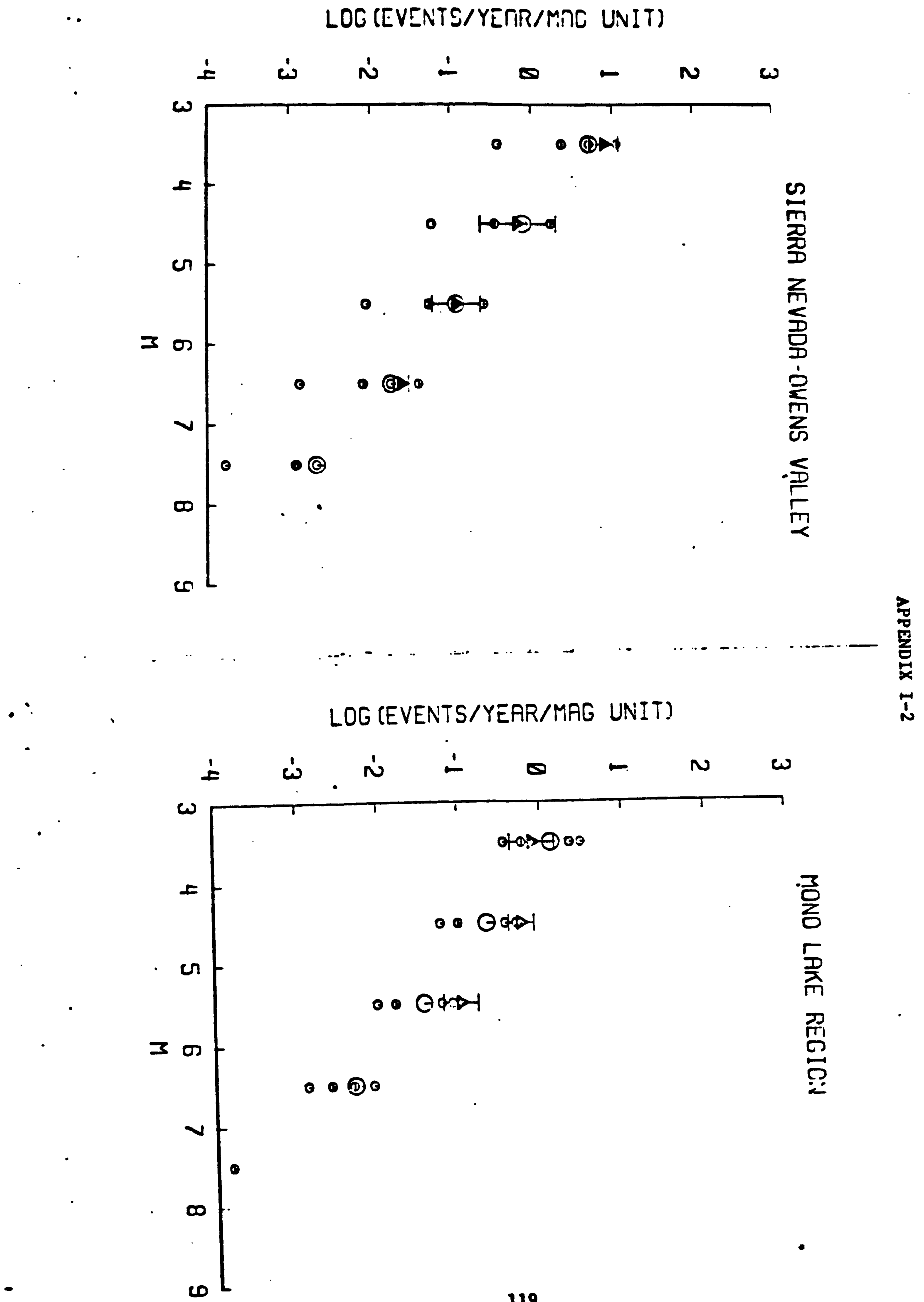



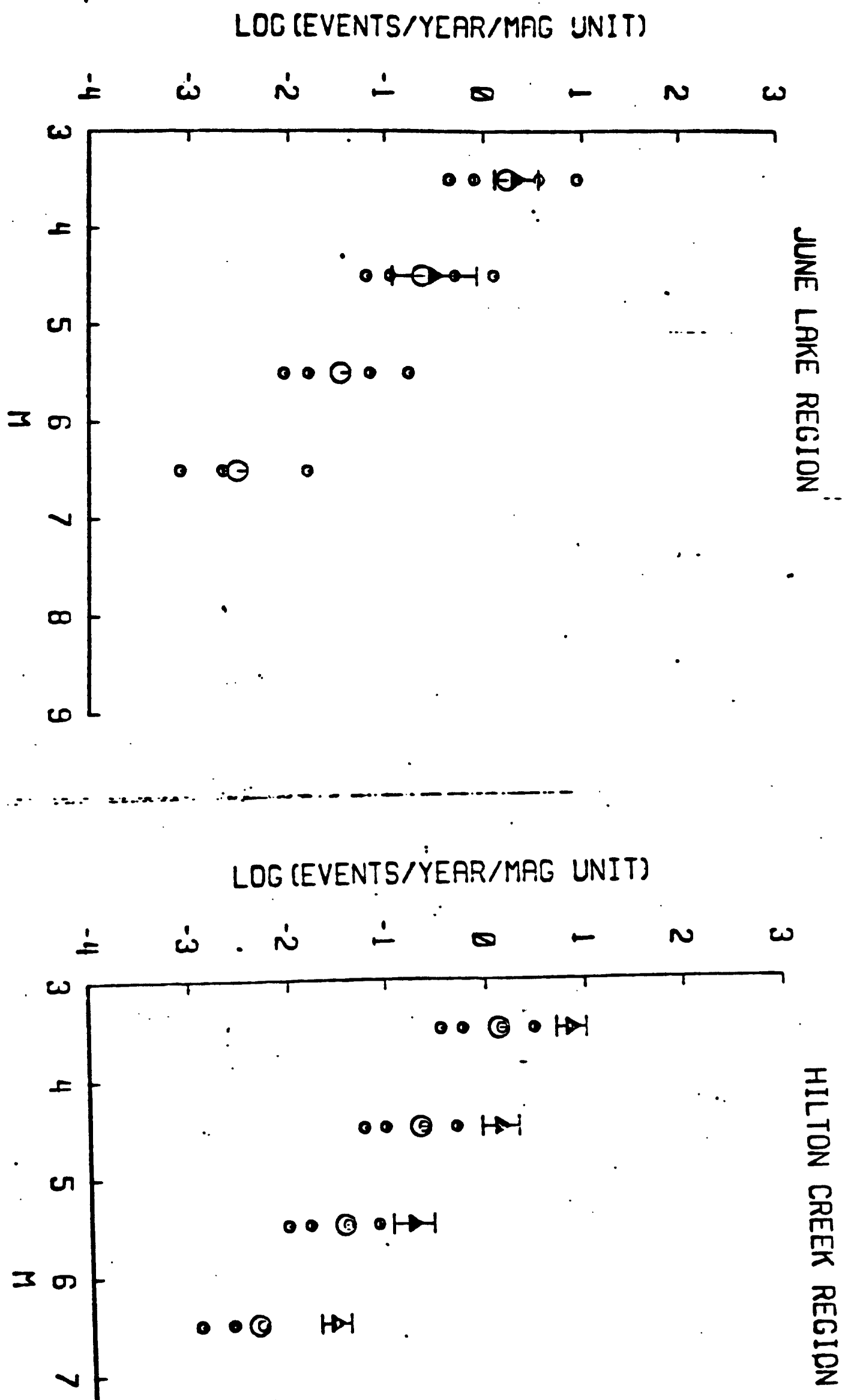
LOG (EVENTS/YEAR/MIE UNIT)
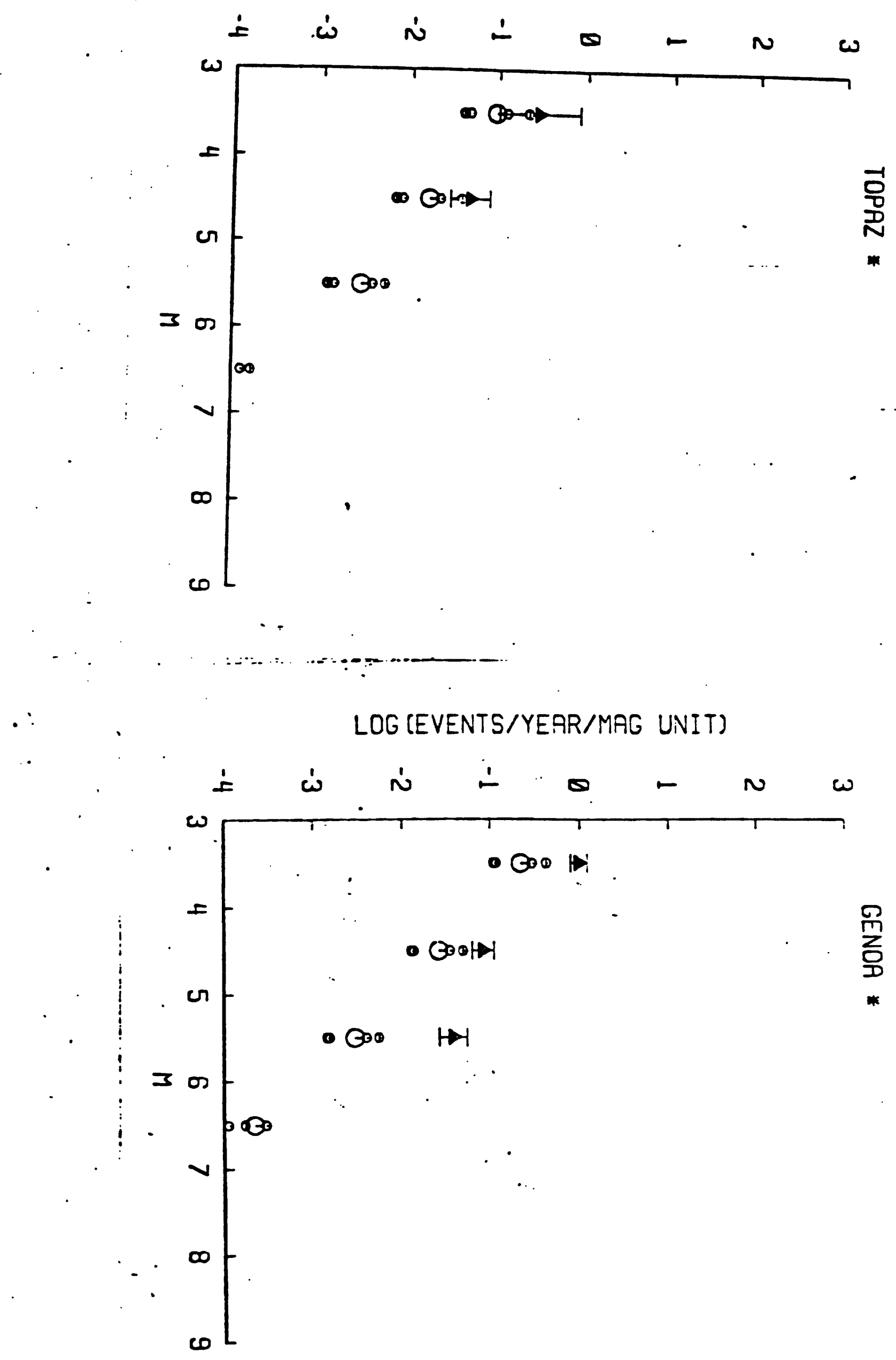

121 
LOG (EVENTS/YEAR/IIAG UNIT)
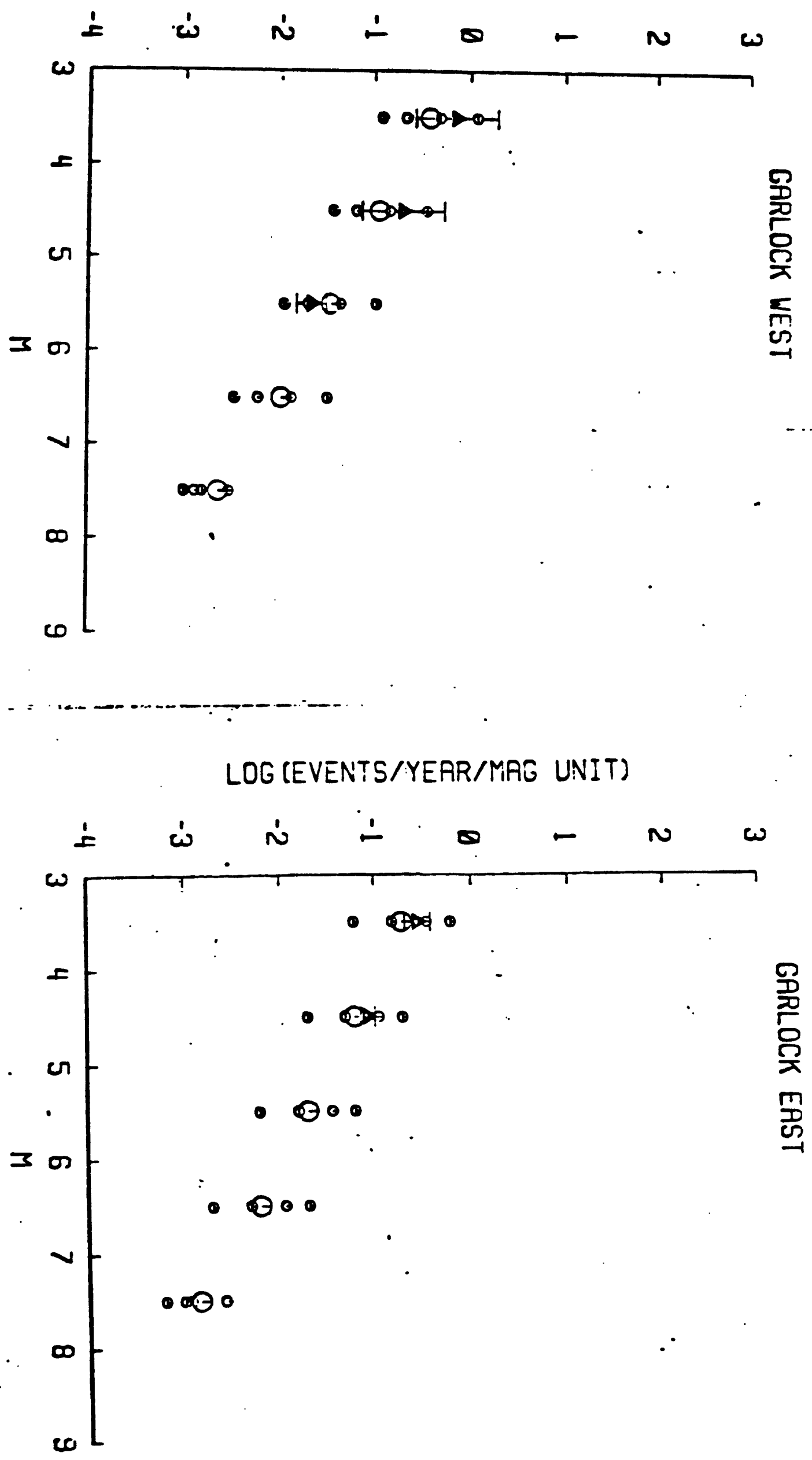
LOC (EVENTS/YEAR/MAG UNIT)

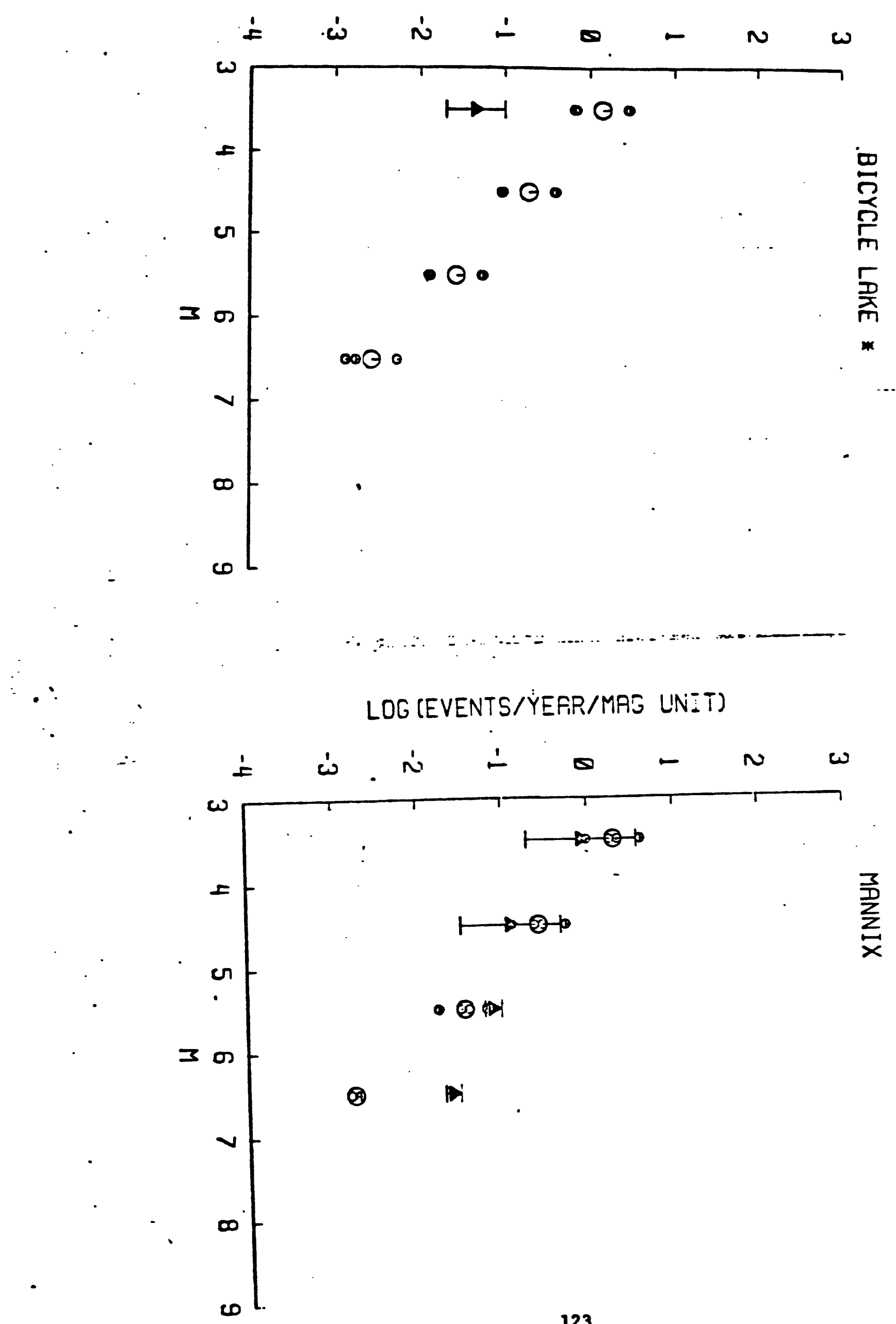


LOC (EVENTS/YEAR/MRE UNIT)
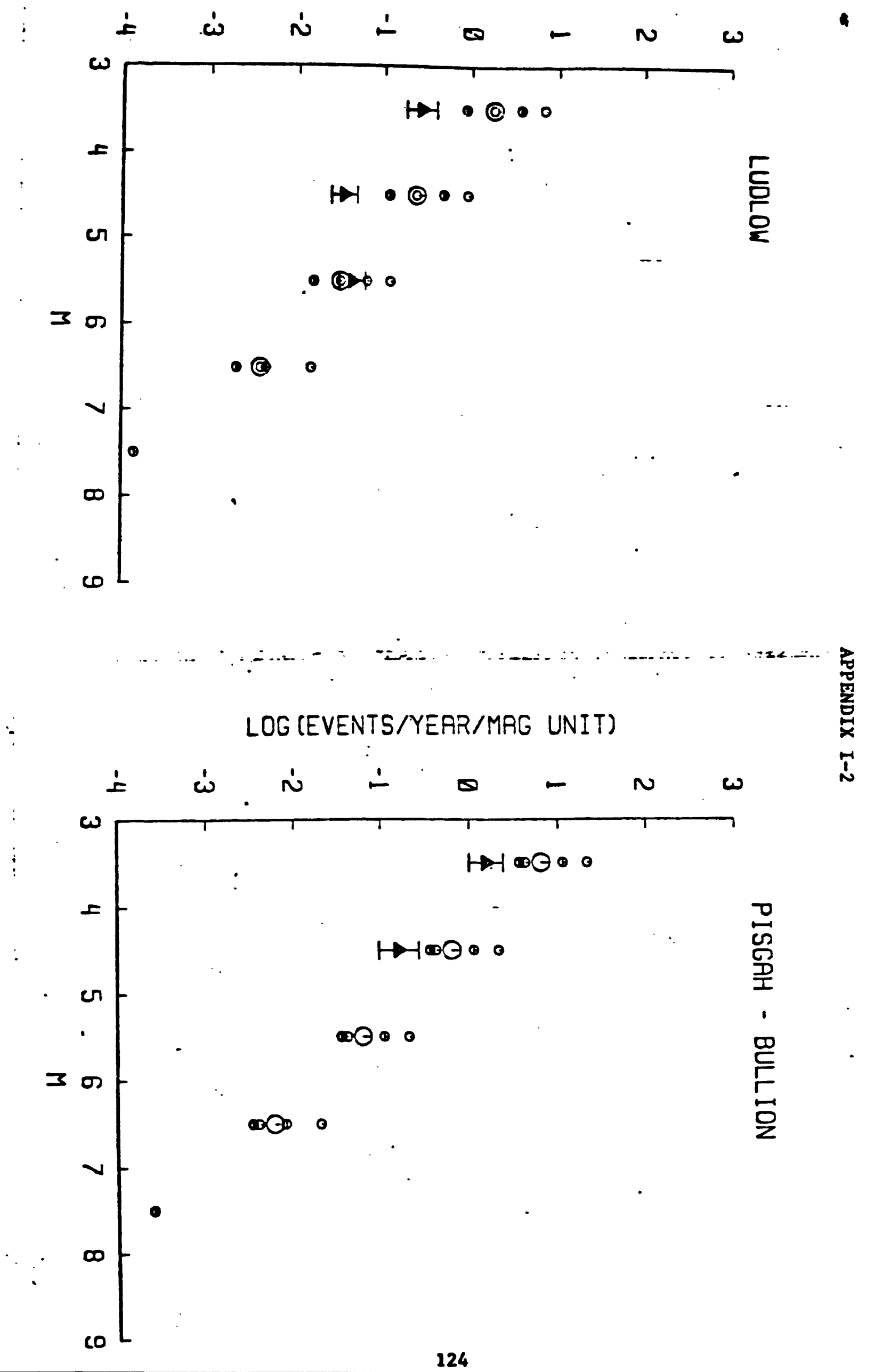
LOG (EVENTS/YEAR/MFGG UNIT)

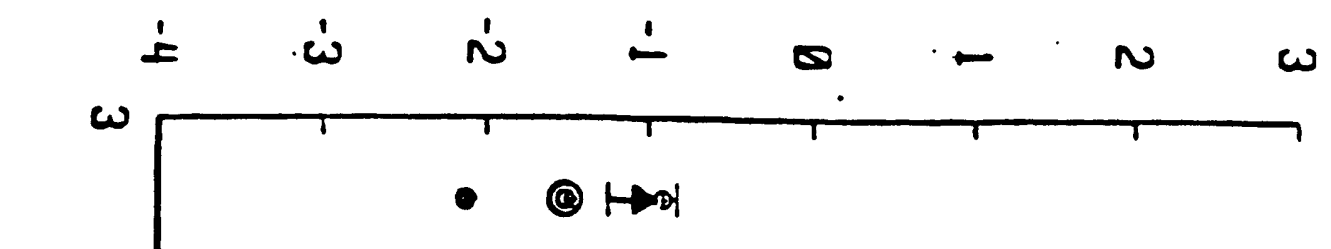

$\therefore$

LOG (EVENTS/YEAR/MPG UNIT)

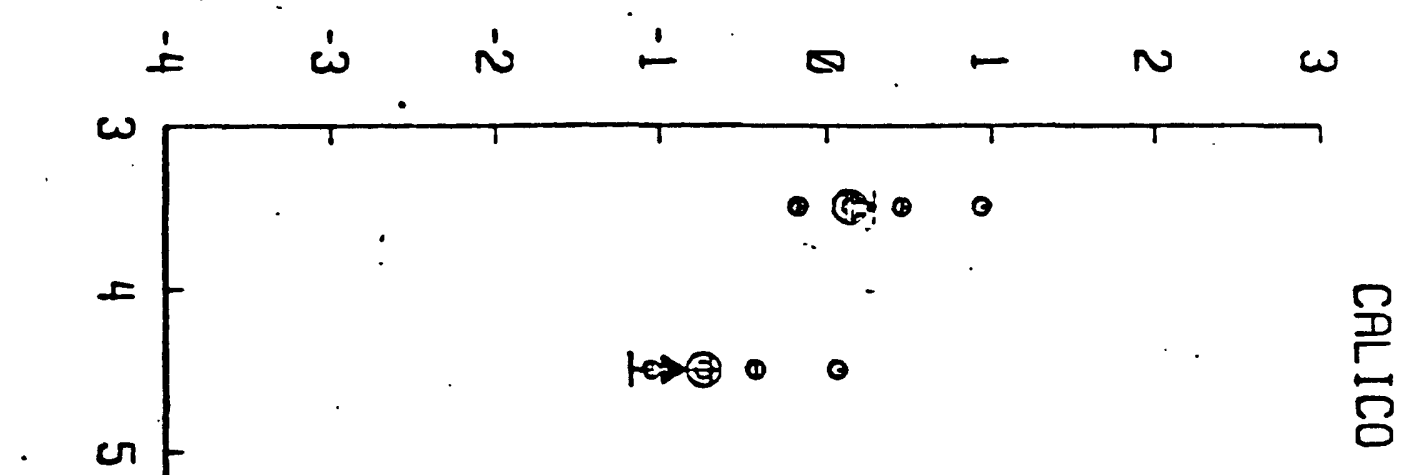

- ODAd 0

- (C) 0 
LOG (EVENTS/YENR/MRC UNIT)
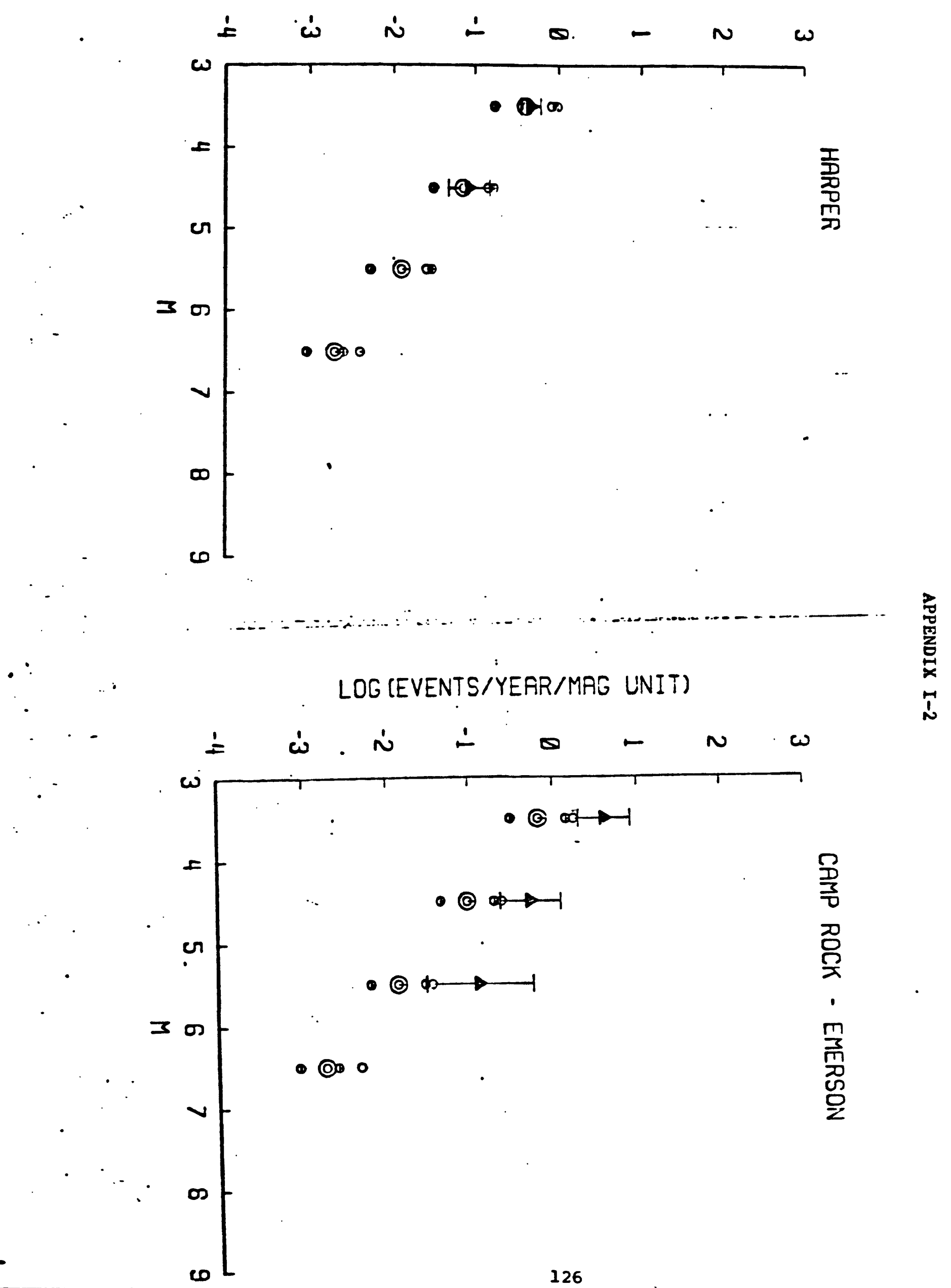
.

LOG (EVENTS/YEAR/MAR, UNIT)

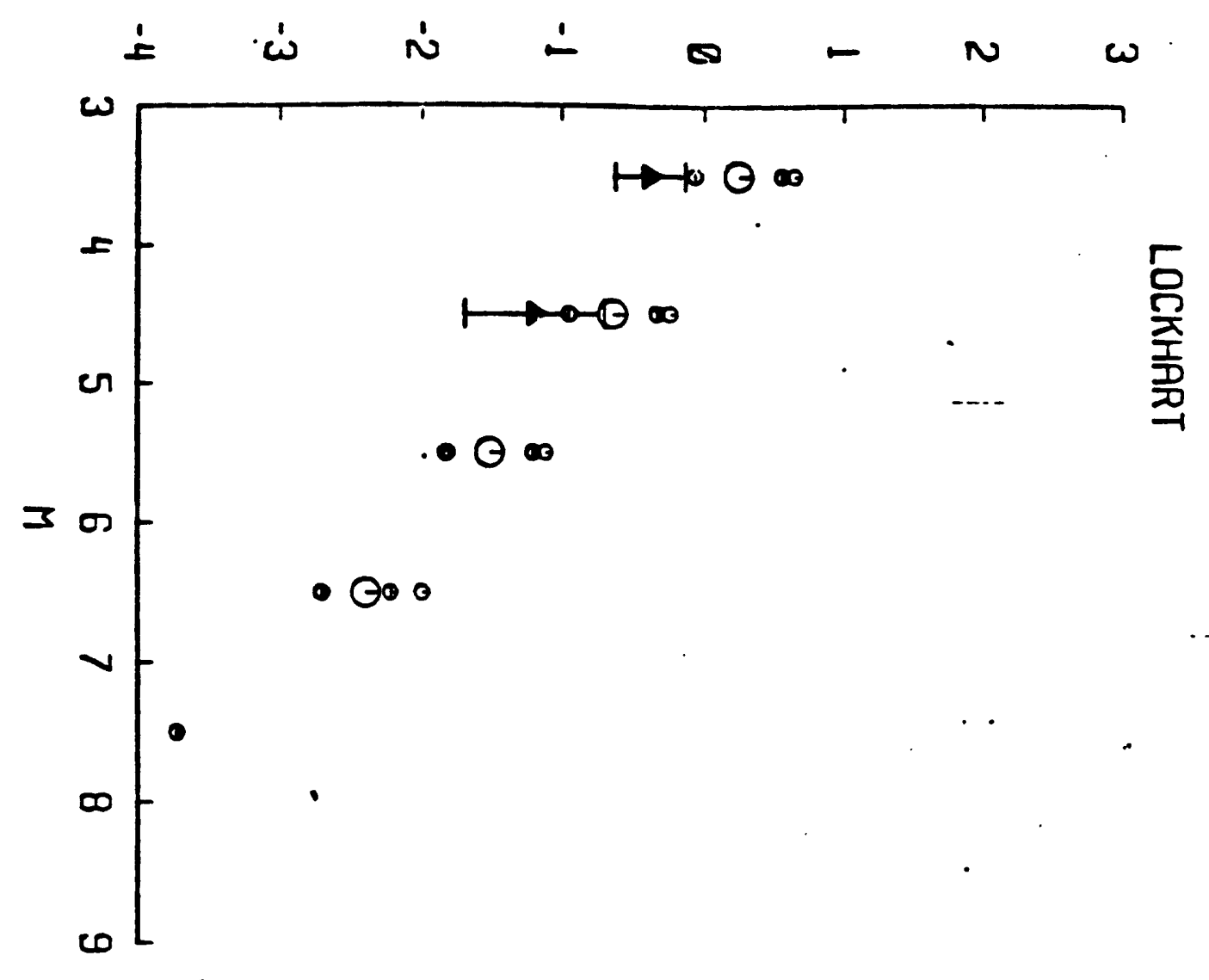

$\therefore \quad$ LOG (EVENTS/YEAR/MFG UNIT)

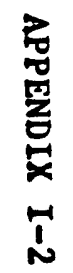

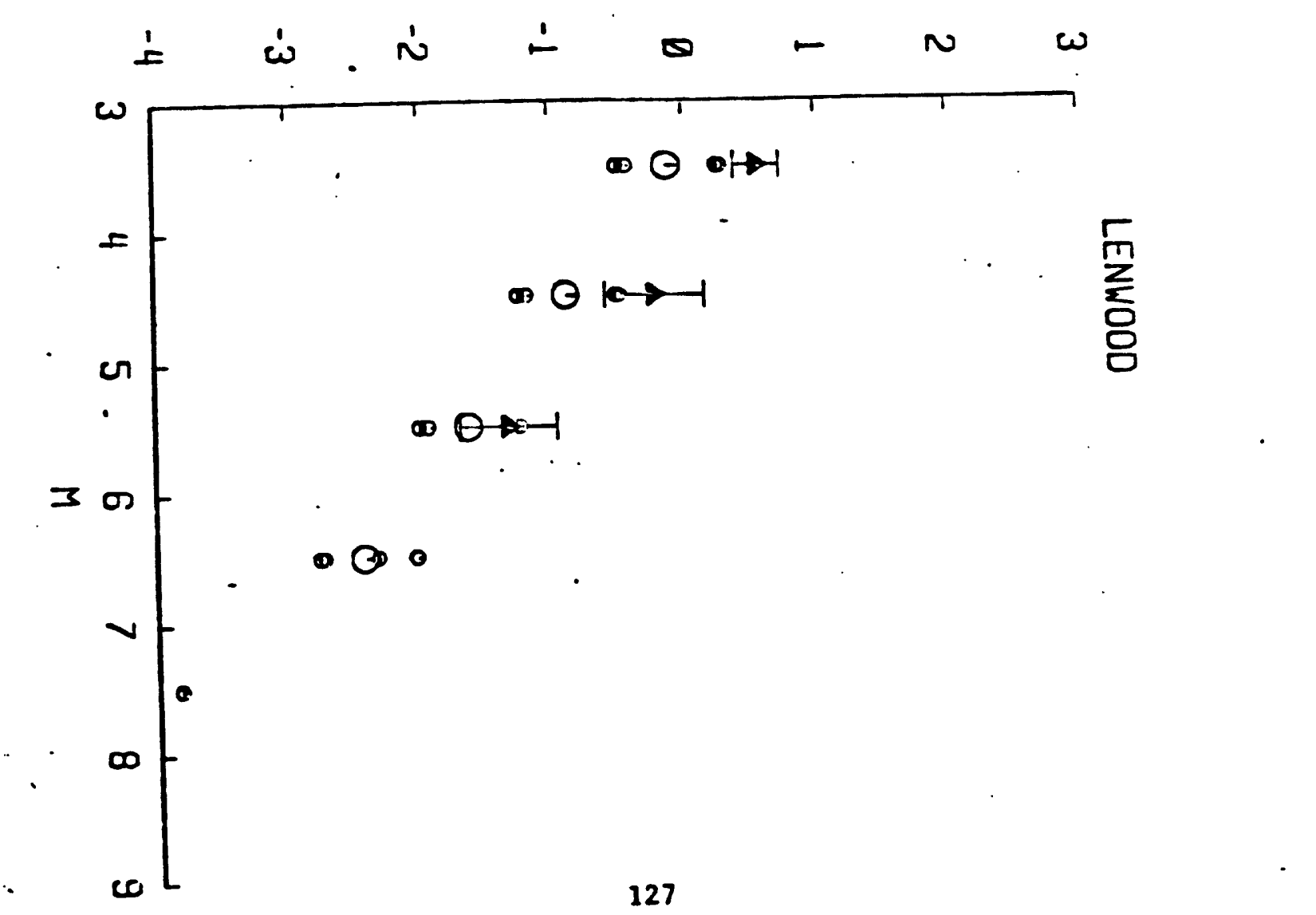


LCG (EVENTS/YEAR/MIG UNIT)
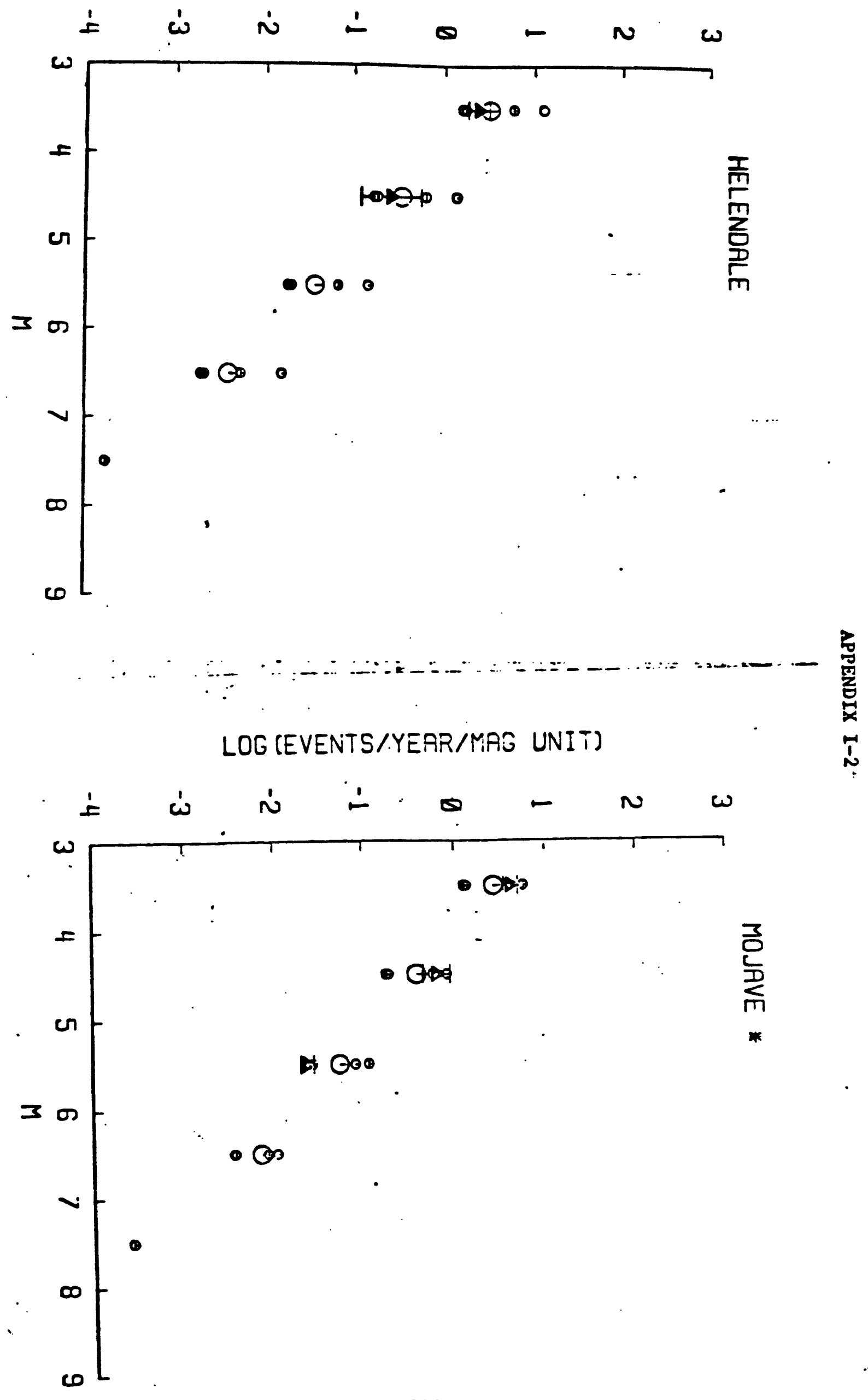

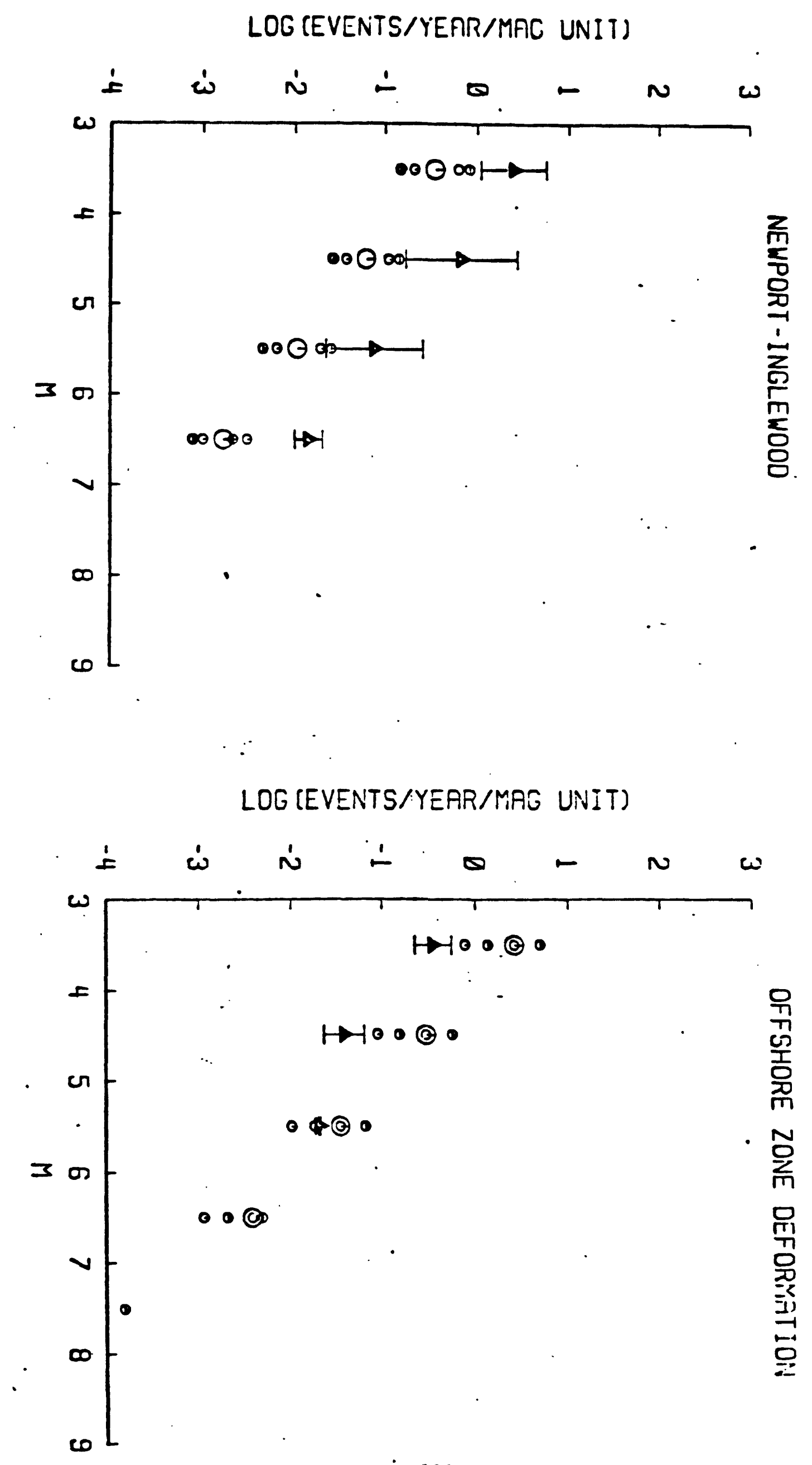
LOC (EVENTS/YEAR/MAS UNIT)
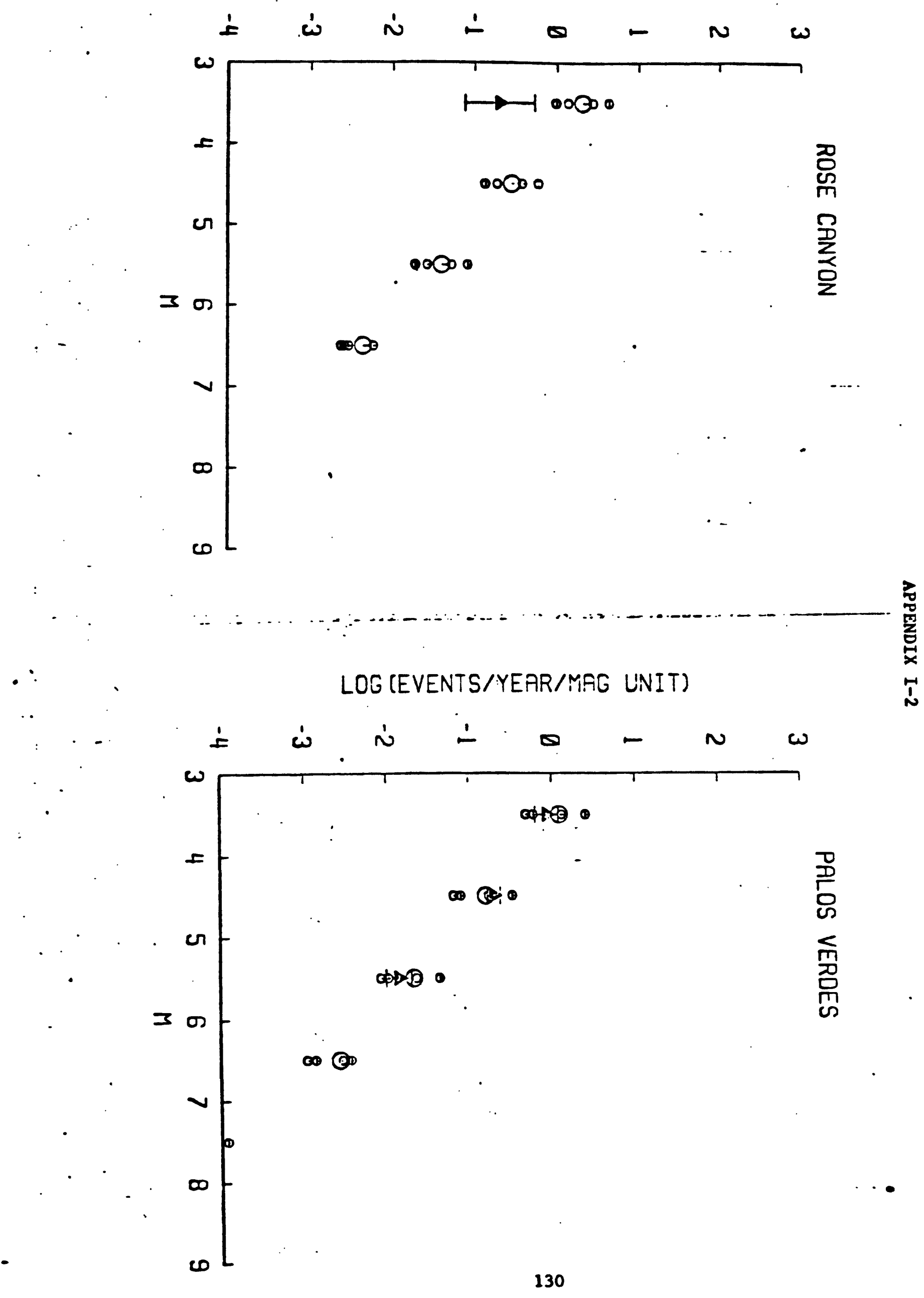
LOG (EVENTS/YEAR/MAC UNIT)
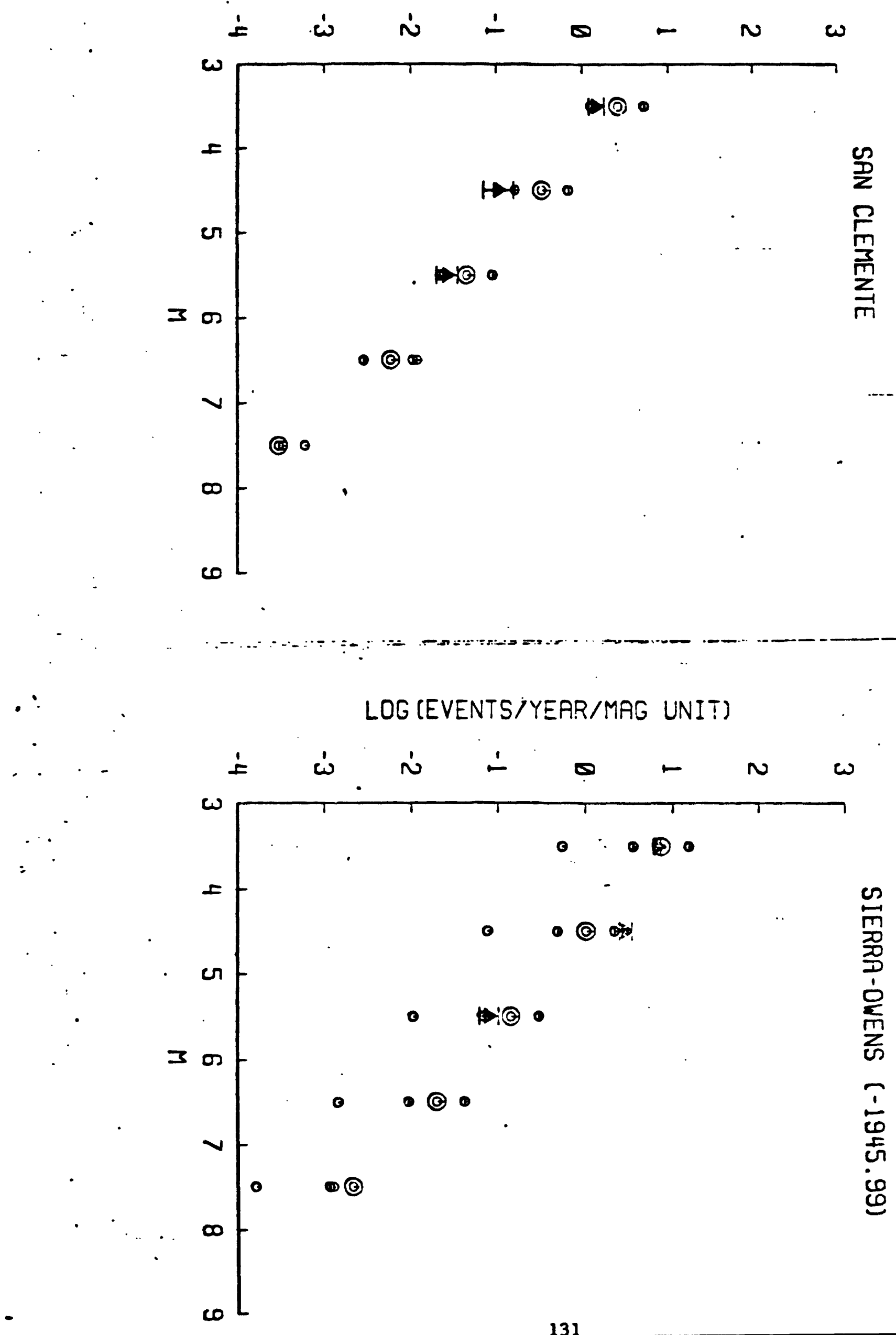
- $\quad$ LOG (EVENTS/YEAR/MAC UNIT)

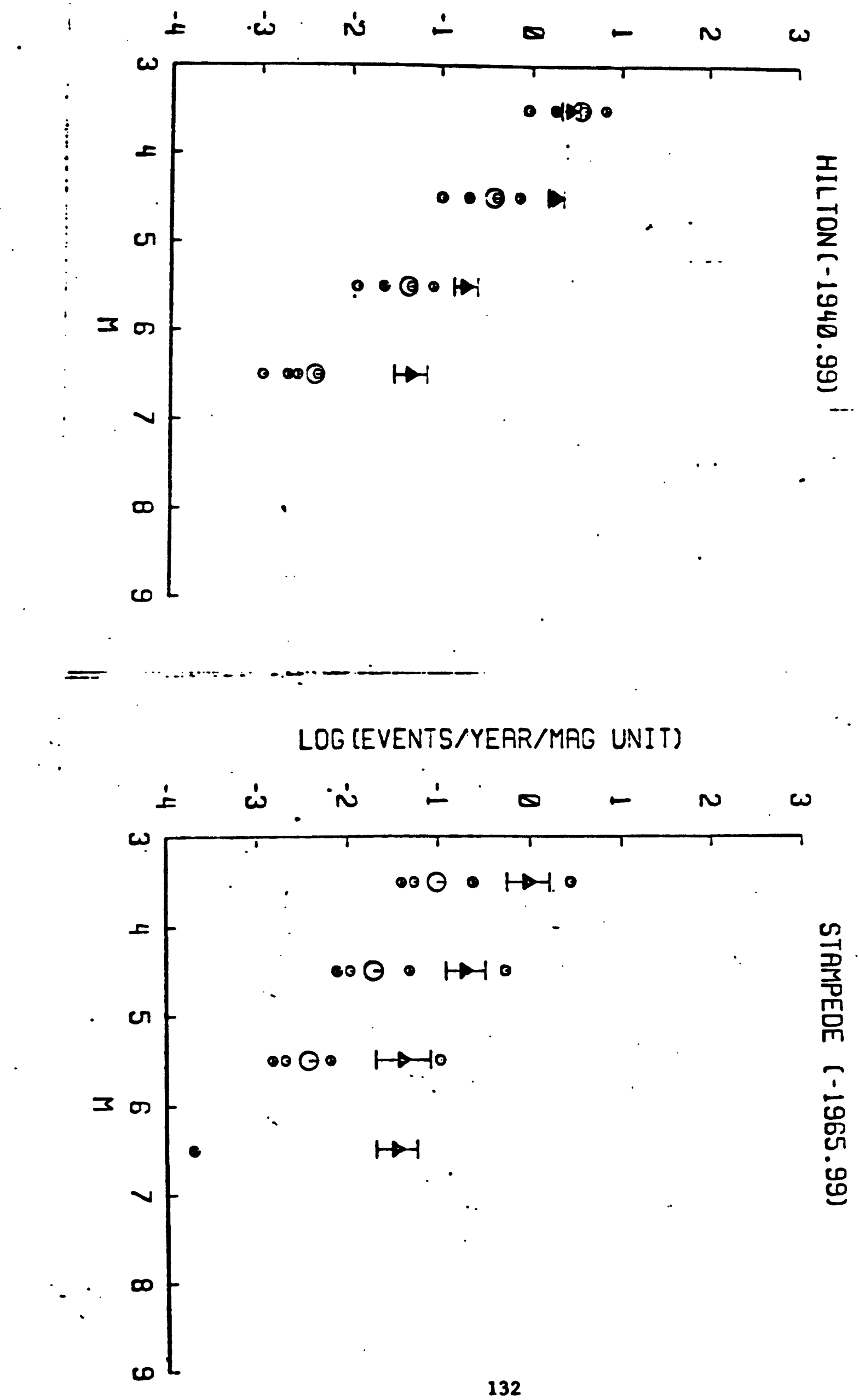




\section{LOG (EVENTS/YERR/MIIC LNIT)}
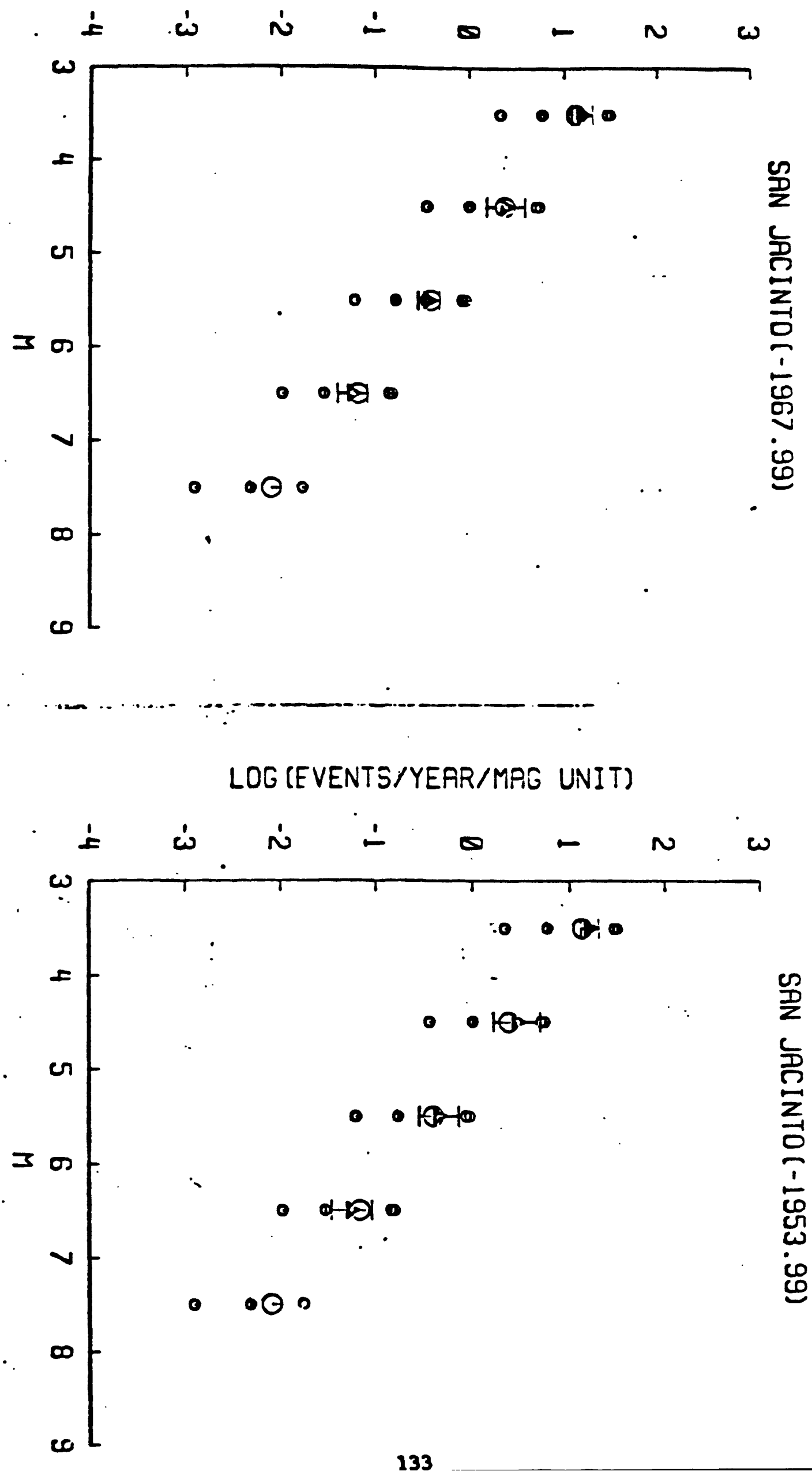
LOG (EVENTS/YEAR/MAC UNIT)
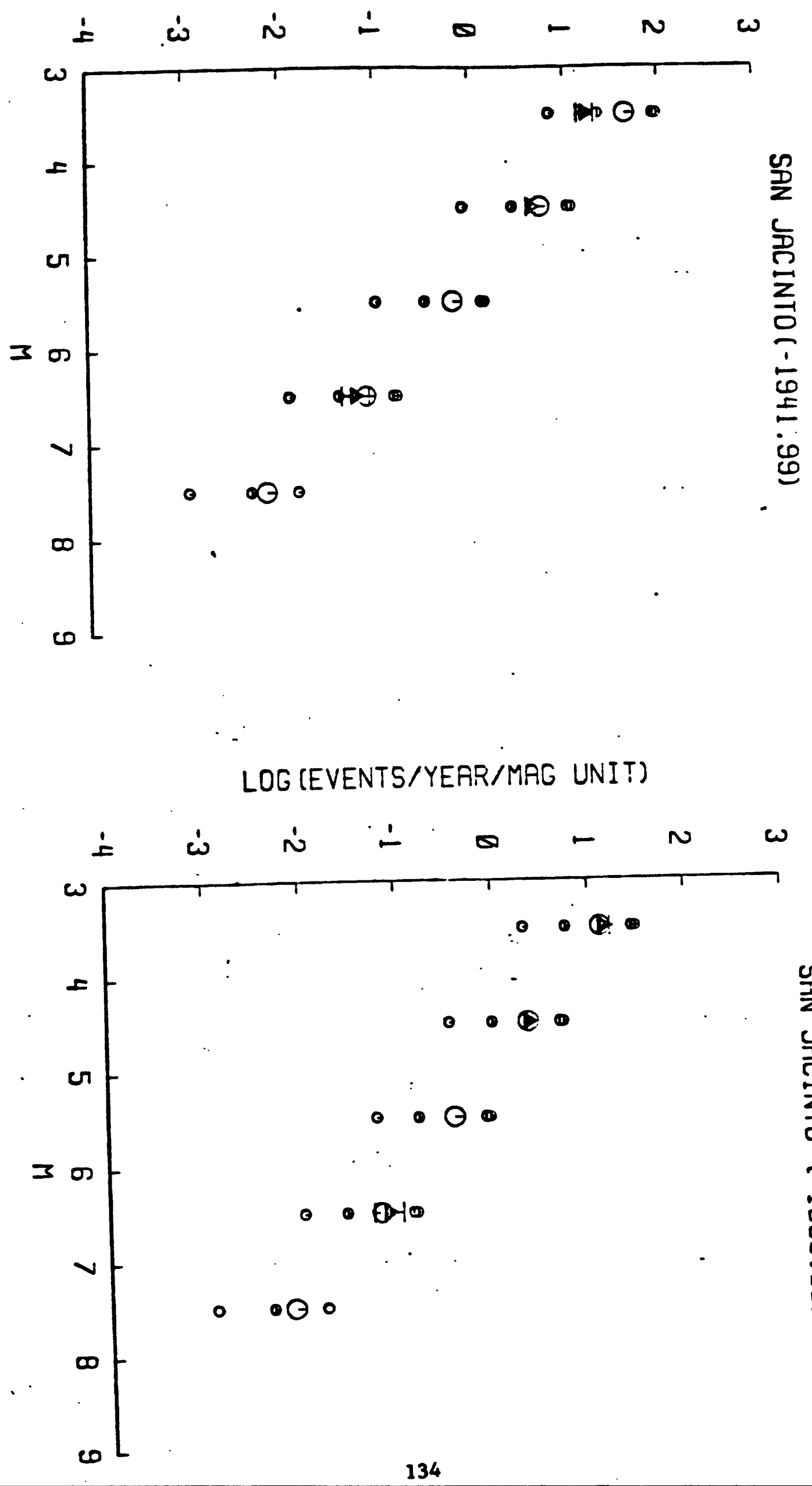

等

吾

1
$\omega$
0
0
0
0 

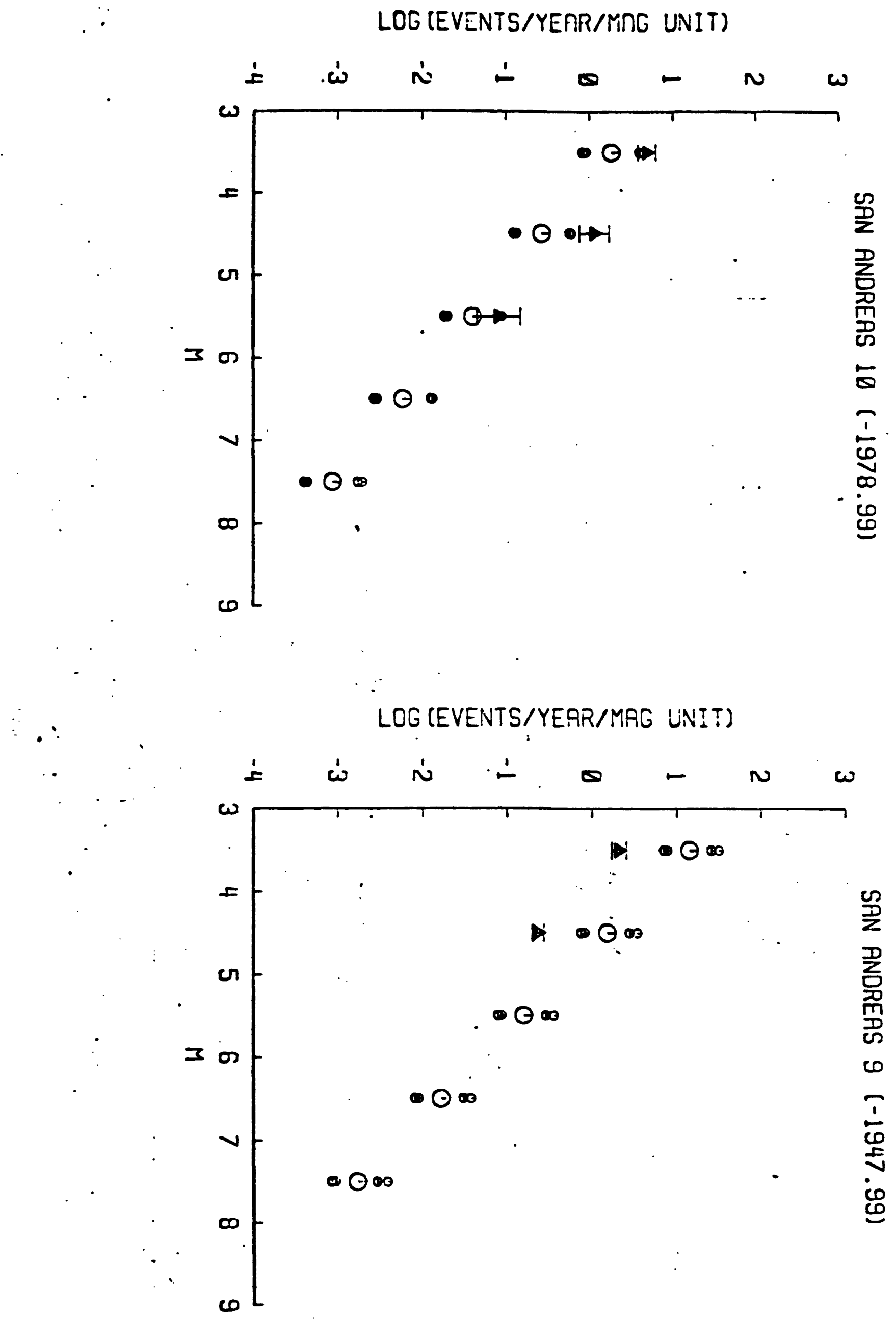

135 
LOG (EVENTS/YEAR/MRIC UNIT)
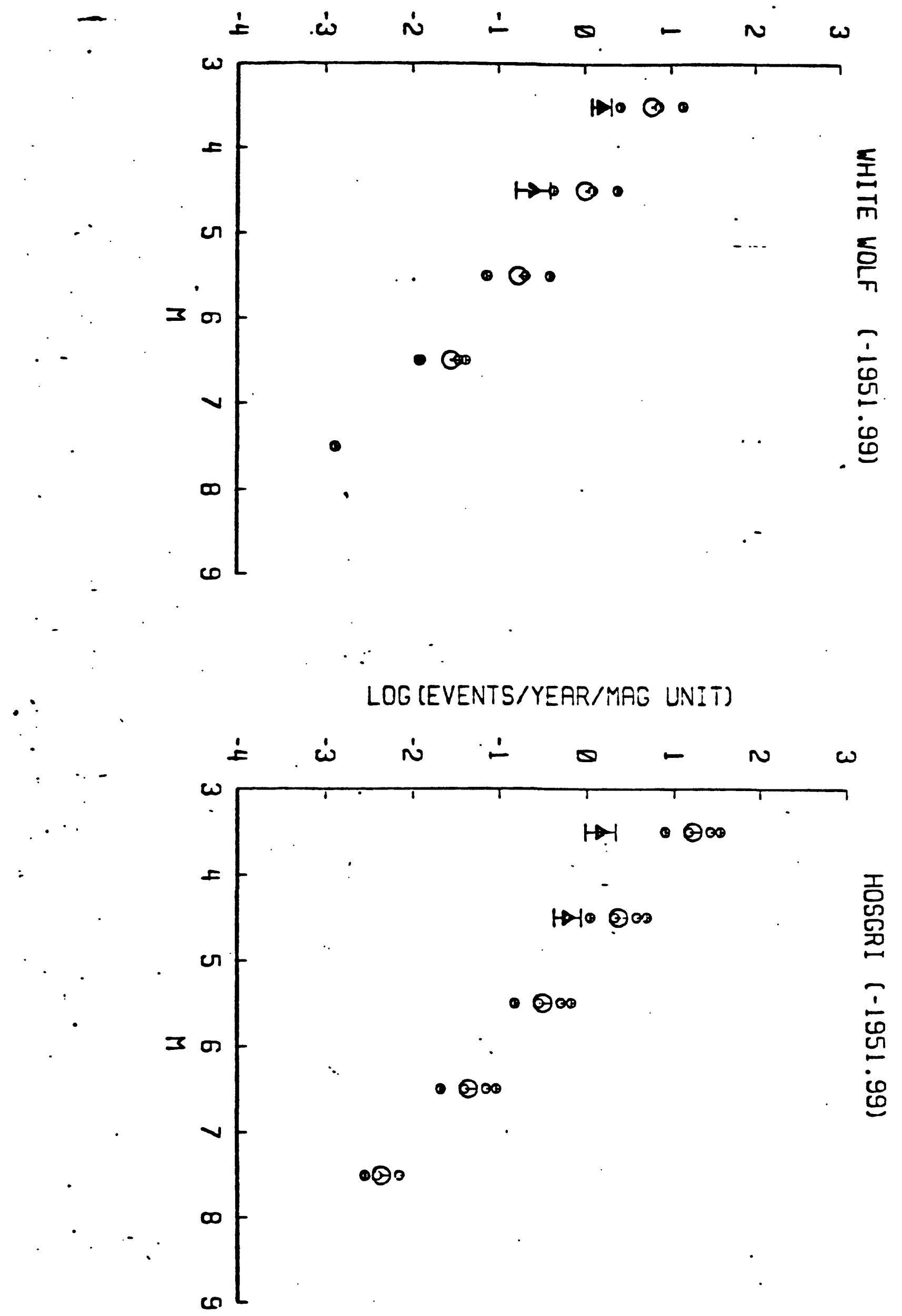
LOG (EVENTS/YEAR/MAG UNIT)

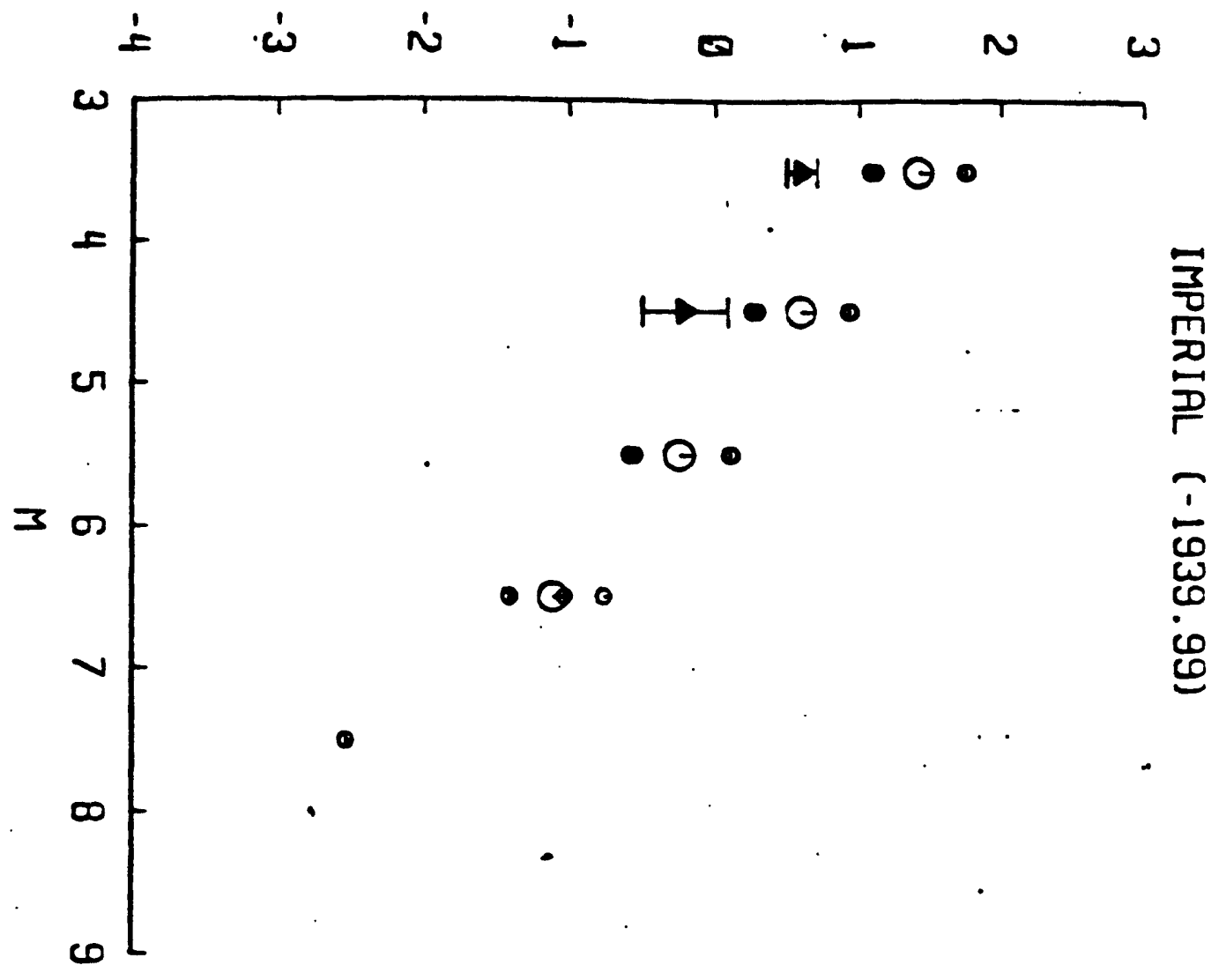

$\cdot$

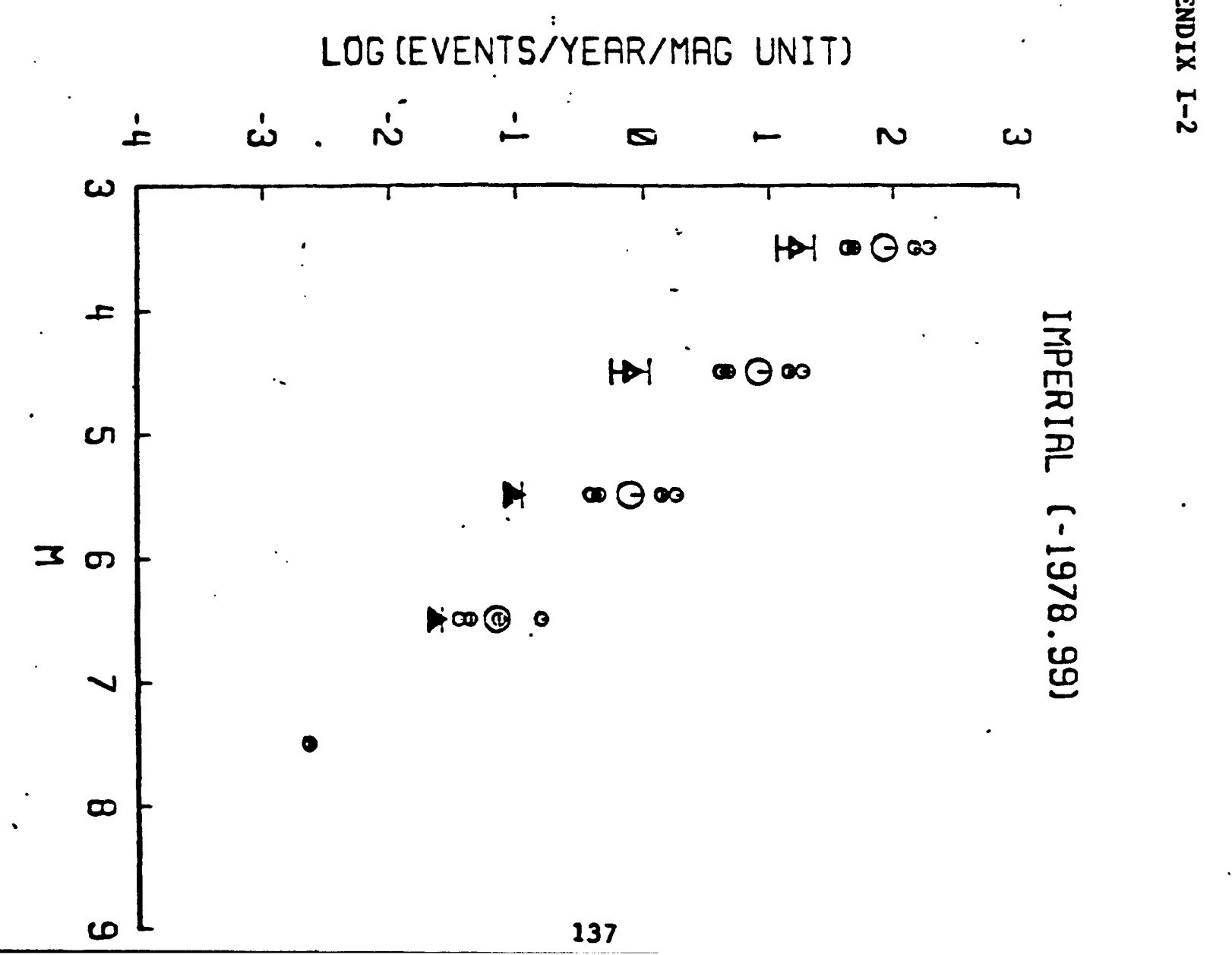



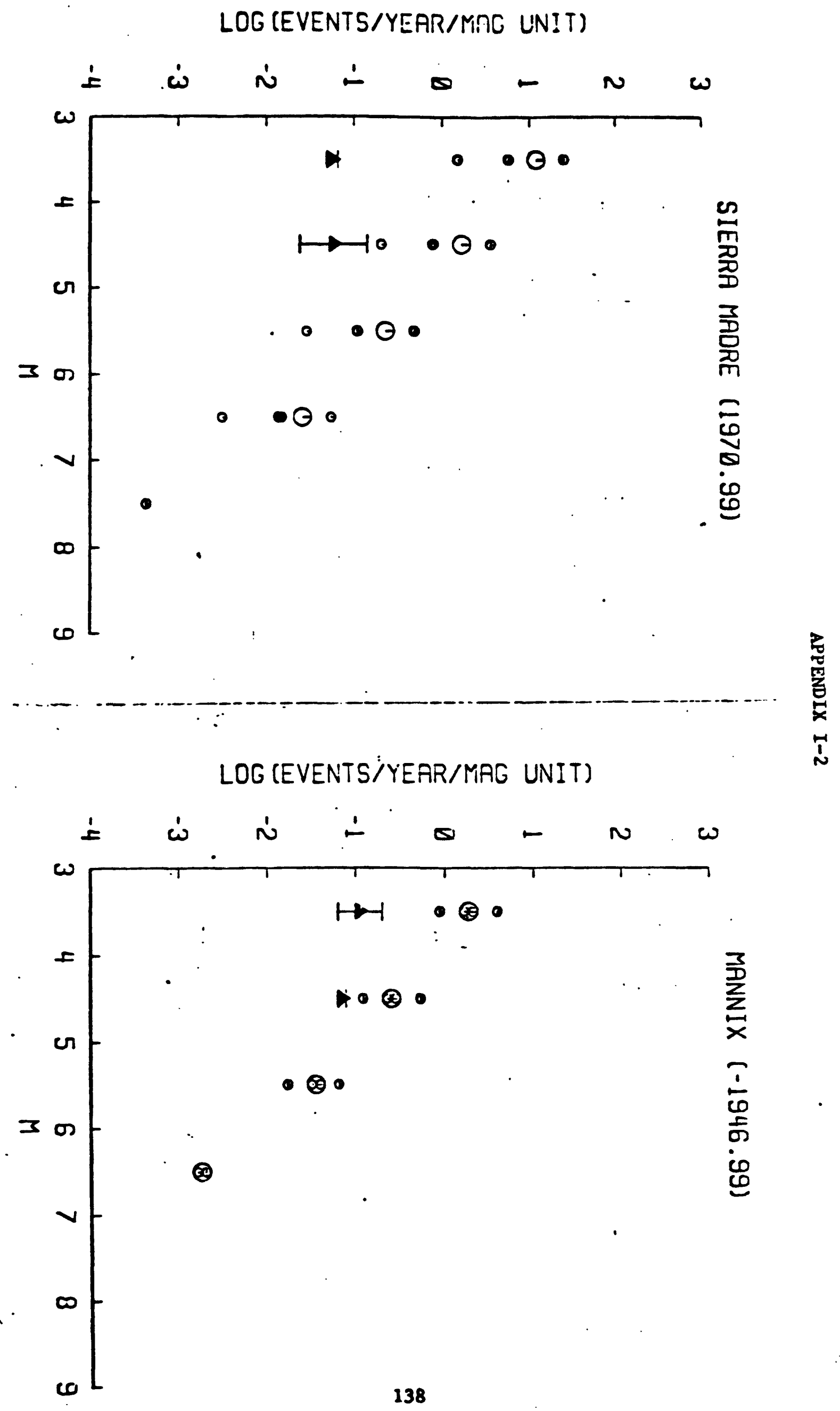


\title{
CONSEQUENCES OF SLIP RATE CONSTRAINTS ON EARTHQUAKE OCCURRENCE RELATIONS
}

\author{
by John G. Anderson and J. Enrique Luco
}

\begin{abstract}
Three functional forms for earthquake occurrence relations are compared, and slip rate constraints on each are derived. Constrained occurtence relations referted to total fault area, to rupture area of the maximum magnitude earthquake, and to a particular site along the fault are presented and discussed. The slip rate constraints provide a means to estimate $M_{\max }$ from occurrence rates of small magnitude earhquakes, or a means to esiimate the threshold of observations in a qualitative earthquake catalog, as well as a means to estimate occurrence rates when $M_{\max }$ is obtained from other considerations. This paper shows examples of these three types of applications.

The relations considered are: $N_{1}(M)$ is such that the cumulative occurrence rate of earthquakes with magnitude greater than $M$ is an exponential function truncated at $M_{\max }, N_{2}(M)$ is such that the cortesponding incremental occurrence rate is a truncated exponential function, and $N_{3}(M)$ is such that the corresponding incremental occurrence rate is an exponential function plus a constant which causes the rate 10 go to zero at $M_{\mathrm{max}}$. A speculative model for the magnitudes of the earthquakes at Pallett Creek observed by Sieh (1978a) suggests that $N_{2}(M)$ is more appropriate than $N_{1}(M)$ or $N_{3}(M)$ for these earhquakes.
\end{abstract}

Institure of Geophysias and Planeiany Physics University of California. San Diego. L Jo!la. CA 92093 UGA).

Depanment of Applied Mechanics and Engineering Sriences. University of Cajifomia, San Diego, L Jolls, CA 92093 (JGA and JEL).

Reprint submitted for publiation May 1982. Revised September 1982. 


\section{- APPENDIX II}

\section{INTRODUCTION}

Earthquake occurrence relations are used extensively in applications which require considerable accuracy, especially seismic risk analysis. It is increasingly common in seismic risk analyses to use geological slip rates or geological deformation rates to constrain the parameters of occurrence rate expressions. However, this has been done with little regard for the effect which the particular functional form of the occurrence rate relation might have on the outcome. Because earthquake occurrence rates are directly related to the rate of tectonic deformation, any of the several parametric forms which have been proposed to describe earthquake occurrence rates can be constrained to be consistent with known deformation rates. In this paper the emphasis is on occurrence relations as constrained by a slip rate on - fault. Anderson (1979), Molnar (1979), and Papastamatiou (1980) have shown how the slip rate can be easily replaced by a regional strain rate when appropriate.

The implications of the slip-rate constraint on occurrence relations have been recognized by several previous studies. Brune (1968) and Davies and Brune (1971) used the cumulative moment of events on a fault to estimate the slip rate. Smith (1976) used the cumulative moment, from geological studies, to try to constrain the maximum magnitude on a fault. Anderson (1979), Molnar (1979), and Campbell (1977) developed methods to obtain occurrence relations from slip rates. Greensfelder et al. (1980) and Doser and Smith (1982) have estimated long-term seismicity of various regions by this method. Papastamatiou (1980) used the slip rate and observed low-magnitude occurtence rates to estimate the maximum magnitude. In this paper the basic equations required for the above applications are derived for each of three functional forms for the occurrence rate relation. We also present an additional application, in which an occurrence rate derived from pre-instrumental sources may be used to estimate the magnitude threshold of the observations.

In the past, slip rate constraints on occurrence relations for individual faults have been derived on the assumption of a given fault length and width. For our purposes, two additional normalizations are convenient and lead to interesting results. As one afternative normalization the occurrence relation is taken to give the number of events over an area of the fault equal to that which ruptures in the 
maximum earthquake $M_{\max }$. The other diernative normalization gives the number of earthquakes which rupture the fault at specific site dong its surface trace. This altemative applies to the risk of direct faulting beneath a site and helps to interpret Beological observations of repeated earthquakes as observed in a single trench. Results for this normalization are most easily derived from results for the first altemative. Both of these alternatives require the use of a relation between the extent of rupture and magnitude. 


\section{EARTHQUAKE OCCURRENCE RELATIONS}

Compbell (1977), Anderson (1979). Molnar (1979), and Papasiamatiou (1980) have all demonstrated how the parameters of earhquake occurrence relations can be selected so that the seismicity is consistent with the known crustal deformation rates. However, the selection of the particular functional form of the occurrence relation from the many which are proposed in the literature has not received scrutiny. The purpose of this section is to discuss briefly the range of proposed forms and their significance to the extension of this method. We limit the discussions to three-parameter functional forms characterized by the rate of occursence at a magnitude of reference, a b-value, and a maximum magnitude $M_{\max }$. Because the assumed distribution of large earthquakes is critical, only the shape of occurrence-sate curves near $M_{\max }$ is considered.

Richter (1958) points out that the frequency of earhquake occurrence within a region, as a function of magnitude, car be written as either a cumulative distribution function, $N(M)$, giving the number of shocks with magnitude $M$ or ereater per unit time, or as a density function $n(M)$, where

$$
n(M)=-\frac{d N(M)}{d M}
$$

This density function is closely related to an incremental occurrence rate $n^{\prime}(M)=N\left(M-\frac{\Delta M}{2}\right)-N\left(M+\frac{\Delta M}{2}\right)$ for earhquakes in a magnitude band of width $1 M^{\prime}$ which for sufficiently small $\Delta M^{\prime}$ can be written in the form $n^{\prime}(M)=n(M) \Delta M^{\prime}$ (e.g. Herrman, 1977 ). Gutenberg and Richter (1954) plotted the worldwide data set, and found that while it approximately obeys the rule $\log n^{\prime}(M)=a-b M$, there is a shortage of earthquakes relative to this rule for $M \geqslant 8$. Bioom and Erdmann (J980) seconfirm this observation. Both of these studies employ magnitude scales which correspond essentially to surface wave magnitude $M_{s}$. Several functional shapes might be used to approximate these observations (e.8. Main and Burion, 1981; Esteva, 1976; Makjanic, 1980. Caputo. 1977). For mathematical simplicity, we use the function

$$
n_{3}(M)=\left(10^{0_{3}-\Delta M^{\circ}}-10^{0_{3}-O M_{\max }}\right) H\left(M_{\max }-M\right)
$$




\section{APPENDIX II}

which is a specific case of a form proposed by Main and Burton (1981). In (2), $H(\cdot)$ denotes the Heaviside step function and $M_{\max }$ is the maximum magnitude.

It could be argued that the relative 'shorage' of earthquakes with $M_{3} \geq 8$ is due to saturation of $M_{3}$ for large events. The theoretical bases for the eventual saturation of the surface wave magnitude scale are generally accepted (Aki, 1967, 1972; Kenamori and Anderson, 1975; Geller, 1976; Kanamori. 1977; Hanks and Kanamori, 1979). Due to the relative scarcity of data for large events, the precise Dature of the saturation is not well determined. In particular, Bloom and Erdmann (1980) based on a statistical analysis of events with $M_{s} \geqslant 8.0$ have concluded that, on the average, no saturation of $M_{\text {s }}$ with respeat to $M_{w}$ (moment magnitude) is observed. On the other hand, the only four events in Kanamori's (1977) compilation with $M_{w} \geqslant 9.0$ have $M_{s} \leqslant 8.4$. It should be mentioned that Chinnery and North (1975) have corrected the world-wide cumulative occurrence rate for a plausible estimate of the effects of saturation and have found a linear relation between $\log N\left(M_{6}\right)$ and $\log M_{0}$ where $M_{0}$ is the seismic moment. This implies a linear relation between $\log N\left(M_{n}\right)$ and $M_{n}$ which differs from the cumulative occurtence rate implied by Eq. (2). Given the uncertainties involved in describing the saturation we do not rule out the possibility that occurrence rates may be described by Eq. (2) and consider this faricular form as one possible alternative.

A second altemative is 10 employ the relationship

$$
n_{2}(M)=10^{\circ}-0 M \quad H\left(M_{\max }-M\right)
$$

which has been used by Bath (1978) and Anderson (1979). Berrill and Dovis (1980) have argued that this form works well at large magnitudes. The alculation of the cumulative oscumence rates from $n_{2}(M)$ and $n_{3}(M)$ is based on the implicit assumption that $N_{3}\left(M_{\max }\right)=N_{2}\left(M_{\max }\right)=0$.

A third possibility is to consider the cumulative occurrence rate suggested by the work of ChinDery and North (1975), namely

$$
N_{1}(M)=10^{\circ}-M \quad H\left(M_{\max }-M\right)
$$

Smith (1976), Campbell (1977) and Molnar (1979) have used this form in conjunction with slip rate 


\section{APPENDIX II}

constraints on occurrence relations. This form, which also seems to be widely used in probabilistic seismic risk studies (e.8. Housner, 1969, McGuire, 1974, Campbell, 1977), is even more enriched in large magnitude earthquakes than the recurrence relation defined by Eq (3). Papasiomatiou (1980) dis. cussed both forms $n_{2}(M)$ and $N_{1}(M)$, but his constraint on the occurrence relation parameters (Eq. (18) in his paper) is derived only for $N_{1}(M)$.

The occurrence relations defined by Egs. (2), (3), and (4) can be summarized by the expression

$$
N_{1}(M)-A_{1}\left[\left(e^{\bar{b}} M-1\right]+B_{1} \bar{b} \Delta M+C_{1}\right] H(\Delta M)
$$

where $\Delta M=M_{\max }-M$. In Eq. (5) and in the sequel we use the notation $\bar{p}-p$ in 10. From Eqs. (1) and (5) one obtains

$$
n_{1}(M)=A_{i}\left[\bar{b} e^{\bar{S} \Delta M} H(\Delta M)+B_{i} \bar{b} H(\Delta M)+C_{i} \delta(\Delta M)\right]
$$

where $\delta(\cdot)$ is the Dirac delta function. The distribution functions defined in Egs. (4), (3), and (2) are obtained from (5) or (6) by setting

$$
\begin{array}{lll}
i=1, & B_{1}=0, & C_{1}=1 ; \\
i=2, & B_{2}=0, & C_{2}=0 ; \text { and } \\
i=3, & B_{3}=-1, & C_{3}=0, \text { respectively. }
\end{array}
$$

The coefficient $A_{1}$ corresponds to $10^{a-b M_{\max }}$ in Eq. (4); $A_{2}$ and $A_{3}$ correspond to $\frac{1}{\bar{b}} 10^{a-b M_{\text {mex }}}$ in Eqs.

(2) and (3). W'e note that Smith (1976), Compbell (1977), and Popostamotiou (1980) fail to include the term in $\delta\left(M_{\max }-M\right)$ when they differentiate Eq. (4). This error is carried throughout each of their analyses.

The three functional forms defined above are illustrated in Fig. 1 for the case $N_{1}(6)=N_{2}(6)-N_{3}(6)-1.0, b=1.0$ and $M_{\max }=8.0$. In the cumulative distributions, $N_{1}\left(M_{\max }\right)$ is Breater than 2ero, while $N_{2}(M)$ and $N_{3}(M)$ approach zero as $M$ tends to $M_{\max }$. Thus, $N_{1}(M)$ represents 2 form of the recurrence relation which is enriched in large magnitude events relative to 
$N_{2}(M)$, and $N_{3}(M)$ is depleted in large magnitude events relative to $N_{2}(M)$. Fig. IB shows the corresponding incremental rates $n f(M), n\}(M)$, and $n\}(M)$. Based on Eq. (6), there are significant differences among the three density functions in the neighborhood of $M_{\max }$. However, in the incremental rates these differences are obscured. The incremental rates shown in Fig. IB correspond to 0.25 magnitude intervals centered at the quarter magnitude points $\left[n^{\prime}(M)-N(M-0.125)-N(M+0.125)\right]$. The point plotted at $M-8.0$ corresponds to the last interval (7.875, 8.125) which extends beyond $M_{\max }=8.0$. Since $N(8.125)=0$, then, $n^{\prime}(8.0)=N(7.875)$ which deviates from the approximation $n^{\prime}(M)=n(M) \times 0.25$ valid at lower mag. nitudes. Nihough this choice accentuates some peculiar behavior near $M_{\text {max }}$ it is representative of the actual situation in which $M_{\max }$ is unknown.

With respect to occurrence rates on single faults some arguments, based on limited data, have been advanced which suggest that the description given by $N_{1}(M)$ is more appropriate than $N_{2}(M)$ or $N_{3}(M)$. In particular, Swan et al. (1980) and Schwarte et al. (1981) have suggested, based on geological observations, that a segment of a fault repeatedly ruptures with a characteristic earthquake with magnitude neas $M_{\max }$. This suggestion may be supported on the San Andreas fault in Califormia by results of Sieh (19780) and Bakun and McEvilly (1979). Mathematically this could be represented by an occurrence relation with form $N_{1}(M)$, and a very small $b$-value. Singh et al. (1981) suggest that this is the case along the subduction zone of Mexico and Lahr and Stephens (1982) suggest that a small 6 value characterizes large events in Naska. This model was adopted by Caputo (1977). Wesnousky and Schol (1983), also, find that the recurrence relation for Japan can be generated from the distribution of fault lengths if each fault in a region ruptures with its own characteristic earhquake. Actually, the idea of "characteristic" earthquakes cannot be interpreted to mean strictly periodic repetition of identical mojor events. Where there are observations of more than one, earthquake on a fault, the sizes usually differ somewhat. This is seen by Sieh (1978a), Bakun and McEvilly (1979), Shimazaki and Nakata (1980), Singh et al. (1981), Sykes and Quittmeyer (1981), and others. The variation in magnitude may be small, but the nature of that variation is unknown. It is desirable to use observations to select the apropriate mathematical form for the occurrence rate relation. 


\section{APPENDIX II}

Considering the previous discussion as well as that pertaining to the issue of magnitude saturation, we shall consider the occurrence relations defined by Eqs. (5) and (6) for $i-1,2$ and 3, designated as Occurtence Relation 1, 2, and 3, respectively, and derive parallel results for these three alternative functional forms. The three forms are representative of the 3-parameter relations in the literature. There remains the possibility that more complex forms involving 4 or more parameters might sometimes be needed. Singh ef al. (1981) and Lahr and Srevens (1982) suggest that a relation with a typical b-value at small magnitudes but a small b-value at lage magnitudes is needed for the subduction zones of Mexico and Naska.

Because occurrence relations 1, 2, and 3 are all truncated, extreme magnitudes will obey the third , symptotic distribution of extremes (Gumbell, 1960), ss required by the results of Yegulalp and Kuo(1974). 


\section{RELATION BETWEEN SEISMDC MOMENT RELEASE RATE AND OCCURRENCE RELA-}

\section{TION PARANTETERS}

The sverage cumulative moment which is released per year within a given repion by earhquakes with magnitude greater than or equal to $M$ is

$$
\dot{M}_{0}^{(M)}=\int_{M}^{\infty} M_{0}\left(M^{\prime}\right) n(M) d M^{\prime}
$$

To evaluate this, we will use the relation

$$
M_{0}(M)=10^{r+d M}=M_{0}\left(M_{\max }\right) e^{-\lambda \Delta M}
$$

where typically, $c-16.0$ and $d=1.5$ for $M_{0}$ in units of dyne-cm (Hanks and Kanamori, 1979). We note that Eq. (8) defines the magnitude scale to be used in this paper. Then from Eqs. (6), (7), and (8),

$$
\dot{M}_{0}(M)=A_{1} M_{0}\left(M_{\max }\right)\left\{\left(\frac{\bar{b}}{\bar{d}-\bar{b}}\right)\left[1-e^{-(\bar{J}-\bar{b}) \Delta M}\right]+\frac{\bar{b}}{\bar{d}} B_{1}\left[1-e^{-\bar{d} \Delta M}\right]+C_{1}\right\}
$$

For $M-\infty$ and $\bar{b}<\bar{d}$, one obtains the total moment per year, $\dot{M}_{0}^{T}$, ss:

$$
\dot{M}_{0}^{T}=\gamma_{1} A_{1} M_{0}\left(M_{\max }\right)
$$

where

$$
\gamma_{1}=\frac{\bar{b}}{\bar{d}-\bar{b}}+\frac{\bar{b}}{\bar{d}} B_{1}+C_{i}
$$

For $i=1,2$, and 3, the values of these coefficients are $\frac{\bar{d}}{\bar{d}-\bar{b}}, \frac{\bar{b}}{\bar{d}-\bar{b}}$, and $\bar{b} / \bar{d}(\bar{d}-\bar{b})$, respectively. Smith (1975), Campbell (1977) and Papastamatiou (1980) obtained $\left(\frac{\bar{b}}{\bar{d}-\bar{b}}\right)$ instead of $\left(\frac{\bar{d}}{\bar{d}-\bar{b}}\right)$ for the coefficient $\gamma_{1}$ for $1-1$ because of the error in differentiation which was pointed out earlier. Nthough this coeffizient coincides with that for $i=2$, these authors did not use the cumulative occurrence relation $N_{2}(M)$, but rather $N_{1}(M)$. 
The fraction of the total moment which is released by earthquakes with magnitude greater than $M$ is $\dot{M}_{0}(M) / \dot{M}_{0}^{\top}$, and

$$
\frac{\dot{M}_{0}(M)}{\dot{M}_{0}^{T}}-1-\gamma_{1}^{-1}\left[\left|\frac{\bar{b}}{\bar{d}-\bar{b}}\right| e^{-(\bar{d}-\bar{\delta}) \Delta M}+\frac{\bar{b}}{\bar{d}} B_{1} e^{-\bar{\tau} \Delta M}\right]
$$

The values of these fractions as a function of $\Delta M$ for three choices of $b$ and for $d-1.5$ are listed in Table 1. Because of the differences near $M_{\max }$ the distribution corresponding to $i=1$ releases the most moment near $M_{\max }$, while the distribution corresponding to $l=3$ releases the least. The ratios for $b=0.25$ were included in Table 1 to show how such small $b$-values could accommodate the hypothesis by Schwarz et al. (1981) of a characteristic magnitude earhquake for a given fault. For $i=1$, and $b=0.25,95 \%$ of the moment is released by earthquakes with magnitude within 0.5 of $M_{\text {mex }}$.

For a given seismic moment release rate $\dot{M}_{0}^{T}$, and, after $M_{\max }$ and $b$ have been selected, Eqs. (10) and (8) can be used to obtain estimates of the parameters $A_{1}$ in Eqs. (5) and (6). This is the procedure used by Anderson (1979) and Molnar (1979). The resulting distribution functions for the case of $\dot{M}_{0}^{T}=8.1 \times 10^{25}$ dyne-cm/year, $b=1.0$ and $M_{\max }=8.0$ are compared in Fig. 2. For this choice of $b$, at $M \ll M_{\max }$, nccurrence relation 2 gives 1.5 times as many small earthquakes as occurrence relation 1 , and occurrence relation 3 gives 2.25 times as many small earthquakes as occurrence relation 1 . For $M$ close to $M_{\max }$ occurrence relations 2 and 3 include a smaller number of earthquakes than occurrence relation 1.

\section{RELATION BETHEEN SLIP RATE, OCCLRRENCE RELATION PARAMETERS AND MAXIMRM MAGNITLDE EARTHQLAKE}

Relations Referred to the Entire Fault. Following Brune (1968) and Anderson (1979), if all the slip on the fault occurs seismically, the slip rate on the fault, $S$, is related to the moment which is released by

$$
S=\frac{\dot{M}_{n}^{T}}{\mu \Sigma}
$$


where $\mu$ is the shear modulus $\left(\mu=3.3 \times 10^{11} \mathrm{dyne} / \mathrm{cm}^{2)}\right.$ and $\Sigma$ is the area of the fault surface over which the total seismic moment is released. Anderson hypothesized that $\dot{M}_{0}^{T}$ must be avenged over several cycles of large earthquakes for Eq. (13) to be valid. Eqs. (10) and (13) give

$$
A_{1}=\frac{\mu \sum S}{\gamma_{1} M_{0}\left(M_{\max }\right)}
$$

If the total area, $\Sigma$, of the fault is known and the occurrence rate is referred to the area $\Sigma$, then, Eqs. (5) and (14) can be used to obtain several useful relationships. If $T_{1}(M)-1 / N_{1}(M)(i-1,2,3)$ represent the estimates of the retum period of earthquakes with magnitude equal or greater than $M$ over the fault area $\Sigma$, then,

$$
T_{1}(M)=\gamma_{1}\left(\frac{M_{0}(0)}{\mu \Sigma S}\right) e^{\bar{\delta} N+(\bar{d}-\bar{b}) M_{\max }} \cdot\left[1-\left(1-C_{i}-B_{1} \bar{b} \Delta M\right) e^{-\bar{\delta} \Delta M}\right]^{-1}
$$

where $M_{0}(0)=10$. From Eq. (15) one can find aso the threshold magnitude $M$ corresponding to a return period $T(M)$ and the assumed maximum magnitude. Nternatively, if $\Sigma, S$ and the retum period $T(M)$ of earhquakes with magnitudes equal or greater than $M$ are known, then the maximum magnitude $M_{\max }$ can be estimated. Equations for $n_{i}, N_{1}, T_{i}, M$, and $M_{\max }$ are given in Tables 2,3 , and 4 for $i=1,2$, and 3 respectively. These equations are given in explicit form where possible, but for some of the results, only an implicit solution is possible. In particulat, setting $M=M_{\max }$ in Eq. (15) for $i=1$ leads to

$$
M_{\max }=\left(\frac{1}{\bar{d}}\right) \ln \left[\left(\frac{\bar{d}-\bar{b}}{\bar{d}}\right) \frac{\mu \sum S T_{1}\left(M_{\max }\right)}{M_{0}(0)}\right]
$$

which can be used to obtain an estimate of $M_{\max }$ if $\Sigma, S$, and $T_{1}\left(M_{\max }\right)$ are known. Finally, given $M$, $T(M), M_{\max }, \Sigma$, and $S$, Eq. (1S) can be used to obtain estimates of the parameter $b$.

Relations Referred to the Rupture Area of the Maximum Earthquake. An important special case of the above equations occurs when the area of reference is taken to be equal to area ruptured by the maximum earthquake $\left[\Sigma=\Sigma\left(M_{\max }\right)\right]$. In this case, the fault area does not appear explicitly in the 
relations involving slip rate, occurrence rates, and maximum magnitude earhquake. The average slip over the ruplure area of the maximum magnitude earthquake is

$$
\Sigma\left(M_{\max }\right)=\frac{M_{0}\left(M_{\max }\right)}{M \Sigma\left(M_{\max }\right)}
$$

Equation (17) an be combined with Eq. (14) to pive

$$
\lambda_{1}=\frac{s}{\gamma_{1} \Sigma\left(M_{\max }\right)}
$$

where $A_{1}$ in Eq. (14) has been replaced by $\boldsymbol{A}_{1}$ in Eq. (18) to denote the value applicable to this special case. The occurrence rates, corresponding to Eqs. (S) and (6), will similurly be denoted as $\hat{N}_{1}(M)$ and $n_{1}(M)$ for this special case.

At this point it is convenient to introduce a relationship between the average slip on the fault and magnitude. Based on historical dat of Sykes and Quitmeyer (1981), Schot (1982) proposes that to a 300 approximation, the average slip $\bar{u}$ in a large earthquake G.e., a earthquake wtich ruptures the total width, $\mathbf{W}$, of the fault ), is proportional to the length of the rupture $\boldsymbol{L}_{r}$. For strike slip events, he finds that the average value of $\frac{E}{4}=a=1.25 \times 10^{-3}$; for thrust foults, $a=2 \times 10^{-3}$. Based on this, the defrition of seismic moment $\left(M_{0}=\mu L, W \bar{z}\right)$, and Eq. (8), we derive the following relationships:

$$
\begin{aligned}
& \bar{u}(M)=\beta 10^{\frac{1}{2} N} \\
& L_{1}(M)=\frac{\beta}{\alpha} 10^{\frac{1}{2} N}
\end{aligned}
$$

where $\beta$ is a constant with dimensions of length defined by $\beta=\sqrt{\frac{a M_{0}(0)}{\mu W}}$. The coefficient of $M$ in eq. (19), for $d-1.5$, is 0.75 , which is 10 percent smaller than Slemmons (1977) worldwide average of 0.833. We note that Stemmons compiled the maximum observed surface orisets, while Eq. (19) is for the average offset over the ruplure area. Since these two parameters are different and not necessarily simply related, the discrepancy does not seem to us to be a serious matter at this time. Eq. (19) does 
sugest an explanation for the scatter in Slemmons data in terms of variations of the parameter $a=\frac{\bar{u}}{L}$ and of the width $\boldsymbol{W}$ of the fault.

Substitution from Eq. (19) into Eq. (18) leads 10 en estimate of $\dot{A}_{1}$ as

$$
\dot{A}_{1}=\frac{S}{\beta \gamma_{i}} e^{-\frac{\pi}{2} M_{m}}
$$

thus defining the level of seismicity on the fault consistent with $S$ and $M_{\max }$. If $f_{1}(M)=1 / \hat{N}_{1}(M)$ ( $i-1,2,3)$ denotes the retum period of earthquakes with magnitude larger or equal to $M$ over an area equal to the rupture area for the maximum magnitude earthquake, $\Sigma\left(M_{\max }\right)=W L_{r}\left(M_{\max }\right)$, then Eqs. (21) and (5) give

$$
f_{i}=\frac{\beta \gamma_{i}}{S} e^{\delta M-\left(\bar{b}-\frac{\delta}{2}\right) M_{\max }} \cdot\left[1-\left(1-C_{i}-B_{i} \bar{b} \Delta M\right) e^{-\delta \Delta M}\right]^{-1}
$$

Panicular expressions for $\dot{A}_{i}, \dot{T}_{i}, M$, and $M_{\max }$ for $i=1,2$ and 3 are given in Tables 2,3 , and 4.

Relations Referred to apecific site on the Fault. To evaluate the probability of rupture at a selected site along the trace of a fault, and to evaluate geological observations of the chronology of ruptures at a site, an extension of the above equations is needed. Some of the large earthquakes with magnitude $M\left(M<M_{\text {max }}\right)$ which occur over the length of $L_{r}\left(M_{\text {mex }}\right)$ will not rupture the surface at the specific observation site. We estimate the fraction $q(M)$ which cause rupture at the observation site by

$$
q(M)=\frac{L_{1}(M)}{L_{1}\left(M_{\max }\right)}-e^{-\frac{\partial}{2}(M M)}
$$

whese we have assumed that the rupture length seales according to Eq. (20).

Now let $N_{u}(M)(i-1,2,3)$ be the number of events with magnitude greater than or equal to $M$ which rupture the fault at the site. We obtain

$$
N_{u}(M)=\int_{M}^{M_{\text {mu }}} q(M) \dot{n}_{1}(M) d M
$$


Since the magnitude dependence of $q(M)$ and $\hat{n}_{1}(M)$ is through $\Delta M-M_{\max }-M$, it is convenient to define

$$
\frac{N_{\Delta}(M)}{N_{1}(M)}=F_{1}(\Delta M)
$$

We note that $F_{1}$ is the ratio of the number of events with magnitude $\geqslant M$ which rupture the site to the number of events with magnitude $\geqslant M$ over $L_{r}\left(M_{\max }\right)$, From Eqs. (6), (21), (23), (24) and (25), we derive

$$
\begin{aligned}
F_{1}(\Delta M) & =\left[1-e^{-\bar{b} \Delta M}+B_{1} \bar{b} \Delta M e^{-\delta \Delta M}+C_{1} e^{-\delta \Delta M}\right]^{-1} \\
& \left.\cdot\left\{\left(\frac{2 \bar{b}}{2 \bar{b}-\bar{d}}\right) \mid 1-e^{-\left(\bar{b}-\frac{\bar{d}}{2}\right) \Delta M}\right]-\frac{2 \bar{b}}{\bar{d}} B_{1}\left[1-e^{\frac{d}{2} \Delta M}\right] e^{-\delta \Delta M}+C_{i} e^{-\left(\bar{b}-\frac{\bar{d}}{2}\right) \Delta M}\right\} \cdot e^{-\frac{\bar{d}}{2} \Delta M}
\end{aligned}
$$

The functions $N_{z}(M)$ differ significantly from $N_{1}(M)$. Fig. 3 illustrates examples based on the same slip rate and maximum magnitude as used in Fig. 2. A notable characteristic of the occurrence relations $N_{2}(M)$, is that they flatten considerably as $M$ decreases, because small magnitude events are less likely than large ones to rupture past the site. Thus the b-value, when measured from events at a single site, appears to be small. Since Schwortz et al. (1981) had only a few earthquakes at each trench site, the effect described hese might completely account for their impression that only characteristic earhquakes repeatedly rupture a fault segment.

One can derive relations pertaining to the sizes and recurrence intervals of earthquakes which rupture a specific site along the fault similar to those presented earlier. If $T_{s i}(M)=1 / N_{\infty}(M)(i=1,2.3)$ denotes the average retum period of earthquakes with magnitude $M$ or larger to rupture past the site, we oblain

$$
T_{-}(M)=f_{1}(M) / F_{1}(\Delta M)
$$

where $\hat{T}_{1}(M)$ was defines in Eq. (22). 
APPENDIX II

Nthough it is not possible to solve Eq. (27) explicitly for either the threshold magnitude $M$ corresponding to $T_{y}(M)$ or for $M_{\text {max }}$ either of these quantities may be obtained by a numerical solution 25 a function of the parameter $\Delta M$. The particular equations for $M_{\max }$ and $M$ for $1-1,2$ and 3 are given in Tables 2, 3, and 4. 


\section{APPLICATIONS}

Relationsbip of $M_{\max }, \mathcal{M}$, and Recurrence Time of Magnitude $\mathcal{M}$. In the previous section relations between maximum magnitude and "average recurrence time" of events with magnitude harger than an arbitrary magnitude $M$ were presented. In these relations, "average recurtence time" was defined in three different ways: (A). $T(M)$, the average recurrence time over a fault of known length: (B). $f(M)$, the average recurrence time over a section of a fault whose leagth is equal to the rupture length of the maximum earthquake; and $(C)$. $f_{3}(M)$, the average time between earhquakes which offset the faul at one particular point. We first explore the behavior of these relations.

The average recurrence times, in the three different meanings, are illustrated in Fig. 4, as a function of $M_{\max }$. Figure $4 \mathrm{~A}$ shows $T(M), 4 \mathrm{~B}$ shows $f(M)$, and $4 \mathrm{C}$ shows $T_{3}(M)$ for $M=5,6,7$ and 8 . Figure 4A shows that in general as $M_{\max }$ increases, the repeat times for smaller events on the same fault segment also increases. This is a consequence of the maximum magnitude event, and events close to it, releasing most of the moment, so that little is left over for the smaller earthquakes. Curves for occurtence relations 2 and 3 show a secment for $M$ close to $M_{\operatorname{mex}}$ in which the repeat time decreases as $M_{\max }$ increases; then as $M_{\max }$ continues to increase, the curve becomes parallel to the curve for occurrence relation 1. This decreasing section of the curve corresponds to the portion of the occurrence rate curve which is plunging rapidly to zero (Fig. 2). While on this decreasing section, most of the seismic moment is seleased by events with magnitude smaller than $M$ rather than by events with magnitude larger than $M$. For occurrence relation 2, the repeat times are smaller than for occurrence relation 1 when $M_{\max }>M+0.5$. This results because a higher level of small magnitude activity is Decessary to compensate for the smaller moment released by earthquakes with magnitude near $M_{\max }$.

$f(M)$, in Fig. $4 \mathrm{~B}$ is referred to a fault segment of length $L_{T}\left(M_{\mathrm{max}}\right)$, rather than to a previously assigned length. One sees that $f(M)$ is, for this b.value, a gradually decreasing function of $M_{\max }$. In particular, for $b=\frac{d}{2}$ and $1-1$, the retum period $T_{1}(M)$ becomes independent of $M_{\max }$. If $\mathcal{T}(M)$ were constant, one would find about the same total number of small magnitude earthquakes in the rupture urea of the maximum earthquake, regardless of the dimension of the maximum earthquake. 


\section{APPENDIX II}

The average repeat times for rupture past $\&$ sile, $T_{8}(M)$, are shown in Fig. $4 C$. This figure shows that $T_{s}(M)$, like $T(M)$ is generally an increasing function of $M_{\max }$.

Figure $S$ shows the estimates for the magnitude, $M$, of the $T$-year earthquake (where $T$ may be $T_{i}$, or $T_{1}$ or $\left.T_{2} i-1,2,3\right)$ which are found under the condition of known $b$-value and slip rate, but unknown $M_{\max }$. Examples are shown for $T_{i}$ (Eq. 15) in SA, B, and $C$, for $T_{1}$ (Eq. 22) in SD, E, and $F$, and for $T_{2}$ (Eq 27) in SG, $H$, and I. Figure SA, for $s T_{1}(M)-10^{3} \mathrm{~mm}$ on a fault which is $500 \mathrm{~km}$ long by $15 \mathrm{~km}$ wide, shows that as $M_{\max }$ increases, the magnitude of the T-year earthquake decreases. This results because the maximum earhquake releases most of the required slip, and thus little needs to be released by smaller events. Figure SB shows that for large $M_{\max }$, occurrence relation 2 exhibits similar behavior, when $M_{\max } \gg M$, but when $M$ is close to $M_{\max }, M$ increases with incteasing $M_{\max }$. This increase corresponds to the portion of the occurrence curve where $N_{2}(M)$ is rapidly plunging toward zero and most of the slip is released at smaller magnitudes, as previously noted. In Figure SC, the curves behave in a manner similar to SB, except that the peaks in the curves are now at large mag. nitudes.

Figure SD, E and $F$ show that when the reference area is equal to the area of rupture zone of the maximum earhquake, the slopes of all the curves become more positive. For slip at a site, Figure SG, $H$ and I are qualitatively similas to SA, B, and C.

Estimates of $M_{\max }$ from Recurrence Time and Slip Rate. Expressions for estimaies of the maximum magnitude are given by Eq. (16) in the text and by several other expressions in Tables 2, 3, and 4. These expressions are for the three different normalizations considered.

The following discussion on estimates of $M_{\max }$ is based on occurrence relation 1 for which $T\left(M_{\max }\right), \hat{T}\left(M_{\max }\right)$, and $T_{3}\left(M_{\max }\right)$ are all finite, as opposed to the recurrence times for occurtence relations 2 and 3, which tend 10 infinity as $M$ approaches $M_{\max }$. Estimates of $M_{\max }$ for occurtence relation 1 are shown in Figure 6 as a function of slip rate, for five choices of recurrence time of $M_{\max }$ between $10^{2}$ years and $10^{6}$ years. The results on Figure $6 \mathrm{~A}$, derived from Eq. (10), are shown specifically for a fauli with area $\Sigma=10 \% \mathrm{~m}^{2}$; resulis in Figure 6B, derived from Eq. 1.13, are independent of the fault area, but do depend on the assumption that $W=10 \mathrm{~km}$ and $a=1.25 \times 10^{-5}$. 
However, these assumptions about $W$ and a are of only second order imporance.

The results in Figure 6B are of considerable interest when compared with results of Woodward. Obde Consuthants (1979). They have observed that for strike-slip faults, the maximum magnitude which bes been observed on each fault appear to be bounded by $\mathbf{a}$ line with larger $\boldsymbol{M}_{\text {mes }}$ for faults with Inger slip rates. In fact, vilues of $M_{\max }$ calculated from Eq. 0.13 ) in Table 2, with $W-10 \mathrm{~km}$, $a-1.25 \times 10^{-5}$ and $f_{1}=2000$ years nearly coincide with the proposed bound. This can be interpreted in either of two ways. The first would be that there is some physial mechenism which requires that the recurrence time of the maximum earthquake over a fault length equil to $L,\left(M_{\text {max }}\right)$ is less than about 2000 years on all fauls. The existence of such a mechanism is unlikely, however. At low slip mes there are examples of faults with recurrence intervals of $10^{5}$ years (Knuepfer a ol., 1981; Bull. et al., 1981: Menges ef al., 1982). Furthermore, rock mechanics results indicate that the strength of a fault increases with the time which has elapsed since the last event, 20 that on fauls with slow slip rates, one might even expect larger earthquakes than on faults with large slip rates. The alternative explanation, which we prefer, is that the apparent bound for the din results from the lack of observations at slow slip rates, because of the short sampling interva.

Figures $6 A$ and $6 B$ are predicated on the validity of occurrence relation 1. For occurtence relations 2 and 3. $M_{\max }$ appears as a mathematical limit which may be approached but not attained. One can, however, derive similas results in which $M_{\operatorname{mex}}$ is replaced by $M_{\max }-\Delta M$, where $\Delta M$ is constant, and the lines are drawn for $T\left(M_{\max }-\Delta M\right)=$ constant or $f\left(M_{\max }-\Delta M\right)=$ constant. From Eq. (II.6) and (II.1), (III.6), (III.10), such lines would appear parallel to those in Figures 6A and 6B.

Comparison wltb Smitb (1976). Eq.(16) gives an estimate of $M_{\max }$ on a fault for which the slip rate, the total area, and the recurrence time of the maximum earhquake are known. The expression which Smith (1976) derived for $M_{\max }$ is, except for the derivational error, equivalent to Eq. (16). To oblain this equivalence, one must associate $S T_{1}\left(M_{\text {max }}\right)$ with one third of the maximum Holocene (2 to $4 \times 10^{\circ}$ years) fault slip in Smith's paper. The factor of one third uas inserted by Smith because of his assumption that the maximum observed displacement is greater than the average.

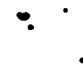


Smith (1976) argues that $2 \times 10^{4}$ years is long enough for at least one maximum earthquake to occur along each of the faults he considered. If the maximum magnitude does not occur in that time interval, then one should use Eq. (1.6) in Table 2 instead of Eq. (16) to evaluate $M_{\max }$. For the sake of comparisons, Eqs (1.6) and (16) were applied to the numerical values described by Smith as applicable to a "third order fault." Smith used a total Holocene moment of $0.7 \times 10^{26}$ dyne-cm on a fault with $L=80 \mathrm{~km}$ and $W=10 \mathrm{~km}$. This implies slip rate less than $0.02 \mathrm{~mm} /$ year. Using $b=0.86$, $d=1.5$, and our Eq. (16), one obtains $M_{\max }=6.3$, identical to $M_{\max }$ derived by Smith. Supposing. bowever, that because of the small slip rate the largest earthquake on the fault in the late Quaternary time period was only $M=6.0$, then Eq. (1.6) gives $M_{\max }-6.7$; if the largest Holocene earthquake was $M=5.5$, then $M_{\max }=7.4$, and if the largest was $M=5.0$, then $M_{\operatorname{mex}}=8.1$. Thus the estimate of $M_{\max }$ is quite sensitive to the hypothesis that the maximum earthquake has occurred on the fault in the Holocene. This hypothesis has the same problems as the conjecture that the maximum earthquake occurs with a repeat time over $L_{r}\left(M_{\mathrm{max}}\right)$ of less than 2000 years, 25 discussed in connection with Fig. ure 6.

$M_{\max }$ in California. The motion of the Pacific Plate relative to the Norh America Plate is, in total, about $60 \mathrm{~mm} /$ year (Bird, 1981), and the length of the San Andreas system from the Gulf of Califormia to Cape Mendocina is about $1300 \mathrm{~km}$. We will treat all the seismicity along this complex plate boundary as if it originated along a single fault $15 \mathrm{~km}$ wide, and use Eqs. (1.6) (II.6) and (III.6) to estimate $M_{\max }$. To accomplish this, we have plotted in Fig. 7 the predicted retum periods for earthquakes with $M \geqslant 5,6,7$ and 8 versus $M_{\max }$ for this particular selection of model parameters. On Fig. 7, we have superimposed sverage occurrence rates for earthquakes associated with the entire plate boundary. These included all the events listed on the Earthquake Data File (Meyers and won Hake, 1976) through Dec. 1979, bounded by a quadrilateral with corners at the following coordinates: $\left(41^{\circ} \mathrm{N}, 128^{\circ} \mathrm{W}\right),\left(41^{\circ}\right.$ $\left.\mathrm{N}, 121^{\circ} \mathrm{W}\right),\left(31^{\circ} \mathrm{N}, 190^{\circ} \mathrm{W}\right)$, and $\left(31^{\circ} \mathrm{N}, 112^{\circ} \mathrm{W}\right)$. Average occurrence rates are sensitive to the time interval over which the sverage is derived; the uncertainty is at least \& factor of 2 . We estimate the following bounds on everage recurrence times within this region : $M \geqslant 7,7.7$ 10 17 years; $M \geqslant 6$ 1.0- 2.0 years: $M \geqslant 5,0.11$ to 0.22 jears. These bounds on recurrence times have been superimposed 
APPENDIX II

on Fig. 7. From the intersection of these bounds with the theoretical curves, one can estimate $M_{\max }$. For occurrence relation 1, estimates for $M_{\max }$ range from 7.8 to 8.4. For occurrence relation 2, they range from about 8.2 to 8.7. These estimates are reasonable. Athough the values of $\boldsymbol{M}_{\max }$ consistent with assumption 3 (8.6 to 9.2) may seem too large to be physically realized, we note that in this case $M_{\max }$ is a mathematical limit which would never be reached and would only rely be closely approsched.

Popastamatiou (1980) used a similar technique to estimate $\boldsymbol{M}_{\max }$ for the $S a n$ Andreas fault between $36^{\circ} \mathrm{N}$ and $39^{\circ} \mathrm{N}$, and obtained $M_{\max }-8.83$. This sesult was based on the occurrence rates of magnitude 2 or larger earthquakes. The longer extrapolation introduces more sensitivity to choice of b and greater reliance on the completeness of the earthquake catalog at small magnitudes. For an individual fault, furthermore, this method of estimating $M_{\max }$ requires great caution because occurrence rates are subject to cycles of activity with periods longer than the duration of instrumental catalogs. Such a cycle may well affect the results in Fig. 7, asso.

Thresbold of Observations Nong the Mexico Subduction Zone. Singh a al. (1981) give a chronology of earhquakes along the Mexican subduction zone. The magnitudes of most of the events are knoun, providing the opportunity to compare some theoretical calculations with data. Singh al. identified six segments of the subduction zone which appear to nupture in distinct earthquakes, and for which the date and magnitude of at least two earthquakes is known.

We note that if adjacent zones do not coalesce into single ruptures, then each zone has a dimension equal 10 the length of its corresponding maximum earthquake, and the relations which are referred to the rupiure area of the maximum earthquake can be used. In particular, based on this assumption we attempted to estimate the magnitude of the smallest earhquake tabulated by Singh a al. (1981) within each of the six zones from the average recurrence interval in the zone. We used Eqs. (I.12), (n.11), and (IIl.11) with the parameters $S=65 \mathrm{~mm} /$ year, $W-70 \mathrm{~km}, \mu=3.3 \times 10^{\prime \prime} d$ fne-cm, and $a=1.33 \times 10^{-5}$. This value of $a$ is averaged from estimates for the 1973 Colima earhquake and the 1978 Oaxaca earthquake, based on data in Sykies and Quitrmever (1981). As seen in Fig SD, the estimates of the threshold of observation, $M$, are nearly independent of $M_{\max }$ for the normal range of 
b-values. The results are listed in Table $S$ for $b=1.0$ and $M_{\max }=8.0$. Estimates for $M$ increase when the parameters $M_{\text {max }}$. S. $\mu$, or $\mathbf{W}$ are increased, and estimates for $M$ decrease when the parameters $b$ or a are increased. However, considerable changes are needed to change $M$ by more than 0.1 , and thus the choice of parameters is not critical. The ereatest discrepancy in Table $\mathbf{2}$ is 0.2 magnitude units, for the San Marcos region. In the other regions, $M$ agrees with the smallest of the observed magnitudes to within 0.1. We consider this agreement satisfactory, although the mange of calculated and observed magnitudes is not large enough to provide an adequate test.

Implications of the San Andreas Fault Data from Pallett Creek. Sieh (19780) studied sediments in a trench across the San Andreas fault at Pallett Creek. These sediments bad been disrupted by several earthquakes, and, based on radiocarbon dating, Sieh derived a chronology of the events. The events and estimated year of occurrence are : D. S45; F, 665; I, 860; N, 965; R, 1190, T, 1245; V, $1470, X, 1745 ; Z, 1857$. Except for event $Z$, the uncerainty in date is typically \pm 50 years. The extent of sediment disruption does not require events $R$, or I to be as large as the 1857 event. Events $V$ and $N$ generated somewhat deeper troughs than the 1857 earhquake, and thus might have been associated with greater right lateral slip, but Sieh (19780) considered all the events, except R and I, were comparable to the 1857 earthquake. The variable trough depths, and the smaller size of events $R$ and I suggest that there is a distribution of event sizes represented at the site. The average waiting time beiween events is $T_{s}=164$ years, based on 8 intervals between 545 and. 1857.

This Pallell Creek record can be used 10 identify the form of the occurrence relation by means of - speculative procedure to estimate the magnitude of each of the earhquakes. The time-predictable and slip-predictable models described by Shimazaki and Nakata (1980) were used to estimate the slip in each of the earthquakes. In the time predictable model, the slip in one earhquake, and the slip rate, determine the waiting time to the next earhquake; in the slip predictable model the waiting time from the previous earthquake and the slip rate determines the slip in the next earthquake. The slip in each eanhquake, as predicted by the two models, is listed in Table 6, based on a slip rate of $37 \mathrm{~mm} /$ year. Equation (19) was used to convert each average slip to magnitude. The consequent empirical cumulative magnitude distribution is shown in Fig $8 \mathrm{~A}$ and $\mathrm{B}$. We note that both the time-predictable model 


\section{APPENDIX II}

and the slip-predictable model lead to the same magnitude distribution, even though the magnitude estimates for each earthquake differ. Since aftershocks are not recognized in the seolopical record, these magnitudes measure the total effect of the earthquake sequences nther than the size of the main shock of the sequence. We note that if events $R$ and I were smaller than most, as indiated by Sieh (19780), this would tend to support the time predictable model.

Fig. 8 also shows the theoretical forms for $N_{2 i}(M)(i=1,2,3)$ for two choices of $b$-value $\left(b=0.86\right.$, Fig. 8A; $b=0.20$, Fig. 8B). In Fig. 8 we used $M_{\max }-8.3$ for Occurrence Relations 1 and 2, and $M_{\max }=8.6$ for occurrence relation 3. Over the magnitude range illustrated in Fig. 8, theoretical curves for $b<0.2$ are not significantly different from the curves, shown, for $b=0.2$. The comparisons in Fig. 8 show that our Pallett Creek magnitude estimates seem to obey occurrence relation 2 with b near zero much betier than they obey occurrence relation 1, and slightly better than they obey relation 3. There is no choice of $M_{\max }$ which can alter the conclusion that occurrence relation 2 fits better. Changes in the other scaling parameters $(S, \alpha, w)$ require that the magnitudes in Table 6 also be modified for intenal consistency, and thus systematically modify both the data and the theoretical curves in Fig. 8 without affecting the conclusion. We cannot rule out the possibility that random errors affecting each datum could change the conclusion. Significant random errors might arise from uncertainty in event dates, variations in scaling parameters from event to event, deviations from the timepredictable or slip-predictable model, and possible incompleteness in the geological record. The $N_{s 2}(M)$ in Fig. 8B is slightly lower than the data because it allows some slip $(\approx 10 \%)$ to be released in smaller events, while the magnitude estimates in Table 6 require that al the slip occurred in these 8 events. Large aftershocks of the main events might or might not affect the shape of the distribution curves as measured from seismograph observations, in the magnitude range shown.

The equations in Tables 2,3 and 4 for the case of rupture past the site can be used to estimate the smallest main shock magnitude in the Pallett Creek record as a function of $M_{\text {max. }}$ Trble 7 shows these estimates for the magnitude corresponding to a 164 year recurrence interval. Even though Tabie 6 suggests that $M_{\max }$ is at least 8.3. Table 7 considers possible values between 7.8 and 8.8 . Since Sieh (1978b) finds that the moment of the 1857 earthquake implies that the magnitude for that event 
APPENDIX II

was 7.8 to 7.9, smaller values see not considered. The upper limit for $M_{\operatorname{mex}}, 8.8$ was suggested by Fig. 7. An exceptionally large earthquake which ruptures from north of Parkfield to the Salton Sea $(600 \mathrm{~km})$, and which is characterized by $a-2.5 \times 10^{-5}, W=20 \mathrm{~km}$, and $\mu-3 \times 10^{11} \mathrm{dyne} / \mathrm{cm}^{2}$, leads to $M=8.5$. However, for occurrence relation 3, $M_{\max }$ is a mathematical limit which would rarely be approached; thus values of $M_{\max } 108.8$ are not necessarily disqualified.

The results in Table 7 indicate that for $M_{\max }$ in the range 8.0 to 8.5, the threshold magnitude $M$ would be in the range 6.5 to 7.5, depending on the occurrence relation and $b$-value used. In particular, - value of $M_{\max }-8.26$ and a threshold magnitude of 7.33 as calculated for the time predictable model listed in Table 6 are not inconsistent with the results in Table 7. Since risk assessment for the southern California region depends upon the Pallet Creek record, an appreciation of this range of magnitudes will likely influence that assessment.

161 


\section{SUMMARY}

Three earthquake occurrence relations with different functional dependence near $M_{\max }$ have been examined. The forms considered while representing a subset of the class of 3-parameter occurrence relations are sufficient to cover the major types of expected behavior near $M_{\max }$. These occurrence relations selate two variables $M$ and $T(M)$ and the parameters corresponding to the rate of occurrence at a magnitude of reference, a $b$-value, and, a maximum magnitude $M_{\max }$. Knowiledge of the slip rates permits one to derive a constraint among the three parameters characterizing the occurrence relation. The resulting slip-constrained occurrence relation can be utilized to obtain one of the following estimates: (i) given $S, M, M_{\max }$, and $b$ find $T(M)$, (ii) given $S, T(M), M_{\max }$ and $b$ find $M$, (iii) given $S, M, T(M)$ and $b$ find $M_{\max }$, (iv) given $S, T\left(M_{\max }\right)$ and $b$ find $M_{\max }$ and $(v)$ given $S, M, T(M)$ and $M_{\max }$ find $b$. The slip-rate constraints and the equations necessary for the above applications have been derived for three occurrence relations of different functional form. Specific application of estimates (i) through (iv) have been illustrated.

We have addressed also the problem of nomalization of the earthquake occurrence relations. We have considered three types of nomalization corresponding to: (i) occurrence over a prescribed fault area, (ii) occurrence over an area equal to the ruplure area dusing the maximum magnitude earthquake, and, (iii) occurrence such that the earthquake rupture area includes a specific point.

\section{Acknow ledgements}

The authors have benefitted from discussions with J.N. Brune and C.H. Scholz, and from a review of the manuscript by $M$. Reichle. This research was supported by the United States Geological Survey Contract No. 14-08-0001-19766. 


\section{REFERENCES}

Aki, K. (1967). Scaling law of seismic spectrum, Journal of Geophysical Research 72 , 1217-1231. Aki, K. (1972). Scaling law of earthquake source time-function, Geophysical J. 31, 3-25.

Anderson, J. G. (1979). Estimating the seismicity from geological structure for seismic-risk studies, Bull. Seism. Soc. Am. 71, 827-843.

Bakun, W.H. and McEvilly, T.V. (1979). Earthquakes near Parkfield, Califomia : comparing the 1934 and 1966 sequences, Science 205, 1375-1477.

Bath, M. (1978). A Note on recurrence relations for earthquakes, Tectonophysies 51, T23.T30.

Berrill, J.B. and R.O. Davis (1980). Maximum entropy and the magnitude distribution, Bull. Seism. Soc. Am. 70, 1823-1831.

Bird, P. Kinematics of present crust and mantle flow in southem Califomia, Bull. Geological Soc. Am. (in press).

Bloom, E. D. and R. C. Erdmann (1980). The observation of a universal shape regularity in earthquake frequency-magnitude distributions, Bull. Seism. Soc. Am. 70, 349-362.

Brune, J. N. (1968). Seismic moment, seismicity, and slip rate along major fault zones, Joumal of Geophysical Research 73, 777-784.

Bull, W.B., S.S. Calvo. P.A. Pearhree and J. Quade (198i). Frequencies and magnitudes of surface nupture along the Pitaycachi fault, northwestern Sonora, Mexico (abstract), Abstracts with programs 1981, 77th Annual Meeting, Cordilleran Section, Geological Society of America, Hermosillo, Sonora, Mexico, 47.

Campbell, K. W. (1977). The use of seismotectonics in the Bayesian estimation of seismic risk, Repor No. UCLA-ENG-7744, School of Engineering and Applied Sciences, University of California, Los Angeles. 
Caputo, M. (1977). A mechanical model for the sutistics of earhquakes, magnitude, moment, and fault distribution, Bull. Seism. Soc. Am. 67, 849-861.

Chinnery, M.A. and R.G. Nonh (1975). The frequency of very large earthquakes, Science 190 1197-1198.

Davis, G. F. and J. N. Brune (1971). Regional and global fault slip rates from seismicity, Nature Physical Science 229, 101-107.

Doser, D.I. and R.B. Smith (1982). Seismic moment mites in the Utah region, Bull. Seism. Soc. Am. $72,525.551$.

Esteva, L. (1976). Seismicity, in Seismic Risk and Engineering Decisions, C. Lomnizz and E. Rosenblueth, editors, Elsevier Scientific Publishing Company, Amsterdam, 179-224.

Geller, R.J. (1976). Scaling relations for earhquake source parameters and magnitudes, Bull. Seism. Soc. Am. 66, 1501-1523.

Greensfelder, R.W., F.C. Kintzer and M.R. Somerville (1980). Seismotectonic regionalization of the Great Basin, and comparison of moment rates computed from Holocene strain and historic seismicity, in Proceedings of Conference X. Earthquake hazards along the Wasateh and SierraNevada frontal fault 200es, Open file Repon 80-801, United States Department of the Interior Geological Survey, Menlo Pask, Califomia, p. 433-493.

Gumbell, E.J. (1960). Extreme value Statistics, Columbia University Press, 375 pp.

Gutenberg, B. and C. F. Richter (1954). Seismicity of the Eanth and Associated Phenomena, 2nd edition, Princeton University Press, Princelon, N. J., 310 p.

Hanks, T.C. and H. Kanamori (1979). A moment magnitude scale, Journal of Geophjsical Research 84, 2348.2350.

Hermann, R. B. (1977). Recurrence relations, Earthquake Notes 18, Nos. 1-2, 47-49. 
Housner, G. W. (1969). Engineering estimates of ground shaking and maximum earhquake magnitude, Proc. 4th World Conference on Earhhquake Engineering, Sentiago, Chile, Vol. 1, 1-13. Kenamori, H. (1977). The energy release in sreat earhquakes, Joumal of Geophysical Research 82. $2981-2987$.

Kanamori, H. and D.L. Anderson (1975). Theoretical basis of some empirical relations in seismology, Bull. Seism. Soc. Am. 65, 1073-1095.

Knuepfer, P.L., K.J. Coppersmith and L.S. Cuff (1981). A framework for classifying fauls based on their relative degree of activity (abstract), Earthquake Notes $\underline{52}, 70-71$.

Lahr, J.C. and C.D. Stephens (1982). Naska seismic 20ne: possible example of non-linear magnitude distribution for faults (abstract), Earthquake Notes $\underline{53}$ No. 1, 66 .

Main, I.G. and P.W. Burton (1981). Rates of crustal deformation inferted from seismic moment and Gumbel's third distribution of extreme magnitude values, in J.E. Beavers, ed., Earhquakes and Earhquake Engineering - eastern United States, Ann Arbor Science Publishers, boc., 937. 951.

Makjanik, B. (1980). On the frequency distribution of earthquake magnitude and intensity, Bull. Seism. Soc. Am. 70, 2253-2260.

McGuire, R.K. (1974). Seismic Structural Response Risk Analysis, Incorporating Peak Response Regressions on Earhhquake Magnitude and Distance, Research Repon R74-51, Department of Civil Engineering, Massachusetts Institute of Technology, Cambridge, Mass. 371 pp.

Menges, C.M., P.A. Pearthree and S. Calvo (1982). Quaremary faulting in southeast Arizona and adjacent Sonora, Mexico (abstract), Abstracts with programs 1982, 78th Annual Meeting. Cordilleran Section, Geological Society of America, Anaheim, Califomia, 215.

Meyers, H. and C.A. vonHake (1976). Earhquake Data File summary, National Geophysical and Solar-Tertestrial Data Center, Boulder, Colorado. 
Molnar, P.E. (1979). Earthquake Recurtence Intervis and Plate Tectonics, Bull. Seism. Soc. Am. 69, 115-133.

Papastamatiou,D. (1980). Incorporation of crustal deformation to seismic hazard analysis, Bull. Seism. Soc. Am. 70, 1321-1335.

Richter, C.F. (1958). Elementary Seismology, W.H. Freeman, San Francisco, California.

Schwarz, D.P., K.J. Coppersmith, F.H. Swan III, P. Somerville, and W.U. Savage (1981). "Characteristic" earthquakes on interpolate normal faults (Abstract), Earthquake Notes 52, No. 1, 71.

Scholz, C.H. (1982). Scaling laws for large earhquakes: consequences for physical models, Bull. Seism. Soc. am. $12,1 \cdot 14$.

Shimazaki, K. and T. Nakata (1980). Time-predictable recurrence model for large earhquakes. Geophysical Research Letters ? 279-282.

Sieh, K.E. (1978a). Prehistoric large earhquake produced by slip on the San Andreas fault at Pallett Creek, Califomia, J. Geophys. Research 83, 3907-3939.

Sieh, K. (1978b). Slip slong the San Andreas fault associated with the great 1857 earthquake, Bull. Seism. Soc. Am. 68, 1421-1448.

Singh, S.K., L. Astiz, and J. Havskov (1981). Seismic gaps and recurrence periods of large earthquakes along the Mexican subduction 20ne: re-examination. Bull. Seism. Soc. Am. 71, 827, 843.

Slemmons, D.B. (1977). State-of-the-art for Assessing Earthquake Hazards in the United States Report 6. Faults and Earhquake Magnitude, Miscellaneous Paper S-73-1, Mackay School of Mines, University of Nevada, Reno.

Smith, S.W. (1976). Delermination of maximum earthquake magnitude, Geophysical Research Letiers, 33, 351-354. 
Sykes, L.R. and R.C. Quittmeyer (1981). Repeat times of great earthquakes along simple place boundaries, in D.W. Simpson and P.G. Richards, eds., Earthquake Prediction, An Intematioral Review, American Geophysical Union, Washington, D.C., p. $21710 \underline{247}$

Swan, F.H., III, D.P. Schwarz and L.S. Cluf (1980). Recurrence of moderate to large magnitude earthquakes produced by surface faulting on the Wasatch fault 20ne, Utah, Bull. Seism. Soc. Am. $70,1431-1462$.

U. S. Geological Survey (1981). Scenarios of Possible Earthquakes Affecting Major Califomia Population Centers, with Estimates of Intensity and Ground Shaking, Open File Repor 81-115. Menio Park, California.

Wallace, R.E. (1970). Earhquake recurrence intervals on the San Andreas fault, Geological Society of America Bulletin 81, 2875-2890.

Wesnousky, S.G. and C.H. Scholz (1983), in preparation.

Woodward-Clyde Consulınts (1979). Repon of the Evaluation of Maximum Earthquake and Site Ground Motion Parameters Associated with the Ofishore zone of Deformation San Onofre Nuclear Generating Station, prepared for Southem California Edison, Rosemead, Califomia.

Yegulap, T.M. and J.T. Kuo (1974). Statistical prediction of the occurrence of maximum magnitude earthquakes, Bull. Seism. Soc. Am. 64, 393-414. 


\section{MGURE CAPTIONS}

Figure 1 A. Cumulative magnitude distribution functions $N_{1}(M), N_{2}(M)$, and $N_{3}(M)$ (Eq. S) for $b=1.0, M_{\max }-8.0$, normalized so that $N_{1}(6)=N_{2}(6)=N_{3}(6)=1.0$. B. Corresponding incremental rates $n\}(M), n\{(M)$ and $n\}(M)$ in 0.25 magnitude unit intervals. Each datum is plotted at the center of its magnitude intervd.

Figuse 2 A. Cumulative magnitude distribution functions $N_{1}(M), N_{2}(M)$ and $N_{3}(M)$ (Eq. 5) for $b-1.0$ and $M_{\max }-8.0$, normalized so that on the average the seismic moment released by the earthquakes is $8.1 \times 10^{25}$ dyne-cm/year. B. Corresponding incremental rates $n !(M)$, $n\{(M)$, and $n\}(M)$ in 0.25 magnitude unit intervals. Each datum is plotted at the center of its magnitude interval.

Figure 3 A. Cumulative magnitude distribution functions $N_{31}(M), N_{32}(M)$ and $N_{s 3}(M)$ (Eq. 25) giving the frequency of a magnitude $M$ or larger earthquake causing ground rupture at a sincle site on a fault. Curves are generated for $b-1.0, M_{\max }=8.0, \alpha-1.25 \times 10^{-5}$, $\mu=3 \times 10^{11} \mathrm{dyne} / \mathrm{cm}^{2}, W=15 \mathrm{~km}, S=40 \mathrm{~mm} / \mathrm{year}$, and the magnitude-rupture length scaling assumptions given by Eq. 20 B. Corresponding incremental rates in 0.25 magnitude unit intervals. Each datum is plotted at the center of its magnitude interval.

Figure 4 A. Average recurrence times $T(M)$ (Eq. 15) for magnitude $M$ or greater earthquakes on a fault with $L=1000 \mathrm{~km}, W=10 \mathrm{~km}$, and $S=40 \mathrm{~mm} / \mathrm{year}$, as a function of $M_{\max }$. Other parameters are $b-1.0, a=1.25 \times 10^{-5}, \mu=3 \times 10^{11} \mathrm{dyne} / \mathrm{cm}^{2}$. B. Average recurtence times $f(M)$ (Eq 22) for magnitude $M$ or greater earthquakes on a fault with $L=L\left(M_{\max }\right)$ as a function of $M_{\text {max. }}$ Other parameters as in fig. $4 A$. C. Average recurrence times $T_{z}(M)$ (Eq. 27) for magnitude $M$ or greater earthquakes nupturing a single site on a fault, as a function of $M_{\max }$. Other parameters as given above. 
Figure 5 Magnitude thresholds of observation consistent with the product (slip rate) $x$ (recurrence time of events exceeding thresholds) $=10^{3} \mathrm{~mm}$. These thresholds are shown as a function of maximum magnitude, and for four b-values. Parameters held constant for all curves are $\alpha=1.25 \times 10^{-5}, \mu-3 \times 10^{11}$ dyne $/ \mathrm{cm}^{-2}, W=15 \mathrm{~km}$. A) Occurrence rate curve hes form $N_{1}(M)$, and recurrence time applies to events occurring any place on the segment of the fault with $L=500 \mathrm{~km}$. B) Equivalent of A for occurrence nate curve $\mathrm{N}_{2}(M)$. C) Equivalent of a for occurrence rate curve $N_{3}(M)$. D) Occurrence rate curve has the form $N_{1}(M)$, and recurrence time applies to events occurring on a segment of the fault ruptured by the maximum magnitude earthquake. E) Equivalent of $D$ for occurrence rate curve $N_{2}(M)$. F) Equivalent of $D$ for occurrence rate curve $N_{3}(M)$. G) Occurence rate curve has the form $N_{1}(M)$ and recurrence time applies to events which rupture the fault at a single site. H) Equivalent of $G$ for occurrence nte curve $N_{2}(M)$. I) Equivalent of $G$ for occurrence rale curve $N_{3}(M)$.

Figure $6 M_{\max }$ as a function of slip rate $S$ for several choices of recurrence times $I_{1}\left(M_{\max }\right)(6 \mathrm{~A})$ and $T_{s 1}\left(M_{\max }\right)$ or $f_{1}\left(M_{\max }\right)$ (6B). $M_{\max }$ in $6 \mathrm{~A}$ is for a fault area $\Sigma-10^{6} \mathrm{~km}^{2} . M_{\max }$ in $6 \mathrm{~B}$ is for a fault with $W=10 \mathrm{~km}$. Other parameters are $b=0.86, \mu=3 \times 10^{11} \mathrm{dyne} \mathrm{cm}^{-2}$, and $\alpha=1.25 \times 10^{-5}$. Curves only apply if seismicity obeys occurrence relation $N_{1}(M)$, but parallel curves for $M_{\operatorname{mex}}-\Delta M, \Delta M$ fixed, can be derived for occurrence relations $N_{2}(M)$ and $N_{3}(M)$.

Figure 7 Repeat times $T_{1}(M)(i=1,2,3)$ for $M=5,6,7$ and 8 when $S=60 \mathrm{~mm} / \mathrm{year}$, $\alpha=1.25 \times 10^{-5}, b=0.91, W=15 \mathrm{~km}, L=1300 \mathrm{~km}$, and $\mu=3 \times 10^{11} \mathrm{dyne} / \mathrm{cm}^{2}$. Superimposed are bounds for the observed repeat limes of events with $M \geqslant 5,6$ and 7 for the $\mathrm{Cal}$. ifornia plate boundary segion from the Gulf of Mexico to Cape Mendocino. Intersections of these observations and theoretical curves are projected down to neas the horizontal axis to infer appropriate range of $M_{\max }$ corresponding to each form of the occurrence relation. 
Figure 8 Cumulative magnitude distribution funetions $N_{s 1}(M), N_{s 2}(M)$ and $N_{s 3}(M)$ (Eq. 25) giving the theoretical frequency of a magnitude $M$ or larger earthquake causing nupture at a single site on a fauls. Curves are generated for $b-0.86(8 A)$ or $b-0.20$ (8B), and for $\alpha=1.25 \times 10^{-5}, \mu=3 \times 10^{11} \mathrm{dyne} / \mathrm{cm}^{2}, W=10.0 \mathrm{~km}$, and $S-37 \mathrm{~mm} /$ year. $N_{s 1}(M)$ and $N_{s 2}(M)$ have $M_{\max }-8.3$, and $N_{23}(M)$ has $M_{\max }=8.6$. Superimposed on each figure is the distribution of magnitudes inferred for the Pallett Creek site on the San Andreas fault. Inferred magnitudes (Table 3) are based on chronology eiven by Sieh (1978a), timepredictable or slip-predictable model of Shimazaki and Nakata (1980), and earthquake scaling relations of Scholz (1982). 
Table 1

Fraction of Moment Released by Earthquakes with

Magnitude between $M_{\max }-\Delta M$ and $M_{\max }$

\begin{tabular}{|c|c|c|c|c|c|c|c|c|c|}
\hline \multirow[b]{2}{*}{$\Delta M$} & \multicolumn{3}{|c|}{$b=0.25$} & \multicolumn{3}{|c|}{$b-0.85$} & \multicolumn{3}{|c|}{$b-1.0$} \\
\hline & O.R. 1 & O.R. 2 & O. R. 3 & O.R. 1 & O.R. 2 & O.R. 3 & O.R. 1 & O.R. 2 & O. R. 3 \\
\hline 0.0 & 0.83 & 0.0 & 0.0 & 0.43 & 0.0 & 0.0 & 0.33 & 0.0 & 0.0 \\
\hline 0.1 & 0.88 & 0.25 & 0.04 & 0.51 & 0.14 & 0.02 & 0.41 & 0.11 & 0.02 \\
\hline 0.25 & 0.92 & 0.51 & 0.19 & 0.61 & 0.31 & 0.11 & 0.50 & 0.25 & 0.09 \\
\hline 0.35 & 0.94 & 0.63 & 0.30 & 0.66 & 0.41 & 0.18 & 0.55 & 0.33 & 0.15 \\
\hline 0.5 & 0.96 & 0.76 & 0.47 & 0.73 & 0.53 & 0.30 & 0.63 & 0.44 & 0.25 \\
\hline 1.0 & 0.99 & 0.94 & 0.82 & 0.87 & 0.78 & 0.63 & 0.79 & 0.68 & 0.54 \\
\hline 2.0 & 1.00 & 1.00 & 0.99 & 0.97 & 0.95 & 0.91 & 0.93 & 0.90 & 0.85 \\
\hline 3.0 & 1.00 & 1.00 & 1.00 & 0.99 & 0.99 & 0.98 & 0.98 & 0.97 & 0.95 \\
\hline 4.0 & 1.00 & 1.00 & 1.00 & 1.00 & 1.00 & 1.00 & 0.99 & 0.99 & 0.99 \\
\hline
\end{tabular}




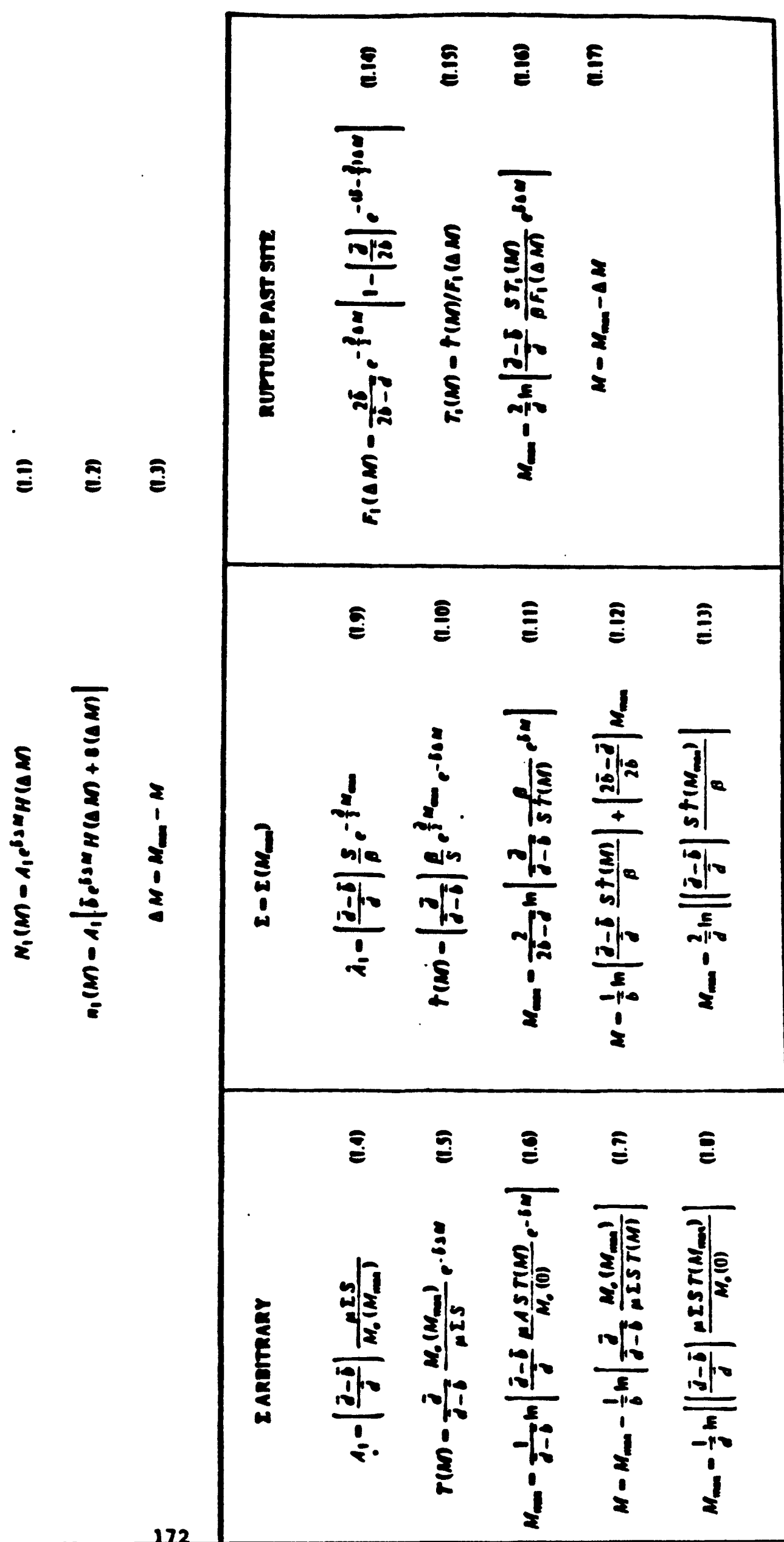



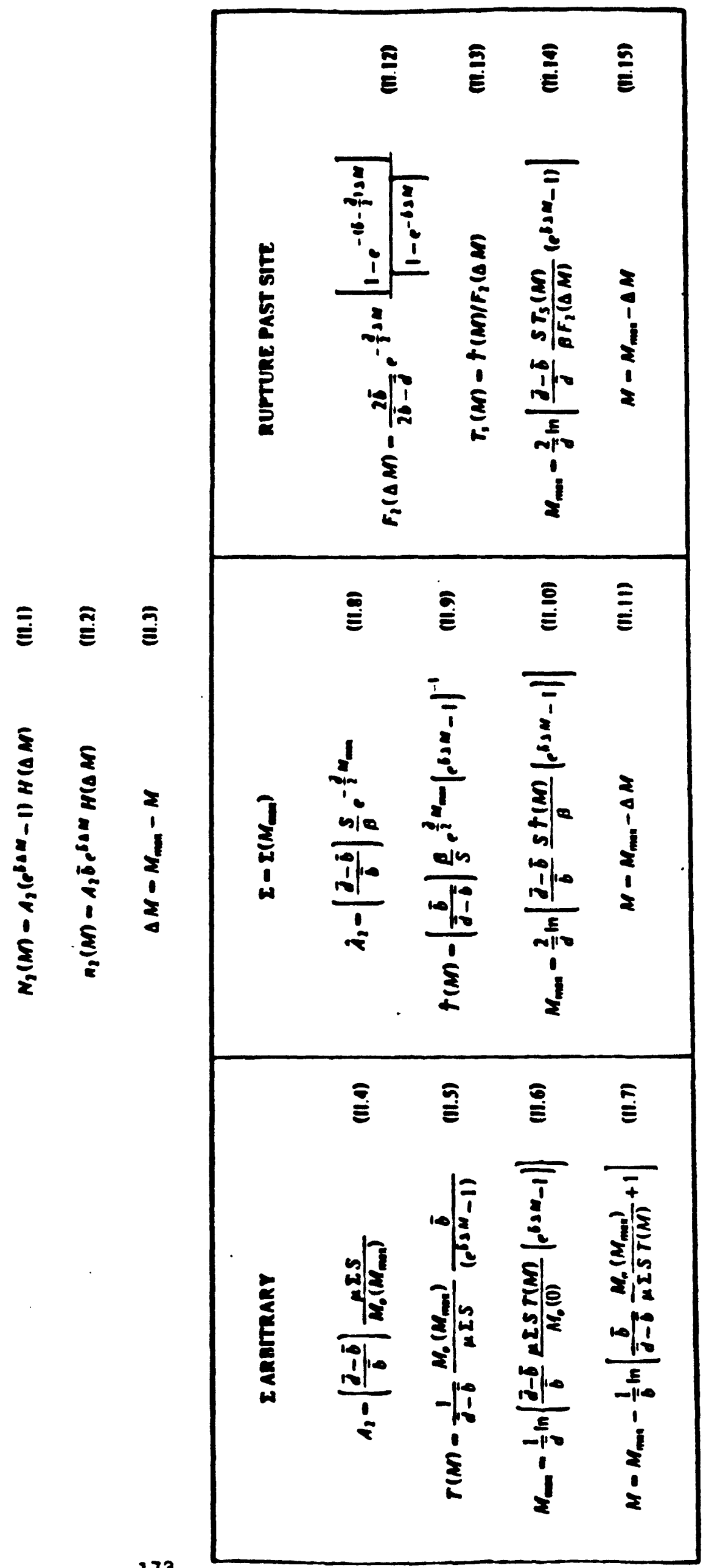


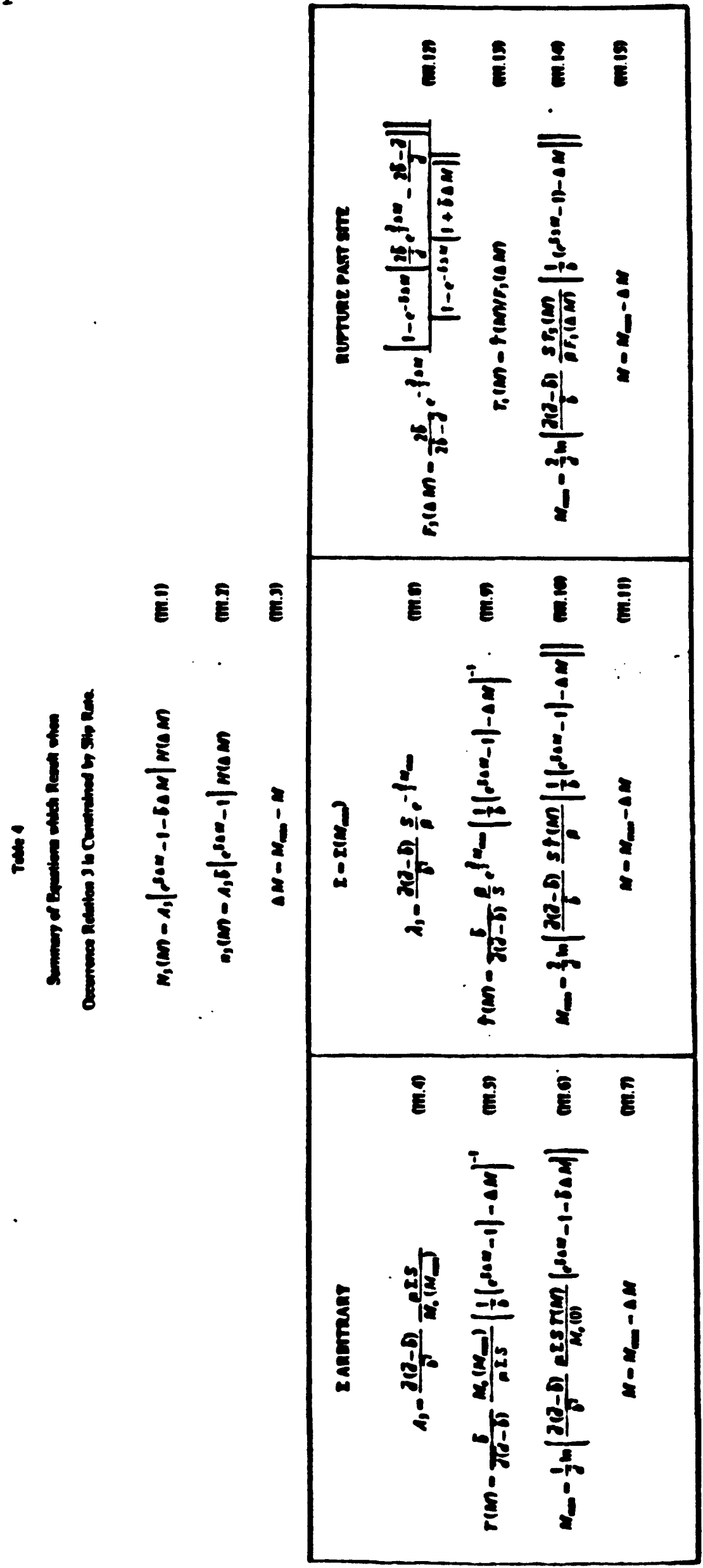


Table 5

\begin{tabular}{|c|c|c|c|c|c|c|c|}
\hline \multirow{2}{*}{ Region } & \multirow{2}{*}{\multicolumn{2}{|c|}{$\begin{array}{l}\text { Approx. } \\
\text { Location }\end{array}$}} & \multirow{2}{*}{$\begin{array}{l}\text { Ave. } \\
\text { Period } \\
\text { Years }\end{array}$} & \multirow{2}{*}{$\begin{array}{l}\text { Smallest } \\
\text { Observed } \\
\text { Magnitude }\end{array}$} & \multicolumn{3}{|c|}{ Calculated Threshold Magnitude ${ }^{1}$} \\
\hline & & & & & (Eq. 1.12) & (Eq. II.11) & (Eq. III.11) \\
\hline 1. Oaxaca & $16.2^{\circ} \mathrm{N}$ & $95.8^{\circ} \mathrm{W}$ & 34 & 7.4 & 7.5 & 7.5 & 7.4 \\
\hline 2. Oaxaca & $16.0^{\circ} \mathrm{N}$ & $96.8^{\circ} \mathrm{W}$ & 54 & 7.8 & 7.7 & 7.6 & 7.5 \\
\hline 3. Oaxaca & $16.6^{\circ} \mathrm{N}$ & $97.7^{\circ} \mathrm{W}$ & 38 & 7.4 & 7.5 & 7.5 & 7.4 \\
\hline 4. San Marcos & $16.7^{\circ} \mathrm{N}$ & $99.2^{\circ} \mathrm{W}$ & 56 & 7.5 & 7.7 & 7.6 & 7.5 \\
\hline 5. Peteilar & $17.3^{\circ} \mathrm{N}$ & $101.4^{\circ} \mathrm{W}$ & 36 & 7.5 & 7.5 & 7.5 & 7.4 \\
\hline 6. Colima & $18.4^{\circ} \mathrm{N}$ & $103.2^{\circ} \mathrm{W}$ & 32 & 7.5 & 7.5 & 7.5 & 7.4 \\
\hline
\end{tabular}

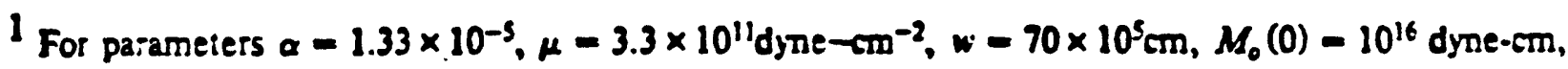
$b=1.0, M_{\max }=8.0,5=65 \mathrm{~mm} / \mathrm{yr}$ 
Table 6

Palletl Creek Events : Mapnitude Estimates

\begin{tabular}{|c|c|c|c|c|c|c|}
\hline & \multicolumn{3}{|c|}{ Time Inferred Model } & \multicolumn{3}{|c|}{ Slip Predictable Model } \\
\hline $\begin{array}{r}\text { Est. } \\
\text { Event Year }\end{array}$ & $\mid \begin{array}{c}\text { Waiting Time } \\
\text { to next Event } \\
\text { (vears) }\end{array}$ & $\begin{array}{l}\text { Inferted slip } \\
\text { in Event }(m)^{l}\end{array}$ & Magnitude ${ }^{2}$ & $\begin{array}{c}\text { Waiting Time } \\
\text { rom prior Event } \\
\text { (vears) }\end{array}$ & $\begin{array}{l}\text { Inferred slip } \\
\text { in Event }(m)^{1}\end{array}$ & Magnitude $^{2}$ \\
\hline $\begin{array}{ll}Z & 1857\end{array}$ & $>125$ & $\begin{array}{c}>4.6 \\
(4.5 \text { to } 4.8)^{3}\end{array}$ & $\begin{array}{c}>7.81 \\
(7.8 \text { 10 } 7.9)^{3}\end{array}$ & 112 & $\left(\begin{array}{c}4.1 \\
\left(4.50^{2} 4.8\right)^{3}\end{array}\right.$ & $\begin{array}{c}7.74 \\
(7.8 \text { to } 7.9)^{3}\end{array}$ \\
\hline$X \quad 1745$ & 112 & 4.1 & 7.74 & 275 & 10.2 & 8.26 \\
\hline V 1470 & 275 & 10.2 & 8.26 & 225 & 8.3 & 8.15 \\
\hline T 1245 & 225 & 8.3 & 8.15 & 55 & 2.0 & 7.33 \\
\hline R 1190 & 55 & 2.0 & 7.33 & 225 & 8.3 & 8.15 \\
\hline $\mathrm{N} \quad 965$ & 225 & 8.3 & 8.15 & 105 & 3.9 & 7.71 \\
\hline 1860 & 105 & 3.9 & 7.71 & 195 & 7.2 & 8.06 \\
\hline $\begin{array}{ll}P & 665\end{array}$ & 195 & 7.2 & 8.06 & 120 & 4.4 & 7.78 \\
\hline D 545 & 120 & 4.4 & 7.78 & $?$ & $?$ & $?$ \\
\hline
\end{tabular}

1 Based on slip rate of $37 \mathrm{~mm}$ (year)

2 Based on Eq. (25) for $W=10 \mathrm{~km}, \frac{\bar{u}}{L}=1.25 \times 10^{-5}$. Uncerainty is $>0.2$ magnitude units.

3 Actual, (Sieh 1978b). 
Table 7

Magnitude of Threshold of Observations Consistent with $S=37 \mathrm{~mm} /$ year and $T_{3}(M)=164$ years $^{1}$ at Palletl Creek, as a function of $M_{\max }$

\begin{tabular}{|l|ccc|ccc|}
\hline & \multicolumn{3}{|c|}{ 6- 0.20 } & \multicolumn{3}{|c|}{ b-0.86 } \\
\hline$M_{\text {ma }}$ & Eq. 1.17 & Eq. I1.15 & Eq. III.15 & Eq. I.17 & Eq. II.15 & Eq. II.15 \\
\hline 7.8 & - & 7.50 & 7.30 & 7.43 & 7.32 & 7.18 \\
7.9 & 7.83 & 7.52 & 7.36 & 7.37 & 7.34 & 7.21 \\
8.0 & 7.23 & 7.53 & 7.39 & 7.31 & 7.34 & 7.24 \\
8.1 & & 7.48 & 7.41 & 7.21 & 7.32 & 7.26 \\
8.2 & & 7.40 & 7.42 & 7.10 & 7.29 & 7.27 \\
8.3 & & 7.19 & 7.40 & 6.95 & 7.24 & 7.27 \\
8.4 & & 6.60 & 7.40 & 6.77 & 7.17 & 7.26 \\
8.5 & & & 7.28 & 6.58 & 7.08 & 7.23 \\
8.6 & & & 7.13 & 6.35 & 6.96 & 7.19 \\
8.7 & & & 6.85 & 6.08 & 6.81 & 7.13 \\
8.8 & & & 6.15 & & 6.64 & 7.05 \\
\hline
\end{tabular}

${ }^{1}$ Orher Parameters $\mu=3 \times 10^{11} \mathrm{dyne} / \mathrm{cm}^{2}, W=10 \mathrm{~km}, \frac{\bar{u}}{L}=1.25 \times 10^{-5}$. 


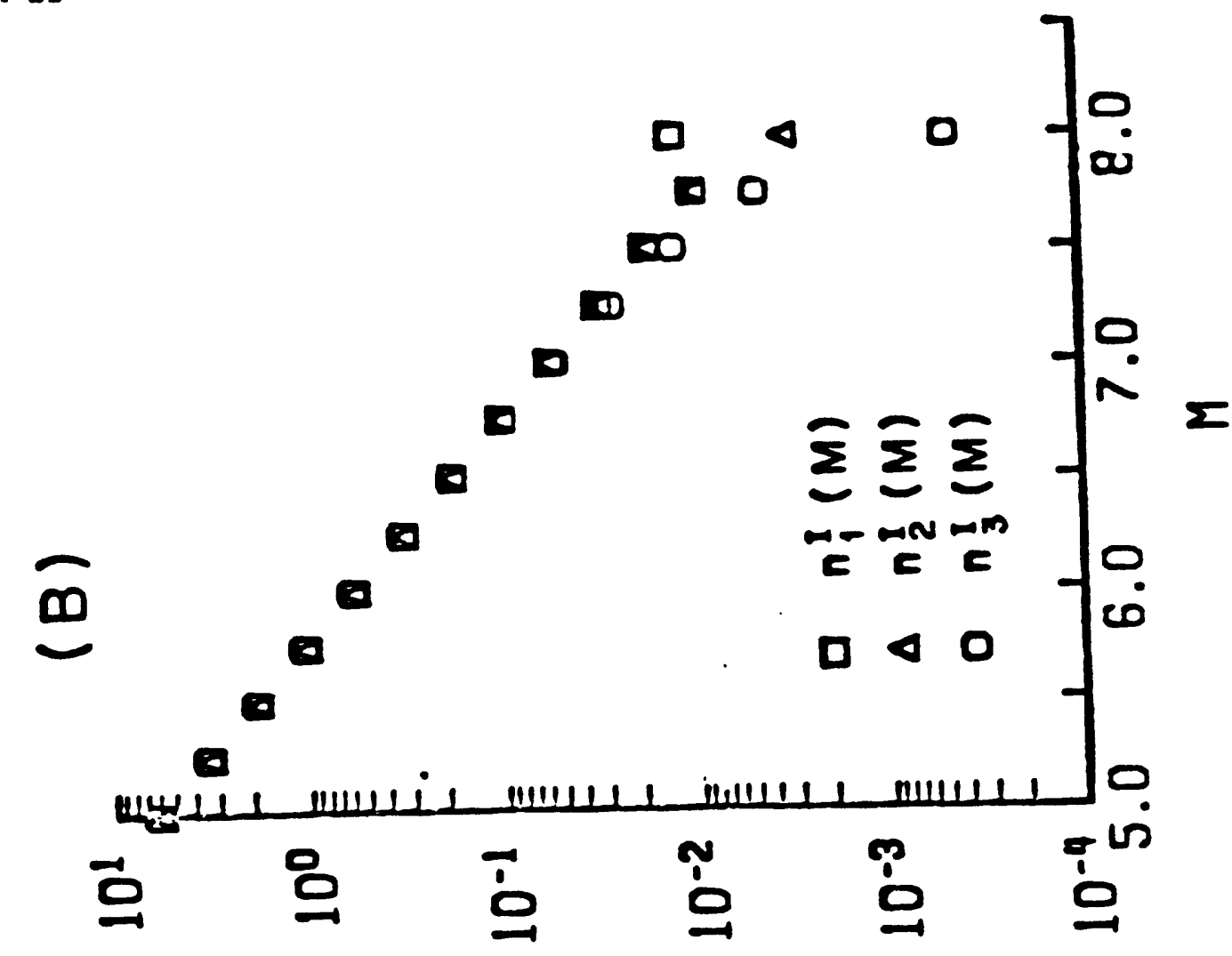

LINก $\exists O \cap L I N O \forall W ~ S Z O / \forall \forall \exists \lambda / S \perp N \exists \wedge \exists$

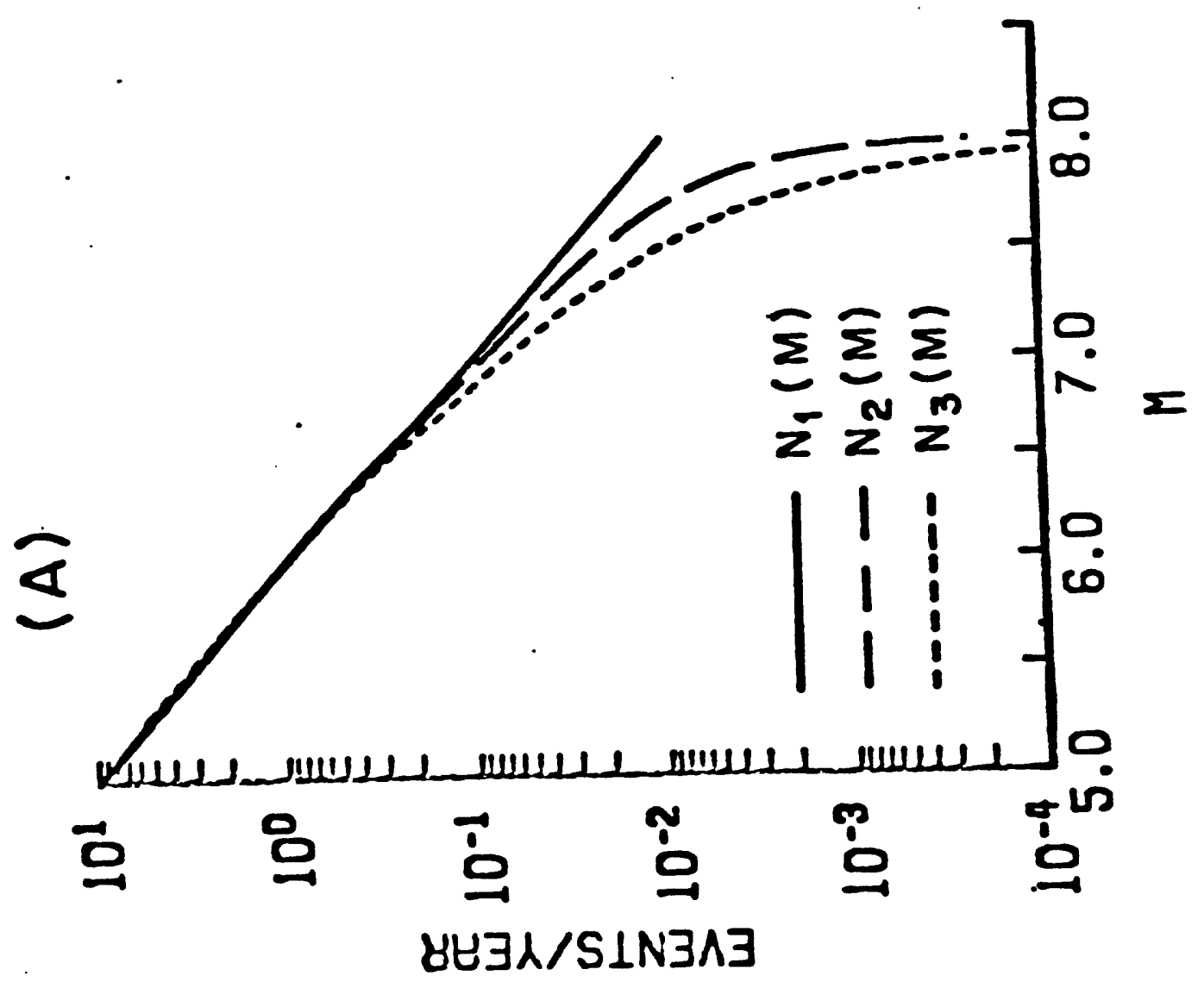


APPENDIX II .

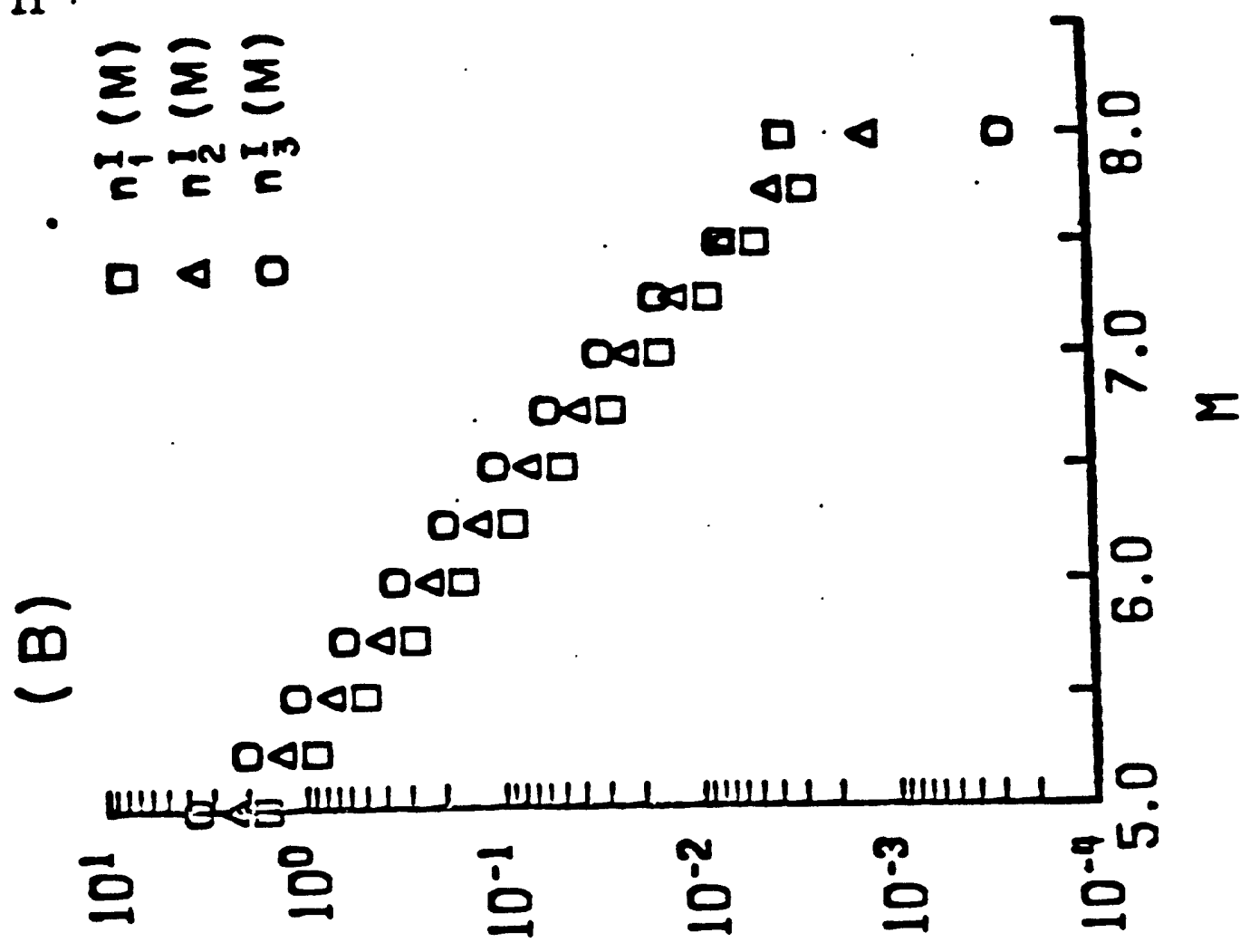

LINก $3 O N \perp I N O \forall W$ SZO/ $\forall \forall 3 \lambda / S \perp N \exists \wedge \exists$

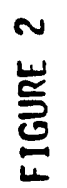

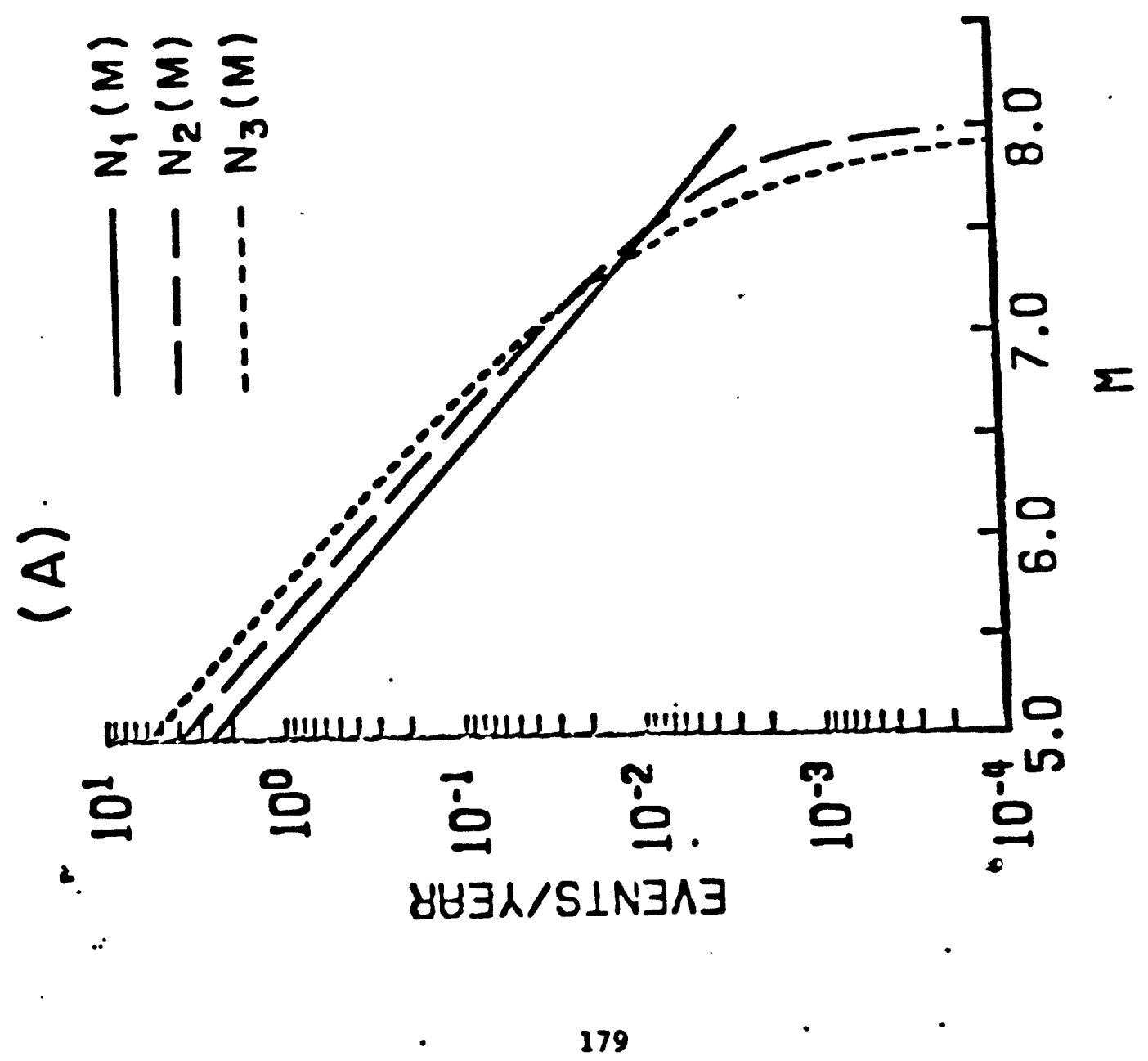




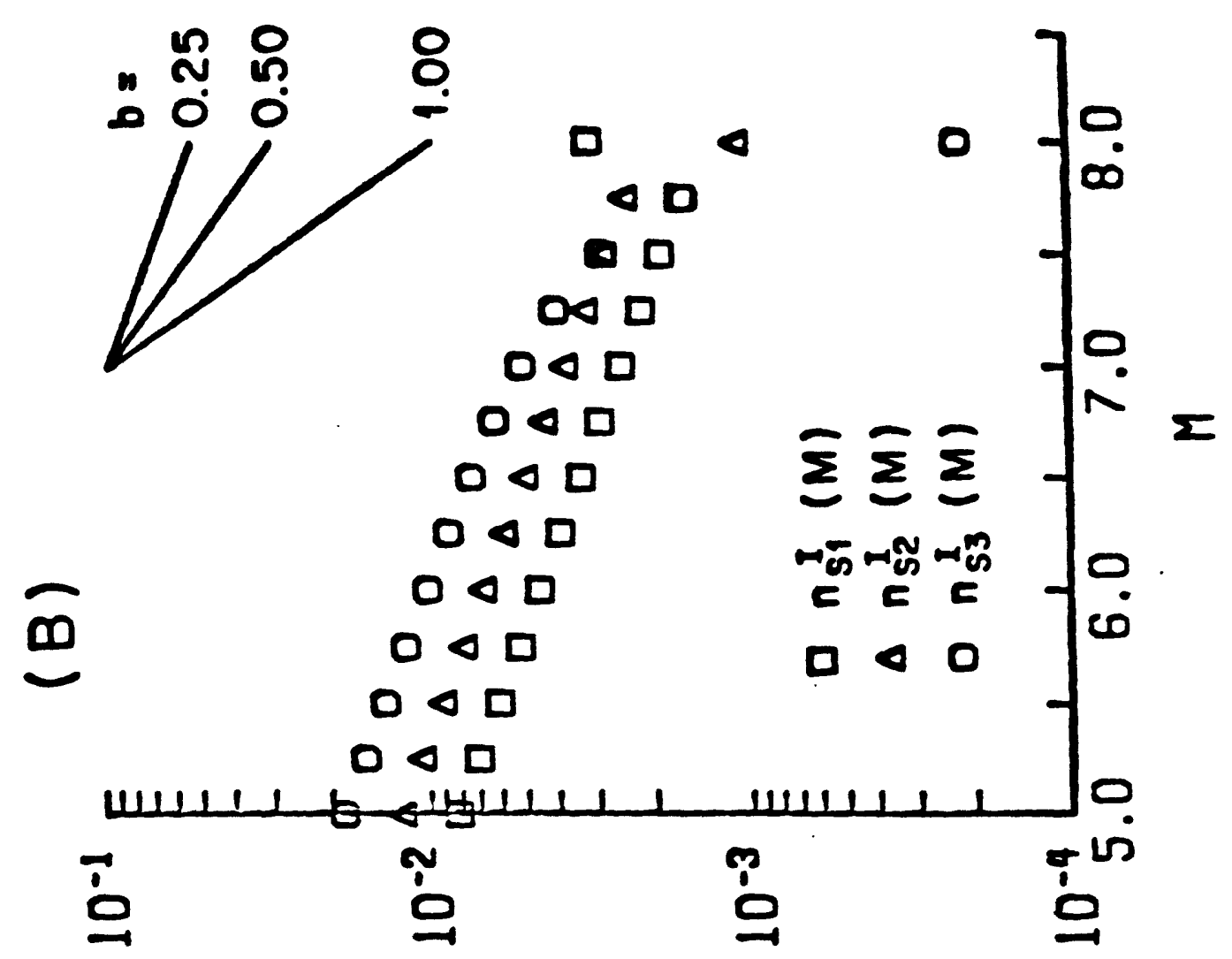

LINก $\exists O \cap \perp I N O \forall W G Z 0 / \forall \forall \exists \Lambda / S \perp N \exists \wedge \exists$

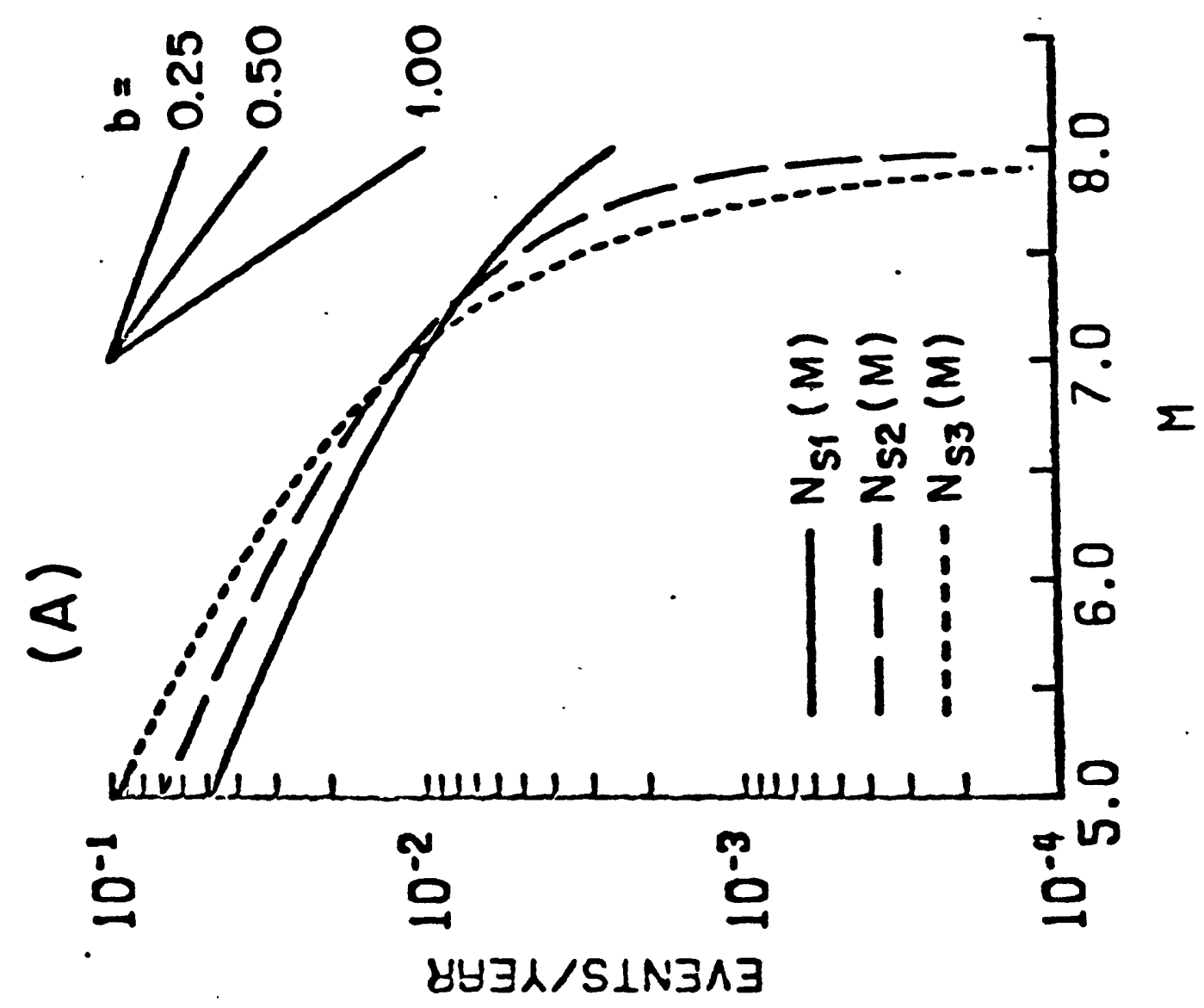


APPENDIX II
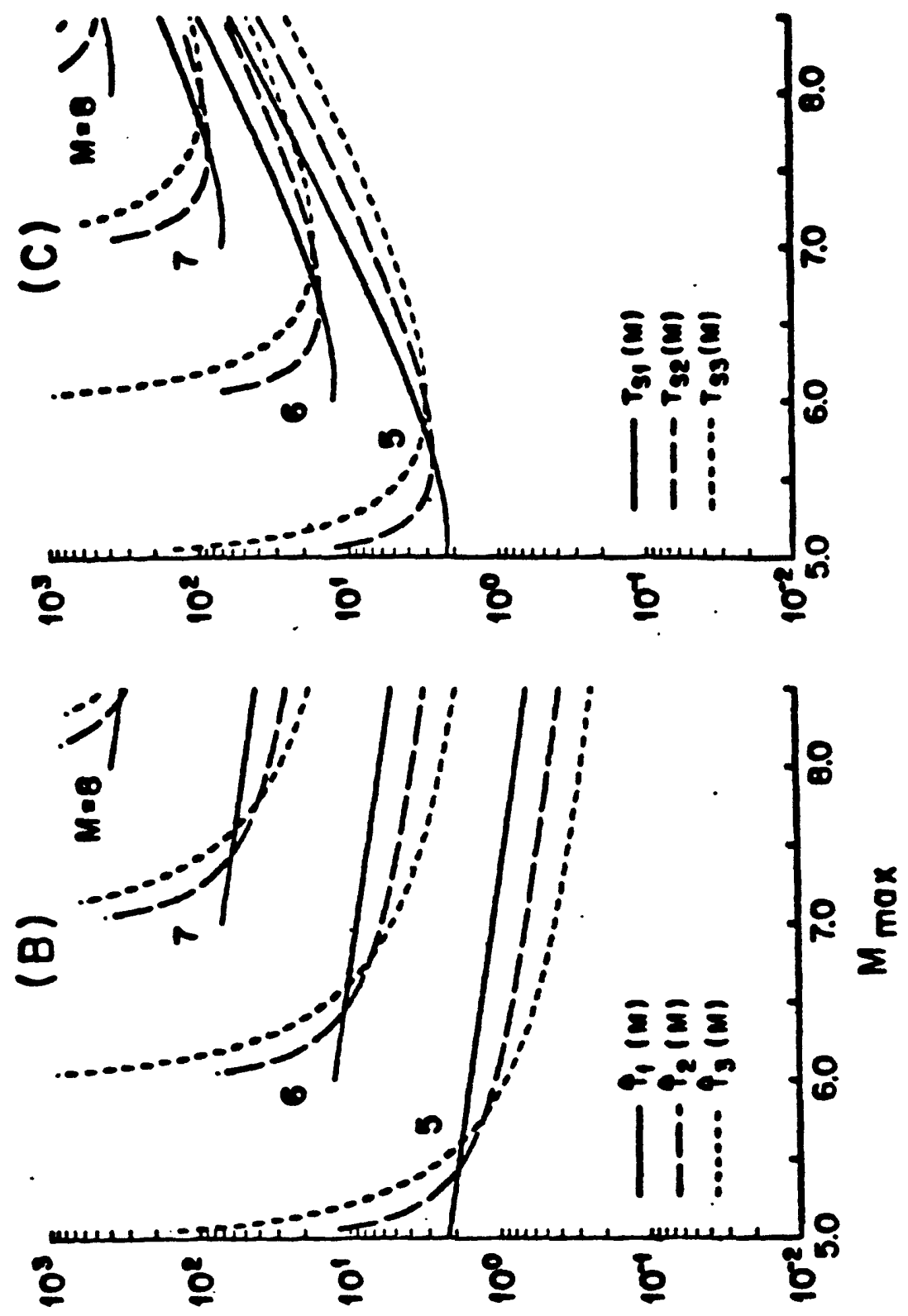

$\sigma$
$\frac{1}{5}$
$\frac{0}{4}$

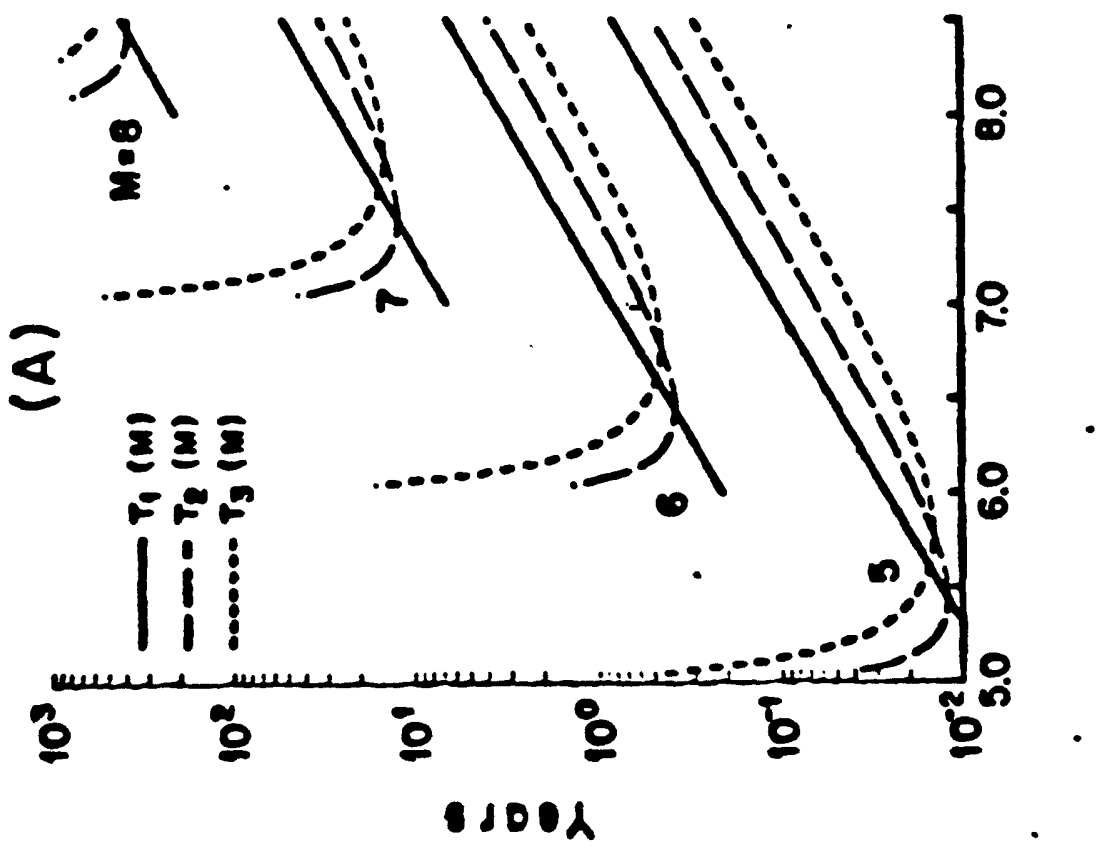



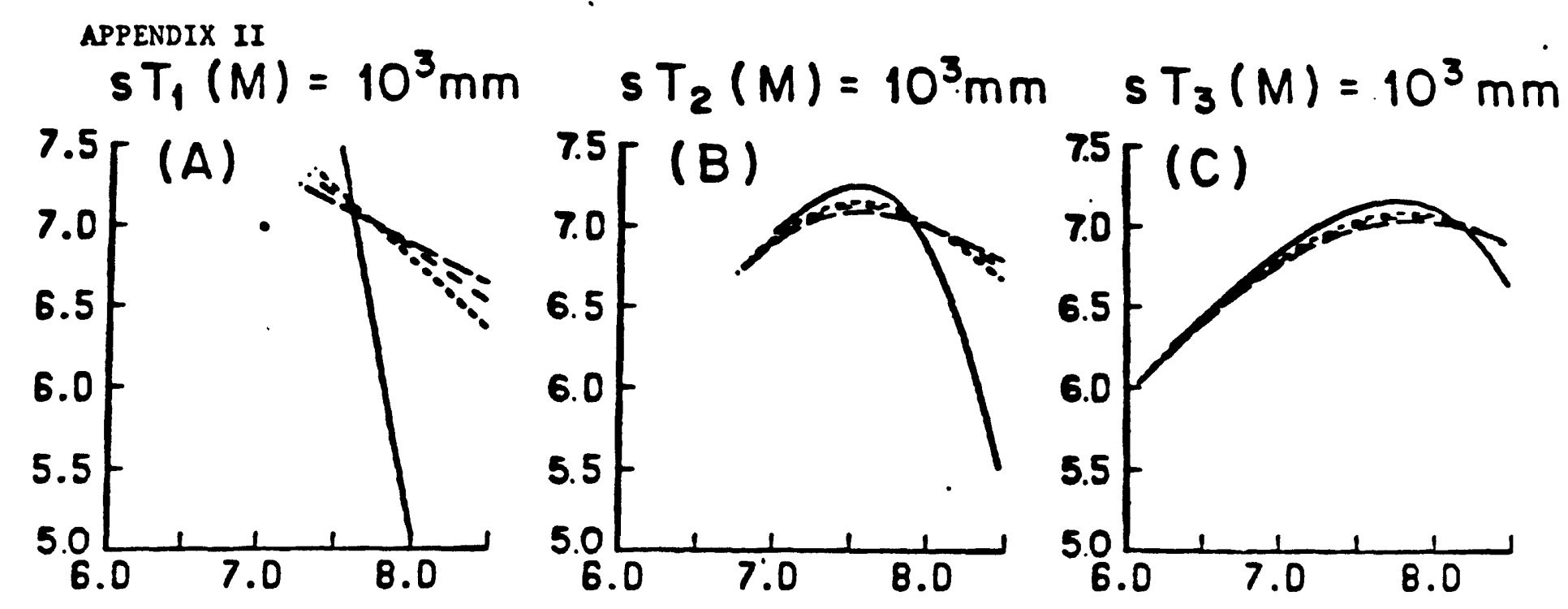

$s \hat{T}_{1}(M)=10^{3} \mathrm{~mm} \quad s \hat{T}_{2}(M)=10^{3} \mathrm{~mm} \quad s \hat{T}_{3}(M)=10^{3} \mathrm{~mm}$
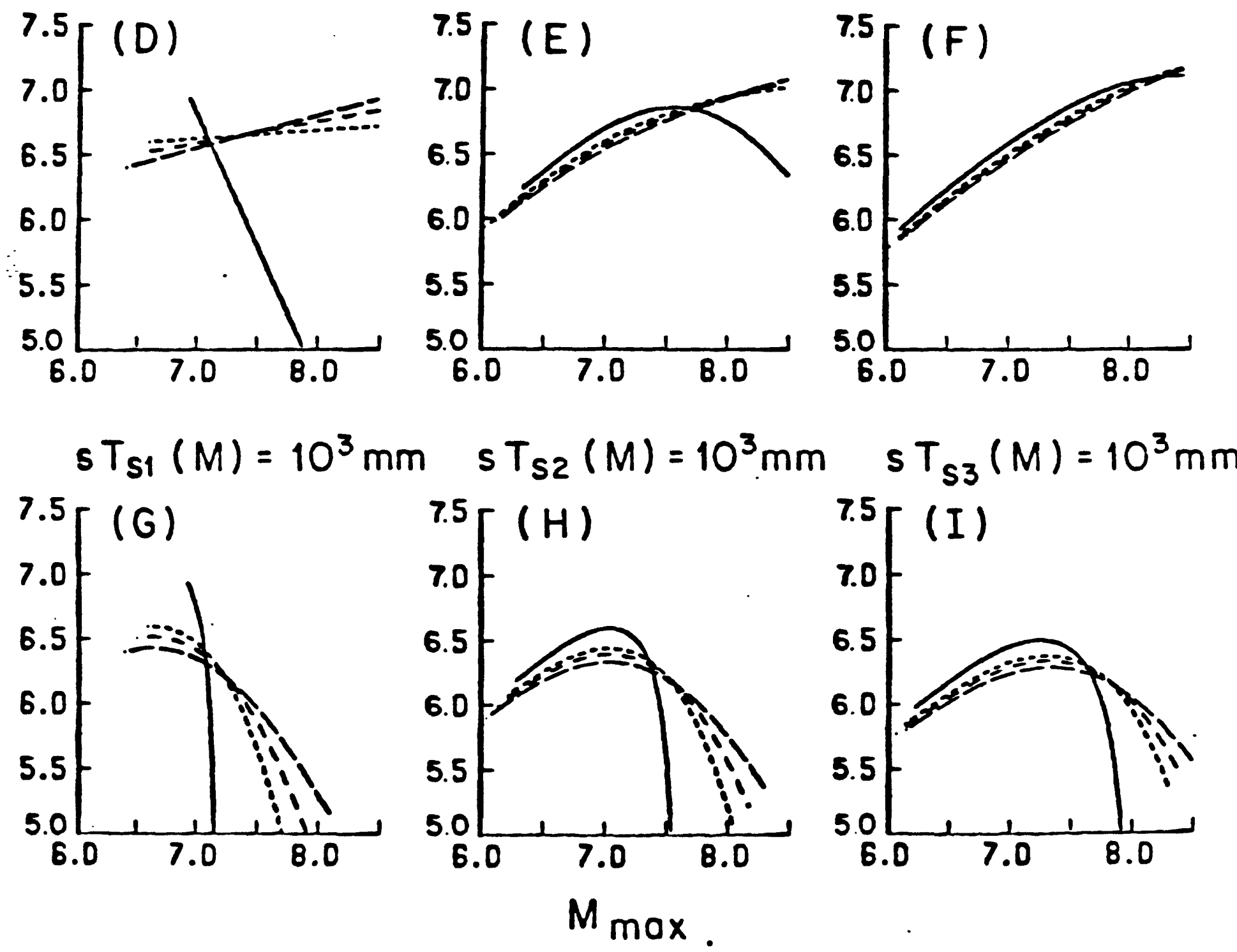

FIGURE 5 


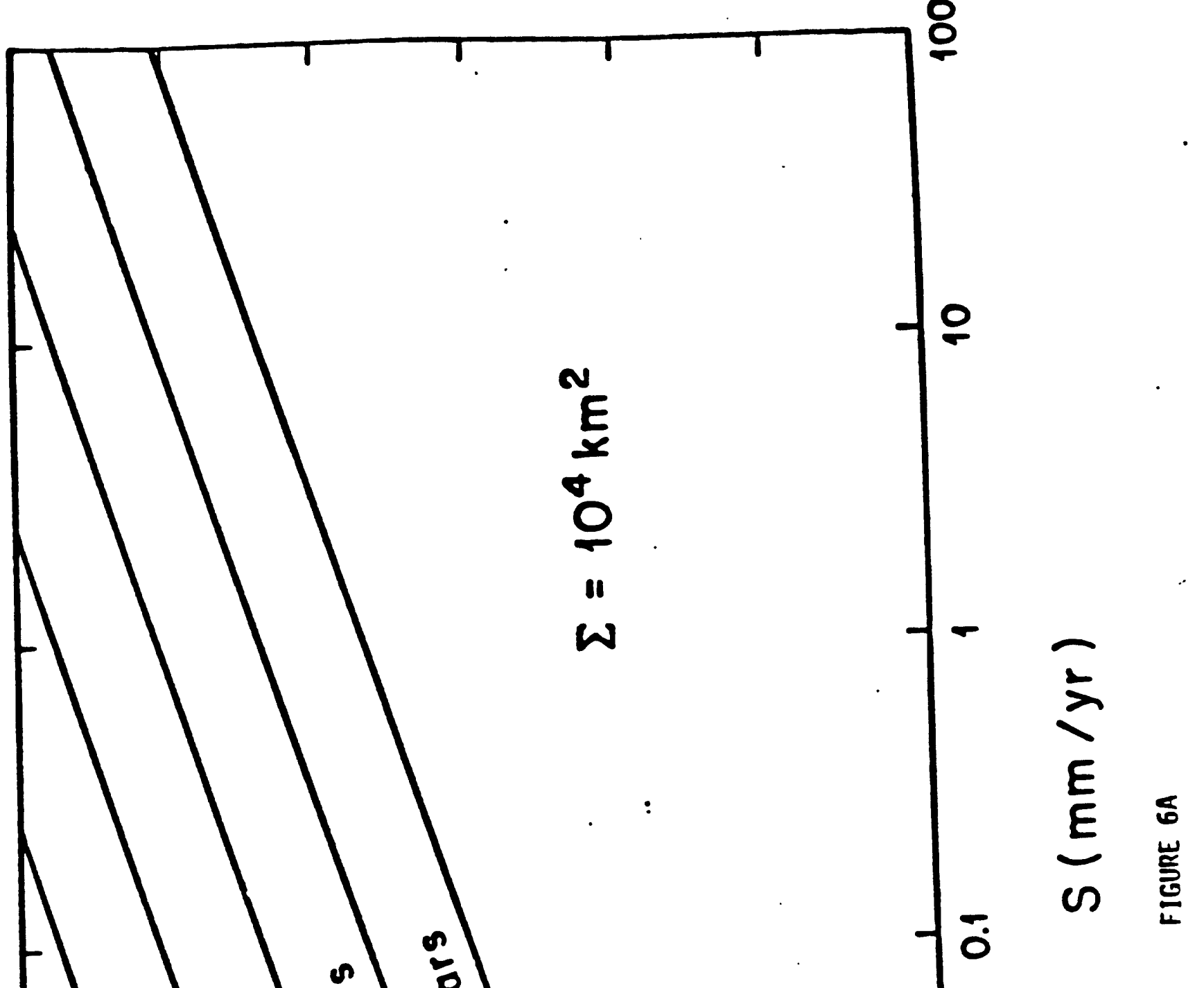


NDIX II

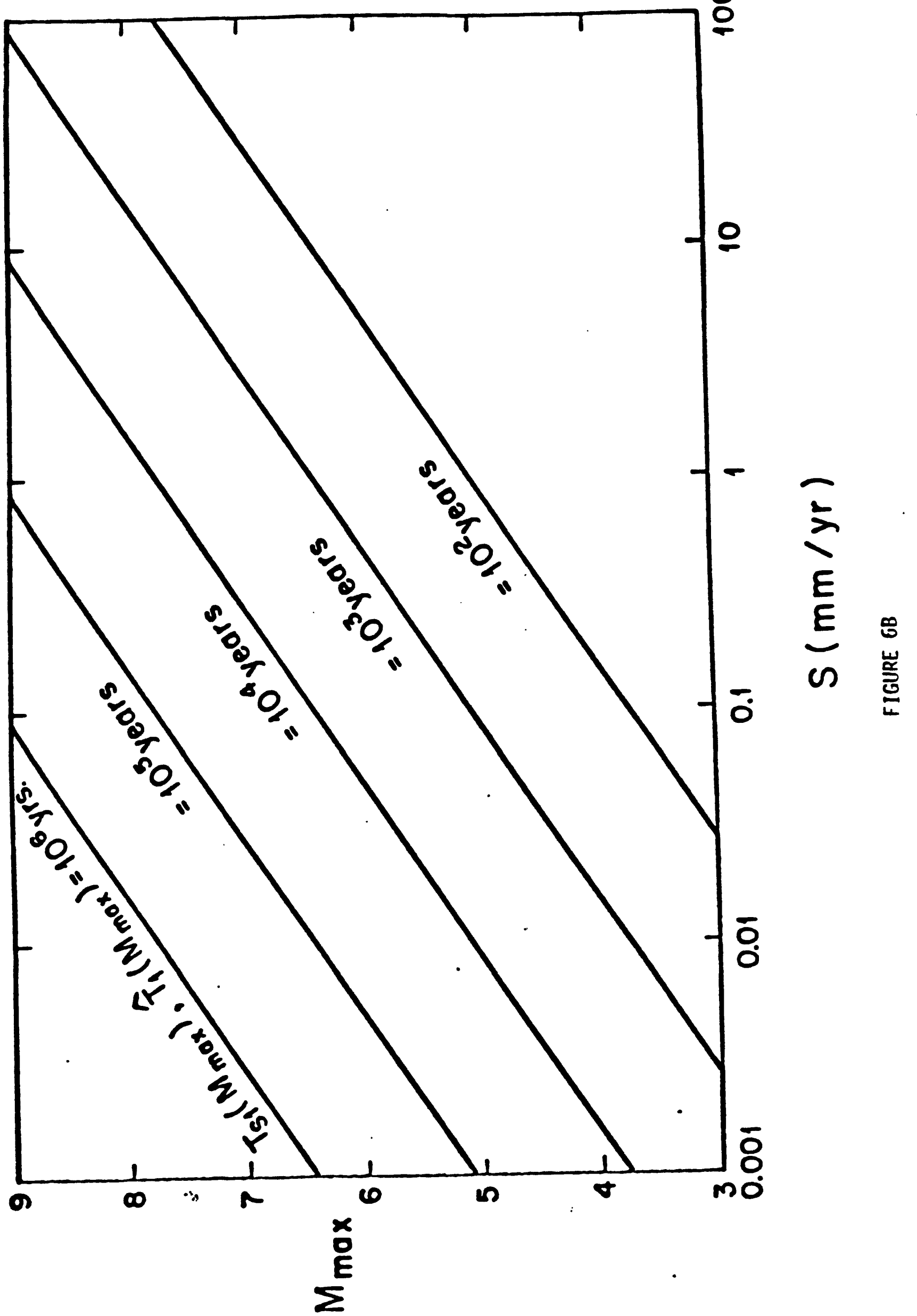




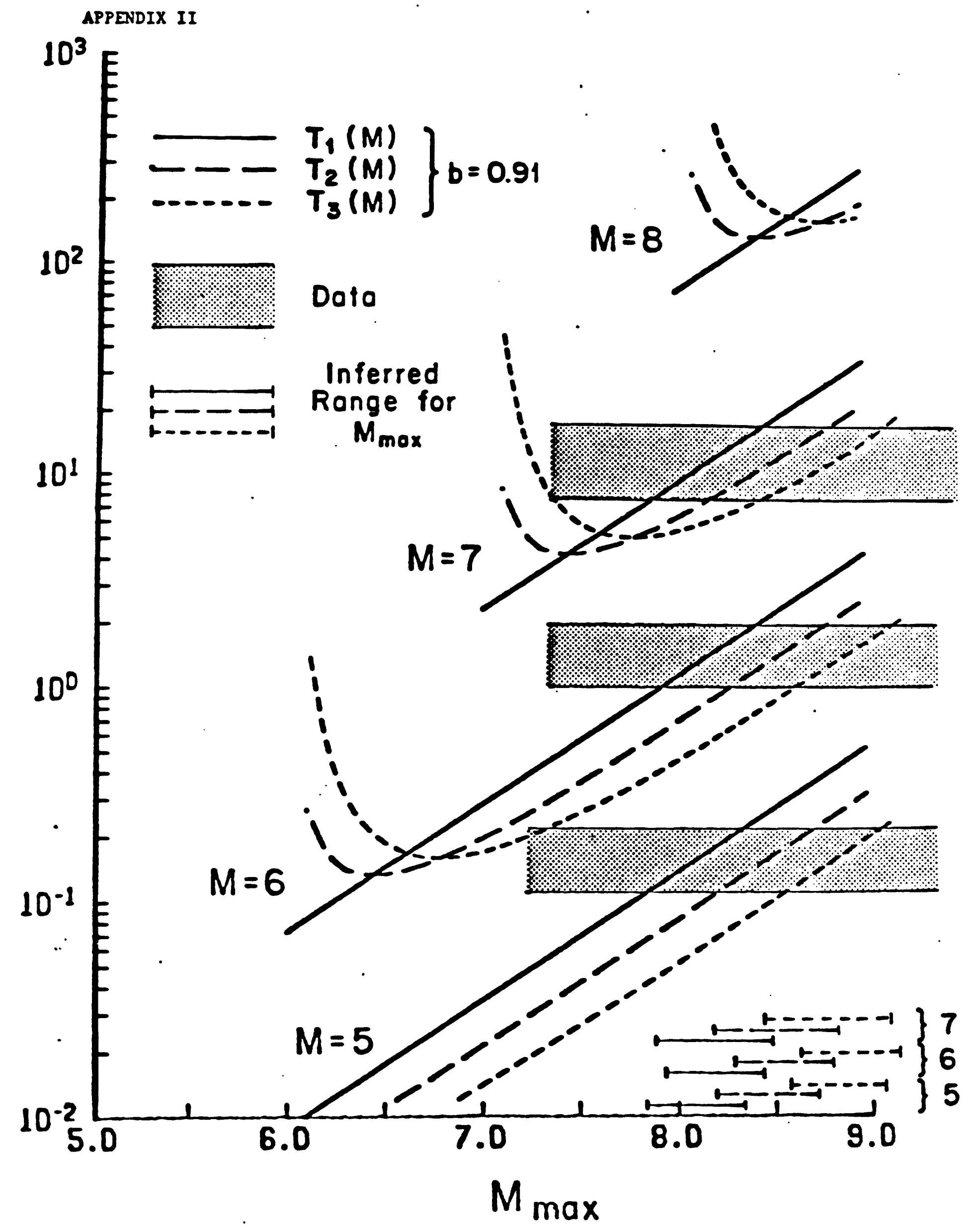

FIGURE 7 


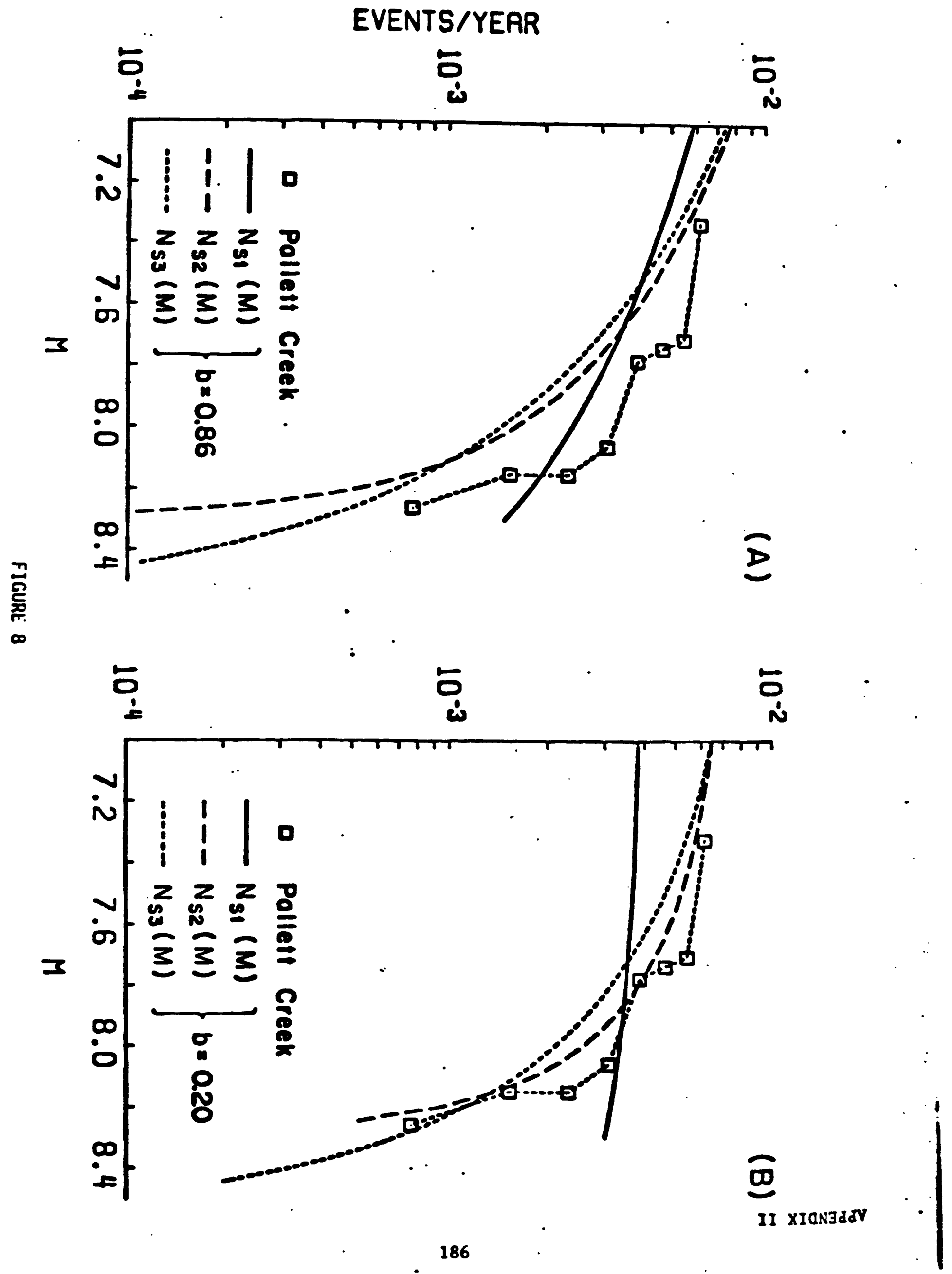

